\title{
JCS 2017/JHFS 2017 Guideline on Diagnosis and Treatment of Acute and Chronic Heart Failure \\ - Digest Version -
}

Hiroyuki Tsutsui; Mitsuaki Isobe; Hiroshi Ito; Hiroshi Ito; Ken Okumura; Minoru Ono;

Masafumi Kitakaze; Koichiro Kinugawa; Yasuki Kihara; Yoichi Goto; Issei Komuro;

Yoshikatsu Saiki; Yoshihiko Saito; Yasushi Sakata; Naoki Sato; Yoshiki Sawa; Akira Shiose;

Wataru Shimizu; Hiroaki Shimokawa; Yoshihiko Seino; Koichi Node; Taiki Higo;

Atsushi Hirayama; Miyuki Makaya; Tohru Masuyama; Toyoaki Murohara; Shin-ichi Momomura;

Masafumi Yano; Kenji Yamazaki; Kazuhiro Yamamoto; Tsutomu Yoshikawa;

Michihiro Yoshimura; Masatoshi Akiyama; Toshihisa Anzai; Shiro Ishihara; Takayuki Inomata;

Teruhiko Imamura; Yu-ki Iwasaki; Tomohito Ohtani; Katsuya Onishi; Takatoshi Kasai;

Mahoto Kato; Makoto Kawai; Yoshiharu Kinugasa; Shintaro Kinugawa; Toru Kuratani;

Shigeki Kobayashi; Yasuhiko Sakata; Atsushi Tanaka; Koichi Toda; Takashi Noda;

Kotaro Nochioka; Masaru Hatano; Takayuki Hidaka; Takeo Fujino; Shigeru Makita;

Osamu Yamaguchi; Uichi Ikeda; Takeshi Kimura; Shun Kohsaka; Masami Kosuge;

Masakazu Yamagishi; Akira Yamashina on behalf of the Japanese Circulation Society and the Japanese Heart Failure Society Joint Working Group

\section{Table of Contents}

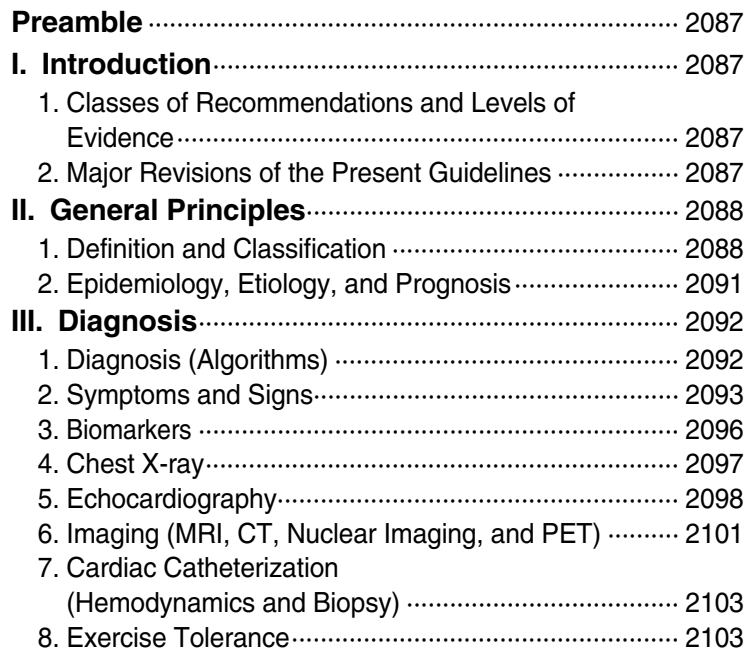

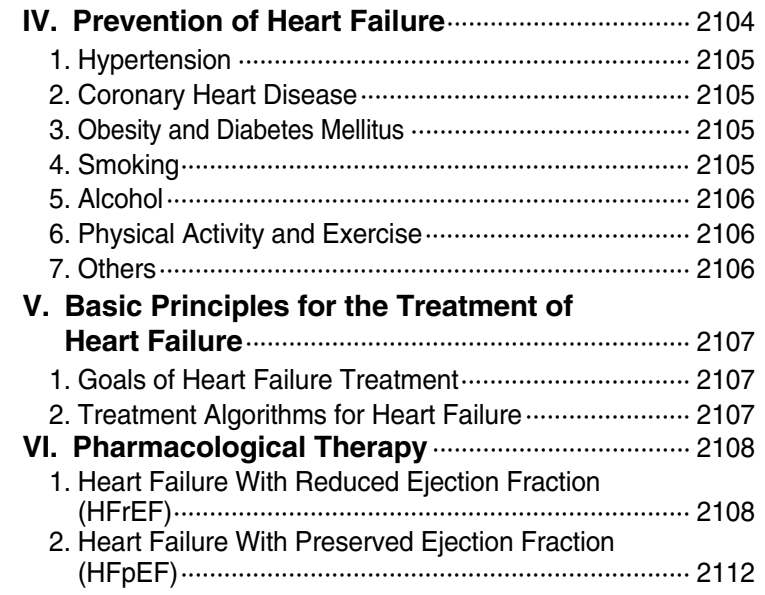

(Table of Contents continued the next page.)

J-STAGE Advance Publication released online September 10, 2019

Mailing address: Scientific Committee of the Japanese Circulation Society, 18F Imperial Hotel Tower, 1-1-1 Uchisaiwai-cho, Chiyoda-ku, Tokyo 100-0011, Japan. E-mail: meeting@j-circ.or.jp

This English language document is a revised digest version of Guidelines for the Diagnosis and Treatment of Acute and Chronic Heart Failure (JCS 2017/JHFS 2017) reported at the Japanese Circulation Society Joint Working Groups performed in 2017 (Website: http://www.j-circ.or.jp/guideline/pdf/JCS2017_tsutsui_d.pdf).

Joint Working Groups: The Japanese Circulation Society; the Japanese Heart Failure Society; the Japanese Association for Thoracic Surgery; the Japanese Society of Hypertension; the Japanese Society of Echocardiography; the Japanese Society for Cardiovascular Surgery; the Japanese College of Cardiology; the Japanese Association of Cardiac Rehabilitation; the Japan Society of Ultrasonics in Medicine; the Japan Diabetes Society; the Japanese Heart Rhythm Society; "the Study Group on Idiopathic Cardiomyopathy" supported by the Health and Labor Sciences Research Grant on Intractable Diseases; and "the Study Group on the Multi-center Observational Study of Dilated- phase Hypertrophic Cardiomyopathy", supported by the "Practical Research Project for Rare/ intractable Diseases by the Japan Agency for Medical Research and Development".

ISSN-1346-9843 All rights are reserved to the Japanese Circulation Society. For permissions, please e-mail: cj@j-circ.or.jp 
VII. Nonpharmacological Therapy ………................ 2112

1. Implantable Cardioverter Defibrillator ............................. 2112

2. Cardiac Resynchronization Therapy ……...................... 2114

3. Respiratory Support..................................................... 2114

4. Exercise Therapy ……................................................... 2116

VIII. Treatment of Underlying Conditions ………...2 2117

1. Basic Treatment Strategies ….................................... 2117

2. Underlying Conditions That May Modify Treatment

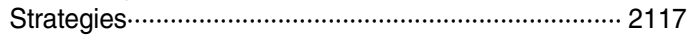

3. Comorbid Conditions Causing Advanced Stage

Heart Failure …….......................................................... 2117

IX. Pathophysiology and Treatment of

Comorbidities …..................................................... 2118

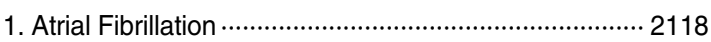

2. Ventricular Arrhythmias ….......................................... 2120

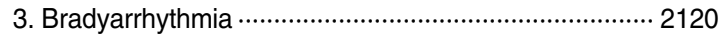

4. Coronary Artery Disease ……..................................... 2121

5. Valvular Heart Disease ……………………………..... 2123

6. Hypertension ……..................................................... 2124

7. Diabetes Mellitus ……………………………................ 2125

8. CKD and Cardiorenal Syndrome ……........................... 2125

9. Hyperuricemia/Gout................................................... 2127

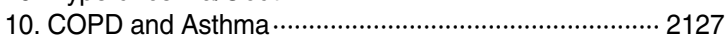

11. Anemia …................................................................ 2128

12. Sleep-Disordered Breathing ........................................ 2128

X. Acute Heart Failure …….................................... 2130

1. Definition and Classification ……................................. 2130

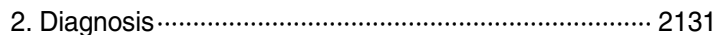

3. Treatment Strategies and Flowcharts …...................... 2132

4. Pharmacological Therapy ………………………......... 2135

5. Nonpharmacological Therapy ……….......................... 2140
XI. Surgical Treatment ……......................................... 2143

1. Surgical Procedures and TAVI ………………............ 2143

2. Mechanical Circulatory Support …................................ 2146

3. Heart Transplantation …………................................... 2148

XII. Disease Management ……................................... 2148

1. Disease Management Programs (e.g., Educational

Programs) and Team Medical Care ………………….. 2148

2. Comprehensive Cardiac Rehabilitation ………............. 2149

XIII. Palliative Care ……............................................ 2149

1. Advance Care Planning and Decision-Making

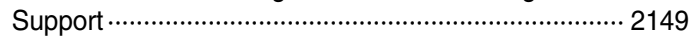

2. End-Stage Heart Failure and Indication for Palliative

Care ..................................................................... 2152

3. Importance of Multidisciplinary Approaches ………..... 2152

4. Symptoms and Treatment of End-Stage Heart

Failure ………………………………………...... 2153

5. Early Introduction of Palliative Care for Heart

Failure …….............................................................. 2156

XIV. Future Treatment ……....................................... 2156

1. Ivabradine (If-Channel Blocker) …….............................. 2156

2. Sacubitril/Valsartan (ARNI) ……….............................. 2156

3. Vericiguat (cGS Activator) …..................................... 2156

4. Omecamtiv Mecarbil (Cardiac Myosin Activator) ….... 2157

5. Percutaneous Mitral Valve Repair System

(MitraClip ${ }^{\circledR}$ ) …………………………………………..... 2158

6. Human (Autologous) Skeletal Muscle-Derived Cell

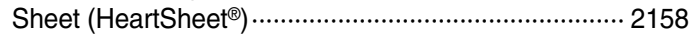

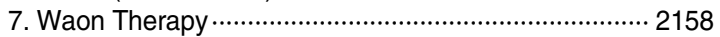

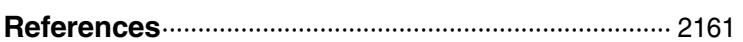

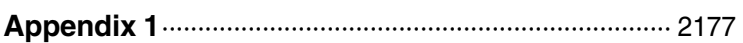

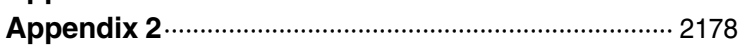

\section{Abbreviations}

\begin{tabular}{|l|l|}
\hline ACC & American College of Cardiology \\
\hline ACCF & American College of Cardiology Foundation \\
\hline ACE & angiotensin converting enzyme \\
\hline ACP & advance care planning \\
\hline ACS & acute coronary syndrome \\
\hline ADL & activities of daily livings \\
\hline AHA & American Heart Association \\
\hline AHI & apnea hypopnea index \\
\hline ANP & atrial (A-type) natriuretic peptide \\
\hline ARB & angiotensin Il receptor blocker \\
\hline ASV & adaptive servo-ventilation \\
\hline BNP & brain (B-type) natriuretic peptide \\
\hline CABG & coronary artery bypass grafting \\
\hline CKD & chronic kidney disease \\
\hline COPD & chronic obstructive pulmonary disease \\
\hline CPAP & continuous positive airway pressure \\
\hline CRT & cardiac resynchronization therapy \\
\hline CS & clinical scenario \\
\hline CSA & central sleep apnea \\
\hline CSR & Cheyne-Stokes respiration \\
\hline CT & computed tomography \\
\hline DOAC & direct oral anticoagulant \\
\hline ECMO & extracorporeal membrane oxygenation \\
\hline ESA & erythropoiesis stimulating agent \\
\hline ESC & European Society of Cardiology \\
\hline
\end{tabular}

\begin{tabular}{|l|l|}
\hline $\mathrm{FiO}_{2}$ & fraction of inspiratory oxygen \\
\hline $\mathrm{HF}$ & heart failure \\
\hline $\mathrm{HFmrEF}$ & heart failure with mid-range ejection fraction \\
\hline $\mathrm{HFpEF}$ & heart failure with preserved ejection fraction \\
\hline $\mathrm{HFrecEF}$ & heart failure with recovered ejection fraction \\
\hline HFrEF & heart failure with reduced ejection fraction \\
\hline IABP & intra-aortic balloon pump \\
\hline ICD & implantable cardioverter defibrillator \\
\hline IL & interleukin \\
\hline JCS & Japanese Circulation Society \\
\hline LVAD & left ventricular assist device \\
\hline LVEF & left ventricular ejection fraction \\
\hline MBP & mean arterial pressure \\
\hline MRA & mineralocorticoid receptor antagonist \\
\hline MRI & magnetic resonance imaging \\
\hline NPPV & noninvasive positive pressure ventilation \\
\hline NSAID & nonsteroidal anti-inflammatory drug \\
\hline NT-proBNP & N-terminal pro-brain (B-type) natriuretic peptide \\
\hline NYHA & New York Heart Association \\
\hline OSA & obstructive sleep apnea \\
\hline PaO & arterial partial pressure of oxygen \\
\hline PCl & percutaneous coronary intervention \\
\hline PCPS & percutaneous cardiopulmonary support \\
\hline PDE & phosphodiesterase \\
\hline QOL & quality of life \\
\hline
\end{tabular}




\begin{tabular}{|l|l|}
\hline SBP & systolic blood pressure \\
\hline SDB & sleep-disordered breathing \\
\hline SGLT & sodium glucose cotransporter \\
\hline SPECT & single-photon emission computed tomography \\
\hline
\end{tabular}

\begin{tabular}{|l|l|}
\hline $\mathrm{SpO}_{2}$ & oxygen saturation \\
\hline $\mathrm{TAVI}$ & transcatheter aortic valve implantation \\
\hline $\mathrm{TAVR}$ & transcatheter aortic valve replacement \\
\hline $\mathrm{VAD}$ & ventricular assist device \\
\hline
\end{tabular}

\begin{tabular}{|c|c|c|c|}
\hline Year & $\begin{array}{c}\text { Japan } \\
\text { (The Japanese Circulation Society) }\end{array}$ & $\begin{array}{c}\text { U.S. } \\
\text { (ACC/AHA) }\end{array}$ & $\begin{array}{l}\text { EU } \\
\text { (ESC) }\end{array}$ \\
\hline 1995 & & $\begin{array}{l}\text { ACC/AHA guidelines for the evaluation } \\
\text { and management of heart failure } \\
\text { (Chair: Williams) }{ }^{2}\end{array}$ & $\begin{array}{l}\text { Guidelines for the diagnosis of heart failure } \\
\text { (The Task Force on Heart Failure of the } \\
\text { European Society of Cardiology) }\end{array}$ \\
\hline 1997 & & & $\begin{array}{l}\text { The treatment of heart failure (Task Force } \\
\text { of the Working Group on Heart Failure of } \\
\text { the European Society of Cardiology) }\end{array}$ \\
\hline 2000 & $\begin{array}{l}\text { Guidelines for Treatment of Chronic Heart } \\
\text { Failure (Chair: Matsuzaki) } \\
\text { Guidelines for Treatment of Severe Acute } \\
\text { Heart Failure (Chair: Takekoshi) }\end{array}$ & & \\
\hline 2001 & & $\begin{array}{l}\text { ACC/AHA guidelines for the evaluation } \\
\text { and management of chronic heart failure } \\
\text { in the adult (Chair: Hunt) })^{3}\end{array}$ & $\begin{array}{l}\text { Guidelines for the diagnosis and treatment } \\
\text { of chronic heart failure (CoChair: Remme } \\
\text { and Swedverg), }{ }^{11} \text { covering both diagnosis } \\
\text { and treatment }\end{array}$ \\
\hline 2005 & $\begin{array}{l}\text { Guidelines for Treatment of Chronic Heart } \\
\text { Failure (Chair: Matsuzaki), revised } \\
\text { version }\end{array}$ & $\begin{array}{l}\text { ACC/AHA } 2005 \text { Guideline Update for the } \\
\text { Diagnosis and Management of Chronic } \\
\text { Heart Failure in the Adult (Chair: Hunt) }\end{array}$ & $\begin{array}{l}\text { Guidelines for the diagnosis and treatment } \\
\text { of chronic heart failure (Chair: Swedberg) })^{12} \\
\text { Guidelines on the diagnosis and treatment } \\
\text { of acute heart failure (Chair: Nieminen) }{ }^{13}\end{array}$ \\
\hline 2006 & $\begin{array}{l}\text { Guidelines for Treatment of Acute Heart } \\
\text { Failure (Chair: Maruyama), revised } \\
\text { version }\end{array}$ & & \\
\hline 2008 & & & $\begin{array}{l}\text { Guidelines for the diagnosis and treatment } \\
\text { of acute and chronic heart failure } \\
\text { (Chair: Dickstein) }\end{array}$ \\
\hline 2009 & & $\begin{array}{l}\text { A revised version that contains a new } \\
\text { section "The Hospitalized Patient"5 }\end{array}$ & \\
\hline 2010 & $\begin{array}{l}\text { Guidelines for Treatment of Chronic Heart } \\
\text { Failure (Chair: Matsuzaki), revised } \\
\text { version }\end{array}$ & & \\
\hline 2011 & $\begin{array}{l}\text { Guidelines for Treatment of Acute Heart } \\
\text { Failure (Chair: Izumi), revised version }\end{array}$ & & \\
\hline 2012 & & & $\begin{array}{l}\text { ESC Guidelines for the diagnosis and } \\
\text { treatment of acute and chronic heart } \\
\text { failure } 2012 \text { (Chair: McMurray), }{ }^{1} \text { as a } \\
\text { revision of the previous version }\end{array}$ \\
\hline 2013 & & $\begin{array}{l}2013 \text { ACCF/AHA Guideline for the } \\
\text { Management of Heart Failure } \\
\text { (Chair: Yancy) })^{7}\end{array}$ & \\
\hline 2016 & & & $\begin{array}{l}\text { ESC Guidelines for the diagnosis and } \\
\text { treatment of acute and chronic heart } \\
\text { failure } 2016 \text { (Chair: Ponikowski) }{ }^{14}\end{array}$ \\
\hline 2017 & & $\begin{array}{l}2017 \text { ACC/AHA/HFSA Focused Update of } \\
\text { the } 2013 \text { ACCF/AHA Guideline for the } \\
\text { Management of Heart Failure } \\
\text { (Chair: Yancy) })^{8}\end{array}$ & \\
\hline 2018 & $\begin{array}{l}\text { Guidelines for diagnosis and treatment of } \\
\text { acute and chronic heart failure } \\
\text { (Chair: Tsutsui), revised version }\end{array}$ & & \\
\hline
\end{tabular}

ACC, American College of Cardiology; ACCF, American College of Cardiology Foundation; AHA, American Heart Association; ESC, European Society of Cardiology. 


\section{Preamble}

In Japan, the Japanese Circulation Society (JCS) published the "Guidelines for Treatment of Chronic Heart Failure" and the "Guidelines for Treatment of Acute Severe Heart Failure" in 2000, and revised the guidelines for chronic heart failure in 2005 and 2010 to reflect new evidence. In 2011, the JCS published "Guidelines for Treatment of Acute Heart Failure" as a revision of the Guidelines for Treatment of Acute Severe Heart Failure. Similarly to the revised guidelines published by the European Society of Cardiology (ESC) in $2012^{1}$ and the American Heart Association (AHA), the revised guideline covered all aspects of heart failure (Table 1). In the United States, the American College of Cardiology (ACC) and the AHA published the Guidelines for the Evaluation and Management of Heart Failure $^{2}$ in 1995, and revised them in 2001, ${ }^{3} 2005,{ }^{4}$ and 2009.5 The 2009 revision added a new section "the Hospitalized Patient" to align with the 2008 ESC Guideline ${ }^{6}$ and covered acute heart failure. The ACC/AHA revised the guideline in $2013^{7}$ and 2017. ${ }^{8}$ In Europe, the ESC published the Guidelines for the Diagnosis of Heart Failure ${ }^{9}$ in 1995, and the Treatment of Heart Failure ${ }^{\mathbf{1 0}}$ in 1997. In 2001, the ESG revised these documents to publish as one document, the Guidelines for the Diagnosis and Treatment of Chronic Heart Failure ${ }^{11}$ and revised the document in 2005.12 In 2005, the ESC published the Guidelines on the Diagnosis and Treatment of Acute Heart Failure, ${ }^{\mathbf{1 3}}$ and then published the Guidelines for the Diagnosis and Treatment of Acute and Chronic Heart Failure to cover both acute and chronic heart failure, ${ }^{6}$ and revised them in $2012^{1}$ and $2016 .{ }^{14}$ The ESC's categorization in heart failure guidelines substantially affected guidelines on acute heart failure published by the AHA and JCS.

This revised version of "the Guidelines for Diagnosis and Treatment of Acute and Chronic Heart Failure" was prepared as joint guidelines by the JCS and the Japanese
Heart Failure Society (JHFS). The working committee for this project includes members and collaborators involved in the previous versions of the heart failure guidelines and members recommended from 11 societies (the JCS, the JHFS, the Japanese Association for Thoracic Surgery, the Japanese Society of Hypertension, the Japanese Society of Echocardiography, the Japanese Society for Cardiovascular Surgery, the Japanese College of Cardiology, the Japanese Association of Cardiac Rehabilitation, the Japan Society of Ultrasonics in Medicine, the Japan Diabetes Society, and the Japanese Heart Rhythm Society). Also, the working group includes members of "the Study Group on Idiopathic Cardiomyopathy" supported by the Health and Labor Sciences Research Grant on Intractable Diseases and those of "the Study Group on the Multi-center Observational Study of Dilated- phase Hypertrophic Cardiomyopathy", supported by the "Practical Research Project for Rare/ intractable Diseases by the Japan Agency for Medical Research and Development".

The working group started the process of fully revising the guideline from October 2016, and developed the first draft in January 2017. Members and collaborators reviewed the guideline according to a total of 885 comments based on blinded review, revised 5 times, and further revised according to a total of 141 comments from the independent assessment committee, before being finalized after detailed discussions at 3 study group meetings. The present guidelines intend to describe standard practice for acute and chronic heart failure according to latest information provided in Western guidelines and the evidence and clinical experience accumulated in Japan.

We hope that this document will help all healthcare professionals involved in the diagnosis and treatment of heart failure.

\section{Introduction}

\section{Classes of Recommendations and Levels of Evidence}

Classification of recommendations and levels of evidence are described similarly to our previous heart failure guidelines using a style similar to those used in the ACC/ AHA guidelines and the ECS guidelines (Tables 2 and 3). In Japan, guidelines for cardiovascular diseases have extensively used a common style that is highly consistent with Western guidelines. On the other hand, the Japan Council for Quality Health Care uses a different style in its Medical Information Network Distribution Service (MINDS) to show grades of recommendations and levels of evidence as described in the "Minds Handbook for Clinical Practice Guideline Development 2007" (Tables 4 and 5). ${ }^{15}$ Accordingly, the present document shows classification of recommendations and level of evidence in the tables including both styles; class of recommendation, level of evidence, grade of recommendation (MINDS) and level of evidence (MINDS).

\section{Major Revisions of the Present Guidelines}

The most important change is that the guidelines on acute heart failure and chronic heart failure are provided in one document, rather than the conventional two separate documents. This reflects our consensus that describing guidelines in two separate documents are not practical since many cases of acute heart failure represents acute worsening of chronic heart failure, and patients require seamless treatment from acute to chronic phase.

In the present guidelines, the following major revisions were made:

1) The definition of heart failure is further clarified, and an easy-to-understand definition is provided for general population. (Section "1. Definition and Classification" in Chapter "II. General Principles").

2) Stages of heart failure, its risk factors, and treatment goals are described (Section "1. Definition and Classifi- 


\begin{tabular}{|c|l|}
\hline \multicolumn{2}{|c|}{ Table 2. Classes of Recommendations } \\
\hline Class I & $\begin{array}{l}\text { Evidence and/or general agreement that a given } \\
\text { procedure or treatment is useful and effective }\end{array}$ \\
\hline Class II & $\begin{array}{l}\text { Conflicting evidence and/or a divergence of opinion } \\
\text { about the usefulness/efficacy of the given procedure } \\
\text { or treatment }\end{array}$ \\
\hline Class IIa & $\begin{array}{l}\text { Weight of evidence/opinion is in favor of usefulness/ } \\
\text { efficacy }\end{array}$ \\
\hline Class IIb & $\begin{array}{l}\text { Usefulness/efficacy is less well established by } \\
\text { evidence/opinion }\end{array}$ \\
\hline Class III & $\begin{array}{l}\text { Evidence or general agreement that the given } \\
\text { procedure or treatment is not useful/effective, and in } \\
\text { some cases may be harmful }\end{array}$ \\
\hline
\end{tabular}

\begin{tabular}{|c|l|}
\hline \multicolumn{2}{|c|}{ Table 3. Level of Evidence } \\
\hline Level A & $\begin{array}{l}\text { Data derived from multiple randomized clinical trials or } \\
\text { meta-analyses }\end{array}$ \\
\hline Level B & $\begin{array}{l}\text { Data derived from a single randomized clinical trial or } \\
\text { large-scale non-randomized studies }\end{array}$ \\
\hline Level C & $\begin{array}{l}\text { Consensus of opinion of the experts and/or small-size } \\
\text { clinical studies, retrospective studies, and registries }\end{array}$ \\
\hline
\end{tabular}

cation" in Chapter "II. General Principles" and Chapter "V. Basic Principles for the Treatment of Heart Failure").

3) In the classification of heart failure based on left ventricular ejection fraction (LVEF), a new category of heart failure with mid-range ejection fraction (HFmrEF) defined as a LVEF of $40-49 \%$, is added to the conventional two categories of heart failure with reduced ejection fraction (HFrEF), and heart failure with preserved ejection fraction ( $\mathrm{HFpEF})$. Another category of patients in whom LVEF recovered after treatment, described as "HFpEF, improved" or "HF with recovered EF", is added as well (Section "1. Definition and Classification" in Chapter "II. General Principles").

4) An algorithm for the diagnosis of heart failure is newly presented (Section "1. Diagnosis" in Chapter "III. Diagnosis").

5) A new chapter is added to describe how to prevent heart failure for each stage of heart failure (Chapter "IV. Prevention of Heart Failure").

6) An algorithm for the treatment of heart failure is newly presented (Chapter "V. Basic Principles for the Treatment of Heart Failure".

7) Pathophysiology and treatment of comorbidities are described in detail (Chapter "IX. Pathophysiology and

\begin{tabular}{|c|l|}
\hline \multicolumn{2}{|c|}{ Table 4. MINDS Grades of Recommendations } \\
\hline Grade A & $\begin{array}{l}\text { Strongly recommended and supported by strong } \\
\text { evidence }\end{array}$ \\
\hline Grade B & $\begin{array}{l}\text { Recommended with moderately strong supporting } \\
\text { evidence }\end{array}$ \\
\hline Grade C1 & $\begin{array}{l}\text { Recommended despite no strong supporting } \\
\text { evidence }\end{array}$ \\
\hline Grade C2 & $\begin{array}{l}\text { Not recommended because of the absence of strong } \\
\text { supporting evidence }\end{array}$ \\
\hline Grade D & $\begin{array}{l}\text { Not recommended as evidence indicates that the } \\
\text { treatment is ineffective or even harmful }\end{array}$ \\
\hline
\end{tabular}

The grade of recommendation is determined based on a comprehensive assessment of the level and quantity of evidence, variation of conclusion, size of effectiveness, applicability to the clinical setting, and evidence on harms and costs. (Adapted from MINDS Treatment Guidelines Selection Committee. 200715)

\begin{tabular}{|c|c|}
\hline \multicolumn{2}{|c|}{$\begin{array}{l}\text { Table 5. MINDS Levels of Evidence (Levels of Evidence in } \\
\text { Literature on Treatment) }\end{array}$} \\
\hline I & $\begin{array}{l}\text { Systematic review/meta-analysis of randomized } \\
\text { controlled trials }\end{array}$ \\
\hline II & One or more randomized controlled trials \\
\hline III & Non-randomized controlled trials \\
\hline IVa & Analytical epidemiological studies (cohort studies) \\
\hline $\mathrm{IVb}$ & $\begin{array}{l}\text { Analytical epidemiological studies (case-control studies } \\
\text { and cross-sectional studies) }\end{array}$ \\
\hline V & Descriptive studies (case reports and case series) \\
\hline $\mathrm{VI}$ & $\begin{array}{l}\text { Not based on patient data, or based on opinions from a } \\
\text { specialist committee or individual specialists }\end{array}$ \\
\hline
\end{tabular}

(Adapted from MINDS Treatment Guidelines Selection Committee. 2007 ${ }^{15}$ )

Treatment of Comorbidities").

8) A flowchart of the treatment and clinical course over time of acute heart failure is newly presented (Chapter "X. Acute Heart Failure").

9) A flowchart on the use of ventricular assist devices for patients with severe heart failure is newly presented (Chapter "XI. Surgical Treatment").

10) Palliative care is described in detail (Chapter "XIII. Palliative Care")

\section{General Principles}

\section{Definition and Classification}

\subsection{Definition of Heart Failure}

Heart failure is defined as a clinical syndrome consisting of dyspnea, malaise, swelling and/or decreased exercise capacity due to the loss of compensation for cardiac pumping function due to structural and/or functional abnormalities of the heart (Table 6).

Heart failure is a disease condition where the heart is
Table 6. Definition of Heart Failure (HF)

\begin{tabular}{l|l} 
Clinical syndrome consisting of dyspnea \\
\hline
\end{tabular}

Definition of HF malaise, swelling and/or decreased exercise in the present capacity due to the loss of compensation for guidelines cardiac pumping function due to structural and/or functional abnormalities of the heart

Definition of HF for the public

(Patient-friendly

Heart failure is a heart disease that causes shortness of breath and swelling, gets worse with time, and shortens life expectancy. 
Table 7. Classification of Heart Failure by Left Ventricular Ejection Fraction (LVEF)

\begin{tabular}{|l|c|l|}
\hline \multicolumn{1}{|c|}{ Definition } & LVEF & \multicolumn{1}{c|}{ Description } \\
\hline $\begin{array}{l}\text { Heart failure with reduced ejection fraction } \\
\text { (HFrEF) }\end{array}$ & $<40 \%$ & $\begin{array}{l}\text { The main feature is systolic dysfunction. In many clinical studies, patients } \\
\text { with a low LVEF despite standard medical treatment for heart failure are } \\
\text { enrolled as patients with HFrEF. }\end{array}$ \\
\hline $\begin{array}{l}\text { Heart failure with preserved ejection fraction } \\
\text { (HFpEF) }\end{array}$ & $\geq 50 \%$ & $\begin{array}{l}\text { The main feature is diastolic dysfunction. Other diseases that may cause } \\
\text { similar symptoms should be ruled out. No effective treatments have been } \\
\text { established. }\end{array}$ \\
\hline $\begin{array}{l}\text { Heart failure with mid-range ejection fraction } \\
\text { (HFmrEF) }\end{array}$ & 40 to $<50 \%$ & $\begin{array}{l}\text { Borderline heart failure. Clinical features and prognosis have not yet been } \\
\text { fully characterized. Treatment should be selected on an individual basis. }\end{array}$ \\
\hline $\begin{array}{l}\text { Heart failure with preserved ejection fraction, } \\
\text { improved (HFpEF improved) or heart failure } \\
\text { with recovered EF (HFrecEF) }\end{array}$ & $\geq 40 \%$ & $\begin{array}{l}\text { Patients with an improvement of LVEF from }<40 \% \text { to } \geq 40 \% \text { after treatment. } \\
\text { It has been suggested that these patients may have a different prognosis } \\
\text { from those with HFrEF, but further studies are required. }\end{array}$ \\
\hline
\end{tabular}

(Source: Prepared based on Yancy CW, et al. $2013^{7}$ and Ponikowski P, et al. 2016'6)

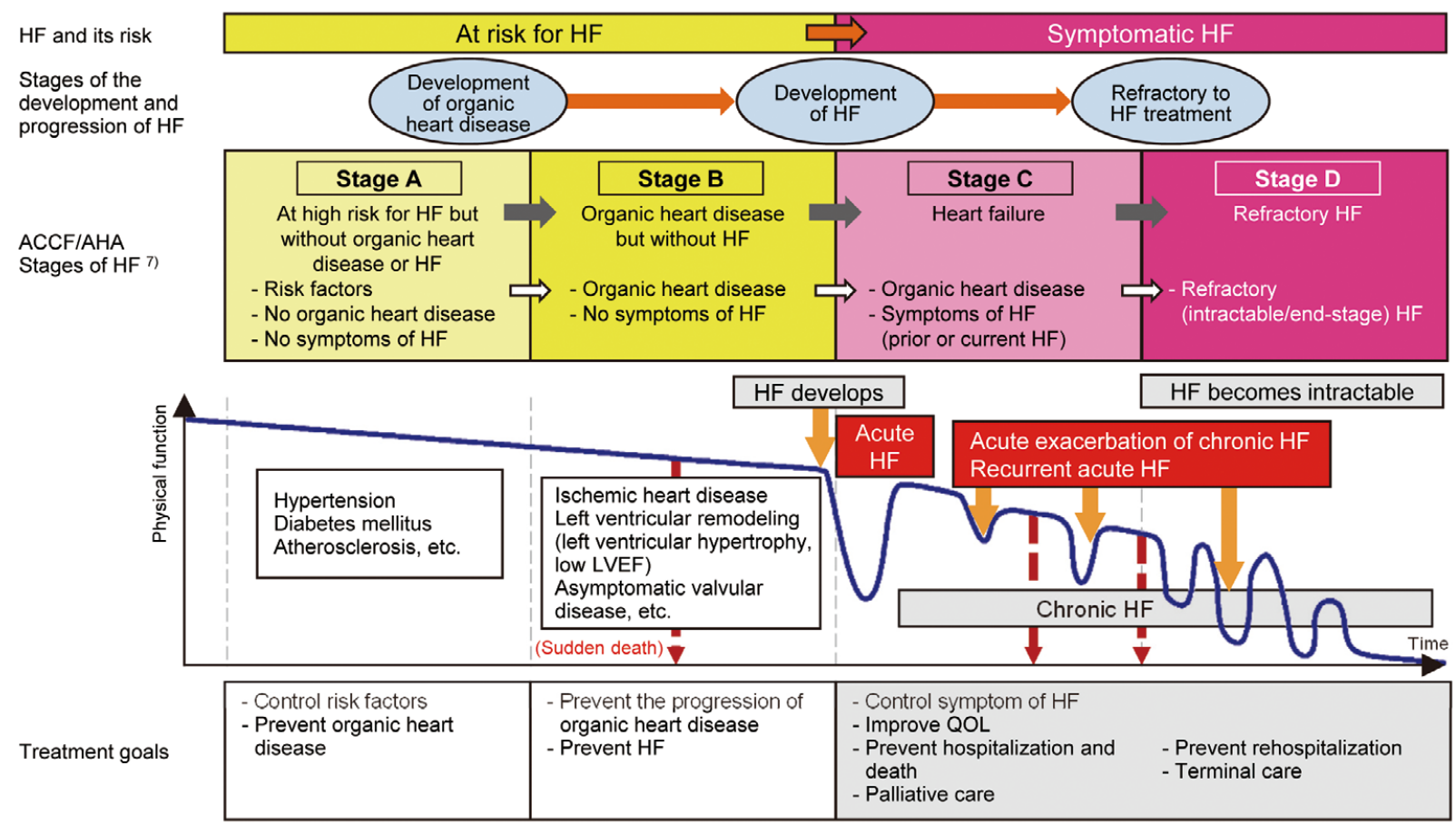

Figure 1. Stages in the development and progression of heart failure and treatment goals by stage. ACCF, American Collage of Cardiology Foundation; AHA, American Heart Association; HF, heart failure; LVEF, left ventricular ejection fraction; QOL, quality of life. (Adapted from The Ministry of Health, Labour and Welfare. $2017^{20}$ with modifications)

unable to fill with and eject enough blood for various reasons such as epicardial, myocardial or endocardial lesions, valvular disease, coronary arterial disease, aortic disease, arrhythmias, and endocrine disorders. However, in many cases left ventricular dysfunction is associated with heart failure, and is the most important factor in determining monitoring and treatment strategies. Heart failure should thus be defined and classified according to left ventricular function.

The Japanese Circulation Society has decided to classify heart failure mainly according to left ventricular ejection fraction in the present guidelines for the treatment of acute heart failure and chronic heart failure as the American College of Cardiology Foundation (ACCF)/American Heart Association (AHA) and the European Society of
Cardiology (ESC) do in their guideline documents.,16 Heart failure with reduced left ventricular ejection fraction (HFrEF) and heart failure with preserved left ventricular ejection fraction (HFpEF) are defined as follows (Table 7), 7,16

\subsubsection{HFrEF}

In many large-scale clinical studies in heart failure, HFrEF was defined as heart failure with a left ventricular ejection fraction $(\mathrm{LVEF})$ of $\leq 35 \%$ or $<40$. In the present guidelines, HFrEF is defined as heart failure with a LVEF of $<40 \%$.

HFrEF is characterized with the high prevalence of left ventricular enlargement, which is present in more than $50 \%$ of patients, and the relatively high prevalence of left ventricular diastolic dysfunction. 


\begin{tabular}{|c|c|}
\hline Stages of HF & NYHA Functional Classification ${ }^{20 a}$ \\
\hline $\begin{array}{l}\text { A. At high risk for } \\
\text { HF but without } \\
\text { organic heart } \\
\text { disease }\end{array}$ & None \\
\hline $\begin{array}{l}\text { B. At high risk for } \\
\mathrm{HF} \text { and with } \\
\text { organic heart } \\
\text { disease }\end{array}$ & None \\
\hline \multirow{4}{*}{$\begin{array}{l}\text { C. Symptomatic } \\
\text { heart failure }\end{array}$} & $\begin{array}{l}\text { I. No limitation of physical activity. } \\
\text { Ordinary physical activity does not } \\
\text { cause severe fatigue, palpitations, } \\
\text { dyspnea or angina. }\end{array}$ \\
\hline & $\begin{array}{l}\text { II. Slight or moderate limitation of physical } \\
\text { activity. Comfortable at rest, but ordi- } \\
\text { nary physical activity causes fatigue, } \\
\text { palpitations, dyspnea or angina. }\end{array}$ \\
\hline & $\begin{array}{l}\text { III. Marked limitation of physical activity. } \\
\text { Comfortable at rest, but less than } \\
\text { ordinary activity causes fatigue, } \\
\text { palpitations, dyspnea or angina. }\end{array}$ \\
\hline & $\begin{array}{l}\text { IV. Unable to carry on any physical activity } \\
\text { without symptoms of HF, or symptoms } \\
\text { of HF and angina at rest. Even slight } \\
\text { activity worsens symptoms. }\end{array}$ \\
\hline \multirow{2}{*}{$\begin{array}{l}\text { D. Refractory heart } \\
\text { failure }\end{array}$} & $\begin{array}{l}\text { III. Marked limitation of physical activity. } \\
\text { Comfortable at rest, but less than } \\
\text { ordinary activity causes fatigue, } \\
\text { palpitations, dyspnea or angina. }\end{array}$ \\
\hline & $\begin{array}{l}\text { IV. Unable to carry on any physical activity } \\
\text { without symptoms of HF, or symptoms } \\
\text { of HF and angina at rest. Even slight } \\
\text { activity worsens symptoms. }\end{array}$ \\
\hline
\end{tabular}

The NYHA functional classification was developed by the New York Heart Association as a system to classify patients with heart diseases according to the severity of symptoms resulting from physical activity, and has been used in the severity classification of heart failure. NYHA class II patients further classified into those with slight limitation of physical activity (Ils) and those with moderate limitation of physical activity (IIm). HF, heart failure; JCS, Japanese Circulation Society; NYHA, New York Heart Association. (Source: Prepared based on Yancy CW, et al. 20137)

\subsubsection{HFpEF}

It has been reported that about half of patients with symptomatic heart failure have normal or preserved LVEF. ${ }^{17}$ In this guideline document, $\mathrm{HFpEF}$ is defined as heart failure with a LVEF of $\geq 50 \%$ to differentiate it clearly from HFrEF. HFpEF may be caused by arrhythmias such as atrial fibrillation, coronary heart disease, diabetes mellitus, and dyslipidemia, but the most common cause of HFpEF is hypertension. ${ }^{\mathbf{1 8}}$

Patients with a mild reduction in LVEF may present some degree of systolic dysfunction, but their clinical manifestations are often similar to those of HFpEF. However, unlike patients with HFpEF, such patients with borderline LVEF may respond well to treatments that have been demonstrated to be effective in the treatment of systolic dysfunction in HFrEF. Accordingly, this condition is defined as heart failure with mid-range LVEF (HFmrEF) or HFpEF borderline. In the present guidelines, HFmrEF is defined as heart failure with a LVEF of 40 to $49 \%$.

In some patients with heart failure initially presented with low LVEF, the LVEF may improve over time during treatment or follow-up. This type of heart failure is referred to as "HFpEF improved" or "HF with recovered EF"

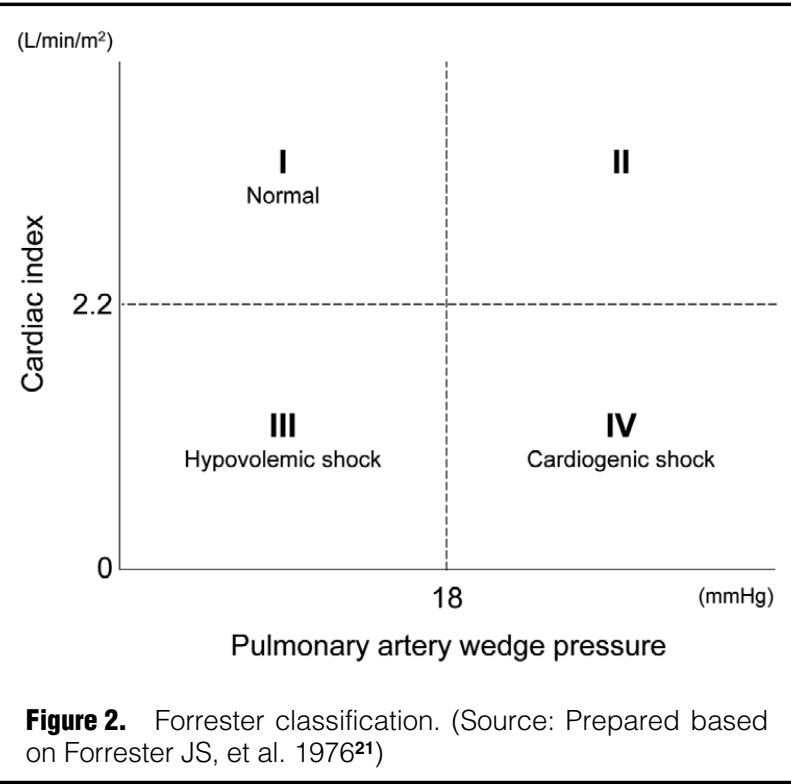

(HFrecEF). ${ }^{19}$ This type of heart failure is often observed in patients with tachycardia-induced cardiomyopathy mainly due to tachycardiac atrial fibrillation, ischemic heart disease, or dilated cardiomyopathy whose cardiac function has improved with $\beta$-blockers. In these patients, left ventricular systolic and/or diastolic function, cardiothoracic ratio (CTR), and brain (B-type) natriuretic peptide (BNP) may return to normal levels.

\section{I1.2 Stages of Heart Failure}

The ACCF/AHA Stages of Heart Failure ${ }^{7}$ is widely used to determine the progression stage of heart failure. The ACCF/AHA created this staging system to help physicians make appropriate treatment intervention, and encourages to treat patients at high risk earlier even when they are asymptomatic. In this guidelines, four stages of heart failure are used according to the ACCF/AHA Stages of Heart Failure: Stage A, asymptomatic patients at high risk of developing heart failure without structural heart disease; Stage B, patients with asymptomatic heart failure who have structural heart disease; Stage C, patients with symptomatic heart failure and structural heart disease, including those with a history of heart failure; and Stage D, patients with refractory heart failure who have had New York Heart Association (NYHA) Class III or IV heart failure despite all available drug therapy or nonpharmacologic therapy with proven efficacy, and are hospitalized for heart failure at least twice a year (Figure 1). ${ }^{\mathbf{2 0}}$

Table 8 outlines a comparison between the JCS stages of heart failure and the NYHA functional classification. ${ }^{7,20 a}$

\subsection{Classification of Heart Failure}

The Forrester classification is one of the most common used criteria to classify the severity of heart failure according to hemodynamic measures (Figure 2). ${ }^{21}$ It was originally developed to predict the prognosis of patients with acute heart failure due to acute myocardial infarction, and the correlation between this severity classification and mortality rate has been demonstrated. The Forrester classification is 


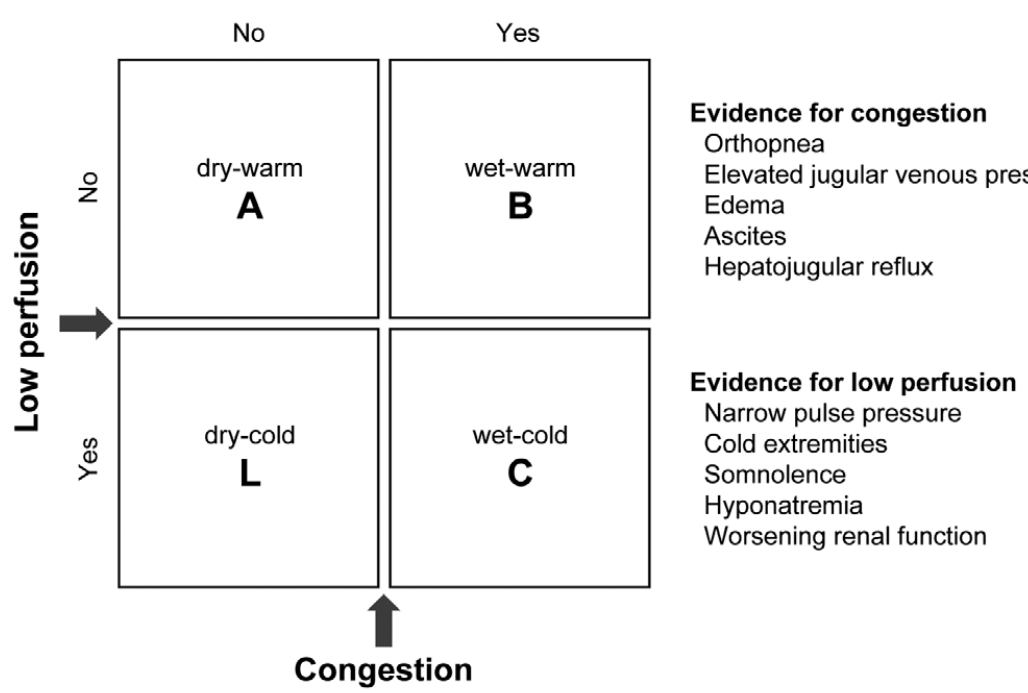

Profile A: No congestion or low perfusion (dry-warm) Profile B: Congestion but no low perfusion (wet-warm) Profile C: Congestion and low perfusion (wet-cold) Profile L: Low perfusion but no congestion (dry-cold)

Figure 3. Nohria-Stevenson classification. (Adapted from Nohria A, et al. $2003^{22}$ with modifications) based on objective measures of organ perfusion and congestion and is thus useful in the assessment of pathophysiological condition of non-ischemic heart failure, but invasive measurements are necessary.

Alternatively, the Nohria-Stevenson classification that can assess the severity of heart failure more easily based only on physical findings is commonly used to assess the risk profile of patients with heart failure according to their peripheral hemodynamics and lung auscultation findings (Figure 3). ${ }^{22}$

\section{Epidemiology, Etiology, and Prognosis}

Heart diseases are the second leading cause of death in Japan, next to malignancy (cancer). Heart failure is the most common cause of death from heart disease. ${ }^{23}$ According to a report of the Japanese registry of all cardiac and vascular diseases, the Japanese Registry of All cardiac and vascular Diseases (JROAD) 2015 study, ${ }^{24}$ the total number of patients hospitalized for heart failure in medical and educational institutions was 238,840 patients in 2015 , showing an increase by more than 10,000 each year. The ratio of patients with acute and chronic heart failure was about half and half. Although there are no accurate statistics on the total number of patients with heart failure in Japan, it has been estimated that the number was about 1 million in 2005 and will reach 1.2 million by $2020 .{ }^{25}$ As the corresponding number in the United States was estimated to be about 5 million in $2005,{ }^{26,27}$ the prevalence of heart failure may be relatively lower in Japan than in the United States. However, it is highly likely that heart failure will increasingly become more common in Japan as the population ages.

In Japan, large-scale registry studies such as the Japanese Cardiac Registry of Heart Failure in Cardiology (JCARECARD; patients registered from 2004 to 2005), ${ }^{28}$ Chronic Heart failure Analysis and Registry in Tohoku district-1
(CHART-1; 2000 to 2004), ${ }^{29}$ and CHART-2 (2006 to $2010)^{30,31}$ have been conducted. The average age of registered patients was 71 years in the JCARE-CARD study, 69 years in the CHART-1 study, and 69 years among Stage C or D heart failure in the CHART-2 study, indicating that elderly people account for large percentages of the registered patients.

An observational study in the United States has reported that LVEF was maintained at $\geq 50 \%$ in nearly half of patients with heart failure. ${ }^{17}$ In Japan, patients with HFpEF account for more than $50 \%$ of all patients with heart failure, and this percentage tends to increase in recent years. ${ }^{30}$ The prognosis of patients with HFpEF has been reported to be poor similarly, although not identically, to those with HFrEF. 32,33 Physicians should be aware that HFpEF will likely become even more common in the super-aged society.

A variety of diseases cause heart failure (Table 9). Almost all types of heart diseases may lead to heart failure. Heart failure may also result from systemic diseases and myocardial injury due to external causes. The most common cause of heart failure is ischemic heart disease, which is followed by hypertension, and valvular diseases. ${ }^{28-30}$ Heart failure due to ischemic heart disease is becoming more common, ${ }^{29}$ while hypertension is considered as the most common cause of HFpEF. ${ }^{34}$

In the assessment of prognosis in the JROAD 2015, inhospital mortality in patients hospitalized for heart failure was about $8 \% .^{24}$ One-year all-cause mortality in patients with heart failure was $7.3 \%$ in the JCARE-CARD and CHART-1 studies. The high rate of rehospitalization due to worsening heart failure is another problem.

According to the JROAD report that described the epidemiology of acute heart failure in Japan, the number of patients hospitalized for acute heart failure was 85,512 in 2013 and increased substantially to 107,049 in $2016 .^{24}$

The epidemiology of acute heart failure in Japan has been extensively studied in the Heart Institute of Japan 


\begin{tabular}{l} 
Table 9. Causes of Heart Failure \\
\hline \multicolumn{1}{c|}{ Myocardial disease } \\
\hline Ischemic heart disease \\
Ischemic cardiomyopathy, stunning, hibernation, microcircula- \\
tory disorder \\
Cardiomyopathy (including genetic forms) \\
Hypertrophic cardiomyopathy, dilated cardiomyopathy, restric- \\
tive cardiomyopathy, arrhythmogenic right ventricular cardio- \\
myopathy, noncompaction, takotsubo cardiomyopathy \\
Cardiotoxic substances and other factors \\
- Addictive and abused substances \\
Alcohol, cocaine, amphetamines, anabolic steroids \\
- Heavy metals \\
Copper, iron, lead, cobalt, mercury \\
- Drugs \\
Antitumor drugs (e.g., anthracycline), immunosuppressive \\
drugs, antidepressant drugs, antiarrhythmic drugs, nonste- \\
roidal anti-inflammatory drugs (NSAIDs), anesthetic drugs \\
- Radiation damage \\
\hline Infectious diseases \\
- Myocarditis \\
e.g., viral, bacterial or rickettsial infections; Chagas' disease \\
\hline Immune disorders \\
e.g., rheumatoid arthritis, systemic lupus erythematosus, \\
polymyositis, mixed connective tissue disease \\
\hline Pregnancy \\
- Peripartum cardiomyopathy \\
Including puerperal cardiomyopathy \\
Infiltrative diseases \\
Sarcoidosis, amyloidosis, hemochromatosis, invasive malignant \\
tumors \\
\hline
\end{tabular}

(Table 9 continued the next column.)

Department of Cardiology - Heart Failure (HIJC-HF) registry, ${ }^{35}$ the JCARE-CARD study, ${ }^{28}$ and the Acute Decompensated Heart Failure Syndromes (ATTEND) registry ${ }^{36}$ in chronological order. The average age of registered patients was over 70 years in all these studies, and many patients had hypertension, diabetes mellitus, dyslipidemia and/or atrial fibrillation. The most common cause of acute heart failure was ischemic heart disease, which accounted for $>30 \%$ in all studies. As compared with epidemiological findings in other countries, patients with acute heart failure in Japan do not differ substantially from those in other countries in terms of age, gender ratio, and prevalence of hypertension, diabetes, and dyslipidemia. ${ }^{37,38}$ However, it should be noted that the prevalence of ischemic

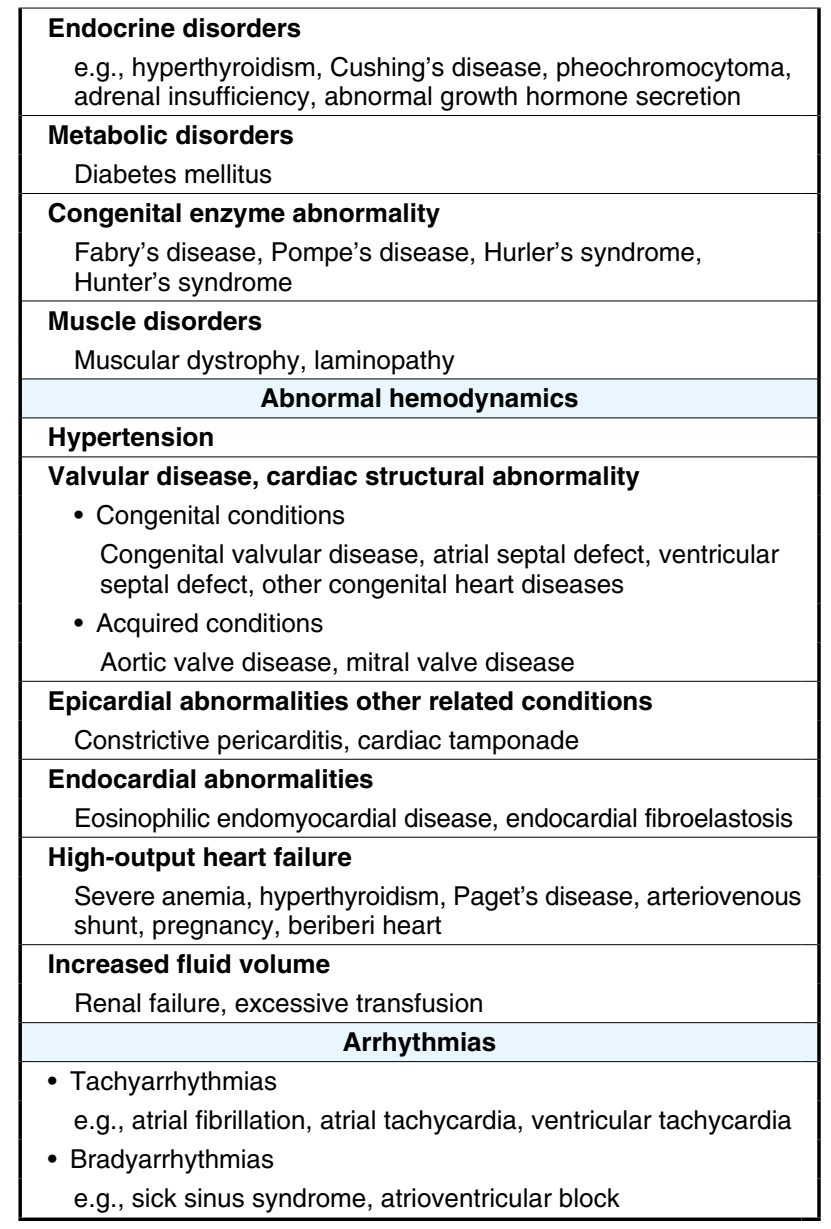

heart disease as an underlying cardiac condition is lower in Japanese patients than those in Western countries, while the prevalence of hypertensive heart disease is higher in Japanese patients than Western patients.

Gender differences should be considered in the diagnosis and treatment of heart failure. Both the results of registry studies in Japan and data in Western countries have indicated that women have a better prognosis than men when adjusted for background characteristics of patients. ${ }^{39}{ }^{42} \mathrm{In}$ Japan where the population is aging rapidly, more women are expected to experience heart failure, but there are only limited data available on gender difference in the treatment of heart failure.

\section{Diagnosis}

\section{Diagnosis (Algorithms) (Figure 4)}

In the diagnosis of heart failure, patients should be examined first for symptoms, medical history, their family history, physical findings, ECG, and chest X-ray findings.

Next, the concentration of brain (B-type) natriuretic peptide (BNP) or N-terminal pro-brain (B-type) natriuretic peptide (NT-proBNP) in the blood should be determined. Figure 4 outlines the cut-off levels of BNP and NT-proBNP for the diagnosis of heart failure. ${ }^{43}$ However, physicians should be aware that BNP and NT-proBNP levels may be lower than these cut-off levels in patients with mild heart failure or patients with severe obese and heart failure. Accordingly, echocardiography is a reasonable diagnostic method to examine for heart failure even in patients with a BNP of $\geq 35$ or $40 \mathrm{pg} / \mathrm{mL}$ or a NT-proBNP of $\geq 125 \mathrm{pg} / \mathrm{mL}$ who are strongly suspected to have heart failure according to their symptoms, patient history or underlying conditions, physical findings, ECG or chest X-ray findings. Patients should be examined comprehensively to determine whether 


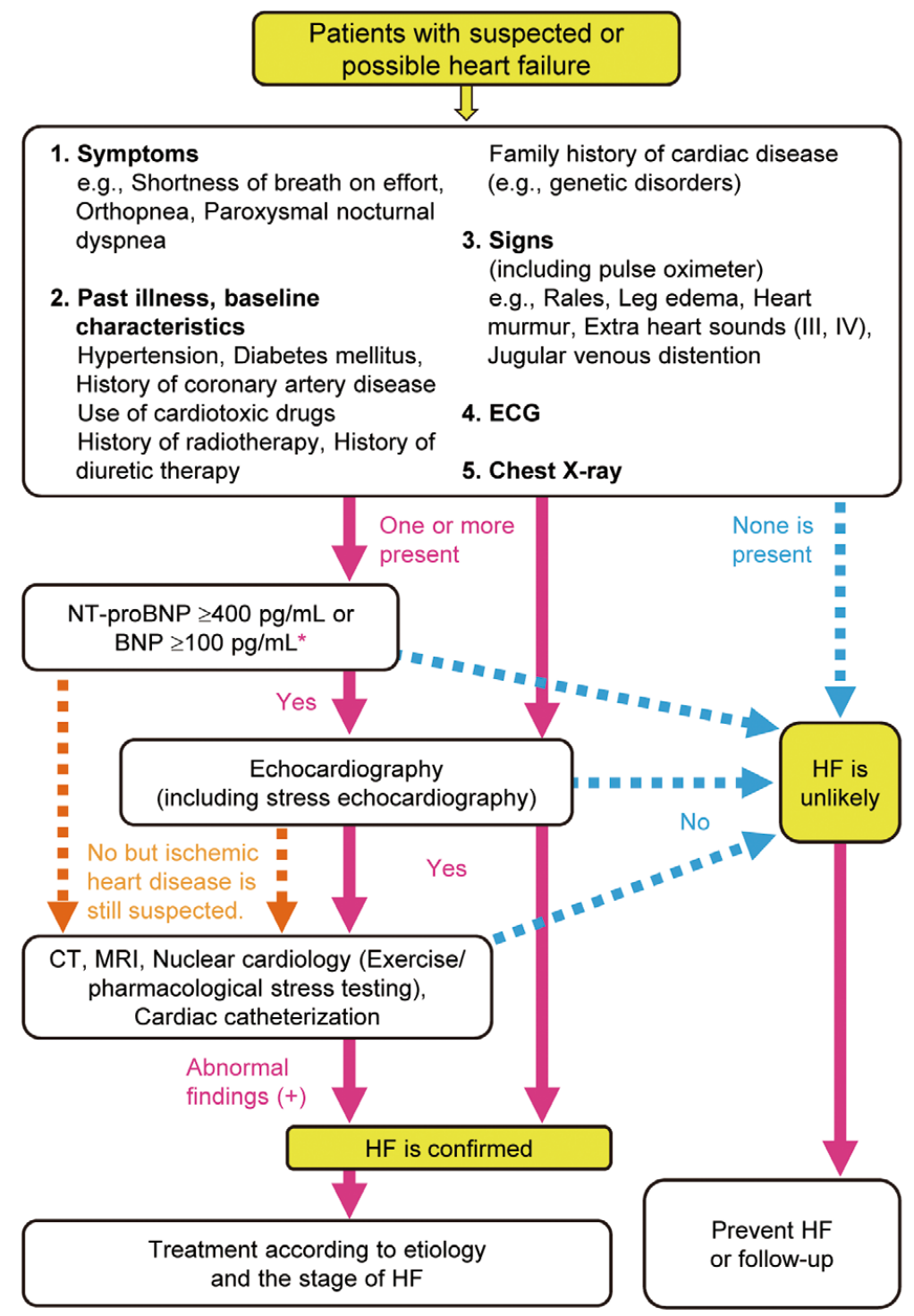

* Mild HF cannot be ruled out in patients with a NT-proBNP of 125 to $400 \mathrm{pg} / \mathrm{mL}$ or a BNP of 35 or 40 to $100 \mathrm{pg} / \mathrm{mL}$. Patients should not be diagnosed based only on NTproBNP/BNP levels. It should be noted that NT-proBNP/BNP levels tend to be high in elderly people, patients with renal dysfunction, and patients with anemia, and low in overweight or obese people. It is needed to assess patients comprehensively based on symptoms, past illness, baseline characteristics, signs, ECG and chest X-ray findings and determine whether echocardiography is indicated or not.
Figure 4. Flowchart for the diagnosis of chronic heart failure. BNP, brain (B-type) natriuretic peptide; CT, computed tomography; ECG, electrocardiogram; $\mathrm{HF}$, heart failure; MRI, magnetic resonance imaging; NT-proBNP, N-terminal pro-brain (B-type) natriuretic peptide. additional examinations should be conducted or not. Echocardiography should be performed in patients who have heart murmur suggestive of valvular disease or abnormal ECG findings clearly indicative of the presence of old myocardial infarction regardless of the level of BNP or NT-proBNP.

Stress echocardiography should also be considered for patients who complain of symptoms inconsistent with echocardiographic findings at rest. When the causative disease cannot be identified with echocardiography, other modalities such as computed tomography (CT), magnetic resonance imaging (MRI), and nuclear imaging should be used. Since some patients with ischemic heart disease may present only with shortness of breath on effort, patients in whom ischemic heart disease cannot be ruled out should be examined for myocardial ischemia using exercise or pharmacological stress test.

Patients confirmed to have heart failure should receive appropriate treatment according to the causative disease and the stage of heart failure.

\section{Symptoms and Signs}

Patients with acute heart failure often show symptoms associated with pulmonary venous congestion due to 


\begin{tabular}{|c|c|c|}
\hline Major criteria & Major or minor criteria & Minor criteria \\
\hline Paroxysmal nocturnal dyspnea & \multirow{10}{*}{$\begin{array}{l}\text { Weight loss of } 4.5 \mathrm{~kg} \text { or more in } 5 \\
\text { days in response to treatment. } \\
\text { When the weight loss is attributable } \\
\text { to the treatment of heart failure, it is } \\
\text { considered } 1 \text { major criterion. } \\
\text { Otherwise it is considered a minor } \\
\text { criterion. }\end{array}$} & Lower leg edema \\
\hline Jugular venous distention & & Nocturnal cough \\
\hline Pulmonary rale & & Dyspnea on ordinary exertion \\
\hline Cardiomegaly on chest X-ray & & Hepatomegaly \\
\hline Acute pulmonary edema & & Pleural effusion \\
\hline Protodiastolic gallop (S3 gallop) & & $\begin{array}{l}\text { Decrease in vital capacity by one } \\
\text { third from maximum recorded }\end{array}$ \\
\hline $\begin{array}{l}\text { Increased central venous pressure } \\
\left(\geq 16 \mathrm{~cm} \mathrm{H}_{2} \mathrm{O}\right)\end{array}$ & & $\begin{array}{l}\text { Tachycardia (heart rate } \\
\geq 120 \text { bpm) }\end{array}$ \\
\hline Increased circulation time $(\geq 25 \mathrm{sec})$ & & \\
\hline Hepatojugular reflux & & \\
\hline $\begin{array}{l}\text { (Pulmonary edema, visceral congestion } \\
\text { of cardiomegaly on autopsy) }\end{array}$ & & \\
\hline
\end{tabular}

Diagnosis of heart failure requires the simultaneous presence of at least 2 major criteria or 1 major criterion in conjunction with 2 minor criteria. (Source: Prepared based on Mckee PA, et al. 197144)

\begin{tabular}{|c|c|c|}
\hline \multicolumn{3}{|l|}{ Congestion } \\
\hline \multirow{2}{*}{$\begin{array}{l}\text { Left-sided } \\
\text { heart failure }\end{array}$} & Symptoms & $\begin{array}{l}\text { Dyspnea, shortness of breath, } \\
\text { tachypnea, orthopnea }\end{array}$ \\
\hline & Signs & $\begin{array}{l}\text { Bubbling rales, wheezing, pink foamy } \\
\text { sputum, third or fourth heart sound }\end{array}$ \\
\hline \multirow[b]{2}{*}{$\begin{array}{l}\text { Right-sided } \\
\text { heart failure }\end{array}$} & Symptoms & $\begin{array}{l}\text { Right hypochondrium pain, anorexia, } \\
\text { abdominal swelling, epigastric } \\
\text { discomfort }\end{array}$ \\
\hline & Signs & $\begin{array}{l}\text { Hepatomegaly, increased hepatobili- } \\
\text { ary enzymes, jugular venous disten- } \\
\text { tion. Signs of pulmonary congestion } \\
\text { are not apparent in patients with } \\
\text { severe right heart failure. }\end{array}$ \\
\hline \multicolumn{3}{|l|}{ Low output } \\
\hline \multicolumn{2}{|l|}{ Symptoms } & $\begin{array}{l}\text { Disturbance of consciousness, } \\
\text { restlessness, memory disorder }\end{array}$ \\
\hline \multicolumn{2}{|l|}{ Signs } & $\begin{array}{l}\text { Cold sweat, cold extremities, } \\
\text { cyanosis, hypotension, oliguria, } \\
\text { agitated or confused }\end{array}$ \\
\hline
\end{tabular}

increased left ventricular end-diastolic pressure or increased left atrial pressure, and/or systemic venous congestion due to increased right atrial pressure, as well as symptoms associated with decreased cardiac output. The Framingham criteria for the diagnosis of heart failure are based on symptoms and findings of left heart failure, right heart failure, and low cardiac output (Table 10) ${ }^{44}$ Patients' symptoms and physical findings should be categorized accordingly to assess their pathophysiological condition (Table 11). Patients with bilateral cardiac failure show signs and symptoms of both left- and right-sided heart failure. The jugular venous pressure can be estimated based on the vertical distance between the horizontal lines drawn from the highest point of internal jugular venous pulse and the sternal angle when the patient is positioned at a $45^{\circ}$ incline (Figure 5). The sternal angle is positioned about $5 \mathrm{~cm}$ above

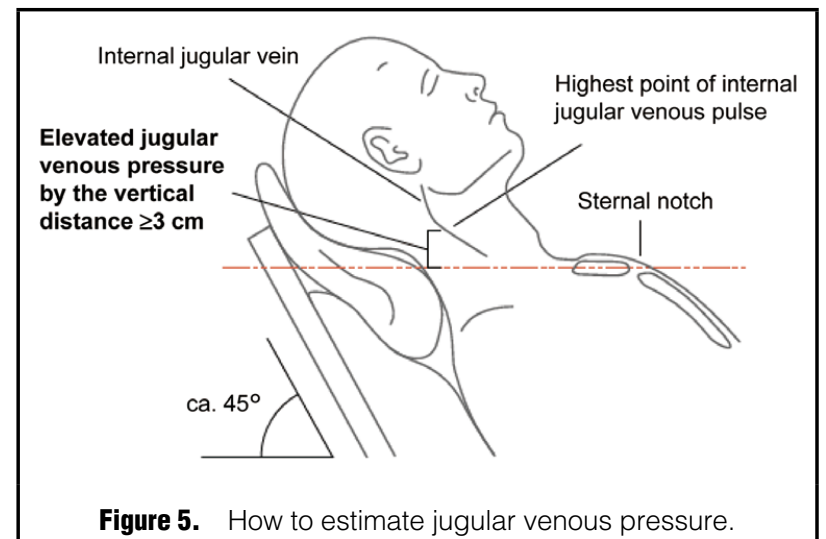

the right atrium. A vertical distance between the sternal angle and the top of the jugular venous pulse of $\geq 3 \mathrm{~cm}$ indicates an increased central venous pressure.

The New York Heart Association (NYHA) Functional Classification provides a simple method of classifying the severity of heart failure based on the patient's symptoms and categorizes patients with heart failure into four groups from Class I to IV. The American College of Cardiology Foundation/American Heart Association (ACCF/AHA) guidelines categorize patients with heart failure into four categories from Stage A (asymptomatic patients at risk for heart failure) to Stage D (patients with refractory heart failure and severe symptoms even at rest) (Table $8^{7}$ in Section "1. Definitions and Classification" in "II. General Principles", and Section "8.1. NYHA Functional Classification" in this chapter). These two classifications are different in nature, but are generally well correlated as can be seen inTable 8. 


\begin{tabular}{|c|c|c|c|c|}
\hline & $\begin{array}{c}\text { Class of } \\
\text { Recommendation }\end{array}$ & $\begin{array}{l}\text { Level of } \\
\text { Evidence }\end{array}$ & $\begin{array}{l}\text { Grade of } \\
\text { Recommendation } \\
\text { (MINDS) }\end{array}$ & $\begin{array}{l}\text { Level of } \\
\text { Evidence } \\
\text { (MINDS) }\end{array}$ \\
\hline \multicolumn{5}{|c|}{ Plasma BNP and serum NT-proBNP } \\
\hline Diagnosis & 1 & A & A & 1 \\
\hline Severity & 1 & A & A & I \\
\hline Prognosis assessment & 1 & A & A & 1 \\
\hline Efficacy evaluation & Ila & B & B & II \\
\hline Screening & Ila & C & B & II \\
\hline \multicolumn{5}{|c|}{ Plasma atrial (A-type) natriuretic peptide (ANP) } \\
\hline Diagnosis & 1 & A & A & I \\
\hline Severity & Ila & B & B & II \\
\hline Prognosis assessment & Ila & B & B & II \\
\hline Efficacy evaluation & Ilb & C & C1 & III \\
\hline Screening & Ilb & C & C1 & III \\
\hline \multicolumn{5}{|c|}{ Myocardial troponins $(\mathrm{T}, \mathrm{I})^{\star}$ and plasma noradrenaline ${ }^{\#}$} \\
\hline Diagnosis & - & - & - & - \\
\hline Severity & Ila & B & B & II \\
\hline Prognosis assessment & Ila & B & B & II \\
\hline Efficacy evaluation & - & - & - & - \\
\hline Screening & - & - & - & - \\
\hline \multicolumn{5}{|c|}{ Aldosterone" and plasma renin activity\# } \\
\hline Diagnosis & - & - & - & - \\
\hline Severity & Ila & C & B & III \\
\hline Prognosis assessment & Ila & C & B & III \\
\hline Efficacy evaluation & - & - & - & - \\
\hline Screening & - & - & - & - \\
\hline \multicolumn{5}{|c|}{ Neurohumoral factors (other than above)" } \\
\hline Diagnosis & - & - & - & - \\
\hline Severity & $\mathrm{Ilb}$ & $\mathrm{C}$ & $\mathrm{C} 1$ & V \\
\hline Prognosis assessment & Ilb & C & $\mathrm{C} 1$ & V \\
\hline Efficacy evaluation & - & - & - & - \\
\hline Screening & - & - & - & - \\
\hline
\end{tabular}

${ }^{*}$ The use of cardiac troponins as biomarkers for heart failure is not covered by the National Health Insurance (NHI) in Japan. However, the guidelines for the management of heart failure proposed by the American College of Cardiology (ACC), the American Heart Association (AHA), and the Heart Failure Society of America (HFSA) suggest the measurement of cardiac troponins as a Class I recommendation with level of evidence A. The guidelines proposed by the European Society of Cardiology (ECS) suggest as a Class I recommendation with level of evidence C. \#The use as a biomarker is not covered by the $\mathrm{NHI}$ in Japan. 


\section{Biomarkers (Table 12)}

Among currently available biomarkers for heart failure, BNP and NT-proBNP are the most significant biomarkers for heart failure and have been used extensively for screening, diagnosis, and prognosis assessment of this condition.

\subsection{Biomarkers Reflecting Sympathetic Activity}

In patients with heart failure, the sympathetic nervous system is overactivated. Congestion and other conditions caused by heart failure reduce the clearance of noradrenaline, and thereby increase noradrenaline levels in the blood. Plasma noradrenaline levels are an indicator of sympathetic activity of the whole body and may be used to assess the prognosis of patients with heart failure. ${ }^{45}$

\subsection{Biomarkers Reflecting the Renin-Angiotensin- Aldosterone System Activity}

In patients with heart failure, the renin-angiotensin-aldosterone (RAA) system is overactivated, and angiotensin II is produced excessively. Plasma renin activity may be high in some patients with mild cardiac dysfunction, and may not be high even in patients with severe heart failure. This finding suggests that the tissue RAA system may be activated independently of the circulatory RAA system to play a role in cardiac remodeling. ${ }^{46} \mathbf{4 8}$

On the other hand, aldosterone levels in the blood are not necessarily high in patients with heart failure, and thus cannot be used as a sensitive marker of heart failure. However, there are many unclear points concerning the secretion and action of aldosterone in heart failure, and the significance of aldosterone/mineral corticoid receptor cascade, including the activation of mineral corticoid receptors, should not be underestimated. ${ }^{49-51}$ Measurements of renin activity and aldosterone levels is strongly recommend in the diagnosis and treatment of hypertension, and is also expected to help physicians understand the cause and pathophysiology of heart failure.

\begin{tabular}{|l|c|c|}
\hline \multicolumn{3}{|c|}{ Table 13. Comparison of BNP and NT-proBNP } \\
\hline & BNP & NT-proBNP \\
\hline Molecular weight & ca. 3,500 & ca. 8,500 \\
\hline Hormonal activity & + & - \\
\hline Cross-reactivity & \multicolumn{2}{|c|}{ proBNP } \\
\hline Half-life & About 20 minutes & About 120 minutes \\
\hline Clearance & NPR-C, NEP, renal & Renal \\
\hline Blood samples & EDTA plasma & $\begin{array}{c}\text { Serum/heparinized } \\
\text { or EDTA plasma }\end{array}$ \\
\hline Reference level & $\leq 18.4 \mathrm{pg} / \mathrm{mL}$ & $\leq 55 \mathrm{pg} / \mathrm{mL}$ \\
\hline $\begin{array}{l}\text { Factors that increase } \\
\text { BNP and NT-proBNP } \\
\text { levels* }\end{array}$ & $\begin{array}{c}\text { Cardiac dysfunction, renal dysfunction, } \\
\text { advanced age, systemic inflammation }\end{array}$ \\
\hline $\begin{array}{l}\text { Factors that decrease } \\
\text { BNP and NT-proBNP } \\
\text { levels }\end{array}$ & \multicolumn{2}{|c}{ Obesity } \\
\hline
\end{tabular}

*Indicating only typical factors that increase or decrease BNP and NT-proBNP levels. Some factors may affect BNP and NT-proBNP levels differently and further studies are needed to characterize the effects of these factors.

BNP, brain (B-type) natriuretic peptide; EDTA; ethylenediamine tetraacetic acid; NEP, neutral endopeptidase; NPR-C, natriuretic peptide receptor-C; NT-proBNP, N-terminal pro-brain (B-type) natriuretic peptide.

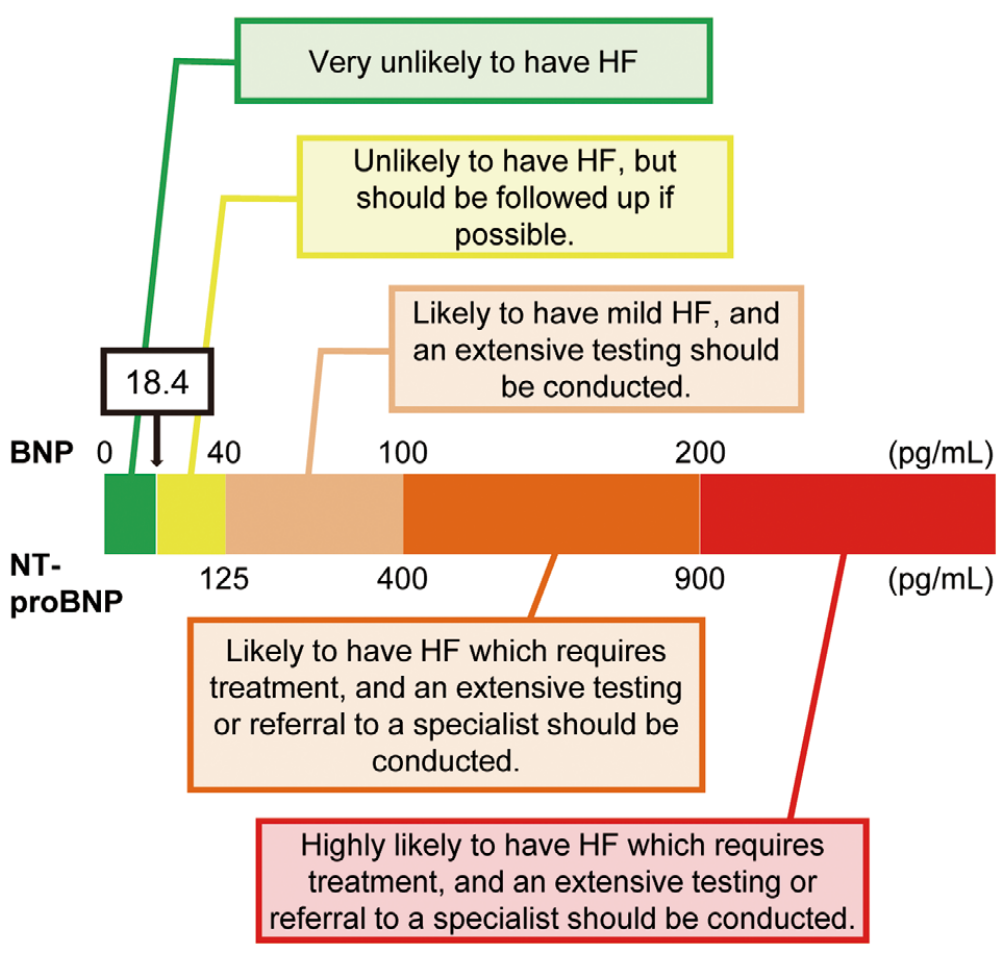

Figure 6. Cut-off levels of plasma BNP and NT-proBNP for the diagnosis of heart failure. BNP, brain (B-type) natriuretic peptide; HF, heart failure; NT-proBNP, N-terminal pro-brain (B-type) natriuretic peptide. (Adopted from Japanese Heart Failure Society ${ }^{43}$ ) 


\section{3.3 Natriuretic Peptides}

Natriuretic peptides include atrial (A-type) natriuretic peptide (ANP), BNP, and C-type natriuretic peptide (CNP). ANP and BNP are cardiac hormones that are synthesized mainly in the atrium and ventricle, respectively. ${ }^{52-54}$ ANP secretion is stimulated by atrial stretch, while BNP secretion is stimulated mainly by ventricular load. Accordingly, BNP levels in the blood reflect the degree of ventricular burden, and thus can be used as a sensitive biochemical marker. ${ }^{54} .57$

Plasma levels of ANP and BNP are high in patients with heart failure because the production of these peptides is enhanced in the heart and their clearance from the blood is delayed. ANP and BNP are degraded through internalization after binding to the natriuretic peptide receptor $\mathrm{C}$ (NPR-C) or metabolized by neutral endopeptidase (NEP). No clear relationship has been shown between the metabolism of ANP and BNP and the pathophysiology of heart failure, but the clearance of these peptides is low in patients with renal dysfunction. When comparing BNP and its $\mathrm{N}$-terminal fragment NT-ProBNP, a precursor of BNP with a larger molecular weight, the effect of renal dysfunction is more substantial on NT-proBNP than on BNP (Table 13).

BNP is superior to ANP in terms of the sensitivity and specificity as a supportive diagnostic marker for heart failure. ${ }^{58} \mathrm{BNP}$ (or NT-proBNP) is useful in confirming the presence and classifying the severity of heart failure, as well as in assessing the prognosis of patients with heart failure. ${ }^{59-64}$ It also plays a substantial role as a marker to monitor the efficacy of treatment over time in individual patients who may not compare with others.

The Japanese Heart Failure Society has published a statement entitled "Points to consider when using BNP and NT-pro BNP levels in the blood for the diagnosis and treatment of heart failure" (Figure 6) ${ }^{43}$ This publication set a cut-off point of $40 \mathrm{pg} / \mathrm{mL}$ for plasma BNP concentration $\left(125 \mathrm{pg} / \mathrm{mL}\right.$ for NT-proBNP $\left.{ }^{43}\right)$ to identify patients susceptible to heart failure according to the results of the J-ABS multicenter study, although the upper normal limit for plasma BNP is set at $18.4 \mathrm{pg} / \mathrm{mL}(55 \mathrm{pg} / \mathrm{mL}$ for NT-pro BNP). ${ }^{65,66}$ Plasma BNP levels differ among individuals, and tend to remain low in obese patients in whom the severity of heart failure may be underestimated.

\subsection{Markers for Myocardial Injury}

Cardiac troponin I and T levels in the blood, which are used as biomarkers for myocardial infarction, have been pointed out to increase in patients with non-ischemic myocardial diseases. Continued increase in troponin levels in the blood indicate a poor prognosis. ${ }^{67,68}$ High-sensitivity troponin assays are useful in the diagnosis of acute coronary syndrome ${ }^{69,70}$ and are expected also useful in risk assessment in patients with chronic heart failure. ${ }^{71,72}$

\subsection{Inflammatory Markers}

It has been pointed out that immune cells and their production of cytokines are involved in the development of heart failure. In fact, blood levels of tumor necrosis factor (TNF) $\alpha$ and interleukin (IL)- 6 are elevated in patients with heart failure, and also are related to their prognosis. ${ }^{73-75} \mathrm{~A}$ report has described that high-sensitivity C-reactive protein (CRP) levels is related to the prognosis of heart failure regardless of whether patients have underlying diseases or not. ${ }^{76}$ In Western countries, a rapid test for ST2, a receptor for IL-33 that is a member of IL-1 family, has been used. Elevated blood levels of ST2 have been reported in patients with acute heart failure, and this is expected to be useful in prognostic assessment of heart failure. ${ }^{77}$

\subsection{Oxidative Stress Markers}

It is considered that oxidative stress is enhanced in patients with heart failure, and causes endothelial damage and cardiac dysfunction. Reports have described that low density lipoprotein (LDL) levels in the blood and levels of 8 -isoprostagrandin F2 $\alpha$ (also known as 8-iso-PGF2 $\alpha$ or 8 -isoprostane) and 8-hydroxy-2'-deoxyguanosine (8-OHdG) in the blood or urine are useful biomarkers of oxidative stress. ${ }^{78} 80$

\subsection{Uric Acid}

Although an association between high uric acid levels and heart failure has been indicated, ${ }^{\mathbf{8 1}-84}$ its sensitivity and specificity as a biomarker of heart failure are not high enough. Further studies are awaited to better clarify its benefits and usage in the diagnosis of or risk assessment for heart failure.

\subsection{Vasopressin}

Vasopressin, a hormone secreted by the posterior pituitary gland, induces vasoconstriction through $\mathrm{V}_{1}$ receptors and affects fluid balance through $\mathrm{V}_{2}$ receptors. Vasopressin secretion is stimulated in heart failure. It has been reported that levels of copeptin, a fragment of the vasopressin precursor, in the blood are related to the prognosis of heart failure. ${ }^{85}$

\subsection{Others}

Metabolic syndrome is a risk factor for ischemic heart disease and heart failure. Reports have described that levels of adiponectin, an adipocytokine related to metabolic syndrome, are high in patients with heart failure and are related to their prognosis. ${ }^{\mathbf{8 6}-\mathbf{8 8}}$

Endothelin (ET) is a potent vasoconstrictor. ${ }^{89}$ Plasma levels of ET-1 and big-ET-1 correlate inversely with LVEF, and are determinants of mortality. ${ }^{\mathbf{9 0}, 91}$

Levels of adrenomedullin in the blood increase as the severity of heart failure progresses, and are related to the poor prognosis of heart failure. ${ }^{92}$ Adrenomedullin is produced in the heart and the systemic vasculature, and has a role in cellular protection.

\section{Chest X-ray}

Plain chest X-ray has remained as a useful technique to detect the presence of and assess the severity of heart failure (Table 14). Pulmonary congestion is an important X-ray finding of left heart failure, and is used to assess the severity of it (Figure 7). Patients with mild heart failure (pulmonary venous pressure: 15 to $20 \mathrm{mmHg}$ ) show redistribution of blood flow towards the apex (cephalization). Patients with interstitial pulmonary edema (pulmonary venous pressure: 20 to $30 \mathrm{mmHg}$ ) show peribronchial or perivascular edema 


\begin{tabular}{|l|c|c||c|c|}
\hline Table 14. Recommendations and Levels of Evidence on the Use of Chest X-ray in Heart Failure \\
\hline & $\begin{array}{c}\text { Class of } \\
\text { Recommendation }\end{array}$ & $\begin{array}{c}\text { Level of } \\
\text { Evidence }\end{array}$ & $\begin{array}{c}\text { Grade of } \\
\text { Recommendation } \\
\text { (MINDS) }\end{array}$ & $\begin{array}{c}\text { Level of } \\
\text { Evidence } \\
\text { (MINDS) }\end{array}$ \\
\hline $\begin{array}{l}\text { Chest X-ray to examine patients with a new-onset or } \\
\text { an acute worsening of heart failure }\end{array}$ & $\mathrm{I}$ & $\mathrm{C}$ & $\mathrm{B}$ & $\mathrm{V}$ \\
\hline
\end{tabular}
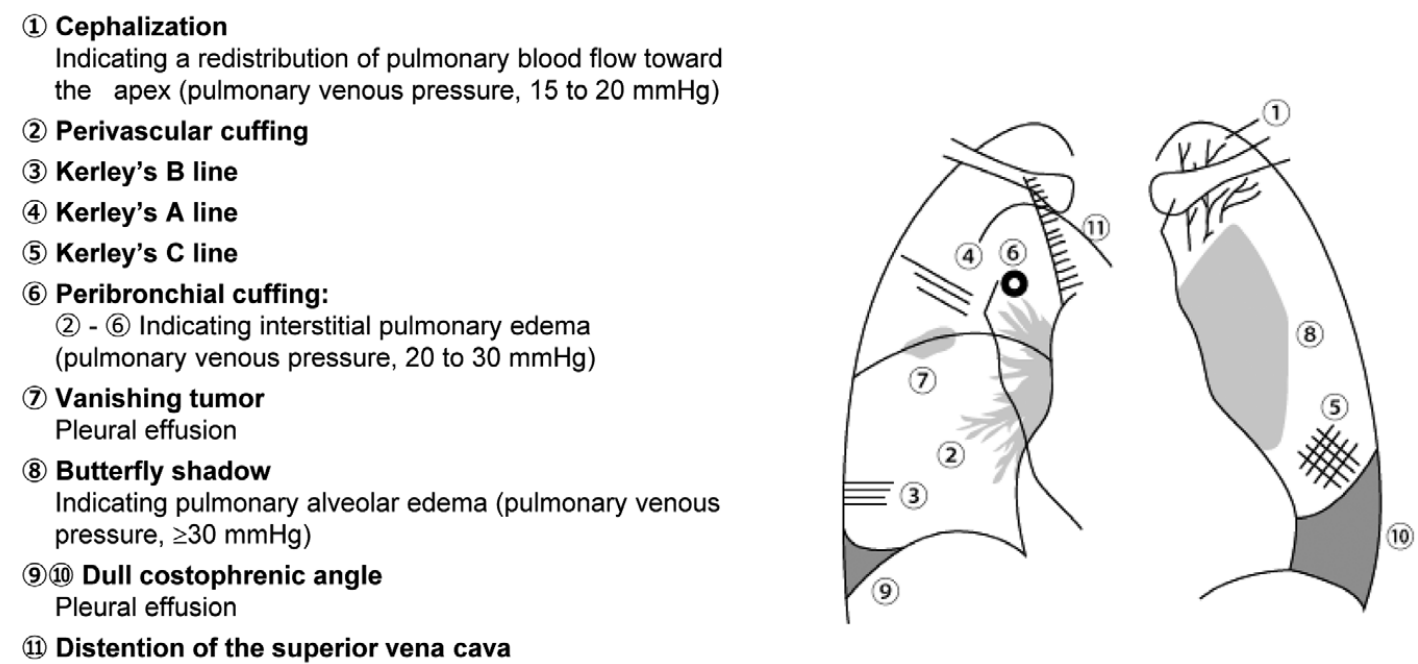

Figure 7. Chest X-ray findings of heart failure (schema)

(cuffing signs) or Kerley's A, B, and/or C lines. More advanced patients show alveolar pulmonary edema (pulmonary venous pressure: $\geq 30 \mathrm{mmHg}$ ) with butterfly shadow. Pleural fluid is often found in patients with bilateral cardiac failure, while it is rarely found in patients with right cardiac failure. ${ }^{93}$ Pleural fluid and pulmonary edema are more commonly found in the right lungs. ${ }^{94}$ Shadows in the mediastinum may be found in association with left atrial enlargement, right ventricular enlargement, or enlarged shadows of the pulmonary artery, but the diagnostic significance of these X-ray findings is not superior to echocardiographic findings.

\section{Echocardiography}

Echocardiography is used to assess cardiac function and hemodynamics, as well as the cause, pathophysiology, and severity of heart failure. Repetitive measurement is also useful in the assessment of treatment efficacy and prognosis (Table 15). Table 16 lists normal values for transthoracic echocardiographic and Doppler parameters obtained in the Japanese population, which are essential in the assessment of cardiac function in patients with heart failure. ${ }^{\mathbf{5 5}, 96}$

\subsection{Assessment of Cardiac Function}

\section{5.1.1 Assessment of Left Ventricular Systolic Function}

Left ventricular systolic function is assessed with LVEF. Patients with heart failure are classified into those with preserved LVEF (HFpEF), and those with reduced LVEF
(HFrEF). LVEF is determined using the modified Simpson method (disc method).

In addition to the LVEF-based assessment of systolic function of the left ventricle as a whole, regional wall motion should also be assessed. Left ventricular global longitudinal strain (GLS) determined with speckle-tracking echocardiography is highly reproducible and useful in early diagnosis of heart failure. ${ }^{97}$

\section{5.1.2 Assessment of Left Ventricular Diastolic Function}

Left ventricular diastolic function consists of left ventricular relaxation that defines early diastolic inflow velocity and left ventricular stiffness that defines mid- and end-diastolic inflow velocity. Left ventricular dilation and inflow may be limited not only by diastolic dysfunction due to left ventricular myocardial damage but also by compression due to right ventricular enlargement, constrictive pericarditis, or cardiac tamponade.

Echocardiographic parameters for the assessment of left ventricular diastolic function are based on secondary changes such as an increase in left atrial pressure and morphological changes. As there is no single parameter that can assess left ventricular diastolic function by itself, multiple parameters as listed below should be assessed comprehensively.

\section{a. Left Ventricular Inflow Velocity Pattern (E/A)}

In patients with sinus rhythm, peak blood flow velocity in early diastole (the $\mathrm{E}$ wave) and peak flow velocity in late diastole caused by atrial contraction (the A wave) are observed. Patients with an initial phase of diastolic dysfunc- 
Table 15. Recommendations and Levels of Evidence for the Use of Echocardiography in Heart Failure

\begin{tabular}{|c|c|c|c|c|}
\hline & $\begin{array}{c}\text { Class of } \\
\text { Recommendation }\end{array}$ & $\begin{array}{l}\text { Level of } \\
\text { Evidence }\end{array}$ & $\begin{array}{l}\text { Grade of } \\
\text { Recommendation } \\
\text { (MINDS) }\end{array}$ & $\begin{array}{l}\text { Level of } \\
\text { Evidence } \\
\text { (MINDS) }\end{array}$ \\
\hline $\begin{array}{l}\text { Echocardiography to assess cardiac function, left } \\
\text { ventricular wall motion, valvular disease, right ventricular } \\
\text { function, and pulmonary hypertension in patients } \\
\text { suspected of having heart failure }\end{array}$ & 1 & C & A & $\mathrm{IVb}$ \\
\hline $\begin{array}{l}\text { Echocardiography to assess cardiac function in } \\
\text { patients with heart failure who are going to receive } \\
\text { drug therapy or device therapy }\end{array}$ & I & C & A & $\mathrm{IVb}$ \\
\hline $\begin{array}{l}\text { Repeat echocardiography to assess patients with a } \\
\text { change in their clinical condition of heart failure }\end{array}$ & I & C & A & $\mathrm{IVb}$ \\
\hline $\begin{array}{l}\text { Stress echocardiography to assess myocardial viability } \\
\text { in patients with HFrEF }\end{array}$ & Ila & B & B & $\mathrm{IVb}$ \\
\hline $\begin{array}{l}\text { Echocardiography to assess whether the limitation of } \\
\text { physical activity is attributable to cardiac dysfunction }\end{array}$ & Ila & B & B & $\mathrm{IVb}$ \\
\hline $\begin{array}{l}\text { Echocardiography as a routine follow-up procedure for } \\
\text { patients with stable heart failure }\end{array}$ & III & B & D & $\mathrm{IVb}$ \\
\hline $\begin{array}{l}\text { Transthoracic echocardiography in patients who can } \\
\text { be diagnosed and assessed with transesophageal } \\
\text { echocardiography }\end{array}$ & III & B & D & $\mathrm{IVb}$ \\
\hline
\end{tabular}

HFrEF, heart failure with reduced ejection fraction.

\begin{tabular}{|c|c|c|}
\hline \multicolumn{3}{|c|}{$\begin{array}{l}\text { Table 16. Normal Range of Echocardiographic Indices of } \\
\text { Cardiac Function in Japanese Male and Females }\end{array}$} \\
\hline & Male & Female \\
\hline $\begin{array}{l}\text { Left ventricular end-diastolic diameter } \\
(\mathrm{mm})\end{array}$ & $48 \pm 4$ & $44 \pm 3$ \\
\hline $\begin{array}{l}\text { Left ventricular end-systolic diameter } \\
(\mathrm{mm})\end{array}$ & $30 \pm 4$ & $28 \pm 3$ \\
\hline $\begin{array}{l}\text { Left ventricular end-diastolic volume } \\
\text { index }\left(\mathrm{mL} / \mathrm{m}^{2}\right)\end{array}$ & $53 \pm 11$ & $49 \pm 11$ \\
\hline $\begin{array}{l}\text { Left ventricular end-systolic volume index } \\
\left(\mathrm{mL} / \mathrm{m}^{2}\right)\end{array}$ & $19 \pm 5$ & $17 \pm 5$ \\
\hline Left ventricular ejection fraction (\%) & $64 \pm 5$ & $66 \pm 5$ \\
\hline Left ventricular mass index $\left(\mathrm{g} / \mathrm{m}^{2}\right)$ & $76 \pm 16$ & $70 \pm 14$ \\
\hline Left atrial dimension $(\mathrm{mm})$ & $32 \pm 4$ & $31 \pm 3$ \\
\hline Left atrial volume index $\left(\mathrm{mL} / \mathrm{m}^{2}\right)$ & $24 \pm 7$ & $25 \pm 8$ \\
\hline $\begin{array}{l}\text { Right ventricular end-diastolic diameter } \\
\text { (apical four-chamber view at the base } \\
\text { level) (mm) }\end{array}$ & $31 \pm 5$ & $28 \pm 5$ \\
\hline Right ventricular area change (FAC, \%) & $44 \pm 13$ & $46 \pm 11$ \\
\hline $\begin{array}{l}\text { Tricuspid annular plane systolic excursion } \\
\text { (TAPSE, mm) }\end{array}$ & \multicolumn{2}{|c|}{$24 \pm 3.5$} \\
\hline $\begin{array}{l}\text { Tricuspid annular peak systolic velocity } \\
\left(\mathrm{s}^{\prime}\right)(\mathrm{cm} / \mathrm{sec})\end{array}$ & \multicolumn{2}{|c|}{$14.1 \pm 2.3$} \\
\hline E/e' (septum) & $7.4 \pm 2.2$ & $7.9 \pm 2.2$ \\
\hline $\mathrm{e}^{\prime}$ (septum, cm/sec) & $10.0 \pm 2.8$ & $10.8 \pm 3.2$ \\
\hline E/e' (lateral wall) & $5.5 \pm 1.8$ & $6.2 \pm 1.8$ \\
\hline $\mathrm{e}^{\prime}$ (lateral wall, $\mathrm{cm} / \mathrm{sec}$ ) & $13.5 \pm 3.9$ & $13.7 \pm 4.1$ \\
\hline
\end{tabular}

FAC, fractional area change. (Source: Prepared based on Daimon $\mathrm{M}$, et al. $2008^{95}$ and Lang RM, et al. 201596)

tion show "relaxation abnormality patterns", which are characterized by a low E/A ratio and prolonged E-wave deceleration time (DT). Patients with advanced diastolic dysfunction and increased left atrial pressure show "pseudonormalized filling pattern" with a high E wave and a high E/A ratio. Patients with more advanced diastolic dysfunction with higher left atrial pressure show "restrictive pattern" characterized by an even higher E/A ratio.

\section{b. Early Diastolic Mitral Annular Velocity ( $\left.\mathbf{e}^{\prime}\right)$}

Patients with diastolic dysfunction show a reduction of early diastolic mitral annular velocity $\left(\mathrm{e}^{\prime}\right)$. This should be determined at either the septal side or lateral wall side of the mitral valve annuls or the mean of the measurements at the two locations.

\section{c. E/e' Ratio}

$\mathrm{E} / \mathrm{e}^{\prime}$ ratio, the ratio of peak early diastolic left ventricular filling (E) to the peak mitral annular velocity ( $\left.e^{\prime}\right)$ is useful in the diagnosis of heart failure independent of LVEF, and positively correlates with left atrial pressure. ${ }^{98}$ However, it is noted that the correlation between $\mathrm{E} / \mathrm{e}^{\prime}$ and the severity of heart failure is poor in patients with hypertrophic cardiomyopathy in whom a high $\mathrm{E} / \mathrm{e}^{\prime}$ ratio may not be associated with high left atrial pressure. ${ }^{99}$

\section{d. Left Atrial Volume Index (LAVI)}

Left atrial enlargement is considered to reflect long-term left atrial load due to diastolic dysfunction, and correlates with the severity of diastolic dysfunction. ${ }^{100}$

\section{e. Tricuspid Regurgitant Velocity}

High left atrial pressure causes secondary pulmonary hypertension and an increase in the right ventricular systolic pressure. Tricuspid regurgitation velocity (TRV) may indicate an increase in left atrial pressure in patients without pulmonary arterial hypertension.

\section{f. Assessment of Diastolic Function in HFpEF}

The presence/absence of diastolic dysfunction in patients with preserved LVEF may be assessed based on E/e', e', TRV, and LAVI (Figure 8). ${ }^{101}$ Patients diagnosed as having diastolic dysfunction should be examined as instructed for patients with reduced LVEF to estimate left atrial pressure. Constrictive pericarditis is a condition that must be differentiated from diastolic dysfunction associated with myocardial disorder, and usually shows high E waves of left and right ventricular inflow with substantial respiratory changes. 


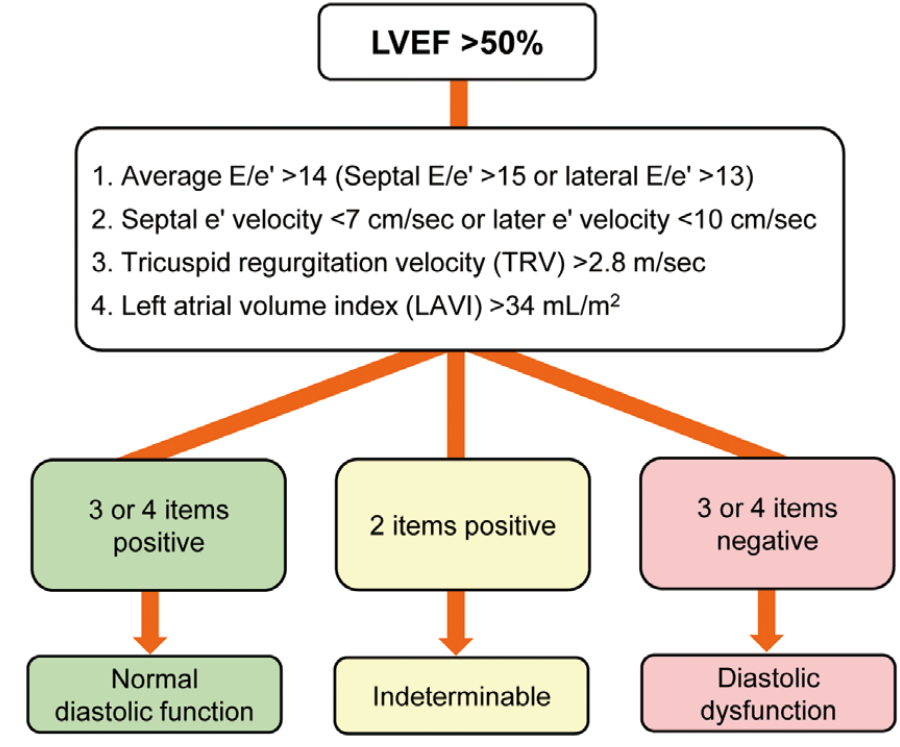

Figure 8. How to diagnose diastolic dysfunction in patients with HFpEF. HFpEF, heart failure with preserved ejection fraction; LVEF, left ventricular ejection fraction. (Source: Prepared based on Nagueh SF, et al. $2016^{101}$ with modification)

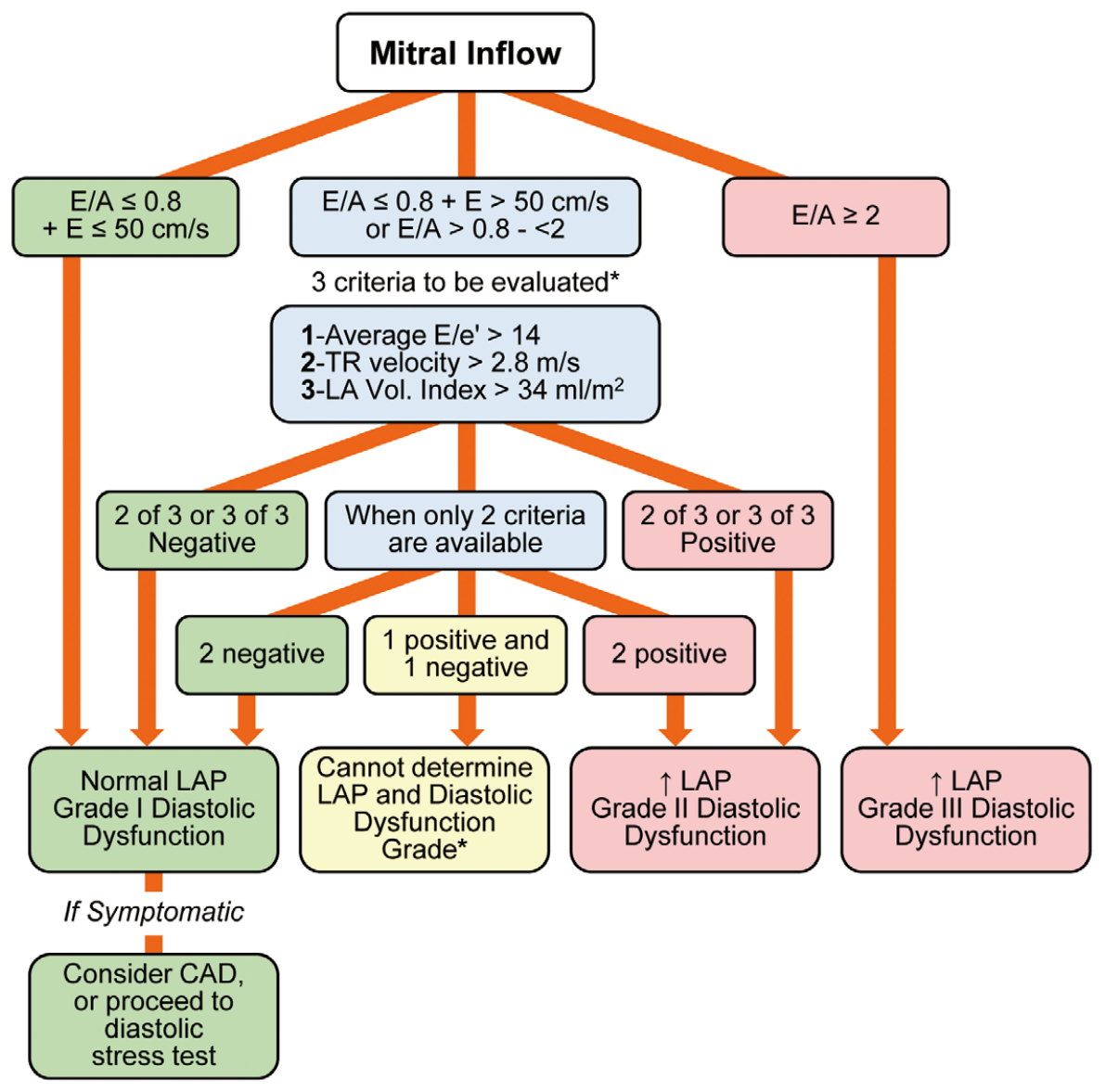

(*LAP indeterminate if only 1 of 3 parameters available. Pulmonary vein S/D ratio $<1$ applicable to conclude elevated LAP in patients with depressed LV EF)

Figure 9. Algorithm for the diagnosis of elevated left atrial pressure by echocardiography. CAD, coronary artery disease; LA, left atrium; LAP, left atrial pressure; TR, tricuspid regurgitation. (Adapted from Nagueh SF, et al. 2016101) 


\section{g. Assessment of Diastolic Function in HFrEF}

Diastolic dysfunction is considered present in all patients with low LVEF. E/A, E wave velocity, E/e', TRV, LAVI, and other parameters are used to assess whether left atrial pressure is high or not (Figure 9). ${ }^{102}$

\section{5.1.3 Assessment of Right Ventricular Function}

Right ventricular function may be assessed with relatively simple parameters, such as fractional area change (FAC), tricuspid annular plane systolic excursion (TAPSE), and tricuspid annular peak systolic velocity (s'). Right ventricular volume cannot be determined using two-dimensional echocardiography because of its complex morphology. Right ventricular volume and ejection fraction may be determined using three-dimensional echocardiography.

\subsection{Assessment of Hemodynamics}

\section{a. Right Ventricular Systolic Pressure (Pulmonary Artery Systolic Pressure)}

Right ventricular systolic pressure (pulmonary artery systolic pressure) may be estimated based on the sum of systolic right ventricular-atrial pressure gradient, which can be calculated from tricuspid regurgitant velocity, and right atrial pressure. However, it cannot be estimated in patients with tricuspid valve separation causing laminar regurgitation flows. Also, it should be noted that patients with substantial right heart dysfunction might show moderately increased or normal pulmonary artery systolic pressure due to low cardiac output.

\section{b. Right Atrial Pressure}

Right atrial pressure may be estimated on the basis of inferior vena cava diameter at a distance of 1 to $2 \mathrm{~cm}$ from the right atrium and whether or not the diameter changes with respiration.

\section{c. Cardiac Output}

Cardiac output is calculated as a product of outflow tract area and velocity-time integral (VTI).

\subsection{Stress Echocardiography}

Contractile reserve and cardiac viability cannot be assessed solely with parameters at rest. Dobutamine-stress or exercise echocardiography may be useful in such cases. Exercise echocardiography is also beneficial in assessing the presence of diastolic dysfunction or pulmonary hypertension in patients with shortness of breath on effort. ${ }^{103}$

\subsection{Assessment for Causative Conditions}

It is important to assess the cause of heart failure and its severity in individual patients. Heart failure may develop in ischemic heart disease, hypertensive heart disease, cardiomyopathy, structural valvular disease, and infective endocarditis. Transesophageal echocardiography should be considered in patients who are suspected to have infective endocarditis but do not show abnormal findings on transthoracic echocardiograms and in patients after valvular surgery whenever necessary.

\subsection{Assessment in Acute Heart Failure}

Hemodynamics should be assessed in patients with acute heart failure. LVEF may be determined by visual estimation in these cases.

Patients with pericardial effusion should be suspected for cardiac tamponade. Myocarditis should be suspected in patients with pericardial effusion associated with transient ventricular wall thickening and diffuse wall hypokinesis as well as elevated levels of inflammatory markers and myocardial proteins in the blood.

Lung ultrasound assessment has been reported to be beneficial in the diagnosis of pulmonary edema. B-lines, that appears as 8 lines in the right and left lungs, are useful for differentiating dyspnea due to acute heart failure than that due to other causes with a $94 \%$ sensitivity and $92 \%$ specificity. ${ }^{104}$

\section{Imaging (MRI, CT, Nuclear Imaging, and PET) (Table 17)}

\begin{abstract}
6.1 Cardiac Magnetic Resonance Imaging (MRI) I 6.1.1 Assessment of Cardiac Morphology and Function Cardiac MRI is the most reliable imaging technique for the assessment of the morphology and ejection fraction of the left and right ventricles, and left ventricular mass because of its accuracy and reproducibility. ${ }^{105}$ Cardiac MRI is used to specify the cause of heart failure according to the results of morphologic assessment and ventricular wall motion based on cine images. ${ }^{106,107}$ MRI is highly useful in the assessment of right ventricular and complex congenital heart diseases that are often difficult to be assessed correctly with echocardiography. ${ }^{108}$ However, MRI should be used alternative to echocardiography only when necessary because of the latter is less time-consuming and inexpensive method that does not require substantial expertise in imaging analysis.
\end{abstract}

\section{6.1.2 Assessment of Myocardial Tissues}

The presence of myocardial fibrosis may be detected with late gadolinium enhancement MRI. The distribution of delayed enhancement is useful information in differentiating from ischemic and non-ischemic cardiomyopathy or in evaluating myocardial viability. ${ }^{105,107} \mathrm{~T} 1$ mapping can be used for similar assessment without using contrast, and is becoming a more common technique. ${ }^{109}$ As high signals in $\mathrm{T} 2$ weighed images are consistent with edema, this technique can be used in the assessment of inflammation associated with acute myocardial infarction, acute myocarditis, or cardiac sarcoidosis. ${ }^{107}$

\subsection{Cardiac CT}

Cardiac CT can be used to assess the morphology and function of the heart in addition to anatomical features of the coronary arteries. Considering its high specificity for the diagnosis of ischemic heart disease, cardiac CT should be considered for patients with heart failure whose pre-test probability of coronary artery disease is low or moderate or in whom diagnosis is difficult with other non-invasive stress tests to rule out coronary artery disease. ${ }^{110,111}$

\subsection{Nuclear Imaging}

1 6.3.1 Thallium or Technetium

Patients with ischemic cardiomyopathy should be assessed for myocardial ischemia and viability using thallium chlo- 


\begin{tabular}{|c|c|c|c|c|}
\hline & $\begin{array}{c}\text { Class of } \\
\text { Recommendation }\end{array}$ & $\begin{array}{l}\text { Level of } \\
\text { Evidence }\end{array}$ & $\begin{array}{l}\text { Grade of } \\
\text { Recommendation } \\
\text { (MINDS) }\end{array}$ & $\begin{array}{l}\text { Level of } \\
\text { Evidence } \\
\text { (MINDS) }\end{array}$ \\
\hline \multicolumn{5}{|l|}{ MRI } \\
\hline $\begin{array}{l}\text { MRI to assess cardiac anatomy and function } \\
\text { Patients who cannot be assessed appropriately with } \\
\text { echocardiography, patients with congenital heart } \\
\text { disease, and patients who require right ventricular } \\
\text { assessment }\end{array}$ & 1 & $\mathrm{C}$ & A & IVb \\
\hline $\begin{array}{l}\text { Delayed-enhancement MRI } \\
\text { To differentiate between ischemic and non-ischemic } \\
\text { cardiomyopathy in patients who cannot be assessed } \\
\text { adequately with other procedures }\end{array}$ & 1 & C & A & IVb \\
\hline $\begin{array}{l}\text { Delayed-enhancement MRI } \\
\text { To identify underlying heart disease in patients with } \\
\text { non-ischemic myocardiopathy }\end{array}$ & Ila & C & B & $\mathrm{IVb}$ \\
\hline $\begin{array}{l}\text { MRI T2-wighed images } \\
\text { To assess the severity of myocardial inflammation }\end{array}$ & Ila & C & B & V \\
\hline \multicolumn{5}{|l|}{ CT } \\
\hline $\begin{array}{l}\text { Coronary artery CT } \\
\text { To rule out coronary artery disease in patients with } \\
\text { heart failure whose pre-test probability of coronary } \\
\text { artery disease is low or moderate }\end{array}$ & Ila & $\mathrm{C}$ & B & IVa \\
\hline \multicolumn{5}{|l|}{ Nuclear cardiology } \\
\hline $\begin{array}{l}\text { SPECT using thallium chloride or technetium- } \\
\text { labeled tracers } \\
\text { To assess myocardial ischemia and myocardial } \\
\text { viability in patients with ischemic cardiomyopathy }\end{array}$ & 1 & B & A & II \\
\hline $\begin{array}{l}\text { SPECT using thallium chloride or technetium- } \\
\text { labeled tracers } \\
\text { To assess myocardial blood flow in patients with } \\
\text { dilated cardiomyopathy }\end{array}$ & $\mathrm{llb}$ & C & C1 & IVa \\
\hline $\begin{array}{l}\text { ECG-gated SPECT } \\
\text { To assess left ventricular volume and LVEF in } \\
\text { patients who cannot be assessed appropriately with } \\
\text { echocardiography }\end{array}$ & Ila & C & B & $\mathrm{IVb}$ \\
\hline $\begin{array}{l}\text { I-123-BMIPP scintigraphy } \\
\text { To differentiate between ischemic and non-ischemic } \\
\text { cardiomyopathy based on a mismatch between } \\
\text { I-123-BMIPP uptake and blood flow distribution }\end{array}$ & $\mathrm{llb}$ & $\mathrm{C}$ & C1 & $\mathrm{IVb}$ \\
\hline $\begin{array}{l}\text { I-123-MIBG scintigraphy } \\
\text { To assess the severity of heart failure }\end{array}$ & Ila & C & B & $\mathrm{IVb}$ \\
\hline $\begin{array}{l}\text { I-123-MIBG scintigraphy } \\
\text { To predict tolerability/efficacy and assess efficacy of } \\
\text { drug therapy in patients with dilated cardiomyopathy }\end{array}$ & I & A & A & II \\
\hline $\begin{array}{l}\text { Cardiac pool scintigraphy } \\
\text { To assess LVEF in patients who cannot be assessed } \\
\text { adequately with other procedures }\end{array}$ & 1 & B & B & III \\
\hline $\begin{array}{l}\text { Cardiac pool scintigraphy } \\
\text { To assess right ventricular function and anatomy in } \\
\text { patients who cannot be assessed adequately with } \\
\text { other procedures }\end{array}$ & Ila & B & B & IVa \\
\hline $\begin{array}{l}\text { FDG PET } \\
\text { To assess myocardial viability in patients who cannot } \\
\text { be assessed adequately with other procedures }\end{array}$ & Ilb & $\mathrm{C}$ & C1 & IVb \\
\hline $\begin{array}{l}\text { FDG PET } \\
\text { To detect active lesions of cardiac sarcoidosis }\end{array}$ & I & C & A & $\mathrm{IVb}$ \\
\hline
\end{tabular}

BMIPP, $\beta$-methyl-p-iodophenyl-pentadecanoic acid; CT, computed tomography; FDG PET, fluorodeoxyglucose positron emission tomography; LVEF, left ventricular ejection fraction; MIBG, metaiodobenzylguanidine; MRI, magnetic resonance imaging; SPECT, single-photon emission computed tomography.

ride or technetium (Tc) labeled radiopharmaceuticals. ${ }^{\mathbf{1 1 1}-\mathbf{1 1 3}}$ Single-photon emission computed tomography (SPECT) may also provide additional information on cardiac function such as left ventricular volume and LVEF.

\subsubsection{I-123 BMIPP and I-123 MIBG}

Iodine-123- $\beta$-methyl-p-iodophenyl-pentadecanoic acid (I-123
BMIPP), a marker for myocardial fatty acid metabolism, is used to detect myocardial damage associated with infarction, myocardial ischemia, or non-ischemic cardiomyopathy. As washout rate of I-123- metaiodobenzylguanidine (I-123 MIBG) increases and heart/superior mediastinum ratio $(\mathrm{H} / \mathrm{M})$ on delayed images decreases in patients with heart failure, this technique can be used in severity assessment. ${ }^{114-118}$ 


\begin{tabular}{|l|c|c|c|c|}
\hline \multicolumn{3}{|c|}{ Table 18. Recommendations and Levels of Evidence for the Use of Invasive Approaches With } \\
Catheterization in Heart Failure
\end{tabular}

ARDS, acute respiratory distress syndrome.

I-123 MIBG is useful in predicting the prognosis of heart failure due to dilated cardiomyopathy and hypertrophic cardiomyopathy, ${ }^{119-121}$ assessing tolerability of and predicting the efficacy of $\beta$-blocker therapy in dilated cardiomyopathy, and evaluating the efficacy of drug therapy in heart failure. ${ }^{122-124}$

\section{6.3.3 Tc-99m Pyrophosphate}

Tc-99 $\mathrm{m}$ pyrophosphate (PYP) is useful in the detection of myocardial necrosis and the diagnosis of mutant or wildtype transthyretin-related cardiac amyloidosis. ${ }^{125}$

\section{| 6.3.4 Gallium Scintigraphy}

Gallium scintigraphy is used to detect new lesions of cardiac sarcoidosis, but its diagnostic sensitivity is lower than fluorodeoxyglucose positron emission tomography (FDG PET). ${ }^{123-125}$ Gallium scintigraphy is used to detect the presence of inflammatory diseases such as myocarditis and infective endocarditis and cardiac lesions of malignant lymphoma. ${ }^{107,112}$

\section{6.3.5 Cardiac Blood Pool Scintigraphy}

Cardiac blood pool scintigraphy is a technique to determine LVEF using Tc-labeled human serum albumin or Tclabeled red blood cells, ${ }^{112,126}$ and can be used to asses left ventricular diastolic function. ${ }^{126}$ This technique is also useful in assessing the function of the right ventricle, which has a complex anatomy. ${ }^{127,128}$ This is used for patients in whom assessment with echocardiography, MRI, CT, and ECGgated SPECT is difficult.

\subsection{PET}

PET can be used in combination with N-13 ammonia to assess the severity of myocardial ischemia, and in combination with F-18 FGD to assess myocardial viability and detect active lesions of cardiac sarcoidosis. ${ }^{\mathbf{1 2 9}, 130}$

\section{Cardiac Catheterization (Hemodynamics and Biopsy)}

Common indications for right side heart catheterization, left side heart catheterization, and endomyocardial biopsy in patients with heart failure are summarized in Table 18.

\section{Exercise Tolerance}

Exercise tolerance is the most important determinant of functional status in patients with heart failure. Exercise intolerance is a major manifestation in patients with heart failure, which reflects the severity of heart failure, and is closely related to decreases in activities of daily living and quality of life (QOL) in patients. One of the main purposes of heart failure treatment is to improve exercise tolerance, which is a factor of better prognosis.

\subsection{NYHA Functional Classification (Table 8) ${ }^{7}$}

The New York Heart Association (NYHA) functional classification is used to assess the severity of heart failure based on the level of ADL, ${ }^{131}$ and reflects the QOL of patients. However, this is not a quantitative or objective scaling system.

\subsection{Specific Activity Scale}

Specific activity scale (SAS) describes the amount of exercise to perform a given activity of daily living with the number of metabolic equivalent units (METs) (Table 19).132,133 With this scale, the minimum amount of exercise that causes 


\section{Table 19. Questionnaire on Physical Activity}

In the Specific Activity Scale (SAS), patients are asked to answer the following questions with "yes," "hard to do" or "I don't know". The amount of exercise (in METs) described in the first question to which the patient answered "hard to do" indicates the minimum amount of physical activity to provoke symptoms, and is recorded as the SAS score.

1. Can you have a comfortable sleep at night? ( $\leq 1 \mathrm{MET})$

2. Do you feel comfortable in the lying position? ( $\leq 1 \mathrm{MET}$ )

3. Can you take meals or wash your face by yourself? (1.6 METs)

4. Can you go to the bathroom by yourself? (2 METs)

5. Can you change your clothes by yourself? (2 METs)

6. Can you do kitchen work or sweep the room with a broom? (2 to 3 METs)

7. Can you make your bed by yourself? ( 2 to 3 METs)

8. Can you swab the floor? ( 3 to 4 METs)

9. Can you have a shower without trouble? ( 3 to 4 METs)

10. Can you practice radio gymnastic exercises without any trouble? ( 3 to $4 \mathrm{METs}$ )

11. Can you walk $100-200 \mathrm{~m}$ of level ground at the same speed as healthy persons do $(4 \mathrm{~km} / \mathrm{hr}$ ) without any trouble? ( 3 to 4 METs)

12. Can you garden (weeding for a brief time, etc.) without any trouble? (4 METs)

13. Can you take a bath by yourself? ( 4 to 5 METs)

14. Can you go upstairs at the same speed as healthy persons do without any trouble? (5 to 6 METs)

15. Can you do light farming (digging the garden, etc.)? (5 to 7 METs)

16. Can you walk $200 \mathrm{~m}$ of level ground at a quick pace without any trouble? (6 to 7 METs)

17. Can you remove snow? (6 to 7 METs)

18. Can you practice tennis (or ping pong) without any trouble? (6 to 7 METs)

19. Can you practice jogging (at about $8 \mathrm{~km} / \mathrm{hr}$ ) over a distance of 300 to 400 meters without any trouble? ( 7 to 8 METs)

20. Can you practice swimming without any trouble? ( 7 to 8 METs)

21. Can you practice rope skipping without any trouble? ( $\geq 8$ METs)

Minimum amount of physical activity to provoke symptoms: METs

METs, metabolic equivalents. (Excerpted from Sasayama S, et al. $1992^{132}$ and The Japanese Intractable Diseases Information Center ${ }^{133}$ )

symptoms of heart failure may be quantified using a unit of oxygen uptake.

\subsection{Six-Minute Walking Test}

The six-minute walking test is a maximal exercise test to measure the maximal distance an individual able to walk in 6 minutes. The reference value for the Japanese population is calculated by multiplying [454-0.87×age (years)$0.66 \times$ weight $(\mathrm{kg})] \pm 82(2 \mathrm{SD})$ by height $(\mathrm{m}) .{ }^{134}$ It has been

\begin{tabular}{|c|c|c|}
\hline \multicolumn{3}{|c|}{$\begin{array}{l}\text { Table 20. A Comparison of Major Exercise Capacity } \\
\text { Measures in Patients With Heart Failure }\end{array}$} \\
\hline $\begin{array}{c}\text { NYHA } \\
\text { classification }\end{array}$ & $\begin{array}{l}\text { Specific Activity } \\
\text { Scale (SAS) }\end{array}$ & $\begin{array}{l}\text { Percent peak oxygen } \\
\text { uptake }\left(\% \text { peak } \mathrm{VO}_{2}\right)\end{array}$ \\
\hline I & 6 METs or more & $\begin{array}{l}80 \% \text { or more of } \\
\text { the reference level }\end{array}$ \\
\hline II & 3.5 to $5.9 \mathrm{METs}$ & $\begin{array}{l}60 \text { to } 80 \% \text { of } \\
\text { the reference level }\end{array}$ \\
\hline III & 2 to $3.4 \mathrm{METs}$ & $\begin{array}{l}40 \text { to } 60 \% \text { of } \\
\text { the reference level }\end{array}$ \\
\hline IV & $\begin{array}{l}1 \text { to } 1.9 \text { METs } \\
\text { or less }\end{array}$ & $\begin{array}{l}\text { Impossible to determine or } \\
<40 \% \text { of the reference level }\end{array}$ \\
\hline
\end{tabular}

There is no established formula indicating exact correspondence between NYHA functional classes and SAS. In this table, according to a consensus among experts, the following assumption was used: the amount of exercise is 2 METs for walking inside a room, 3.5 METs for usual walking, 4 METs for light exercise or stretching exercise, 5 to 6 METs for fast walking, and 6 to 7 METs for walking upstairs.

METs, metabolic equivalents; NYHA, New York Heart Association. (Adapted from The Japanese Intractable Diseases Information Center ${ }^{133}$ )

reported that the six-minute walking distance well correlates with NYHA functional classification and peak oxygen uptake (peak $\mathrm{VO}_{2}$ ), ${ }^{135}$ and is useful in predicting the prognosis of patients with heart failure. ${ }^{136}$

\subsection{Cardiopulmonary Exercise Testing}

The most objective index of exercise tolerance is oxygen uptake during maximal exercise. Peak $\mathrm{VO}_{2}$, which is measured during cardiopulmonary exercise testing (CPX), ${ }^{137}$ is suitable parameter in assessing the prognosis of patients with heart failure, ${ }^{138-141}$ selecting candidates for heart transplantation, ${ }^{\mathbf{1 3 8}, \mathbf{1 4 1}-\mathbf{1 4 3}}$ and classifying the severity of heart failure. ${ }^{144}$ Patients with a Peak $\dot{\mathrm{VO}}_{2}$ of $<14 \mathrm{~mL} / \mathrm{kg} / \mathrm{min}$ have a poor prognosis, ${ }^{138}$ and those with $<10 \mathrm{~mL} / \mathrm{kg} / \mathrm{min}$ have an extremely poor prognosis. When peak $\dot{\mathrm{VO}}_{2}$ is expressed as percentage of age-predicted peak $\dot{\mathrm{VO}}_{2}\left(\%\right.$ peak $\left.\dot{\mathrm{VO}}_{2}\right)$, patients with a $\%$ peak $\dot{\mathrm{VO}}_{2}$ of $<50 \%$ are considered to have a poor prognosis. ${ }^{\mathbf{1 4 5}}$ Table 20 shows the relationship between the NYHA classification, SAS, and \% peak $\mathrm{VO}_{2}{ }^{133}$

The anaerobic threshold, that is defined as the point during exercise when anaerobic metabolism occurs in addition to aerobic metabolism, accounts for about 50 to $55 \%$ of the maximal exercise capacity. This threshold is used as an index of daily activity level, ${ }^{137,146}$ on which allowable exercise level ${ }^{\mathbf{1 4 7}}$ and exercise prescriptions ${ }^{\mathbf{1 4 8}}$ are determined.

The $\dot{\mathrm{VE}} / \dot{\mathrm{VCO}}_{2}$ slope indicates the tidal volume needed to eliminate carbon dioxide produced during metabolism, and is considered as a factor related to dyspnea on exertion in patients with heart failure. Patients with a $\dot{\mathrm{VE}} / \dot{\mathrm{VCO}}_{2}$ slope of $>35$ are considered to have a poor prognosis. ${ }^{149}$

Table 21 summarizes recommendations for exercise capacity evaluation in heart failure and their evidence levels.

\section{Prevention of Heart Failure}

The development, progression (exacerbations), and recurrence of heart failure should be prevented through lifestyle management such as diet and exercise and treatment inter- ventions to control risk factors for heart failure and manage asymptomatic heart failure (Table 22). It is also important that patients are managed continuously in hospitals, local 


\begin{tabular}{|c|c|c|c|c|}
\hline & $\begin{array}{c}\text { Class of } \\
\text { Recommendation }\end{array}$ & $\begin{array}{l}\text { Level of } \\
\text { Evidence }\end{array}$ & $\begin{array}{l}\text { Grade of } \\
\text { Recommendation } \\
\text { (MINDS) }\end{array}$ & $\begin{array}{l}\text { Level of } \\
\text { Evidence } \\
\text { (MINDS) }\end{array}$ \\
\hline $\begin{array}{l}\text { Medical interview } \\
\text { To survey the patient's exercise capacity, mental } \\
\text { status, cognitive function, and social environment }\end{array}$ & 1 & B & B & IVa \\
\hline $\begin{array}{l}\text { Cardiopulmonary exercise testing } \\
\text { To consider the indication of heart transplantation } \\
\text { and other advanced treatment }\end{array}$ & 1 & B & B & II \\
\hline $\begin{array}{l}\text { Cardiopulmonary exercise testing } \\
\text { To specify the cause in patients in whom dyspnea on } \\
\text { exertion or easy fatigability limits their physical activities }\end{array}$ & 1 & B & B & $\mathrm{IVb}$ \\
\hline $\begin{array}{l}\text { Measurement of peak oxygen uptake } \\
\text { To assess prognosis }\end{array}$ & 1 & B & B & II \\
\hline $\begin{array}{l}\text { Cardiopulmonary exercise testing } \\
\text { To develop an exercise prescription }\end{array}$ & Ila & B & B & II \\
\hline $\begin{array}{l}\text { Cardiopulmonary exercise testing } \\
\text { In patients with atrial fibrillation or pacing, to assess } \\
\text { heart rate response, to determine optimal exercise } \\
\text { programs, to evaluate blood pressure, arrhythmia, } \\
\text { strength of physical activities during exercise, to } \\
\text { assess change in exercise capacity over time, and to } \\
\text { assess treatment efficacy }\end{array}$ & Ila & B & B & II \\
\hline $\begin{array}{l}\text { Cardiopulmonary exercise testing } \\
\text { As a routine test procedure }\end{array}$ & III & C & C2 & VI \\
\hline
\end{tabular}

communities, and their home by multidisciplinary approach involving diverse healthcare professionals, including physicians, nurses, pharmacists, dieticians, and physical therapists and hospital-clinic collaborations.

\section{Hypertension}

Antihypertensive treatment has been shown to prevent the development of heart failure and improve the prognosis of patients with hypertension. ${ }^{\mathbf{1 5 0 - 1 5 3}}$ In addition to lifestyle modifications such as low-salt diet and body weight management, patients should be treated with antihypertensive drugs (e.g., angiotensin converting enzyme [ACE] inhibitors, angiotensin II receptor blockers [ARBs]), diuretics and $\beta$-blockers. ${ }^{154}$

\section{Coronary Heart Disease}

Patients with coronary artery disease should be treated with ACE inhibitors to prevent cardiovascular events including heart failure and improve the ptognosis. ${ }^{155}$ Patients after myocardial infarction should be treated with ACE inhibitors, ${ }^{156-158} \beta$-blockers, ${ }^{159}$ statins, ${ }^{160-162}$ and/or mineralocorticoid receptor antagonists (MRA) $)^{163-165}$ as secondary prevention for cardiovascular events. ${ }^{166} \mathrm{ARBs}$ are indicated for patients who are intolerant to ACE inhibitors, especially those with left ventricular dysfunction. ${ }^{\mathbf{1 6 7 , 1 6 8}}$

In the Occluded Artery Trial (OAT) ${ }^{169}$ that investigated the efficacy of percutaneous coronary intervention (PCI) in the prevention of heart failure in patients after acute myocardial infarction with a LVEF of $<50 \%$, PCI to the culprit lesion of complete occlusion during the period between 3 and 28 days after the onset was not effective in preventing cardiac accidents including heart failure for four years after PCI.

\section{Obesity and Diabetes Mellitus}

As obesity and diabetes mellitus are associated with the development of heart failure, ${ }^{170-173}$ and diabetes mellitus and metabolic syndromes, which are conditions caused by insulin resistance, are major risk factors for cardiovascular diseases, patients with these conditions should receive comprehensive risk management including lifestyle modifications for weight management and exercise therapy as well as drug therapy. ${ }^{174}$

In the Empagliflozin Cardiovascular Outcome Event Trial in Type 2 Diabetes Mellitus Patients (EMPA-REG OUTCOME), the sodium-glucose cotransporter 2 (SGLT2) inhibitor empagliflozin reduced the risk of hospitalization for and death from heart failure in patients with type 2 diabetes mellitus and a history of cardiovascular disease, and reduced the rate of hospitalization for heart failure in patients without a history of cardiovascular events. ${ }^{175-177}$ Similarly, in the Canagliflozin Cardiovascular Assessment Study (CANVAS), canagliflozin reduced the risk of hospitalization for heart failure in patients with type 2 diabetes and a high cardiovascular risk $(34 \%$ of the participants received treatment for the primary prevention of cardiovascular events and the remaining $64 \%$ had a history of cardiovascular disease). ${ }^{178}$ These findings indicate that SGLT2 inhibitors are effective in preventing heart failure in patients with type 2 diabetes mellitus who have a history of cardiovascular disease, but further studies should be conducted to demonstrate their efficacy in primary prevention of cardiovascular events or in people aged 75 and over.

\section{Smoking}

Smokers are strongly advised to receive smoking cessation treatment. 


\begin{tabular}{|c|c|c|c|c|}
\hline & $\begin{array}{c}\text { Class of } \\
\text { Recommendation }\end{array}$ & $\begin{array}{l}\text { Level of } \\
\text { Evidence }\end{array}$ & $\begin{array}{l}\text { Grade of } \\
\text { Recommendation } \\
\text { (MINDS) }\end{array}$ & $\begin{array}{l}\text { Level of } \\
\text { Evidence } \\
\text { (MINDS) }\end{array}$ \\
\hline \multicolumn{5}{|l|}{ Hypertension } \\
\hline $\begin{array}{l}\text { Treatment of hypertension including low-salt diet and } \\
\text { weight reduction }\end{array}$ & I & A & A & I \\
\hline Thiazide diuretics & 1 & A & A & I \\
\hline \multicolumn{5}{|l|}{ Coronary artery disease } \\
\hline ACE inhibitors in patients with coronary artery disease ${ }^{*}$ & 1 & A & A & I \\
\hline Statins in patients with coronary artery disease & I & A & A & I \\
\hline $\begin{array}{l}\text { ACE inhibitors in patients with left ventricular contractile } \\
\text { dysfunction }\end{array}$ & 1 & B & A & II \\
\hline$\beta$-blockers in patients with myocardial infarction & 1 & B & A & II \\
\hline MRAs in patients with myocardial infarction & 1 & B & A & II \\
\hline $\begin{array}{l}\mathrm{PCI} \text { to the culprit lesion of complete occlusion during } \\
\text { the period between } 3 \text { and } 28 \text { days after the onset of } \\
\text { myocardial infarction }\end{array}$ & III & B & $\mathrm{C} 2$ & II \\
\hline \multicolumn{5}{|l|}{ Obesity and diabetes mellitus } \\
\hline $\begin{array}{l}\text { General lifestyle modifications through weight reduction } \\
\text { and increased physical activity }\end{array}$ & I & A & A & I \\
\hline $\begin{array}{l}\text { Treatment with SGLT2 inhibitors (empagliflozin, }{ }^{* *} \\
\text { canagliflozin }{ }^{\star \star *} \text { ) in patients with type } 2 \text { diabetes } \\
\text { mellitus and a history of cardiovascular disease }\end{array}$ & I & A & B & II \\
\hline Smoking cessation & 1 & C & B & $\mathrm{IVb}$ \\
\hline Alcoholic control & Ila & $\mathrm{C}$ & C1 & VI \\
\hline Physical activity and exercise habits & 1 & B & B & IVa \\
\hline \multicolumn{5}{|l|}{ Others } \\
\hline $\begin{array}{l}\text { Comprehensive multidisciplinary (educational) } \\
\text { programs and team medical care }\end{array}$ & I & C & C1 & VI \\
\hline Preventions of infectious disease including vaccinations & Ila & C & B & $\mathrm{IVb}$ \\
\hline
\end{tabular}

${ }^{*} \mathrm{ARBs}$ are recommended for patients intolerant of ACE inhibitors (especially those with left ventricular dysfunction). ${ }^{* *}$ In the EMPA-REG OUTCOME study of empagliflozin, ${ }^{175}$ all participants had a history of cardiovascular disease. ${ }^{\star * *}$ In the CANVAS study of canagliflozin, ${ }^{178} 34 \%$ of the participants were at high risk of cardiovascular events and received the treatment for primary prevention, and $66 \%$ of the participants had a history of cardiovascular disease. The dose range of canagliflozin in the CANVAS study was wider than the approved dose range in Japan. ARB, angiotensin II receptor blocker; ACE, angiotensin converting enzyme; MRA, mineralocorticoid receptor antagonist; $\mathrm{PCl}$, percutaneous coronary intervention; SGLT, sodium glucose cotransporter.

\section{Alcohol}

As there is a U-shaped curve between alcohol consumption and the incidence of heart failure, ${ }^{179-181}$ people who have habitual drinking should be advised to drink moderately.

\section{Physical Activity and Exercise}

A dose-related inverse relation between physical activity and the risk of heart failure has been reported.

\section{Others}

Patients with stable, Stage C heart failure should be managed appropriately to prevent rehospitalizations due to worsening heart failure. In order to prevent rehospitalizations for heart failure, patients and their family members should be educated well on the nature of heart failure and the importance of keeping treatment adherence, and receive comprehensive programs (such as patient education) through social supports and multidisciplinary healthcare support. 


\section{Basic Principles for the Treatment of Heart Failure}

\section{Goals of Heart Failure Treatment (Figure 1)}

The present guidelines classify the development and progression of heart failure into 4 stages. Stages A and B represent conditions at high risk of heart failure rather than the presence of heart failure. The guidelines include recommendations on treatment for patients at risk stages because it is critically important to prevent the onset of heart failure. This staging classification is based on the criteria that was first described in the ACC/AHA guidelines in 2005 and the concept of this classification has remained important for more than a decade also in Japan.

The primary goals of treatment for each stage of heart failure are to prevent the progression to the next stage. Specifically, the primary goals are to prevent structural heart disease that may cause heart failure in Stage A (patients at risk of heart failure); to prevent the progression of structural heart disease and prevent the onset of heart failure in Stage B (patients with structural heart disease); and to improve the prognosis and control symptoms of heart failure in Stage C (patients with established heart failure). The primary goals for patients with stage $\mathrm{D}$ heart failure (refractory heart failure) are essentially the same for those in Stage C, but controlling symptoms are the most important goal in patients with end-stage heart failure. Stage-based treatment is therefore important to achieve optimal treatment goals for different stages of patients (See
Figure $\mathbf{1}^{20}$ in Section "1. Definition and Classification" in Chapter "II. General Principles").

\section{Treatment Algorithms for Heart Failure (Figure 10)}

The clinical course of heart failure is generally chronic and progressive. Heart failure often manifests as acute heart failure, and then progresses to compensated, chronic heart failure (Stage $\mathrm{C}$, the stage of heart failure). Patients with established heart failure show chronic progression, and may have repeated episodes of acute decompensated heart failure. Repeated acute exacerbations gradually lead to the development of more severe heart failure. Sudden death may occur during the progression of heart failure. Accordingly, heart failure does not progress linearly from Stage C to Stage D (refractory heart failure), and it is quite difficult to predict how the disease progresses (See Figure $\mathbf{1}^{\mathbf{2 0}}$ in Section "1. Definition and Classification" in Chapter "II. General Principles"). Heart failure progresses in a way quite different from malignant tumors. Patients who do not respond to standard treatment and have exacerbations repeatedly progress to Stage D heart failure. The clinical course from Stage C to D differs substantially among patients depending on the severity of underlying heart disease and comorbidities. This makes it even difficult to predict the course of heart failure.

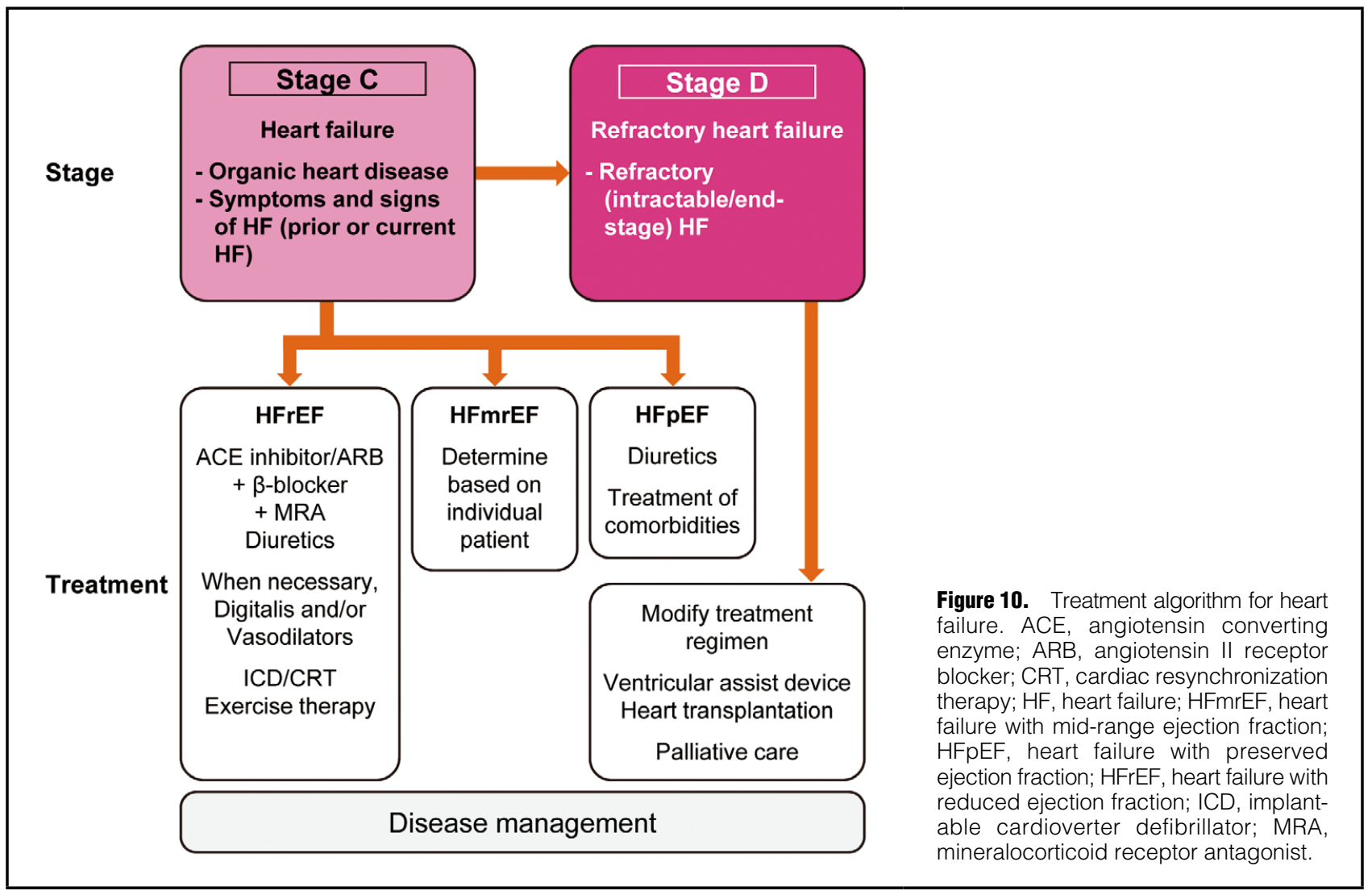


Patients with Stage $\mathrm{C}$ heart failure need treatment both for chronic heart failure and for acute exacerbations of chronic heart failure. As many patients with heart failure are in Stage $C$ and will stay in this stage even after symptomatic improvement, smooth transition from acute-phase to chronic-phase treatment is important. Treatment modalities for Stage $\mathrm{C}$ heart failure include those for heart failure with reduced LVEF (HFrEF) and those for heart failure with preserved LVEF (HFpEF) (Figure 10). As treatments for heart failure with mid-range LVEF (HFmrEF) have not been fully evaluated, physicians should select treatments for them according to the individual patient's condition. Although many patients require diuretics to control their symptoms of heart failure, no evidence has demonstrated that diuretics improve the prognosis of patients with heart failure. Dose adjustment of diuretics based on the severity of organ congestion is important. Patients who still have severe symptoms at rest despite sufficient Stage $\mathrm{C}$ treatment and are repeatedly hospitalized for worsening heart failure should receive Stage D treatment.

\section{Pharmacological Therapy}

\section{Heart Failure With Reduced Ejection Fraction (HFrEF) (Tables 23, 24, and 25)}

\subsection{Drugs for the Treatment of HFrEF}

\subsubsection{ACE Inhibitors}

The results of large-scale clinical studies such as the Cooperative North Scandinavian Enalapril Survival Study (CONSENSUS) ${ }^{182}$ and the Studies of Left Ventricular Dysfunction (SOLVD) trial ${ }^{\mathbf{1 8 3}, \mathbf{1 8 4}}$ have demonstrated that angiotensin converting enzyme (ACE) inhibitors improve the prognosis of patients with heart failure due to left heart dysfunction and a reduction of the risk of cardiovascular events. Long-term follow-up of patients who participated in these large-scale studies have demonstrated that ACE inhibitors are also effective in those with asymptomatic left ventricular systolic dysfunction in reducing hospitalizations for heart failure and improving prognosis. ${ }^{185}$ ACE inhibitors should thus be given to all patients with left ventricular systolic dysfunction.

\section{1.1.2 Angiotensin II Receptor Blockers (ARBs)}

The results of large-scale clinical studies ${ }^{\mathbf{1 8 6 - 1 8 8}}$ have indicated that ARBs are as effective as ACE inhibitors in reducing cardiovascular events in patients with chronic heart failure due to left ventricular systolic dysfunction. Accordingly, ARBs should be used for patients who cannot receive ACE inhibitors because of intolerance or other reasons.

\section{1.1.3 Mineralocorticoid Receptor Antagonists (MRAs)}

In two large-scale clinical studies in patients with contractile dysfunction and clinical studies in Japan, the benefits of spironolactone and eplerenone have been confirmed. ${ }^{163,164,189,190}$ Accordingly symptomatic patients with $\mathrm{LVEF}<35 \%$ should be treated with MRAs if not contraindicated. However, it has been reported that the use of spironolactone in combination with ACE inhibitors or ARBs may increase the risk of death and hospitalization through increasing serum potassium levels. ${ }^{191}$ Spironolactone should not be used in combination with both ACE inhibitors and ARBs. Careful monitoring should be performed when patients with an estimated glomerular filtration rate (eGFR) of $<30 \mathrm{~mL} / \mathrm{min}$ or a serum potassium level of $\geq 5.0 \mathrm{mEq} / \mathrm{L}$ at the start of the treatment with MRAs.

\section{| 1.1.4 $\beta$-Blockers}

Large-scale clinical studies have demonstrated that bisoprolol, metoprolol succinate, and carvedilol, a nonselective $\beta$-blocker $/ \alpha_{1}$-blocker, improves prognosis in patients with heart failure. ${ }^{192-195}$ Evidence has also been published on the efficacy of $\beta$-blockers in patients with left ventricular dysfunction without heart failure symptoms.

Treatment with $\beta$-blockers for patients with NYHA class III or IV heart failure should be started in the hospital setting to confirm improvement in fluid retention and until the patient is in a stable condition. The dose should then be gradually titrated upwards in intervals of a few days to 2 weeks. Before initiating $\beta$-blocker therapy, the absence of underlying conditions that are contraindicated for $\beta$-blockers should be confirmed. Dose escalation should be made according to symptoms, pulse rate, blood pressure, cardiothoracic ratio, and chamber size measured with echocardiography, and patients should be monitored carefully for any signs/symptoms of worsening heart failure, excessive hypotension, and bradycardia.

$\beta$-blocker therapy should be initiated in the hospital setting during the recovery phase of acute exacerbation of heart failure. ${ }^{196}$ Patients should receive the initial doses in the hospital setting, and the dose should then be escalated in the ambulatory setting. When heart failure worsens during $\beta$-blocker therapy, the treatment should be continued whenever possible, but discontinuation may be unavoidable depending on the severity of heart failure. $\beta$-blocker therapy should be restarted whenever possible after the condition becomes stable. ${ }^{197}$

Large-scale clinical studies of $\beta$-blockers in chronic heart failure have demonstrated the efficacy of carvedilol, bisoprolol, and metoprolol succinate. In Japan, the use of carvedilol and bisoprolol in chronic heart failure is covered by the National Health Insurance.

\subsubsection{Diuretics}

Diuretics are the most effective drugs in the treatment of symptoms of congestion in heart failure, such as dyspnea on exertion and edema. Loop diuretics should be tried first, and thiazide diuretics may be added for patients who do not respond well to loop diuretics. However, these diuretics may cause hypokalemia and hypomagnesemia, increase the risk of digitalis intoxication, and induce serious ventricular arrhythmia. During diuretic therapy, serum levels of potassium and magnesium should be monitored to keep appropriate levels.

Loop diuretics have been used commonly to alleviate congestion during acute exacerbations of heart failure. Many patients with chronic heart failure have routinely received long-term treatment with loop diuretics. Retrospective analyses using data of large-scale clinical studies 
Table 23. Recommendations and Levels of Evidence for Medications for HFrEF

\begin{tabular}{|c|c|c|c|c|}
\hline & $\begin{array}{c}\text { Class of } \\
\text { Recommendation }\end{array}$ & $\begin{array}{l}\text { Level of } \\
\text { Evidence }\end{array}$ & $\begin{array}{c}\text { Grade of } \\
\text { Recommendation } \\
\text { (MINDS) }\end{array}$ & $\begin{array}{l}\text { Level of } \\
\text { Evidence } \\
\text { (MINDS) }\end{array}$ \\
\hline \multicolumn{5}{|l|}{ ACE inhibitors } \\
\hline $\begin{array}{l}\text { Use in all patients (including asymptomatic patients) } \\
\text { unless contraindicated }\end{array}$ & 1 & A & A & I \\
\hline \multicolumn{5}{|l|}{ ARBs } \\
\hline Use in patients intolerable ACE inhibitors & 1 & A & A & I \\
\hline Concomitant use with ACE inhibitors & Ilb & B & $\mathrm{C} 2$ & II \\
\hline \multicolumn{5}{|l|}{$\beta$-blockers } \\
\hline Use in symptomatic patients to improve prognosis & 1 & A & A & 1 \\
\hline $\begin{array}{l}\text { Use in asymptomatic patients with left ventricular } \\
\text { systolic dysfunction }\end{array}$ & Ila & B & A & II \\
\hline $\begin{array}{l}\text { Use for rate control in patients with atrial fibrillation with } \\
\text { a rapid ventricular response }\end{array}$ & Ila & B & B & II \\
\hline \multicolumn{5}{|l|}{ MRAs } \\
\hline $\begin{array}{l}\text { Use in patients with NYHA Class II-IV, LVEF }<35 \% \\
\text { who are receiving loop diuretics and ACE inhibitors }\end{array}$ & 1 & A & A & I \\
\hline \multicolumn{5}{|l|}{ Loop diuretics, thiazide diuretics } \\
\hline Use in patients with symptoms of congestion & 1 & C & $\mathrm{C} 1$ & III \\
\hline \multicolumn{5}{|l|}{ Vasopressin $V_{2}$ receptor antagonists } \\
\hline $\begin{array}{l}\text { Start treatment during hospitalization to relieve symptoms } \\
\text { of fluid retention due to heart failure in patients who do } \\
\text { not respond well to other types of diuretics including } \\
\text { loop diuretics }\end{array}$ & Ila & B & B & II \\
\hline \multicolumn{5}{|c|}{ Other diuretics such as carbonate dehydratase inhibitors and osmotic diuretics } \\
\hline $\begin{array}{l}\text { Diuretics other than loop diuretics, thiazide diuretics, } \\
\text { and MRAs }\end{array}$ & Ilb & C & $\mathrm{C} 2$ & III \\
\hline \multicolumn{5}{|l|}{ Digitalis } \\
\hline $\begin{array}{l}\text { Patients in sinus rhythm (maintain digoxin concentration } \\
\text { in blood at } \leq 0.8 \mathrm{ng} / \mathrm{mL} \text { ) }\end{array}$ & Ila & B & $\mathrm{C} 1$ & II \\
\hline $\begin{array}{l}\text { Use for rate control in patients with atrial fibrillation with } \\
\text { a rapid ventricular response }\end{array}$ & Ila & B & B & II \\
\hline \multicolumn{5}{|l|}{ Oral inotropic drugs } \\
\hline $\begin{array}{l}\text { Use short-term to improve QOL and discontinue } \\
\text { intravenous inotropic drugs }\end{array}$ & Ila & B & $\mathrm{C} 1$ & II \\
\hline Use when initiating $\beta$-blockers & Ilb & B & C1 & II \\
\hline Long-term use in asymptomatic patients & III & C & $\mathrm{D}$ & III \\
\hline \multicolumn{5}{|l|}{ Amiodarone } \\
\hline $\begin{array}{l}\text { Use in patients with a history of serious ventricular } \\
\text { arrhythmia leading to cardiac arrest }\end{array}$ & Ila & B & C1 & II \\
\hline \multicolumn{5}{|l|}{ Concomitant use of isosorbide dinitrate and hydralazine } \\
\hline Use as an alternative to ACE inhibitors or ARBs & Ilb & B & $\mathrm{C} 2$ & II \\
\hline \multicolumn{5}{|l|}{ Others } \\
\hline $\begin{array}{l}\text { Treatment with calcium channel blockers in patients } \\
\text { without angina pectoris or hypertension }\end{array}$ & III & B & $\mathrm{C} 2$ & II \\
\hline $\begin{array}{l}\text { Long-term oral treatment with Vaughan Williams Class } \\
\text { I antiarrhythmic agents }\end{array}$ & III & B & D & III \\
\hline Use of $a$-blockers & III & B & D & II \\
\hline
\end{tabular}

ARB, angiotensin II receptor blocker; ACE, angiotensin converting enzyme; LVEF, left ventricular ejection fraction; MRA, mineralocorticoid receptor antagonist; NYHA, New York Heart Association; QOL, quality of life; SGLT, sodium glucose cotransporter. 


Table 24. Medications for HFrEF According to Class of
Recommendation

$\mathrm{ARB}$, angiotensin II receptor blocker; ACE, angiotensin converting enzyme; LVEF, left ventricular ejection fraction; MRA, mineralocorticoid receptor antagonist; NYHA, New York Heart Association; $\mathrm{QOL}$, quality of life; SGLT, sodium glucose cotransporter.

have concluded that furosemide and other loop diuretics may deteriorate prognosis in patients with heart failure. . $^{198-201}$ The long-acting loop diuretic azosemide is considered not to affect neurohumoral factors substantially as it does not cause significant hemodynamic changes. In a study that compared azosemide and furosemide in Japan, the primary composite endpoint of cardiovascular death or hospitalization for worsening heart failure occurred less frequently in patients receiving azosemide than those receiving furosemide. ${ }^{202}$

Tolvaptan, a vasopressin $\mathrm{V}_{2}$ receptor antagonist, blocks vasopressin $V_{2}$ receptors on renal medullary collecting duct cells, and thereby increases water excretion. In the Efficacy of Vasopressin Antagonism in Heart Failure Outcome Study with Tolvaptan (EVEREST), a randomized, placebocontrolled study of tolvaptan in patients with acute worsening heart failure, the vasopressin $V_{2}$ receptor antagonist improved symptoms of congestion but did not improve

\begin{tabular}{|c|c|}
\hline \multicolumn{2}{|c|}{$\begin{array}{l}\text { Table 25. Medications for HFrEF: Drugs and Dosing } \\
\text { Regimens }\end{array}$} \\
\hline Drugs* $^{*}$ & Dosing regimen \\
\hline \multicolumn{2}{|l|}{ ACE inhibitors } \\
\hline Enalapril & $\begin{array}{l}\text { Start at } 2.5 \mathrm{mg} / \mathrm{day} \text {, and maintain at } 5 \text { to } \\
10 \mathrm{mg} / \text { day once daily }\end{array}$ \\
\hline Lisinopril & $\begin{array}{l}\text { Start at } 5 \mathrm{mg} / \text { day, and maintain at } 5 \text { to } \\
10 \mathrm{mg} / \text { day once daily }\end{array}$ \\
\hline \multicolumn{2}{|l|}{ ARBs } \\
\hline Candesartan & $\begin{array}{l}\text { Start at } 4 \mathrm{mg} / \text { day }(2 \mathrm{mg} / \text { day in severe cases } \\
\text { or renal dysfunction), and maintain at } 4 \text { to } \\
8 \mathrm{mg} / \text { day once daily (maximum daily dose: } \\
12 \mathrm{mg} / \text { day) }\end{array}$ \\
\hline \multicolumn{2}{|l|}{ MRAs } \\
\hline Spironolactone & $\begin{array}{l}\text { Start at } 12.5 \mathrm{mg} / \text { day, and maintain at } 25 \text { to } \\
50 \mathrm{mg} / \text { day once daily }\end{array}$ \\
\hline Eplerenone & $\begin{array}{l}\text { Start at } 25 \mathrm{mg} / \text { day, and maintain at } \\
50 \mathrm{mg} / \text { day once daily }\end{array}$ \\
\hline \multicolumn{2}{|l|}{$\beta$-blockers } \\
\hline Carvedilol & $\begin{array}{l}\text { Start at } 2.5 \mathrm{mg} / \mathrm{day},{ }^{* *} \text { and maintain at } 5 \text { to } \\
20 \mathrm{mg} / \text { day twice daily }\end{array}$ \\
\hline Bisoprolol & $\begin{array}{l}\text { Start at } 0.625 \mathrm{mg} / \text { day, }{ }^{* *} \text { and maintain at } \\
1.25 \text { to } 5 \mathrm{mg} / \text { day once daily }\end{array}$ \\
\hline \multicolumn{2}{|l|}{ Diuretics } \\
\hline Furosemide & 40 to $80 \mathrm{mg} /$ day once daily \\
\hline Azosemide & $60 \mathrm{mg} /$ day once daily \\
\hline Torasemide & 4 to $8 \mathrm{mg} /$ day once daily \\
\hline Tolvaptan & 7.5 to $15 \mathrm{mg} /$ day once daily \\
\hline Trichlormethiazide & 2 to $8 \mathrm{mg} /$ day once daily \\
\hline \multicolumn{2}{|c|}{ Antiarrhythmic drugs } \\
\hline Amiodarone & $\begin{array}{l}\text { Start at } 400 \mathrm{mg} / \mathrm{day} \text {, and maintain at } \\
200 \mathrm{mg} / \text { day once or twice daily }\end{array}$ \\
\hline \multicolumn{2}{|l|}{ Digitalis } \\
\hline Digoxin & 0.125 to $0.25 \mathrm{mg} /$ day once daily \\
\hline \multicolumn{2}{|c|}{ Oral inotropic drugs } \\
\hline Pimobendan & 2.5 to $5.0 \mathrm{mg} /$ day once daily \\
\hline
\end{tabular}

*National Health Insurance-covered medications. ** Start at a half dose in severe cases. ARB, angiotensin II receptor blocker; ACE, angiotensin converting enzyme; MRA, mineralocorticoid receptor antagonist.

long-term outcome of patients with heart failure. ${ }^{203,204}$

\section{1.1.6 Antiarrhythmic Drugs}

Amiodarone is expected to prevent serious ventricular arrhythmias such as ventricular tachycardia and ventricular fibrillation, and reduce the risk of sudden death in patients with heart failure. Patients receiving amiodarone should periodically undergo thyroid function tests, pulmonary function tests, chest X-ray, determination of KL-6 concentration in the blood, and ophthalmological tests to detect adverse drug reactions to amiodarone (e.g., thyroid function disorder, interstitial pneumonia, corneal pigmentation, and abnormal liver function tests) promptly. As the use of amiodarone for the treatment of atrial fibrillation associated with heart failure is covered by the National Health Insurance in Japan, this drug is used also to maintain sinus rhythm or control heart rate.

\section{| 1.1.7 Vasodilators}

Western guidelines recommend combination therapy using hydralazine and isosorbide dinitrate to improve prognosis in patients who cannot receive ACE inhibitors for various 


\begin{tabular}{|c|c|c|c|c|}
\hline & $\begin{array}{c}\text { Class of } \\
\text { Recommendation }\end{array}$ & $\begin{array}{l}\text { Level of } \\
\text { Evidence }\end{array}$ & $\begin{array}{l}\text { Grade of } \\
\text { Recommendation } \\
\text { (MINDS) }\end{array}$ & $\begin{array}{l}\text { Level of } \\
\text { Evidence } \\
\text { (MINDS) }\end{array}$ \\
\hline \multicolumn{5}{|l|}{ Diuretics } \\
\hline Use of diuretics to relieve symptoms of congestion & I & $\mathrm{C}$ & C1 & VI \\
\hline $\begin{array}{l}\text { Preference of long-acting drugs when using loop } \\
\text { diuretics }\end{array}$ & $\mathrm{Ilb}$ & C & C1 & III \\
\hline $\begin{array}{l}\text { Out-patient use of tolvaptan introduced during hospital- } \\
\text { ization for acute heart failure to control congestion* }\end{array}$ & Ila & C & C1 & $\mathrm{IVb}$ \\
\hline \multicolumn{5}{|l|}{ ACE inhibitors/ARBs } \\
\hline $\begin{array}{l}\text { Increasing the dose of ACE inhibitors/ARBs to } \\
\text { maximum tolerable level to reduce the risk of clinical } \\
\text { events }\end{array}$ & $\mathrm{Ilb}$ & C & C1 & III \\
\hline \multicolumn{5}{|l|}{$\beta$-blockers } \\
\hline $\begin{array}{l}\text { Increasing the dose of } \beta \text {-blockers to maximum tolerable } \\
\text { level to reduce the risk of clinical events }\end{array}$ & Ilb & C & C1 & III \\
\hline \multicolumn{5}{|l|}{ MRAs } \\
\hline $\begin{array}{l}\text { Increasing the dose of MRAs to maximum tolerable } \\
\text { level to reduce the risk of clinical events }\end{array}$ & $\mathrm{Ilb}$ & C & C1 & III \\
\hline \multicolumn{5}{|l|}{ Nitrates } \\
\hline $\begin{array}{l}\text { Use of nitrates to improve prognosis and increase } \\
\text { activities of daily living }\end{array}$ & III & B & D & II \\
\hline
\end{tabular}

*Tolvaptan must be introduced during hospitalization. There are no data on the efficacy and safety of long-term treatment with tolvaptan. ARB, angiotensin II receptor blocker; ACE, angiotensin converting enzyme; MRA, mineralocorticoid receptor antagonist.

reasons. ${ }^{205,206}$ In Japan, such combination therapy is not used proactively. Calcium channel blockers are not generally recommended as long-term treatment because calcium channel blockers may worsen heart failure.

\subsubsection{Digitalis}

In 1997, results from the Digitalis Investigation Group (DIG) trial were published and described that digoxin reduces the risk of hospitalization for worsening heart failure in patients with normal sinus rhythm, but does not improve their prognosis. ${ }^{207}$ The risk of death related to arrhythmia rather tended to increase with the use of digoxin in this population. On the other hand, patients with heart failure and atrial fibrillation are often treated with digitalis to control heart rate and increase left ventricular filling period. Digitalis is used to relieve symptoms, but there is no evidence regarding whether it may improve the prognosis of patients with left ventricular systolic dysfunction and atrial fibrillation.

\section{1.1.9 Oral Inotropic Drugs}

Since 1980 s, large clinical studies have failed to demonstrate the efficacy of oral inotropic drug in heart failure, ${ }^{208,209}$ and experts in the United States do not recommend oral inotropic drugs for the treatment of heart failure. However, given the perspective that prolonging the survival is not the sole purpose of the treatment for patients with chronic heart failure, the possible clinical benefits of oral inotropic drugs in this patient population should be reconsidered.

\subsection{Dug Therapy for Heart Failure With Mid-Range Ejection Fraction (HFmrEF)}

Some data have indicated that $\beta$-blockers and other drugs used to treat HFrEF are also effective in the treatment of
HFmrEF . ${ }^{34}$ However, no conclusive evidence has been obtained in this patient population and further studies are awaited.

\subsection{Heart Failure Treatment by Stage}

\section{1.3.1 Stage C (Symptomatic Heart Failure)}

NYHA class II: Introduce $\beta$-blockers in addition to ACE inhibitors. Patients with symptoms of fluid retention such as pulmonary congestion and generalized edema should receive diuretics. MRAs should be added to patients with $\mathrm{LVEF}<35 \%$.

NYHA class III: Similar to NYHA class II patients, ACE inhibitors, $\beta$-blockers, and diuretics should be used. MRAs should be added to patients with LVEF $<35 \%$.

NYHA class IV: Patients should be hospitalized and receive parenteral medications such as catecholamines, phosphodiesterase (PDE) III inhibitors, diuretics, and carperitide to stabilize the condition. After the condition is stabilized, these regimens should be switched to oral drugs such as ACE inhibitors, diuretics, MRAs, and digitalis. $\beta$-blockers should also be tried.

\section{1.3.2 Stage D (Refractory Heart Failure)}

Treatment regimens should be reviewed whether the patient is receiving appropriate fluid management and drug therapy. The indication of heart transplantation should be considered (See Section “3. Heart Transplantation” in Chapter "XI. Surgical Treatment" Tables 70, 71, ${ }^{522}$ and 72). Patients who are not indicated for heart transplantation or ventricular assist devices should receive palliative care to alleviate symptoms based on a consent given by the patient and his or her family members (See Chapter "XIII. Palliative Care" for details). 


\section{Heart Failure With Preserved Ejection Fraction (HFpEF) (Table 26)}

No prospective interventional studies on drugs for the treatment of $\mathrm{HFpEF}$ have demonstrated a clear reduction in the risk of death or clinical events. At present, patients with HFpEF should be treated to control the causative condition and thereby alleviate heart failure symptoms, and to treat comorbid conditions that may worsen heart failure.

\subsection{Interventions to Reduce Disease Burden}

\section{2.1.1 Treatment for Congestion}

Diuretics are beneficial in improving subjective symptoms caused by congestion. Loop diuretics are used commonly. In the Japanese Multicenter Evaluation of Long-versus short-acting Diuretics in Congestive heart failure (J-MELODIC) trial conducted in Japan, the long-acting loop diuretic azosemide was superior to the short-acting loop diuretic furosemide in improving prognosis, especially in preventing re-worsening heart failure. ${ }^{\mathbf{2 0 2}}$ In Japan, an increasing number of patients start tolvaptan therapy during hospitalization for acute heart failure, and continue the treatment after discharge.
2.1.2 Treatment for Hypertension

See Section “6. Hypertension” in Chapter "IX. Pathophysiology and Treatment of Comorbidities".

\subsection{Interventions Not Directly Aiming at Reducing the Burden of Heart Failure}

ACE inhibitors, ${ }^{211}$ ARBs, ${ }^{212,213} \beta$-blockers, ${ }^{214}$ MRA, ${ }^{215}$ and digitalis $^{\mathbf{2 1 6}}$ did not reduce the incidence of the primary endpoint in their prospective interventional studies in HFpEF. However, large-scale observational studies and meta-analyses have indicated that ACE inhibitors/ARBs, ${ }^{217}$ and $\beta$-blockers, ${ }^{\mathbf{2 1 8 , 2 1 9}}$ improve the prognosis of patients with HFpEF. MRAs also significantly reduced hospitalizations for heart failure. ${ }^{215}$

In addition to the above-described common medications for HFrEF, the efficacy of nitrates in HFpEF has been evaluated. In the NEAT-HFpEF (Nitrate's Effect on Activity Tolerance in Heart Failure with Preserved Ejection Fraction) trial, a prospective interventional study, nitrates did not improve exercise capacity of patients with HFpEF, and did reduce their physical activity. ${ }^{220}$ In a large-scale observational study, the Swedish Heart Failure Registry, nitrates deteriorated the prognosis of patients with HFpEF. ${ }^{221}$

\section{Nonpharmacological Therapy}

\section{Implantable Cardioverter Defibrillator}

\subsection{Secondary Prevention of Sudden Death} (Table 27)

Patients with sustained ventricular tachycardia or ventricular fibrillation associated with heart failure and patients resuscitated from sudden cardiac death are at a high risk of recurrent arrhythmias. Implantable cardioverter defibrillators (ICDs) are highly effective in secondary prevention of sudden cardiac death associated with coronary artery disease in these patients. ${ }^{\mathbf{2 2 2}-224}$ Especially, patients with heart failure and LVEF $\leq 35 \%$ are expected to benefit more from ICDs. ${ }^{14,225,226}$ However, sustained ventricular tachy- cardia or ventricular fibrillation developed during acute phase (within 48 hours after onset) of acute coronary syndrome are not necessarily indicated for ICDs as the risk of recurrent arrhythmias is low after ischemia is treated and arrhythmic substrates are stabilized.227 As the risk of recurrent arrhythmias is high in patients in whom sustained ventricular tachycardia or ventricular fibrillation developed at least 48 hours after the onset of myocardial infarction, they are indicated for ICDs. ${ }^{226,227}$

Although data on ICDs in secondary prevention of sudden death in patients with heart failure associated with non-ischemic dilated cardiomyopathy are limited, these patients are considered to benefit from ICDs similarly as patients with coronary disease are. ${ }^{\mathbf{2 2 2}-224}$

Catheter ablation is now available for hemodynamically

\begin{tabular}{|c|c|c|c|c|}
\hline & $\begin{array}{c}\text { Class of } \\
\text { Recommendation }\end{array}$ & $\begin{array}{l}\text { Level of } \\
\text { Evidence }\end{array}$ & $\begin{array}{l}\text { Grade of } \\
\text { Recommendation } \\
\text { (MINDS) }\end{array}$ & $\begin{array}{l}\text { Level of } \\
\text { Evidence } \\
\text { (MINDS) }\end{array}$ \\
\hline $\begin{array}{l}\text { Patients who meet both of the following criteria: } \\
\text { (1) Have heart failure associated with structural } \\
\text { heart disease } \\
\text { (2) Sustained ventricular tachycardia, ventricular } \\
\text { fibrillation, or resuscitated from sudden cardiac } \\
\text { death }\end{array}$ & I & A & A & 1 \\
\hline $\begin{array}{l}\text { Patients who meet either of the following criteria: } \\
\text { (1) Have limited physical activity due to chronic } \\
\text { diseases } \\
\text { (2) Can neither express consent nor cooperate with } \\
\text { treatment due to mental disorder or other } \\
\text { reasons } \\
\text { (3) Suspected with a life expectancy of } 1 \text { year or less }\end{array}$ & III & C & C2 & VI \\
\hline
\end{tabular}




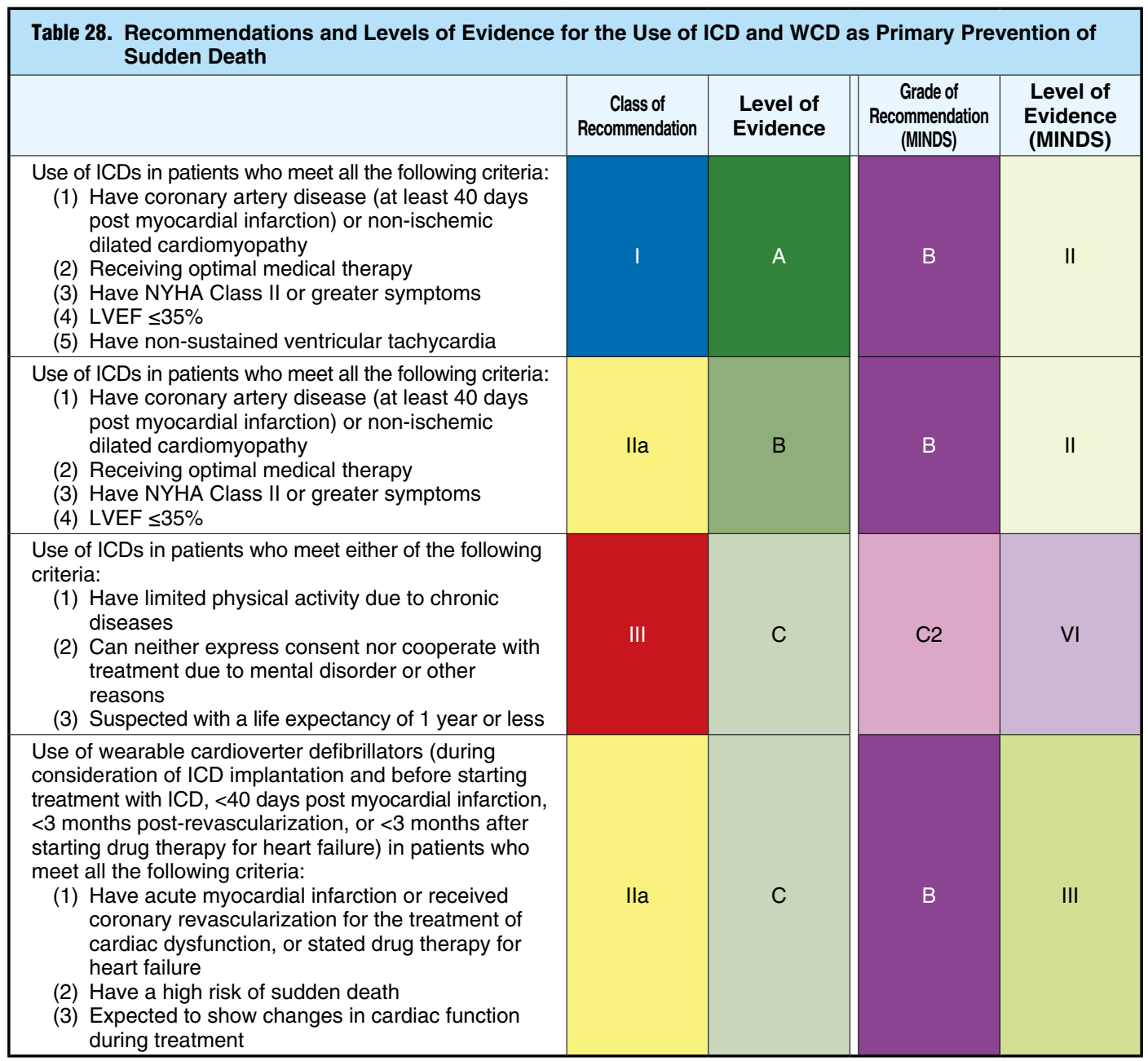

ICD, implantable cardioverter defibrillator; LVEF, left ventricular ejection fraction; NYHA, New York Heart Association.

unstable patients with ventricular tachycardia or ventricular fibrillation, ${ }^{228}$ but ICD therapy should be considered for these patients even after successful ablation.

\section{I1.2 Primary Prevention of Sudden Death (Table 28)}

The benefits of ICDs in patients with coronary artery disease and low LVEF have been demonstrated in clinical studies conducted mainly in North America, ${ }^{\mathbf{1 4 , 2 2 6}}$ including the Multicenter Automatic Defibrillator Implantation Trial (MADIT-I), ${ }^{229}$ MADIT-II, ${ }^{230}$ Multicenter Unsustained Tachycardia Trial (MUSTT), ${ }^{231}$ and Defibrillator in Acute Myocardial Infarction Trial (DINAMIT) ${ }^{232}$ in patients with coronary artery disease, the Defibrillators in Non-Ischemic Cardiomyopathy Treatment Evaluation (DEFINITE) trial in patients with non-ischemic dilated cardiomyopathy, ${ }^{233}$ and the Sudden Cardiac Death in Heart Failure Trial (SCD-HeFT) in patients with coronary artery disease or non-ischemic dilated cardiomyopathy. ${ }^{234}$

Cohort studies on the prognosis of patients with coronary artery disease in Japan have indicated that patients in Japan generally have a favorable prognosis, and ICDs may not be cost effective if ICD therapy is indicated according to the criteria used in the MADIT-II trial. It is recommended that appropriate evaluations such as electrophysi- ological testing should be used to stratify the risk of patients with coronary artery disease. ${ }^{229-231}$ The use of ICD for primary prevention after myocardial infarction should be considered for patients who survived for at least 40 days after the onset of myocardial infarction.

A meta-analysis of five clinical studies ${ }^{233-237}$ in nonischemic dilated cardiomyopathy $(n=1,854)$ revealed that ICDs significantly reduced relative mortality risk. A recent meta-analysis including the data from the Danish Study to Assess the Efficacy of ICDs in Patients with Non-ischemic Systolic Heart Failure on Mortality (DANISH) trial238 indicated similar results.

There are only limited data on the incidence of sudden death among patients with non-ischemic heart failure in Japan. However, the results of a cohort study on the outcome of patients with chronic heart failure ${ }^{35}$ and the Chronic Heart Failure Analysis and Registry in the Tohoku District (CHART) trial239 suggested that the prognosis of heart failure and incidence of sudden death in patients with non-ischemic dilated cardiomyopathy in Japan may be similar to those in Western countries, and thus such patients should be considered for ICD therapy. 


\section{Cardiac Resynchronization Therapy (Table 29)}

\subsection{Clinical Efficacy}

Since 2001, several randomized prospective studies have been conducted to assess the efficacy of cardiac resynchronization therapy (CRT) in heart failure. ${ }^{\mathbf{2 3 7 , 2 4 0 - 2 4 7}}$ These studies have demonstrated that CRT improves exercise capacity and other QOL measures as well as left ventricular remodeling, and reduced all-cause mortality and hospitalizations for heart failure. A meta-analysis has indicated that CRT reduced all-cause mortality. ${ }^{248}$ In addition, the RD-CHF trial ${ }^{249}$ and the Biventricular versus Right Ventricular Pacing in Heart Failure Patients with Atrioventricular Block (BLOCK HF) trial ${ }^{250}$ demonstrated the benefits of CRT in patients with heart failure who are indicated for pacemaker.

\subsection{Points to Consider When Planning CRT}

\subsubsection{Use of Defibrillation Function}

No studies have compared a CRT-pacemaker (CRT-P) and a combined CRT defibrillator (CRT-D) in Japan. The Comparison of Medical Therapy, Pacing, and Defibrillation in Heart Failure (COMPARISON) trial ${ }^{237}$ and a prospective registry in four European medical institutions ${ }^{251}$ demonstrated that CRT-D was superior to CRT-P in reducing the incidence of sudden cardiac death. CRT-D is recommended for many patients, but is more expensive than CRT-P. Cost-effectiveness should also be considered.

\section{2.2.2 CRT in Patients With Atrial Fibrillation}

The Multisite Stimulation in cardiomyopathy - Atrial Fibrillation (MUSTIC-AF) trial ${ }^{\mathbf{2 4 2}}$ demonstrates the benefits of CRT in patients with heart failure in whom pacing is indicated to treat chronic bradycardic atrial fibrillation. The percentage of ventricular pacing after rate control in atrial fibrillation is also important. The Heart Rhythm Society (HRS)/European Heart Rhythm Association (EHRA)/Asia-Pacific Heart Rhythm Society (APHRS)/ Sociedad Latinoamericana de Estimulacion Cardiaca y Electrofisiologia (SOLAEC) expert consensus recommends to produce the highest achievable percentage of ventricular pacing, preferably $\geq 98 \%$ in ICD patients with biventricular pacing. ${ }^{252}$ In patients with chronic atrial fibrillation in whom an adequate pacing percentage cannot be obtained in CRT, atrioventricular node ablation should be considered. ${ }^{\mathbf{1 4}}$

\section{2.2.3 Effects of CRT by QRS Configuration and Duration}

It has been reported that about 30 to $40 \%$ of patients undergoing CRT implantation do not respond well to CRT therapy, that is non-responders. A meta-analysis of randomized controlled trials that assessed the influence of QRS configuration on the benefits of CRT therapy has revealed that only patients with a left bundle branch block (LBBB) benefit from CRT. ${ }^{253}$ The results of the Cardiac Resynchronization Therapy in Patients with Heart Failure and Narrow QRS (RethinQ) trial ${ }^{254}$ and the Echocardiography Guided Cardiac Resynchronization Therapy (EchoCRT) trial ${ }^{255}$ have suggested that CRT therapy is less effective in patients with a QRS duration of $<130 \mathrm{msec}^{\mathbf{1 4 , 2 2 6}}$

\subsubsection{Indications for Patients With Mild Heart Failure} The Resynchronization Reverses Remodeling in Systolic
Left Ventricular Dysfunction (REVERSE) trial, ${ }^{256}$ the Multicenter Automatic Defibrillator Implantation Trial with Cardiac Resynchronization Therapy (MADIT-CRT) trial,257 and the Resynchronization-Defibrillation for Ambulatory Heart Failure Trial (RAFT) trial258 have reported that $\mathrm{CRT}$ is beneficial in patients with mild heart failure (NYHA class II or greater), and that CRT is especially indicated for patients with a QRS duration of $\geq 150$ msec.

\section{2.2.5 Combination With Drug Therapy}

Indication for CRT should be considered only for patients who are receiving optimal medical therapy. Other than exceptional cases, CRT is not indicated for patients who underwent revascularization within the past 3 months and patients who introduced new drugs for the treatment of heart failure within the past 3 months. As some patients can receive higher doses of $\beta$-blockers after CRT is introduced, ${ }^{259}$ patients should be assessed regularly for whether their drug therapy is optimal.

\subsection{Telemetry Monitoring (Table 30)}

Current implantable devices such as ICD, CRT-P, and CRT-D have telemetry functions that can send data on arrhythmic events and device information to the data center. As telemetry monitoring can send highly accurate data, device malfunctions and arrhythmias can be detected promptly. ${ }^{260-264}$ In the Implant-based multiparameter telemonitoring of patients with heart failure (IN-TIME) trial in patients with heart failure, ${ }^{265}$ heart failure management through telemetry monitoring significantly reduced all-cause mortality, but these findings should be interpreted carefully with clear understanding on their methods of intervention. In Japan, only a limited number of medical institutions have introduced telemetry monitoring systems. Further studies are awaited to clarify how to utilize telemetry data in clinical practice.

\section{Respiratory Support (Table 31)}

Respiratory support for patients with acute decompensated heart failure and patients with sleep-disordered breathing is described in the relevant sections. This section describes respiratory support for patient with chronic heart failure.

In chronic severe heart failure, respiratory support especially positive pressure ventilation improves hemodynamics and symptoms of chronic heart failure independent of improvement of sleep-disordered breathing by 1) reducing pulmonary congestion and left ventricular preload, 2) reducing left ventricular afterload, and 3) reducing the activity of the sympathetic nerve system. Continuous positive airway pressure (CPAP) can promptly increase cardiac output in patients with severe congestion, but there is no evidence on its long-term efficacy in patients with chronic heart failure with no (or only mild) sleep-disordered breathing. As adaptive servo-ventilation (ASV) has an acute effect similar to that of CPAP, ${ }^{266}$ and may maintain a stable tidal volume, it is considered to be more effective in reducing the activity of the sympathetic nerve system..$^{\mathbf{2 6 7 , 2 6 8}}$ In fact, reports have described that ASV decreases the incidence of cardiac events in patients with heart failure with and without sleep-disordered breathing in Japan. ${ }^{269} \mathrm{In}$ the Confirmatory, Multicenter, Randomized, Controlled 
Table 29. Recommendations and Levels of Evidence for CRT

\section{NYHA Class III/IV}

Patients who meet all the following criteria:

(1) Receiving optimal medical therapy

(2) LVEF $\leq 35 \%$

(3) Left bundle branch block (LBBB) with QRS interval $\geq 120 \mathrm{msec}$

(4) Sinus rhythm

Patients who meet all the following criteria:

(1) Receiving optimal medical therapy

(2) LVEF $\leq 35 \%$

(3) Non-LBBB with QRS interval $\geq 150 \mathrm{msec}$

(4) Sinus rhythm

Patients who meet all the following criteria:

(1) Receiving optimal medical therapy

(2) LVEF $\leq 35 \%$

(3) Non-LBBB with QRS interval 120 to $149 \mathrm{msec}$

(4) Sinus rhythm

Patients who meet all the following criteria:

(1) Receiving optimal medical therapy

(2) LVEF $<50 \%$

(3) Indicated for pacing or ICD

(4) Expected to require ventricular pacing frequently

Patients who meet all the following criteria:

(1) Receiving optimal medical therapy

(2) LVEF $\leq 35 \%$

(3) LBBB with QRS $\geq 120$ msec, or non-LBBB with QRS interval $\geq 150 \mathrm{msec}$

(4) Have atrial fibrillation and can undergo biventricular pacing at a high pacing percentage

\begin{tabular}{|c|c||}
$\begin{array}{c}\text { Class of } \\
\text { Recommendation }\end{array}$ & $\begin{array}{c}\text { Level of } \\
\text { Evidence }\end{array}$
\end{tabular}

\begin{tabular}{c|c}
$\begin{array}{c}\text { Grade of } \\
\text { Recommendation } \\
\text { (MINDS) }\end{array}$ & $\begin{array}{c}\text { Level of } \\
\text { Evidence } \\
\text { (MINDS) }\end{array}$
\end{tabular}

\section{NYHA Class I}

Patients who meet all the following criteria:

(1) Receiving optimal medical therapy

(2) LVEF $\leq 30 \%$

(3) LBBB with QRS interval $\geq 150 \mathrm{msec}$

(4) Sinus rhythm

Patients who meet all the following criteria:

(1) Receiving optimal medical therapy

(2) LVEF $\leq 30 \%$

(3) Non-LBBB with QRS interval $\geq 150 \mathrm{msec}$

(4) Sinus rhythm

Patients who meet all the following criteria:

(1) Receiving optimal medical therapy

(2) LVEF $\leq 30 \%$

(3) QRS interval 120 to $149 \mathrm{msec}$

(4) Sinus rhythm

Patients who meet all the following criteria:

(1) Receiving optimal medical therapy

(2) LVEF $<50 \%$

(3) Indicated for pacing or ICD

(4) Expected to require ventricular pacing frequently
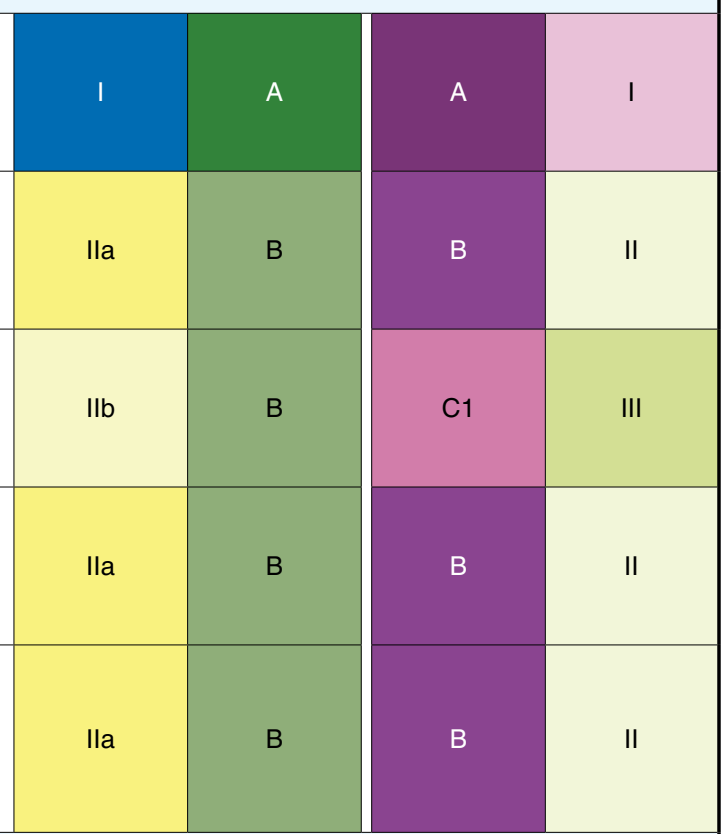

NYHA Class I

Patients who meet all the following criteria:

(1) Receiving optimal medical therapy

(2) LVEF $<50 \%$

(3) Indicated for pacing or ICD

(4) Expected to require ventricular pacing frequently
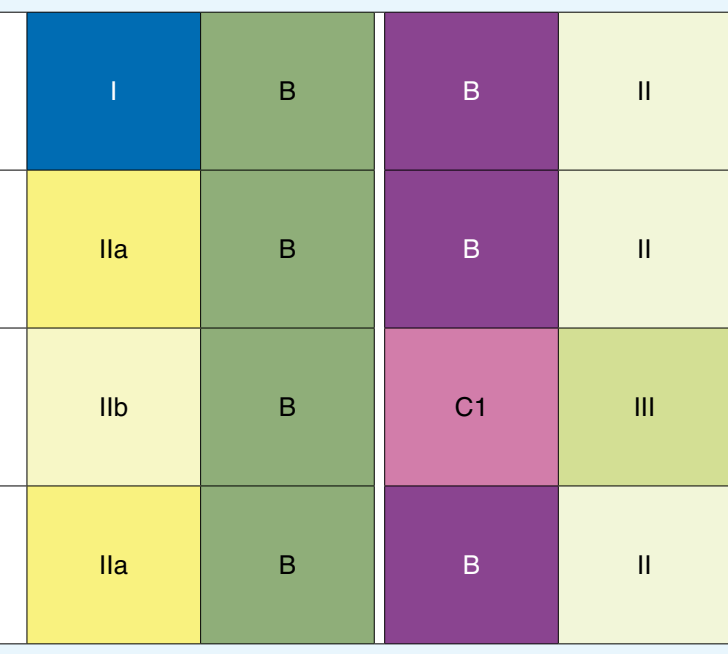

NYHA Class I to IV

Patients who meet either of the following criteria:

(1) Have limited physical activity due to chronic diseases

(2) Can neither express consent nor cooperate with treatment due to mental disorder or other reasons.

(3) Suspected with a life expectancy of 1 year or less

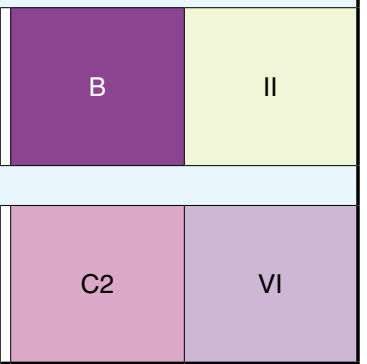

Different criteria are set for NYHA Class III/IV and II patients in sinus rhythm:

1) LVEF cutoff value is $\leq 35 \%$ for NYHA Class III/IV patients and, $\leq 30 \%$ for NYHA Class II patients.

2) In patients with a QRS interval of 120 to $149 \mathrm{msec}$, the use of CRT is a Class I and IIb recommendation for NYHA Class III/IV patients with LBBB and non-LBBB, respectively, and is a Class Ilb recommendation for NYHA Class II patients regardless of whether LBBB or non-LBBB is present.

CRT, cardiac resynchronization therapy; ICD, implantable cardioverter defibrillator; LBBB, left bundle branch block; LVEF, left ventricular ejection fraction; NYHA, New York Heart Association. 


Table 30. Recommendations and Levels of Evidence for the Use of Telemetry Monitoring of Implantable
Device Therapy
\begin{tabular}{l|c|c||c|c|}
\hline $\begin{array}{c}\text { Class of } \\
\text { Recommendation }\end{array}$ & $\begin{array}{c}\text { Level of } \\
\text { Evidence }\end{array}$ & $\begin{array}{c}\text { Grade of } \\
\text { Recommendation } \\
\text { (MINDS) }\end{array}$ & $\begin{array}{c}\text { Level of } \\
\text { Evidence } \\
\text { (MINDS) }\end{array}$ \\
\hline $\begin{array}{l}\text { Introduction and management of telemetry monitoring } \\
\text { in patients with implantable cardiac devices }\end{array}$ & Ila & A & B & I \\
\hline
\end{tabular}

\begin{tabular}{|l|c|c||c|c|}
\hline \multicolumn{2}{|l|}{ Table 31. Recommendations and Levels of Evidence for Adaptive Servo-Ventilation (ASV) } \\
\hline & $\begin{array}{c}\text { Class of } \\
\text { Recommendation }\end{array}$ & $\begin{array}{c}\text { Level of } \\
\text { Evidence }\end{array}$ & $\begin{array}{c}\text { Grade of } \\
\text { Recommendation } \\
\text { (MINDS) }\end{array}$ & $\begin{array}{c}\text { Level of } \\
\text { Evidence } \\
\text { (MINDS) }\end{array}$ \\
\hline $\begin{array}{l}\text { Use of ASV in the hospital setting to relieve symptoms } \\
\text { of congestion in patients receiving guideline-based, } \\
\text { optimized treatment for heart failure }\end{array}$ & Ila & B & B & II \\
\hline $\begin{array}{l}\text { Continued use of ASV in patients satisfying the above } \\
\text { criterion who respond well to the ASV and are } \\
\text { expected to worsen by discontinuing ASV }\end{array}$ & Ila & C & B & VI \\
\hline $\begin{array}{l}\text { Continued use of ASV after improvement of heart } \\
\text { failure without reviewing its necessity }\end{array}$ & III & C & C1 & VI \\
\hline
\end{tabular}

\begin{tabular}{|l|c|c||c|c|}
\hline \multicolumn{2}{|c|}{ Table 32. Recommendations and Levels of Evidence for Exercise Therapy in Patients With Heart Failure } \\
\hline $\begin{array}{l}\text { Patients with HFrEF } \\
\text { Combination with drug therapy to relieve symptoms } \\
\text { and improve exercise capacity }\end{array}$ & $\begin{array}{c}\text { Class of } \\
\text { Recommendation }\end{array}$ & $\begin{array}{c}\text { Level of } \\
\text { Evidence }\end{array}$ & $\begin{array}{c}\text { Grade of } \\
\text { Recommendation } \\
\text { (MINDS) }\end{array}$ & $\begin{array}{c}\text { Level of } \\
\text { Evidence } \\
\text { (MINDS) }\end{array}$ \\
\hline $\begin{array}{l}\text { Patients with HFrEF } \\
\text { To improve QOL, reduce cardiac accidents, and } \\
\text { improve life expectancy }\end{array}$ & Ila & B & A & I \\
\hline $\begin{array}{l}\text { Patients with HFpEF with low exercise capacity } \\
\text { To improve exercise capacity }\end{array}$ & Ila & C & B & IVa \\
\hline $\begin{array}{l}\text { Patients with heart failure after ICD or CRT-D } \\
\text { implantation } \\
\text { To improve exercise capacity and QOL }\end{array}$ & Ila & C & B & IVa \\
\hline $\begin{array}{l}\text { Patients with pulmonary hypertension whose } \\
\text { symptoms are stable on drug therapy } \\
\text { Consider supervised exercise therapy at experienced } \\
\text { institutions to improve exercise capacity and QOL }\end{array}$ & Ila & B & B & II \\
\hline $\begin{array}{l}\text { Patients with advanced deconditioning and } \\
\text { patients with reduced physical function } \\
\text { Resistance training to improve ADL and QOL by } \\
\text { increasing muscle strength and endurance }\end{array}$ & Ila & C & B & IVb \\
\hline
\end{tabular}

ADL, activities of daily living; CRT-D, cardiac resynchronization therapy defibrillator; HFrEF, heart failure with reduced ejection fraction; ICD, implantable cardioverter defibrillator; QOL, quality of life.

Study of Adaptive Servo-Ventilation in Patients with Chronic Heart Failure (SAVIOR-C) trial that evaluated the efficacy of ASV in patients with chronic heart failure with and without sleep-disordered breathing in Japan, LVEF assessed as the primary endpoint did not differ significantly between the ASV and guideline-directed medical therapy, but a clinical composite response assessed as a secondary endpoint improved significantly in the ASV group as compared with the medical therapy group. ${ }^{270}$ In 2016, the National Health Insurance started to cover the use of ASV for the treatment of congestion in patients with heart failure who meet particular conditions. The Japanese Circulation Society and the Japanese Heart Failure Society published the second statement on appropriate use of ASV to clarify who are indicated for ASV (See Supplement 1). ${ }^{271}$
As the Treatment of Sleep-Disordered Breathing with Predominant Central Sleep Apnea by Adaptive Servo Ventilation in Patients with Heart Failure (SERVE-HF) trial ${ }^{272}$ suggested that ASV may increase the risk of cardiovascular death, patients who meet the inclusion criteria for the SERVE-HF trial should be considered for discontinuing ASV or switching to CPAP when heart failure is stabilized after introducing ASV.

\section{Exercise Therapy (Table 32)}

4.1 Effects of Exercise Therapy (Supplement 2) ${ }^{148}$ Exercise therapy increases peak $\mathrm{V}_{2}$ by 15 to $30 \%$ (mean of about 20\%), and also improves anaerobic threshold 
(AT). ${ }^{273-283}$ It has been described that exercise therapy may elevate exercise capacity by increasing the muscular mass and volume density of mitochondria in skeletal muscle, ${ }^{279}$ enhancing the metabolism and function of skeletal muscles, ${ }^{278,284}$ improving the function of respiratory muscles, ${ }^{285,286}$ and improving the endothelial function through increased nitric oxide (NO) production, ${ }^{287,288}$ among other peripheral mechanisms. ${ }^{275,279}$ Exercise therapy also exerts beneficial effects on neurohumoral factors such as the reduction of $\mathrm{C}$ reactive protein (CRP), an inflammatory substance, ${ }^{289}$ and cytokines (e.g., TNF- $\alpha$ and IL-6 ${ }^{290}$ ), and improves autonomic nervous system dysfunction, which is an important prognostic factor. ${ }^{291-293} \mathrm{~A}$ considerable body of evidence has been accumulated on the beneficial effects of exercise therapy on patients with heart failure through relieving anxiety and depression, and improving QOL. ${ }^{273,276,282,294}$

The findings from the Exercise Training Meta Analysis of Trials in Chronic Heart Failure (ExTraMATCH) have indicated that exercise therapy improves the prognosis of patients with heart failure. ${ }^{295}$ In the Participants in Heart Failure: A Controlled Trial Investigating Outcomes of Exercise Training (HF-ACTION) trial, a large-scale randomized controlled study, ${ }^{296}$ exercise therapy reduced the risk of all-cause death or hospitalization by $11 \%$ and the risk of cardiovascular death or hospitalization for heart failure by $15 \%$ after adjusting for confounding factors. A Cochrane systematic review of exercise-based cardiac rehabilitation for heart failure has indicated that exercise therapy significantly reduces the risk of all-cause and heart-failure-related hospitalizations in patients with heart failure. ${ }^{297}$

\subsection{Heart Failure in Patients With Special Conditions}

The findings of randomized controlled traials ${ }^{298-300}$ and a meta-analysis ${ }^{301}$ in patients with heart failure with preserved ejection fraction (HFpEF) have indicated that exercise training improves exercise capacity measured by peak oxygen uptake as well as QOL in this patient population.
Randomized controlled trials of exercise therapy in patients with implantable devices have reported that patients in the exercise therapy group showed significant improvement in peak oxygen uptake, NYHA functional class, and QOL score, among other measures. ${ }^{302,303} \mathrm{~A}$ recent randomized controlled trial that evaluated effectiveness of exercise therapy in patients with pulmonary hypertension ${ }^{304}$ reported that patients in the exercise therapy group showed better improvement in exercise capacity and QOL as compared with the control group. The 2015 ESC/ERS guidelines for the diagnosis and treatment of pulmonary hypertension recommend supervised exercise rehabilitation as a Class IIa recommendation. ${ }^{305}$

\section{4.3 Methodology of Exercise Training}

In patients with deconditioning, elderly patients with low muscle strength, and patients with sarcopenia or frailty, resistance training may be highly effective. ${ }^{306-310} \mathrm{~A}$ recent study addressed the efficacy of high-intensity interval training (HIT) in heart failure. ${ }^{311}$ However, a randomized controlled study has concluded that HIT is not superior to continuous exercise training in terms of increasing exercise capacity and preventing left ventricular remodeling. ${ }^{312}$

\section{4.4 Contraindications for Exercise Therapy}

Supplement $3^{148}$ lists contraindications for exercise therapy.

\subsection{Exercise Prescription}

Exercise therapy for patients with heart failure should be conducted according to appropriate exercise prescriptions (Supplement 4). ${ }^{148}$ Supervised exercise therapy is required especially for elderly patients and patients with severe left ventricular dysfunction, high-risk arrhythmias, or a risk of ischemia. These patients may benefit from exercise therapy even with low or intermediate intensity (40 to $60 \%$ of peak $\left.\dot{\mathrm{V}} \mathrm{O}_{2}\right) .{ }^{148,280,313}$

\section{Treatment of Underlying Conditions}

\section{Basic Treatment Strategies}

Heart failure management consists of two strategies. The first strategy is to treat heart failure, and the second is to treat the cause of heart failure. When patients showed signs and symptoms of heart failure, heart failure is related directly to patients' complaints and sometimes risk of death, and treatment for heart failure should generally be prioritized over treatment for causative disease.

\section{Underlying Conditions That May Modify Treatment Strategies}

Some underlying cardiac disorders causing heart failure may require special plan for treatment sequencing. Patients with such cardiac disorders show ever-changing conditions should be treated for the causative disease and the condi- tions simultaneously. These conditions include acute coronary syndrome and pulmonary thromboembolism, for which revascularization is effective, arrhythmias which can be treated well by defibrillation and pacing, and acute myocarditis for which outcome cannot be readily predicted. Other cardiac disorders require careful decongestion because an abrupt change in intravascular volume may compromise hemodynamics. These disorders include structural heart diseases with significant pressure gradient such as aortic valve stenosis; severe right ventricular dysfunction and other right heart disease causing a significant increase in pulmonary vascular resistance; and severe cardiac diastolic dysfunction such as constrictive pericarditis and restrictive cardiomyopathy.

\section{Comorbid Conditions Causing Advanced Stage Heart Failure}

Lifestyle-related diseases such as hypertension, diabetes 
mellitus, and dyslipidemia are typical risk factors for Stage A heart failure, while there is little evidence on the management of these factors in Stage C or D heart failure. Conditions affecting non-cardiac organs such as chronic kidney disease and chronic obstructive pulmonary disease (COPD) also modify the risk of heart failure, but treatment strategies for these conditions in patients with heart failure have not been established yet.

\section{Pathophysiology and Treatment of Comorbidities}

\section{Atrial Fibrillation (Table 33)}

\subsection{Pathophysiology}

Atrial fibrillation is one of the most common types of arrhythmias associated with heart failure, and is known to negatively affect cardiac function and hemodynamics, and worsen heart failure. ${ }^{314}$ A meta-analysis ${ }^{315}$ has revealed that $\beta$-blockers for the treatment of atrial fibrillation do not improve the prognosis of patients with severe chronic heart failure associated with atrial fibrillation. Moreover, $\beta$-blockers reduced mortality in patients with heart failure in sinus rhythm and achieving a lower heart rate, but it was not observed in patients with atrial fibrillation. However, atrial fibrillation in the patients with acute heart failure which causes or is expected to cause an abrupt disturbance of hemodynamics or worsening symptoms should receive appropriate treatments. Treatment strategies for atrial fibrillation are classified into "rate control" that accepts the presence of atrial fibrillation and controls heart rate, and "rhythm control" that aims to return to and maintain sinus rhythm. As the effect of atrial fibrillation on hemodynamics differs between patients with acute heart failure and patients with chronic heart failure, appropriate treatment strategies should be selected to address the relevant condition.

\subsection{Treatment}

\section{1.2.1 Treatment for Atrial Fibrillation With a Rapid Ventricular Response Complicated With Acute Heart Failure}

When atrial fibrillation develops during the treatment of acute heart failure and is considered highly likely to negatively affect hemodynamics, electrical cardioversion should be performed immediately. Patients who are not receiving appropriate anticoagulation therapy in whom the duration of atrial fibrillation is unknown should undergo transesophageal echocardiography to confirm the absence of thrombus in the left atrium before starting defibrillation. ${ }^{316-318}$ Patients with symptoms of heart failure who need rate control therapy immediately may be treated with intravenous digitalis. ${ }^{319}$ Landiolol has been reported to be beneficial effect for controlling the heart rate as compared with digoxin in the atrial fibrillation or atrial flatter with left ventricular dysfunction, and the use of this drug for this indication is covered with the National Health Insurance in Japan. ${ }^{320}$ Non-dihydropyridine calcium channel blockers (e.g., verapamil and diltiazem) are contraindicated for patients with decompensated heart failure as they may worsen heart failure via their negative inotropic effects. ${ }^{16}$

\section{1.2.2 Rate Control}

A meta-analysis of clinical trials in Western countries has concluded that $\beta$-blockers do not improve the prognosis of patients with chronic heart failure and atrial fibrillation, but many studies included in the analysis were conducted in patients with severe heart failure such as NYHA Class III or IV and patients with LVEF $<30 \% .{ }^{315}$ It is likely that atrial fibrillation rather than heart rate affects the prognosis of this patient population. On the other hand, a registry of patients with moderate or severe heart failure associated with atrial fibrillation has reported that $\beta$-blockers significantly reduced all-cause mortality, and mortality increased significantly in patients with a heart rate of $>100 \mathrm{bpm}^{321}$ Accordingly, physicians should be aware that the benefits of $\beta$-blockers on prognosis may differ depending on the severity of heart failure. Patients with atrial fibrillation who have severe symptom due to tachycardia, and those with elevated and sustained heart rate of $>130 \mathrm{bpm}$ are at high risk for developing heart failure, and thus should receive rate control. ${ }^{322}$ In the Guidelines for Pharmacological of Atrial Fibrillation (JCS 2013) proposed by the Japanese Circulation Society, the target heart rate at rest is set at $<110 \mathrm{bpm}$ for patients without heart failure. When no improvement in symptoms or cardiac function is observed, the target should be set at $<80 \mathrm{bpm}$ at rest and $<110 \mathrm{bpm}$ during moderate exercise. ${ }^{323}$

Patients with chronic heart failure and atrial fibrillation with mild symptoms and stable hemodynamic should be considered for rate control in atrial fibrillation first. Carvedilol or bisoprolol is an oral $\beta$-blocker of choice, and should be started at a low dose considering the severity of heart failure. Oral digoxin exerts rate control and cardiotonic actions, but unlike $\beta$-blockers, may reduce heart rate at night. ${ }^{324,325}$

\section{1.2.3 Rhythm Control}

Rhythm control is selected for patients in whom rate control cannot be achieved with drug therapy and patients in whom maintaining sinus rhythm is beneficial in maintaining hemodynamics and managing heart failure. Amiodarone is the first-choice of oral drugs for rhythm control used in patients with cardiac dysfunction. In Japan, low-dose amiodarone therapy has been effective in maintaining sinus rhythm and reducing heart rate in patients with heart failure and atrial fibrillation, ${ }^{326}$ and this use is covered by the National Health Insurance in Japan. Regardless of whether heart failure is acute or chronic, sodium channel blockers (with slow kinetic activation kinetics), which may exert negative inotropic action, must not be used to maintain sinus rhythm in patients with heart failure and atrial fibrillation. ${ }^{327}$

\subsubsection{Anticoagulant Therapy}

The CHADS 2 score has been used extensively to assess the risk of cerebral infarction and systemic embolism in patients with atrial fibrillation (Supplement 5), ${ }^{328}$ and is used when initiating anticoagulant therapy in Japan. As the stroke rate without antithrombotic therapy is as high as 1.9 per 100 patient-years even in patients with a $\mathrm{CHADS}_{2}$ score of $0,{ }^{328}$ Western countries use the $\mathrm{CHA}_{2} \mathrm{DS}_{2}$-VASc score to specify truly low-risk patients. ${ }^{329,330}$ As patients with heart 
Table 33. Recommendations and Levels of Evidence for Treatment of Atrial Fibrillation in Patients With Heart Failure

\begin{tabular}{|c|c|c|c|c|}
\hline & $\begin{array}{c}\text { Class of } \\
\text { Recommendation }\end{array}$ & $\begin{array}{l}\text { Level of } \\
\text { Evidence }\end{array}$ & $\begin{array}{c}\text { Grade of } \\
\text { Recommendation } \\
\text { (MINDS) }\end{array}$ & $\begin{array}{l}\text { Level of } \\
\text { Evidence } \\
\text { (MINDS) }\end{array}$ \\
\hline \multicolumn{5}{|c|}{ Treatment of atrial fibrillation with a rapid ventricular response in patients with acute heart failure } \\
\hline $\begin{array}{l}\text { Urgent electrical cardioversion } \\
\text { To restore to sinus rhythm in the patients with hemodynamically compromised } \\
\text { atrial fibrillation in whom heart rate control is difficult with drug therapy }\end{array}$ & 1 & $\mathrm{C}$ & C1 & VI \\
\hline $\begin{array}{l}\text { Landiolol } \\
\quad \text { To control heart rate }\end{array}$ & Ila & B & B & II \\
\hline $\begin{array}{l}\text { Digoxin } \\
\text { To control heart rate }\end{array}$ & Ila & C & B & II \\
\hline $\begin{array}{l}\text { Oral or intravenous non-dihydropyridine calcium channel blockers } \\
\text { To control heart rate }\end{array}$ & III & $\mathrm{C}$ & $\mathrm{D}$ & II \\
\hline $\begin{array}{l}\text { Sodium channel blockers (with slow activation kinetics) } \\
\text { To maintain sinus rhythm in patients who returned to sinus rhythm and those } \\
\text { who received defibrillation }\end{array}$ & III & $\mathrm{C}$ & $\mathrm{D}$ & II \\
\hline \multicolumn{5}{|l|}{ Rhythm control } \\
\hline $\begin{array}{l}\text { Oral amiodarone } \\
\text { To maintain sinus rhythm }\end{array}$ & Ila & B & B & II \\
\hline $\begin{array}{l}\text { Elective electrical cardioversion } \\
\text { To treat persistent atrial fibrillation lasting for }<1 \text { year without substantial left } \\
\text { atrial enlargement }\end{array}$ & Ila & C & $\mathrm{C} 1$ & VI \\
\hline $\begin{array}{l}\text { Catheter ablation } \\
\text { To treat symptomatic atrial fibrillation in patients with heart failure who do not } \\
\text { respond well to rate control therapy or drug therapy for heart failure }\end{array}$ & $\mathrm{Ilb}$ & C & B & II \\
\hline $\begin{array}{l}\text { Oral sodium channel blockers (with slow activation kinetics) } \\
\text { To maintain sinus rhythm in patients who returned to sinus rhythm and those } \\
\text { who received defibrillation }\end{array}$ & III & A & $\mathrm{D}$ & II \\
\hline \multicolumn{5}{|l|}{ Rate control } \\
\hline $\begin{array}{l}\text { Oral } \beta \text {-blockers and oral digoxin } \\
\text { To control heart rate }\end{array}$ & Ila & B & A & 1 \\
\hline $\begin{array}{l}\text { Oral amiodarone } \\
\text { To control heart rate in patients in whom monotherapy with } \beta \text {-blockers or } \\
\text { digoxin or combination of the two drugs are not effective in rate control }\end{array}$ & $\mathrm{llb}$ & C & $\mathrm{C} 1$ & VI \\
\hline $\begin{array}{l}\text { Oral non-dihydropyridine calcium channel blockers } \\
\text { To control heart rate }\end{array}$ & III & $\mathrm{C}$ & $\mathrm{D}$ & II \\
\hline \multicolumn{5}{|l|}{ Anticoagulant therapy } \\
\hline $\begin{array}{l}\text { Use of the } \mathrm{CHADS}_{2} \text { score and the HAS-BLED score to predict the benefits of } \\
\text { anticoagulant therapy }\end{array}$ & I & B & A & II \\
\hline $\begin{array}{l}\text { Oral anticoagulant therapy for the treatment of atrial fibrillation in patients with } \\
\text { heart failure (unless contraindicated) }\end{array}$ & 1 & A & A & 1 \\
\hline $\begin{array}{l}\text { Anticoagulant therapy for } 3 \text { weeks before and } 4 \text { weeks after pharmacological or } \\
\text { electrical cardioversion in patients with atrial fibrillation lasting } \geq 48 \text { hours }\end{array}$ & 1 & $\mathrm{~B}$ & A & II \\
\hline $\begin{array}{l}\text { Electrical cardioversion with heparin after ruling out intracardiac thrombi by } \\
\text { transesophageal echocardiography in patients with atrial fibrillation who are not } \\
\text { receiving anticoagulant therapy }\end{array}$ & 1 & C & A & II \\
\hline Considering DOACs as first-line therapy & Ila & B & A & II \\
\hline $\begin{array}{l}\text { Concomitant use of DAPT and anticoagulation after coronary intervention in } \\
\text { patients with heart failure and ischemic heart disease }\end{array}$ & $\mathrm{llb}$ & C & $\mathrm{C} 2$ & II \\
\hline $\begin{array}{l}\text { Use of DOACs in patients using prosthetic valves (mechanical or bioprosthetic } \\
\text { valves) and in patients with rheumatic mitral valve disease }\end{array}$ & III & $\mathrm{B}$ & $\mathrm{D}$ & II \\
\hline
\end{tabular}

DAPT, dual antiplatelet therapy; DOAC, direct oral anticoagulant.

failure and atrial fibrillation have a $\mathrm{CHADS}_{2}$ score of $\geq 1$, anticoagulant therapy should be considered for them unless it is contraindicated.

Atrial fibrillation in patients with heart failure have been treated with anticoagulant therapy using warfarin. However, direct oral anticoagulants (DOACs), that have been launched recently, have changed anticoagulant strategies for atrial fibrillation in patients with heart failure. 331-334 DOACs are as effective as warfarin in patients with heart failure, and are safer than warfarin as the risk of major bleeding such as intracranial hemorrhage is lower in patients treated with DOACs than those treated with warfarin. 335,336 However, DOACs are indicated only for patients with non-valvular atrial fibrillation, and warfarin should be used for patients with severe mitral valve stenosis and patients using valve prostheses (mechanical valves or bioprosthetic valves). ${ }^{337}$ As renal function may change as heart failure advances or improves during treatment, the dose of anticoagulant drugs, especially DOACs, should be adjusted carefully according to the criteria for dose reduction or careful administration. The HAS-BLED score has been used to assess the risk of bleeding during anticoagulant 


\begin{tabular}{|l|c|c||c|c|}
\hline \multicolumn{3}{|c|}{ Table 34. Recommendations and Levels of Evidence for Treatment of Ventricular Arrhythmias in Patients } \\
With Heart Failure
\end{tabular}

therapy. ${ }^{337 a}$

Patients with heart failure due to ischemic heart disease often receive dual antiplatelet therapy (DAPT) for percutaneous coronary intervention (PCI). When accompanied by atrial fibrillation, anticoagulant therapy is added and the risk of bleeding may further increase. ${ }^{338}$ The European Society of Cardiology (ESC) guidelines for the management of atrial fibrillation provide recommendations on the contents and duration of anticoagulant and antiplatelet therapy according to the risk of stroke, the risk of bleeding, and patient characteristics. ${ }^{339}$ In the What is the Optimal antiplatelet and anticoagulant therapy in patients with oral anticoagulation and coronary Stenting (WOEST) trial, 338 patients receiving warfarin for the treatment of stable angina underwent PCI were randomized to triple therapy (warfarin, aspirin, and clopidogrel) or duel therapy (warfarin, and clopidogrel). Comparisons between the two groups in terms of the incidence rates of bleeding events and thromboembolic events revealed that all-cause mortality and the incidence of bleeding events were significantly lower in the duel therapy group, and the incidence rates of myocardial infarction, stroke, and in-stent thrombosis did not differ between the two groups.

\section{Ventricular Arrhythmias (Table 34)}

Ventricular arrhythmias associated with heart failure includes premature ventricular contractions, non-sustained/ sustained ventricular tachycardia and ventricular fibrillation. Especially hemodynamically intolerable ventricular tachycardia and ventricular fibrillation should be treated electrical defibrillation immediately. Intravenous amiodarone and nifekalant, as antiarrhythmic drugs, have a rapid onset of actions and are expected to be highly effective in preventing ventricular arrythmias..$^{\mathbf{3 4 0 , 3 4 1}}$ Also, risk factors and predisposing factors for life-threatening ventricular arrhythmias, such as electrolyte imbalance and use of proarrhythmic drugs, should be identified and treated accordingly. When myocardial ischemia is involved in the development of arrhythmia, revascularization to treat the ischemia is important. Polymorphic ventricular tachycardia with prolonged QT interval ${ }^{342}$ and torsade de pointes in the patients with heart failure should be confirmed and treated for electrolyte imbalance such as hypokalemia and hypomagnesemia. Intravenous magnesium sulfate is also effective. ${ }^{343}$

In patients with an implantable cardioverter defibrillator (ICD), the experience of ICD shocks may cause physical and/or mental stress, leading to frequent ICD shocks. Patients who have three or more episodes of life-threatening ventricular arrhythmia within 24 hours, so-called "electrical storm", and in case of refractory to ICD therapy should receive percutaneous cardiopulmonary support (PCPS) to stabilize hemodynamics and treat arrhythmias. When sustained ventricular arrhythmia cannot be controlled with drug therapy, catheter ablation should also be considered. ${ }^{344,345}$ Oral $\beta$-blockers are effective in preventing the recurrence of life-threatening ventricular arrhythmia and sudden death in patients with chronic heart failure. ${ }^{192-194}$ Amiodarone is another treatment option, ${ }^{346}$ but careful observation is required because of its serious adverse drug reactions. Nonpharmacologic therapy using ICDs is mainly used to prevent sudden death in patients with heart failure. ${ }^{234}$ Antiarrhythmic drugs are used as adjunctive therapy to reduce the frequency of arrhythmic episodes.

\section{Bradyarrhythmia (Table 35)}

When patients have symptoms of cerebral ischemia associated with bradycardia caused by drug therapy, dose reduction should be considered first. The ESC Guidelines for the diagnosis and treatment of acute and chronic heart failure recommend that when sinus arrest lasting for $>3$ seconds, bradycardia of $<50 \mathrm{bpm}$ in sinus rhythm or 


\begin{tabular}{|c|c|c|c|c|}
\hline & $\begin{array}{c}\text { Class of } \\
\text { Recommendation }\end{array}$ & $\begin{array}{l}\text { Level of } \\
\text { Evidence }\end{array}$ & $\begin{array}{l}\text { Grade of } \\
\text { Recommendation } \\
\text { (MINDS) }\end{array}$ & $\begin{array}{c}\text { Level of } \\
\text { Evidence } \\
\text { (MINDS) }\end{array}$ \\
\hline $\begin{array}{l}\text { Pacing for patients with symptomatic heart failure due } \\
\text { to bradycardia caused by poor sinus function, sinoatrial } \\
\text { block, sinus arrest, or poor rate response during exercise, } \\
\text { or caused by second-degree, advanced, or third- } \\
\text { degree atrioventricular block (including patients with } \\
\text { bradycardia caused by long-term necessary drug } \\
\text { therapy) }\end{array}$ & 1 & C & A & $\mathrm{VI}$ \\
\hline $\begin{array}{l}\text { Pacing for patients with symptomatic heart failure due } \\
\text { to bradycardic atrial fibrillation (including patients with } \\
\text { bradycardia caused by long-term necessary drug } \\
\text { therapy) }\end{array}$ & 1 & C & A & VI \\
\hline $\begin{array}{l}\text { Pacing for patients with symptomatic heart failure which } \\
\text { has not been confirmed to be caused by bradyarrhythmia }\end{array}$ & Ila & C & B & VI \\
\hline
\end{tabular}

$<60 \mathrm{bpm}$ in atrial fibrillation is occurred, the dose of rate limiting medications should be reconsidered. ${ }^{\mathbf{1 6}}$ In patients with atrial fibrillation and heart failure, $\beta$-blockers and other drugs are effective in the treatment of heart failure. Patients in whom continuation or dose escalation of $\beta$-blocker therapy for heart failure is necessary may be considered for pacemaker implantation. Patients with heart failure and bradyarrhythmia who are indicated for pacemaker should receive atrioventricular synchronization pacing unless permanent atrial fibrillation is present. Some patients with heart failure may have a wide QRS complex as a result of ventricular pacing for the treatment of bradyarrhythmia, and need biventricular cardiac pacing (See Section "2. Cardiac Resynchronization Therapy" in Chapter "VII. Nonpharmacologic Therapy").

\section{Coronary Artery Disease (Table 36)}

\section{I.1 Pathophysiology}

In addition to hypertension and dilated cardiomyopathy, coronary artery disease is one of the most common conditions that underlies heart failure. ${ }^{347}$ The prevalence of coronary heart disease among patients with heart failure was $23 \%$ in the Chronic Heart Failure Analysis and Registry in the Tohoku District (CHART)-1 Study in which patients were registered from 2000 to 2004 , but increased to $47 \%$ in the CHART-2 Study in which patients were registered from 2006 to $2010 .^{30,348}$ The prevalence of coronary heart disease among patients with acute heart failure was $31 \%$ in the Acute Decompensated Heart Failure Syndromes (ATTEND) registry ${ }^{349}$ and $32 \%$ in the Japanese Cardiac Registry of Heart Failure in Cardiology (JCARE-CARD). ${ }^{32}$ The prevalence of patients with ischemic heart failure with preserved LVEF is increasing. For example, in the CHART Studies, the prevalence of ischemic heart failure among patients with $\mathrm{LVEF} \geq 50 \%$ was increased from $19 \%$ in the CHART-1 Study to $45 \%$ in the CHART-2 Study. ${ }^{31}$

In the CHART-1 Study, three-year mortality in patients with heart failure following myocardial infarction was $29 \%$, which was higher than that in patients with nonischemic heart failure $(12 \%) .{ }^{350}$ In the ATTEND study, the mortality in patients with acute heart failure due to ischemic heart disease was similar to those in patients with acute heart failure due to other diseases among patients with $\mathrm{LVEF} \geq 40 \%$, while it was as high as in patients with acute heart failure due to valvular heart disease, both of which were higher that the mortality in those with acute heart failure due to other diseases among those with LVEF $<40 \%{ }^{351}$ Three-year mortality in patients with ischemic heart disease with a NYHA class of II or greater was $29 \%$ in the CHART-1 Study, and 15\% in the CHART-2 Study, showing a decrease in mortality over time in the CHART Studies. ${ }^{31}$

Myocardial ischemia impairs systolic and dilative functions of the heart, and myocardial injury due to myocardial infection causes ventricular dysfunction. Myocardial ischemia and injury may cause fatal arrhythmias and compromise hemodynamics. Patients with coronary risk factors such as lifestyle-related diseases should be monitored carefully as they are susceptible to arteriosclerosis or cardiac dysfunction. Treatment of ischemic heart disease should aim at the management of 1) cardiac function, 2) myocardial ischemia, 3) arrhythmia, and 4) coronary risk factors.

\subsection{Treatment}

\subsubsection{Acute Heart Failure}

\section{a. Heart Failure Associated With Acute Myocardial Infarction}

In patients with acute myocardial infarction, an abrupt loss of cardiac pump function may lead to acute heart failure. Accordingly, patients with acute myocardial infarction should also receive oxygen therapy and vasodilators to treat acute heart failure as well (See Section "3. Treatment Strategies and Flowcharts" in Chapter "X. Acute Heart Failure"). Whenever necessary, hemodynamics monitoring via Swan-Ganz catheterization should be conducted and PCI, coronary artery bypass grafting (CABG), thrombolysis or other appropriate reperfusion therapy should be conducted to treat myocardial ischemia. Additional treatment should be initiated in the acute phase to prevent left ventricular remodeling, and intra-aortic balloon pumping (IABP) or other circulatory assist devices should also be considered if necessary (See Section "2.2. Percutaneous Circulatory Support for Patients With Acute Heart Failure" in Chapter "XI. Surgical Treatment"). Moreover, angiotensin converting enzyme (ACE) inhibitors should be started in acute phase to prevent long-term cardiac remodeling, ${ }^{352}$ and $\beta$-blockers should be started immediately after hemodynamics is stabilized. ${ }^{353}$ Treatment of arrhythmias, and surgical treatment of mechanical complications and 


\begin{tabular}{|c|c|c|c|c|}
\hline & $\begin{array}{c}\text { Class of } \\
\text { Recommendation }\end{array}$ & $\begin{array}{l}\text { Level of } \\
\text { Evidence }\end{array}$ & $\begin{array}{l}\text { Grade of } \\
\text { Recommendation } \\
\text { (MINDS) }\end{array}$ & $\begin{array}{l}\text { Level of } \\
\text { Evidence } \\
\text { (MINDS) }\end{array}$ \\
\hline \multicolumn{5}{|l|}{ ACE inhibitors } \\
\hline $\begin{array}{l}\text { Use in patients with congestive heart failure or left } \\
\text { ventricular systolic dysfunction }\end{array}$ & 1 & B & A & 1 \\
\hline $\begin{array}{l}\text { Use within } 24 \text { hours after onset of acute myocardial } \\
\text { infarction in patients who are highly likely to have left } \\
\text { ventricular dysfunction (LVEF }<40 \% \text { ) or heart failure }\end{array}$ & I & A & A & 1 \\
\hline $\begin{array}{l}\text { Use in post-myocardial infarction patients with left heart } \\
\text { dysfunction }\end{array}$ & 1 & A & A & 1 \\
\hline $\begin{array}{l}\text { Use in patients with myocardial infarction who have } \\
\text { normal left heart function, but have hypertension, } \\
\text { diabetes mellitus, or a moderate to high risk of } \\
\text { developing cardiovascular accidents }\end{array}$ & 1 & A & A & 1 \\
\hline $\begin{array}{l}\text { Use in all patients with acute myocardial infarction } \\
\text { within } 24 \text { hours after onset }\end{array}$ & Ila & B & B & II \\
\hline $\begin{array}{l}\text { Use in patients with normal cardiac function and low } \\
\text { risk of cardiovascular accidents }\end{array}$ & Ila & B & B & II \\
\hline \multicolumn{5}{|l|}{ ARBs } \\
\hline $\begin{array}{l}\text { Starting treatment in the acute phase of myocardial } \\
\text { infarction in patients intolerable to ACE inhibitors who } \\
\text { have symptomatic heart failure or LVEF of } \leq 40 \%\end{array}$ & I & A & A & 1 \\
\hline $\begin{array}{l}\text { Use in combination with ACE inhibitors for the treatment } \\
\text { of myocardial infarction in patients with left ventricular } \\
\text { systolic dysfunction in whom the risk of renal dysfunction } \\
\text { is considered low }\end{array}$ & Ilb & B & C2 & II \\
\hline \multicolumn{5}{|l|}{$\beta$-blockers } \\
\hline $\begin{array}{l}\text { Use in patients other than low-risk patients* who are } \\
\text { not contraindicated for } \beta \text {-blockers }\end{array}$ & I & A & A & I \\
\hline $\begin{array}{l}\text { Use with upward dose titration in patients with moderate } \\
\text { or severe left heart dysfunction }\end{array}$ & I & B & A & II \\
\hline Use in low-risk patients* & Ila & B & B & II \\
\hline $\begin{array}{l}\text { Monotherapy in patients in whom coronary spasm is } \\
\text { involved }\end{array}$ & III & B & C2 & V \\
\hline \multicolumn{5}{|l|}{ MRAs } \\
\hline $\begin{array}{l}\text { Use at low doses for the treatment of moderate or } \\
\text { severe heart failure in patients without renal dysfunction } \\
\text { or hyperkalemia }\end{array}$ & Ila & B & B & II \\
\hline
\end{tabular}

${ }^{*}$ Patients after successful revascularization of the culprit artery of myocardial infarction who have normal or nearly normal left heart function and do not have serious ventricular arrhythmia. ACE, angiotensin converting enzyme; ARB, angiotensin II receptor blocker; LVEF, left ventricular ejection fraction; MRA, mineralocorticoid receptor antagonist.

ischemic mitral valve insufficiency are described in other sections (From Section "1. Atrial Fibrillation" to "3. Bradyarrhythmia" in Chapter "IX. Pathophysiology and Treatment of Comorbidities", and "5.5. Treatment of Mechanical Complications Associated With Acute Myocardial Infarction" in Chapter "X. Acute Heart Failure").

\section{b. Acute Exacerbations of Ischemic Heart Failure}

In patients with ischemic heart failure, progression of coronary artery lesions, coronary spasm, anemia due to gastrointestinal bleeding, tachycardia due to paroxysmal atrial fibrillation, and/or excessive daily activities may cause imbalance of oxygen supply and demand, and then myocardial (subendocardial) ischemia may occur, resulting in development of acute heart failure due to acute diastolic or systolic dysfunction. ${ }^{354}$ Patients with diabetes mellitus or hypertension who have cardiac hypertrophy are susceptible to subendocardial ischaemia, ${ }^{355}$ and may experience an abrupt onset of pulmonary edema due to acute diastolic dysfunction. ${ }^{356}$ Such patients should be carefully observed, and should undergo reperfusion therapy such as PCI and CABG whenever necessary. Patients with systolic dysfunction due to chronic myocardial ischemia (myocardial hibernation) $)^{357}$ should also be considered for PCI or CABG.

\section{4.2.2 Chronic Heart Failure}

Treatment of chronic ischemic heart failure is basically same as other types of heart failure, and mainly consists of assessment of cardiac function (cardiac protection) and myocardial ischemia, prevention of arrhythmic events, and management of coronary risk factors.

For cardiac protection in patients with ischemic heart failure and reduced LVEF, $\beta$-blockers and renin-angiotensin inhibitors (e.g., ACE inhibitors, ARBs, and mineralocorticoid receptor antagonists [MRAs]) are mainly used (Table 36). ${ }^{192-194,215,358-360}$ These drugs should be started at low doses to avoid worsening heart failure. Nitrates have not been demonstrated to improve long-term prognosis, ${ }^{205}$ but have been shown to improve symptoms of heart failure and hemodynamics ${ }^{361}$ and are the first-line treatment for 


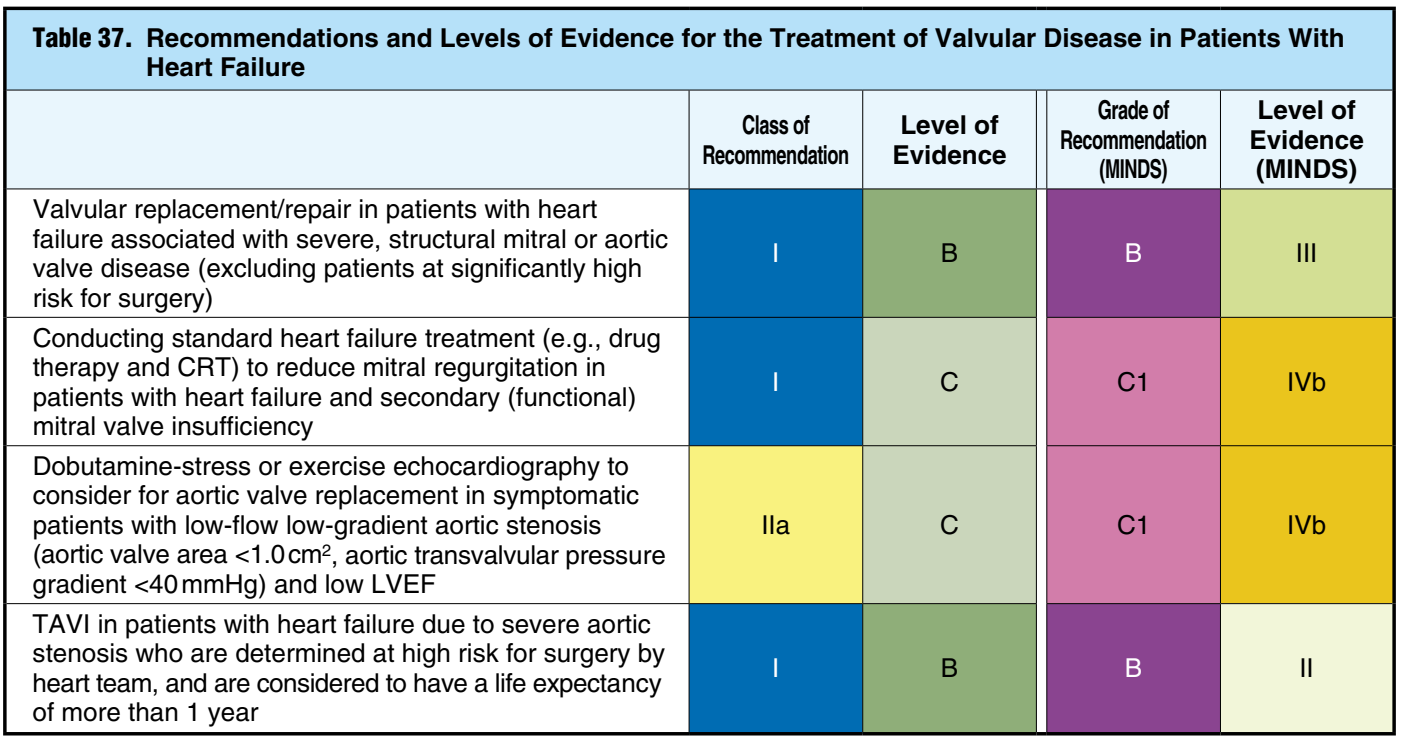

CRT, cardiac resynchronization therapy; LVEF, left ventricular ejection fraction; TAVI, transcatheter aortic valve implantation.

angina pectoris. Nicorandil and diuretics should also be considered as needed.

Patients with angina symptoms or proven to have ischemia due to cardiac dysfunction should be considered for PCI or CABG. ${ }^{362,363}$ A cohort study in Japan have suggested that the CABG is superior to PCI in patients with heart failure associated with severe coronary artery disease. ${ }^{364}$ According to the recommendations in the Guidelines for Non-Pharmacotherapy of Cardiac Arrhythmias (JCS 2011) issued by the Japanese Circulation Society, indications for ICD should be considered as a primary prevention therapy. ${ }^{365}$

For management of risk factors of coronary heart disease and details about exercise therapy, see Sections "6. Hypertension" to "9. Hyperuricemia/Goat" in Chapter "IX. Pathophysiology and Treatment of Comorbidities" and Section "4. Exercise Therapy" in Chapter "VII. Nonpharmacologic Therapy". Regarding management of dyslipidemia and smoking that are not described in the present guidelines, refer to other relevant guidelines.

\section{Valvular Heart Disease (Table 37)}

Patients with heart failure and valvular disease are at high risk for poor outcome. If the main cause of heart failure is valvular disease itself, following the treatment strategy for valvular disease are recommended (See the Guidelines for Surgical and Interventional Treatment of Valvular Heart Disease [JCS 2012]). ${ }^{366}$ Patients with valvular disease secondary to dilated cardiomyopathy or other heart disease should be treated for the relevant underlying cardiac diseases.

\subsection{Mitral Valve Insufficiency}

In patients with dilated or ischemic cardiomyopathy, mitral valve insufficiency secondary to mitral valve tethering or mitral annular enlargement may lead to further worsening of hemodynamics. However, no consensus has been reached whether interventions for mitral insufficiency may improve the prognosis of patients with moderate or severe secondary mitral valve insufficiency. In 2016, the Cardiothoracic Surgical Trials Network conducted an interventional study and reported that $\mathrm{CABG}$ plus mitral valve repair does not improve the outcome in patients with moderate secondary mitral valve insufficiency and ischemic heart disease. ${ }^{367} \mathrm{On}$ the basis of these findings, the ACC/AHA guideline for the management of patients with valvular heart disease, which was revised partially in 2017, describes that the usefulness of mitral valve repair in patients with moderate secondary mitral valve insufficiency and ischemic heart disease who are undergoing $\mathrm{CABG}$ is unclear. ${ }^{368}$

\subsection{Tricuspid Valve Insufficiency}

As a result of right ventricular overload due to left-sided heart failure or pulmonary hypertension, tricuspid valve insufficiency secondary to tricuspid annular enlargement and tricuspid valve tethering is often observed and is a factor of poor prognosis. ${ }^{369}$ Patients with secondary tricuspid valve insufficiency should first be treated to correct underlying condition causing heart failure. During surgery for left-sided valve surgery, concomitant tricuspid valve repair is recommended. $366,370,371$

\subsection{Aortic Valve Stenosis}

When aortic stenosis develops in patients with left ventricular systolic dysfunction due to underlying cardiac condition, the severity of aortic stenosis should be examined carefully. Treatment strategies for patients with low-flow, low-gradient aortic stenosis and reduced LVEF should be based on changes in aortic valve area and aortic transvalvular pressure gradient before and after an increase of stroke volume during dobutamine stress echocardiography.

For details about transcatheter aortic valve implantation (TAVI) and transcatheter aortic valve replacement (TAVR), see Section "1. Surgical Procedures and TAVI" in Chapter "XI. Surgical Treatment". 


\begin{tabular}{|l|c|c||c|c|}
\hline \multicolumn{1}{|l|}{$\begin{array}{l}\text { Table 38. Recommendations and Levels of Evidence for Drug Therapy for HFrEF in Patients With } \\
\text { Hypertension }\end{array}$} & $\begin{array}{c}\text { Class of } \\
\text { Recommendation }\end{array}$ & $\begin{array}{c}\text { Level of } \\
\text { Evidence }\end{array}$ & $\begin{array}{c}\text { Grade of } \\
\text { Recommendation } \\
\text { (MINDS) }\end{array}$ & $\begin{array}{c}\text { Level of } \\
\text { Evidence } \\
\text { (MINDS) }\end{array}$ \\
\hline ACE inhibitors & I & A & A & I \\
\hline ARBs (use in patients intolerable to ACE inhibitors) & I & A & A & I \\
\hline$\beta$-blockers & I & A & A & I \\
\hline MRAs & I & A & A & II \\
\hline Diuretics & I & B & A & I \\
\hline Calcium channel blockers* & Ila & B & B & II \\
\hline
\end{tabular}

${ }^{*}$ Calcium channel blockers other than long-acting dihydropyridines should not be used as they have negative inotropic effects. ACE, angiotensin converting enzyme; ARB, angiotensin II receptor blocker; MRA, mineralocorticoid receptor antagonist.

\begin{tabular}{|c|c|c|c|c|}
\hline & $\begin{array}{c}\text { Class of } \\
\text { Recommendation }\end{array}$ & $\begin{array}{l}\text { Level of } \\
\text { Evidence }\end{array}$ & $\begin{array}{l}\text { Grade of } \\
\text { Recommendation } \\
\text { (MINDS) }\end{array}$ & $\begin{array}{l}\text { Level of } \\
\text { Evidence } \\
\text { (MINDS) }\end{array}$ \\
\hline Appropriate blood pressure management & 1 & B & B & II \\
\hline Identification and treatment of underlying disease & I & C & B & VI \\
\hline
\end{tabular}

\section{Hypertension}

\subsection{Pathophysiology}

Hypertension is a major risk factor on heart disease independent of age and left ventricular dysfunction. ${ }^{172,372}$ Appropriate treatment for hypertension reduces the risk of the development of heart failure. ${ }^{150-152}$

\subsection{Treatment}

Patients with hypertension and cardiovascular disease are classified as high risk, and it is recommended to start antihypertensive treatment promptly, as well as lifestyle modifications (e.g., low-salt healthy diet, exercise, weight reduction in obesity patients, and reducing alcohol consumption). ${ }^{154}$ However, no clear evidence has been accumulated on treatment goals of blood pressure in patients with heart failure and hypertension, as the etiology and pathophysiology of heart failure are diverse. Although, there have been controversies about optimal blood pressure targets for this patient population, ${ }^{373,374}$ and it is difficult to establish common goals for diverse patients, target systolic blood pressure of 110 to $130 \mathrm{mmHg}$ has been supported in the United States, ${ }^{375}$ and is the same in Japan.

\subsubsection{Patients With HFrEF and Hypertension (Table 38)}

ACE inhibitors ${ }^{182,184,376}$ and $\beta$-blockers ${ }^{193-195,377,378}$ have been demonstrated to improve the long-term prognosis of patients with heart failure and hypertension, and monotherapy or combination therapy of these drug classes are first-line treatment. Patients intolerable to ACE inhibitors may be treated with ARBs. ${ }^{\mathbf{1 6 8 , 1 8 7 , 1 8 8}}$ Treatment with $\beta$-blockers should be started at low doses, and the dose should be titrated gradually based on tolerability. In patients who do not respond well to antihypertensive drugs or patients with heart failure associated with organ congestion, diuretics should be added, and MRAs added to standard therapy is expected to improve prognosis in patients with severe conditions. ${ }^{163,164,189}$ Among calcium channel blockers, long-acting dihydropyridines can be used safely without compromising the prognosis of patients with heart failure, ${ }^{379}$ but other types of calcium channel blockers with negative inotropic effects should be avoided.

I 6.2.2 Patients With HFpEF and Hypertension (Table 39) As heart failure with preserved ejection fraction (HFpEF) is generally caused by both cardiovascular diseases (e.g., atrial fibrillation, hypertension, coronary artery diseases, and pulmonary hypertension) and non-cardiovascular diseases (e.g., diabetes, chronic kidney disease, anemia, and COPD), patients should be examined for these underlying conditions and should be treated accordingly. ${ }^{\mathbf{3 8 0 , 3 8 1}}$

As hypertension is one of the most common underlying conditions of HFpEF, ${ }^{\mathbf{3 8 2}}$ blood pressure control is considered essential. However, there is no sufficient evidence regarding optimal antihypertensive regimens or treatment targets for this patient population, and patients should be treated individually to control blood pressure.

\subsubsection{Acute Heart Failure}

Patients with acute heart failure except for those corresponding to the clinical scenario (CS) \#3 are treated with vasodilators and diuretics according to their conditions. 


\begin{tabular}{|c|c|c|c|c|}
\hline & $\begin{array}{c}\text { Class of } \\
\text { Recommendation }\end{array}$ & $\begin{array}{l}\text { Level of } \\
\text { Evidence }\end{array}$ & $\begin{array}{l}\text { Grade of } \\
\text { Recommendation } \\
\text { (MINDS) }\end{array}$ & $\begin{array}{c}\text { Level of } \\
\text { Evidence } \\
\text { (MINDS) }\end{array}$ \\
\hline $\begin{array}{l}\text { Comprehensive approach including life style modification } \\
\text { such as diet and exercise }\end{array}$ & 1 & A & A & 1 \\
\hline SGLT2 inhibitors (empagliflozin, ${ }^{*}$ canagliflozin ${ }^{\star \star}$ ) & Ila & A & B & II \\
\hline Thiazolidinediones & III & A & $\mathrm{D}$ & 1 \\
\hline
\end{tabular}

See Chapter "X. Acute Heart Failure" for detail.

\section{Diabetes Mellitus}

\subsection{Pathophysiology}

The prevalence of diabetes mellitus among patients with heart failure increased from $13 \%$ in 1989 to $47 \%$ in 1999.383 Also, about half of patients with diabetes mellitus have been reported to have left ventricular diastolic dysfunction ${ }^{\mathbf{3 8 4}}$ and poor cardiovascular outcome including heart failure. ${ }^{385}$

As diabetes mellitus is an independent risk factor for heart failure, ${ }^{386}$ interventions for diabetes mellitus are needed to prevent the development or progression of heart failure.

\subsection{Treatment}

\subsubsection{Treatment of Heart Failure in Patients With Diabetes Mellitus}

Although no clinical studies have evaluated the effectiveness of ACE inhibitors, ARBs, or $\beta$-blockers with proven efficacy in heart failure in patients with heart failure and diabetes mellitus, sub-analyses of large-scale clinical trials of ACE inhibitors and ARBs have demonstrated efficacy in patients with heart failure with or without diabetes mellitus. ${ }^{187,387,388}$ $\beta$-blockers are expected to exert similar efficacy regardless of whether diabetes mellitus is present or not. ${ }^{389,390}$ The efficacy of MRAs in the treatment of heart failure has also been demonstrated in patients with and without diabetes mellitus. ${ }^{164,391}$

These findings suggest that patients with heart failure and diabetes mellitus should be treated similarly to those without diabetes mellitus.

\subsubsection{Treatment of Diabetes Mellitus in Patients With Heart Failure (Table 40)}

Although no evidence has been obtained on the efficacy of specific treatment strategies to control diabetes mellitus in patients with heart failure, comprehensive approach depending on individual pathology using guidelines-based antidiabetic drugs, as well as lifestyle modifications such as diet and exercise, is important.

In cardiovascular outcome trials of most of the currently available incretin-based drugs, neither beneficial effects on heart failure nor increased the risk of poor outcome was observed in patients with heart failure. However, in the Saxagliptin Assessment of Vascular Outcomes Recorded in Patients with Diabetes Mellitus - Thrombolysis in Myocardial Infarction 53 (SAVOR-TIMI 53) trial, ${ }^{392}$ the incidence of hospitalizations for heart failure increased significantly in patients receiving saxagliptin. ${ }^{393}$

Among currently available SGLT2 inhibitors, empagliflozin ${ }^{\mathbf{1 7 5}}$ and canagliflozin ${ }^{\mathbf{1 7 8}}$ have been demonstrated to reduce the composite endpoint of major adverse cardiovascular events including cardiovascular death, nonfatal myocardial infarction, or nonfatal stroke, and the number of hospitalizations for heart failure in patients with type 2 diabetes mellitus and high cardiovascular risk, and are expected to improve the cardiovascular prognosis of patients with type 2 diabetes mellitus and high cardiovascular risk regardless of the presence or absence of heart failure. ${ }^{176,177}$ However, as patients complicated with heart failure account for only 10 to $15 \%$ of patients enrolled in these large-scale clinical studies of SGLT2 inhibitors, further studies are necessary to clarify the beneficial effects of these drugs on heart failure. Also, as there has been no evidence indicating that these results reflect class effects of SGLT2 inhibitors, the results of large-scale clinical studies of other SGLT2 inhibitors are awaited. In addition, further studies should be conducted to clarify the efficacy of SGLT2 inhibitors in patients aged 75 and over.

Accordingly, physicians should treat patients with diabetes mellitus and heart failure carefully considering pharmacological characteristics of antidiabetic agents and results of clinical trials while avoiding hypoglycemia.

\section{CKD and Cardiorenal Syndrome}

\subsection{Pathophysiology}

As patients with heart failure often have renal dysfunction, treatment strategies should be developed based on the patient's estimated glomerular filtration rate (eGFR), a clinical indicator of renal function.

The present guidelines describe the benefits of drugs according to chronic kidney disease (CKD) stages that are based on eGFR. Patients with an eGFR of $<60 \mathrm{~mL} /$ $\mathrm{min} / 1.73 \mathrm{~m}^{2}$ are classified into CKD stage 3 (eGFR: 30 to $\left.59 \mathrm{~mL} / \mathrm{min} / 1.73 \mathrm{~m}^{2}\right)$, stage $4\left(15\right.$ to $\left.29 \mathrm{~mL} / \mathrm{min} / 1.73 \mathrm{~m}^{2}\right)$ and stage $5\left(<15 \mathrm{~mL} / \mathrm{min} / 1.73 \mathrm{~m}^{2}\right)$.

\subsection{Treatment (Table 41)}

Many large-scale clinical studies in acute or chronic heart diseases excluded patients with renal dysfunction. In 


\begin{tabular}{|c|c|c|c|c|}
\hline & $\begin{array}{c}\text { Class of } \\
\text { Recommendation }\end{array}$ & $\begin{array}{l}\text { Level of } \\
\text { Evidence }\end{array}$ & $\begin{array}{l}\text { Grade of } \\
\text { Recommendation } \\
\text { (MINDS) }\end{array}$ & $\begin{array}{l}\text { Level of } \\
\text { Evidence } \\
\text { (MINDS) }\end{array}$ \\
\hline \multicolumn{5}{|c|}{ CKD Stage 3 (eGFR 30 to $59 \mathrm{~mL} / \mathrm{min} / 1.73 \mathrm{~m}^{2}$ ) } \\
\hline$\beta$-blockers & I & A & A & I \\
\hline ACE inhibitors & I & A & A & 1 \\
\hline ARBs & 1 & B & A & II \\
\hline MRAs & 1 & A & A & I \\
\hline Loop diuretics & I & C & C1 & VI \\
\hline \multicolumn{5}{|c|}{ CKD Stage 4 to $5\left(\right.$ eGFR $\left.<30 \mathrm{~mL} / \mathrm{min} / 1.73 \mathrm{~m}^{2}\right)$} \\
\hline$\beta$-blockers & Ila & B & B & II \\
\hline ACE inhibitors & $\mathrm{Ilb}$ & B & C1 & III \\
\hline ARBs & $\mathrm{Ilb}$ & C & C1 & $\mathrm{IVb}$ \\
\hline MRAs & $\mathrm{Ilb}$ & C & C2 & V \\
\hline Loop diuretics & Ila & C & C1 & VI \\
\hline
\end{tabular}

ACE, angiotensin converting enzyme; ARB, angiotensin II receptor blocker; CKD, chronic kidney disease; MRA, mineralocorticoid receptor antagonist.

general, patients with CKD stage 3 can be treated almost similarly to patients without CKD. However, little evidence has been obtained in terms of treatment of heart failure in patients with CKD stage 4 or 5 , and such patients are treated at the discretion of the attending physicians and/or consulting specialists.

\section{8.2.1 $\beta$-Blockers}

The efficacy of $\beta$-blockers in the treatment of heart failure has been established. A meta-analysis of the data from the Carvedilol Prospective Randomized Cumulative Survival (COPERNICUS ) trial ${ }^{394}$ and Carvedilol Post-infarct Survival Controlled Evaluation (CAPRICORN ) trial159 that assessed the efficacy of carvedilol in patients with heart failure revealed that carvedilol significantly improved the prognosis of patients with CKD stage 3 with an eGFR of 45 to $60 \mathrm{~mL} / \mathrm{min} / 1.73 \mathrm{~m}^{2}{ }^{395}$ In a sub-analysis of the Cardiac Insufficiency Bisoprolol Study II (CIBIS II) trial that assessed the efficacy of bisoprolol, the drug improved the prognosis of patients with an eGFR of $<45 \mathrm{~mL} / \mathrm{min} /$ $1.73 \mathrm{~m}^{2}$ or 45 to $60 \mathrm{~mL} / \mathrm{min} / 1.73 \mathrm{~m}^{2} .^{396}$ In a cohort study investigating the efficacy of $\beta$-blockers in patients with heart failure who are undergoing hemodialysis, oral $\beta$-blockers significantly improved the prognosis of this patient population. ${ }^{397}$

\subsubsection{ACE Inhibitors and ARBs}

The efficacy of angiotensin converting enzyme (ACE) inhibitors and angiotensin II receptor blockers (ARBs) in patients with heart failure has been established. In the Cooperative North Scandinavian Enalapril Survival Study (CONSENSUS) trial182 in which patients with a serum creatinine level of $\geq 3.4 \mathrm{mg} / \mathrm{dL}$ were excluded, participants had a mean serum creatinine level of $1.4 \mathrm{mg} / \mathrm{dL}$ and an eGFR of about $45 \mathrm{~mL} / \mathrm{min} / 1.73 \mathrm{~m}^{2}$, which indicate that
CKD was prevalent among the participants. In a subanalysis that dichotomized patients according to mean serum creatinine level, the efficacy of enalapril was comparable between patients with higher and lower serum creatinine levels. In a study in patients with heart failure with a serum creatinine level of $\geq 2.4 \mathrm{mg} / \mathrm{dL}$ or a creatinine clearance of $<30 \mathrm{~mL} / \mathrm{min}$ (CKD stage 4 or 5 ), renin-angiotensin (RA) system inhibitors significantly improved the prognosis of these patients. ${ }^{398}$ It has also been reported that addition of oral RAS inhibitors improved the prognosis of hemodialysis patients receiving oral $\beta$-blockers as compared with no addition of RAS inhibitors. ${ }^{397}$ As ACE inhibitors and ARBs may rarely reduce renal function or cause hypokalemia in patients with CKD stage 4 or 5 and elderly patients with CKD, these drugs should be started at low doses. ${ }^{399}$

\subsubsection{MRAs}

The Randomized Aldactone Evaluation Study (RALES) trial ${ }^{189}$ and the Eplerenone Post-Acute Myocardial Infarction Heart Failure Efficacy and Survival Study (EPHESUSHF) trial ${ }^{163}$ have reported the benefits of mineralocorticoid receptor antagonists (MRAs) in patients with heart failure, but patients with a serum creatinine level of $\geq 2.5 \mathrm{mg} / \mathrm{dL}$ and patients with an eGFR of $<30 \mathrm{~mL} / \mathrm{min} / 1.73 \mathrm{~m}^{2}$ were excluded respectively and almost no evidence is available on the benefits of MRAs in patients with CKD stage 4 or 5. However, in patients with CKD stage $3(\mathrm{eGFR}<60 \mathrm{~mL} /$ $\mathrm{min} / 1.73 \mathrm{~m}^{2}$ ), who accounted for $48 \%$ and $33 \%$ of the participants in the RALES and EPHESUS-HF trials, MRAs improved prognosis in a similar degree to patients with an eGFR $\geq 60 \mathrm{~mL} / \mathrm{min} / 1.73 \mathrm{~m}^{2}{ }^{400,401} \mathrm{MRAs}$ should be used carefully in patients receiving ACE inhibitors or ARBs because of concern about hyperkalemia or renal dysfunction. 


Table 42. Recommendations and Levels of Evidence for the Management of Hyperuricemia in Patients With
Heart Failure

\section{| 8.2.4 Diuretics}

Diuretics are often prescribed to patients with heart failure, and loop diuretics are essential for treatment of patients with congestive heart failure. However, as overuse of loop diuretics may reduce renal function and worsen the prognosis of patients, ${ }^{200,402}$ loop diuretics should be limited to the minimum required for treatment.

\subsubsection{Other Drugs}

No evidence is available on the efficacy of digitalis in patients with a serum creatinine level of $\geq 3.0 \mathrm{mg} / \mathrm{dL}$. When digitalis is administered to patients with renal dysfunction, they should be carefully observed for signs of digitalis intoxication. ${ }^{403}$ In the Aliskiren Trial on Acute Heart Failure Outcomes (ASTRONAUT) trial, ${ }^{404}$ aliskiren, a direct renin inhibitor, reduced renal function.

\section{8.2.6 Drugs Mainly Used for the Treatment of Acute Heart Failure}

In Japan, carperitide is often used for the treatment of acute heart failure, but no conclusion has been reached on whether carperitide has a renal protective effect. ${ }^{405}$ Tolvaptan, a vasopressin $V_{2}$ receptor antagonist, has been reported to reduce the dose of furosemide in patients with CKD stage $3 / 4$ with an eGFR of 15 to $60 \mathrm{~mL} / \mathrm{min} / 1.73 \mathrm{~m}^{2}$ in a small study. ${ }^{406}$ Hemofiltration should be considered for patients with acute heart failure in whom drug therapy do not lead sufficient diuresis, or do not improve hemodynamics or symptoms.

\section{Hyperuricemia/Gout}

\subsection{Pathophysiology}

Hyperuricemia is a common comorbid condition in patients with heart failure. Hyperuricemia is defined as a serum uric acid level of $>7.0 \mathrm{mg} / \mathrm{dL}$ regardless of gender or age. ${ }^{407}$ Patients with heart failure have serum uric acid levels higher than healthy individuals in genral. ${ }^{84}$ It has been suggested that hyperuricemia in heart failure may be explained by excessive production and reduced excretion of uric acid. Xanthine oxidase (XO), the enzyme involved in the final process of uric acid production, is present in a small amount in the myocardium. In patients with myocardial ischemia or heart failure, XO activity is elevated, and uric acid production is enhanced, while uric acid excretion is reduced by decrease in renal blood flow and glomerular filtration rate. Moreover, furosemide and other diuretics that are commonly used for the treatment of heart failure may suppress the uric acid excretion and elevate serum uric acid level even further.

Although a relationship between serum uric acid level and prognosis has been suggested in patients with heart failure and the pathophysiological significance of uric acid in heart failure has gained attention, the details have not been revealed yet. Anker et al ${ }^{\mathbf{1} 1}$ conducted a prospective study to investigate a possible relationship between uric acid level and life expectance in 112 patients with heart failure and concluded that a serum uric acid level of $\geq 9.5 \mathrm{mg} / \mathrm{dL}$ may predict poor prognosis. In a subsequent interventional trial of allopurinol in patients with heart failure, the treatment reduced uric acid levels but did not result in an improvement of cardiovascular outcomes. ${ }^{408}$ Studies on novel drugs that decrease uric acid production such as febuxostat and topiroxostat have been conducted to investigate their effects in patients with heart failure, but no conclusive evidence has been found on whether high uric acid levels and the use of these drugs to reduce uric acid levels may affect the pathophysiology and prognosis of heart failure (Table 42).

\subsection{Treatment}

Many patients with heart failure also have underlying diseases such as hypertension, ischemic heart disease, diabetes mellitus, and chronic kidney disease. In Japan, an intervention to control hyperuricemia, consisting of lifestyle modification followed by pharmacotherapy if needed, is recommended for patients with gouty arthritis or gouty tophus with a serum uric acid level of $>7.0 \mathrm{mg} / \mathrm{dL}$ and patients with underlying disease such as renal dysfunction, hypertension, ischemic heart disease and diabetes mellitus with a serum uric acid level of $\geq 8.0 \mathrm{mg} / \mathrm{dL} .{ }^{407}$ Although no evidence has been found regarding the optimal goal of serum uric acid level in patients with chronic heart disease, it would be appropriate to set a goal of $\leq 7.0 \mathrm{mg} / \mathrm{dL}$ considering the above findings.

\section{COPD and Asthma (Table 43)}

\subsection{Pathophysiology}

In patients with bronchial asthma, chest X-ray findings are usually normal, and severe symptoms develop during asthma attack. ${ }^{409}$

Chronic obstructive pulmonary disease (COPD) is observed in about 20 to $30 \%$ of patients with left-sided heart failure, ${ }^{\mathbf{4 1 0}-\mathbf{4 1 2}}$ and is an independent risk factor for the development of left-sided heart failure and cardiovascular death associated with heart failure. ${ }^{413,414}$ BNP or NTproBNP is a useful tool to differentiate heart failure from exacerbation of COPD in patients with respiratory failure. ${ }^{412,415}$ 


\begin{tabular}{|c|c|c|c|c|}
\hline & $\begin{array}{c}\text { Class of } \\
\text { Recommendation }\end{array}$ & $\begin{array}{l}\text { Level of } \\
\text { Evidence }\end{array}$ & $\begin{array}{c}\text { Grade of } \\
\text { Recommendation } \\
\text { (MINDS) }\end{array}$ & $\begin{array}{l}\text { Level of } \\
\text { Evidence } \\
\text { (MINDS) }\end{array}$ \\
\hline \multicolumn{5}{|l|}{ Examinations } \\
\hline $\begin{array}{l}\text { Measurement of BNP levels for the diagnosis of HFrEF } \\
\text { in patients who also have COPD or bronchial asthma }\end{array}$ & 1 & A & A & 1 \\
\hline \multicolumn{5}{|l|}{ Treatments } \\
\hline $\begin{array}{l}\text { Use of ACE inhibitors or ARBs for the treatment of } \\
\text { HFrEF in patients who also have COPD or bronchial } \\
\text { asthma }\end{array}$ & 1 & A & A & 1 \\
\hline $\begin{array}{l}\text { Use of } \beta \text {-blockers for the treatment of HFrEF in patients } \\
\text { who also have COPD }\end{array}$ & 1 & A & A & I \\
\hline $\begin{array}{l}\text { Careful administration of } \beta_{1} \text { selective blockers for the } \\
\text { treatment of HFrEF in patients who also have bronchial } \\
\text { asthma }\end{array}$ & Ila & B & B & II \\
\hline $\begin{array}{l}\text { Continuing treatment of COPD or bronchial asthma } \\
\text { during treatment of HFrEF }\end{array}$ & Ila & B & B & III \\
\hline
\end{tabular}

$\mathrm{ACE}$, angiotensin converting enzyme; ARB, angiotensin II receptor blocker; COPD, chronic obstructive pulmonary disease; HFrEF, heart failure with reduced ejection fraction.

\begin{tabular}{|c|c|c|c|c|}
\hline & $\begin{array}{c}\text { Class of } \\
\text { Recommendation }\end{array}$ & $\begin{array}{l}\text { Level of } \\
\text { Evidence }\end{array}$ & $\begin{array}{l}\text { Grade of } \\
\text { Recommendation } \\
\text { (MINDS) }\end{array}$ & $\begin{array}{l}\text { Level of } \\
\text { Evidence } \\
\text { (MINDS) }\end{array}$ \\
\hline $\begin{array}{l}\text { Red blood cell transfusion } \\
\text { in patients in whom anemia worsens heart failure and } \\
\text { blood transfusion is expected to improve the condition }\end{array}$ & Ilb & C & C1 & V \\
\hline Oral iron supplementation & III & B & D & II \\
\hline Erythropoiesis stimulating agent & III & B & D & II \\
\hline
\end{tabular}

\subsection{Treatment}

\subsubsection{Treatment of Heart Failure in Patients With Heart Failure and COPD}

Treatment with ACE inhibitors, ARBs, $\beta$-blockers and/or diuretics are also recommended for patients with heart failure and COPD. 410,412 $^{2}$-blockers can be used safely in most patients with heart failure and COPD. ${ }^{192,412,415}$ 417 $\beta$-blocker therapy should be initiated using $\beta_{1}$ selective blockers at low doses, and the dose should be titrated upward slowly. $\beta$-blockers should be used carefully in patients with COPD and uncontrolled asthma. ${ }^{418}$

\section{10.2.2 Treatment of Heart Failure in Patients With Bronchial Asthma}

Treatment with ACE inhibitors, ARBs, and/or diuretics are also recommended for patients with heart failure and bronchial asthma. ${ }^{409,419}$

I 10.2.3 Treatment of COPD in Patients With Heart Failure Monotherapy or combination therapy using long-acting $\beta_{2}$ agonists and long-acting anticholinergics for the treatment of COPD should be continued in combination with treatment for heart failure. ${ }^{410}$

\section{I0.2.4 Treatment of Bronchial Asthma in Patients With Heart Failure}

Inhaled corticosteroids for the treatment of bronchial asthma are safe and recommended for patients with asthma and heart failure. ${ }^{409}$

\section{Anemia (Table 44)}

Patients with heart failure often have anemia, defined as hemoglobin levels of $<13.0 \mathrm{~g} / \mathrm{dL}$ in men and $<12.0 \mathrm{~g} / \mathrm{dL}$ in women by World Health Organization (WHO). Anemia is an independent prognostic factor in heart failure. ${ }^{420,421}$

Anemia in patients with heart failure is treated with red blood cell transfusion, iron supplementation, and/or erythropoiesis stimulating agents (ESAs). Table $\mathbf{4 4}$ lists recommendations and levels of evidence for the treatment of anemia in patients with heart failure.

\section{Sleep-Disordered Breathing}

The most common pathology of sleep-disordered breathing (SDB) is sleep apnea, which is classified into obstructive sleep apnea (OSA) caused by the obstruction of the upper airway and central sleep apnea (CSA) caused by the loss of respiratory drive. Patients with CSA and heart failure often have Cheyne-Stokes respiration (CSR), which is referred to as central sleep apnea with Cheyne-Stokes respiration (CSR-CSA). 


\begin{tabular}{|l|c|c||c|c|}
\hline Table 45. Recommendations and Levels of Evidence for the Treatment of OSA in Patients With Heart Failure \\
\hline & $\begin{array}{c}\text { Class of } \\
\text { Recommendation }\end{array}$ & $\begin{array}{c}\text { Grade of } \\
\text { Level of } \\
\text { Evidence }\end{array}$ & $\begin{array}{c}\text { Level of } \\
\text { Recommendation } \\
\text { (MINDS) }\end{array}$ & $\begin{array}{c}\text { Evidence } \\
\text { (MINDS) }\end{array}$ \\
\hline $\begin{array}{l}\text { Guideline-based CPAP treatment } \\
\text { in patients with symptomatic OSA }\end{array}$ & I & A & A & I \\
\hline $\begin{array}{l}\text { CPAP treatment } \\
\text { in patients with HFrEF and moderate* or severe OSA } \\
\text { to improve left ventricular function }\end{array}$ & Ila & A & I \\
\hline $\begin{array}{l}\text { CPAP treatment } \\
\text { in patients with heart failure and moderate* or severe } \\
\text { OSA to improve prognosis }\end{array}$ & Ilb & C & C2 & III \\
\hline
\end{tabular}

${ }^{*}$ Moderate OSA is commonly defined as $\mathrm{AHI} \geq 15$, but the National Health Insurance in Japan covers OSA treatment for patients with $\mathrm{AHI} \geq 20$. CPAP, continuous positive airway pressure; OSA, obstructive sleep apnea.

\subsection{Pathophysiology}

\subsubsection{Prevalence of SDB in Patients With Heart Failure} The prevalence of OSA is high among patients with cardiovascular diseases including heart failure. In addition to OSA, CSR-CSA is frequently found in patients with heart failure (about 50\%). ${ }^{\mathbf{4 2 2}} \mathbf{4 2 6}$ A considerable percentage of patients with heart failure have both OSA and CSR-CSA.

\section{12.1.2 Effects of SDB on the Onset and Progression of Heart Failure}

OSA increases the risk of the onset or exacerbation of cardiovascular diseases through different mechanisms such as hypoxemia associated with apnea, sympathetic hyperactivity, increased left ventricular afterload due to intrathoracic negative pressure, endothelial dysfunction, oxidative stress, inflammation, hypercoagulability, obesity, and insulin resistance, ${ }^{427-429}$ and is involved in the development of heart failure. ${ }^{430} \mathrm{CSR}-\mathrm{CSA}$ is caused by the occurrence of low arterial partial pressure of carbon dioxide $\left(\mathrm{PaCO}_{2}\right)$ due to pulmonary congestion and excessive response to low $\mathrm{PaCO}_{2},{ }^{427,431}$ as well as prolonged circulation time. Nocturnal rostral leg fluid displacement ${ }^{\mathbf{4 3 2}}$ worsen OSA by causing upper airway edema that narrows the airways and CSA by pulmonary congestion.

\subsubsection{Effects of SDB on the Prognosis of Patients With Heart Failure}

Moderate or severe OSA is associated with a poor prognosis in patients with heart failure, ${ }^{\mathbf{4 3 3}}$ and the presence of even mild or severer CSR-CSA is a prognostic factor in patients with heart failure. ${ }^{434}$

\subsection{Treatment}

\subsubsection{Screening for SDB in Patients With Heart Failure}

As SDB is often asymptomatic in patients with heart failure, ${ }^{\mathbf{4} 5}$ screening for SDB is recommended for patients with heart failure who do not respond well to standard treatment to identify underlying conditions. See the Guidelines for Diagnosis and Treatment of Sleep Disordered Breathing in Cardiovascular Disease (JCS 2010) ${ }^{\mathbf{4 2 7}}$ for detail.

\subsubsection{Treatment of Heart Failure}

Modifications of lifestyle as risk factors or worsening factors of OSA should be tried first as they are beneficial for the treatment of heart failure. As CSR-CSA is caused by heart failure, optimization of treatment for heart failure is most important.

\subsubsection{Positive Pressure Ventilation for the Treatment of SDB in Patients With Heart Failure}

a. Positive Pressure Ventilation for OSA (Table 45)

In randomized controlled trials and meta-analyses of continuous positive airway pressure (CPAP) in patients with OSA and reduced LVEF, CPAP improved LVEF. ${ }^{\mathbf{4 3 6}, 437}$ Observational studies have reported that positive pressure ventilation improves the prognosis of patients with heart failure, ${ }^{\mathbf{3 8} 8,439}$ no large-scale clinical studies have been conducted to date.

At present, OSA should be treated according to the guidelines for the treatment of SDB even in patients with heart failure. CPAP should be considered in patients with heart failure with reduced LVEF and moderate or severe OSA to improve LVEF.

\section{b. Positive Pressure Ventilation for Patients With Heart Failure and CSR-CSA (Table 46)}

Positive pressure ventilation is generally considered for patients who still have CSR-CSA even after optimal treatment for heart failure. In the Canadian Continuous Positive Airway Pressure for Patients with Central Sleep Apnea and Heart Failure (CANPAP) study that investigated the effects of CPAP on the prognosis of patients with CSR-CSA and HFrEF (LVEF $\leq 45 \%)$, ${ }^{440}$ the severity of CSR-CSA decreased by about $50 \%$ and LVEF increased in patients receiving CPAP, but no improvement in prognosis was observed. However, patients in whom CPAP suppressed CSA at 3 months showed better prognosis than in patients in the control group. ${ }^{\mathbf{4 4 1}}$

Adaptive servo-ventilation (ASV) has been reported to be more effective in suppression of CSR-CSA, and randomized controlled trials and meta-analyses have indicated that ASV improves LVEF in patients with CSR-CSA and $\mathrm{HFrEF}(\mathrm{LVEF} \leq 45 \%)$ and decreases BNP. ${ }^{442} \mathbf{4 4 5} \mathrm{A}$ prospective observational study has reported that ASV may improve the prognosis of patients with heart failure and CSR-CSA, ${ }^{446}$ while in the Adaptive Servo-Ventilation for Central Sleep Apnea in Systolic Heart Failure (SERVEHF) trial, ${ }^{272}$ a randomized clinical trial of ASV in patients with heart failure with $\mathrm{LVEF} \leq 45 \%$ and predominant CSA, ASV did not improve long-term prognosis, and did significantly increased all-cause deaths and cardiovascular deaths. Accordingly, the 2016 ESC guidelines and the 2017 ACC/AHA/HFSA guidelines descried that ASV is not recommended for patients with chronic heart disease with LVEF $\leq 45 \%$ and predominant CSA. ${ }^{\mathbf{8} 14}$ However, in Japan, the use of ASV in this patient population is covered with the National Health Insurance even with certain 


\begin{tabular}{|c|c|c|c|c|}
\hline & $\begin{array}{c}\text { Class of } \\
\text { Recommendation }\end{array}$ & $\begin{array}{l}\text { Level of } \\
\text { Evidence }\end{array}$ & $\begin{array}{l}\text { Grade of } \\
\text { Recommendation } \\
\text { (MINDS) }\end{array}$ & $\begin{array}{l}\text { Level of } \\
\text { Evidence } \\
\text { (MINDS) }\end{array}$ \\
\hline $\begin{array}{l}\text { Optimization of heart failure treatment according to the } \\
\text { heart failure guideline }\end{array}$ & I & A & A & 1 \\
\hline $\begin{array}{l}\text { CPAP treatment } \\
\text { in patients with heart failure and moderate or severe } \\
\text { CSR-CSA to improve symptoms, exercise capacity, } \\
\text { and left ventricular function }\end{array}$ & Ila & B & B & II \\
\hline $\begin{array}{l}\text { ASV treatment } \\
\text { in patients with HFpEF and moderate or severe } \\
\text { CSR-CSA who are intolerable or refractory to CPAP to } \\
\text { improve symptoms and exercise capacity }\end{array}$ & Ila & B & B & II \\
\hline $\begin{array}{l}\text { ASV treatment } \\
\text { Use in patients with HFrEF (LVEF } \leq 45 \% \text { ) and moderate } \\
\text { or severe CSR-CSA who are intolerable or refractory to } \\
\text { CPAP to improve symptoms and exercise capacity }\end{array}$ & Ilb & B & B & II \\
\hline $\begin{array}{l}\text { Aimless continuation of ASV treatment } \\
\text { in patients with HFrEF (LVEF } \leq 45 \%) \text { and CSR-CSA to } \\
\text { aimlessly continue ASV as CSR-CSA treatment even } \\
\text { after improvement or stabilization of heart failure }\end{array}$ & III & A & C1 & II \\
\hline
\end{tabular}

ASV, adaptive servo-ventilation; CSR-CSA, central sleep apnea with Cheyne-Stokes respiration; CPAP, continuous positive airway pressure; HFpEF, heart failure with preserved ejection fraction; HFrEF, heart failure with reduced ejection fraction; OSA, obstructive sleep apnea.

\begin{tabular}{|c|c|c|c|c|}
\hline & $\begin{array}{c}\text { Class of } \\
\text { Recommendation }\end{array}$ & $\begin{array}{l}\text { Level of } \\
\text { Evidence }\end{array}$ & $\begin{array}{l}\text { Grade of } \\
\text { Recommendation } \\
\text { (MINDS) }\end{array}$ & $\begin{array}{l}\text { Level of } \\
\text { Evidence } \\
\text { (MINDS) }\end{array}$ \\
\hline $\begin{array}{l}\text { Home oxygen therapy } \\
\text { in patients with moderate* or severe CSR-CSA and } \\
\text { NYHA Class III or VI HFrEF (LVEF } \leq 45 \%) \text { to improve } \\
\text { cardiac function and symptoms }\end{array}$ & Ila & B & B & II \\
\hline
\end{tabular}

${ }^{*}$ Moderate OSA is commonly defined as apnea hypopnea index $(\mathrm{AHI}) \geq 15$, but the National Health Insurance in Japan covers OSA treatment for patients with $A H I \geq 20$. CSR-CSA, central sleep apnea with Cheyne-Stokes respiration; HFrEF, heart failure with reduced ejection fraction; LVEF, left ventricular ejection fraction; NYHA, New York Heart Association.

limitations, and the Japanese Circulation Society and the Japanese Heart Failure Society have published a statement (second report) for appropriate use of ASV with a consideration of the requirement for NHI coverage (Supplement 1). ${ }^{271}$

\subsubsection{Oxygen Therapy (Table 47)}

Oxygen therapy increases arterial partial pressure of oxygen $\left(\mathrm{PaO}_{2}\right)$, which reduces central carbon dioxide $\left(\mathrm{CO}_{2}\right)$ sensitivity and hyperventilation and slightly increases $\mathrm{PaCO}_{2}$, 447 and thereby suppresses CSR-CSA. Short-term studies have reported that nocturnal oxygen therapy is effective in suppressing CSR-CSA, reducing sympathetic nerve activity, improving exercise capacity, and reducing BNP levels in patients with chronic heart failure. ${ }^{448,449}$ In a multicenter clinical study of oxygen therapy in patients with CSR-CSA and HFrEF ( $\mathrm{LVEF} \leq 45 \%$ ) in Japan, three-month oxygen therapy reduced the severity of CSR-CSA and improved the Specific Activity Scale score, and the efficacy of treatment was maintained in patients who continued oxygen therapy for one year. ${ }^{450,451}$ In Japan, oxygen therapy for patients with NYHA class III or IV chronic heart failure and CSR with an apnea hypopnea index (AHI) of $\geq 20$ is covered with the National Health Insurance.

\section{Acute Heart Failure}

\section{Definition and Classification}

\subsection{Definition}

Acute heart failure is defined as the rapid onset or exacer- bation of signs and symptoms caused by acute disturbance of pump function that leads to insufficient or inadequate blood filling and poor blood delivery to peripheral tissues due to structural and/or functional abnormalities of the heart. 


\subsection{Classification}

\subsubsection{Clinical Classification of Acute Heart Failure in Initial Management: CS Classification}

The clinical scenario (CS) classification is a tool to classify patients with acute heart failure according to pathophysiological condition with reference on systolic blood pressure, and provide appropriate initial management for each type of patients. ${ }^{452}$

\begin{tabular}{|c|l|}
\hline \multicolumn{2}{|c|}{ Table 48. Killip Classification } \\
\hline Class I & No clinical signs of heart failure \\
\hline Class II & $\begin{array}{l}\text { Mild to moderate heart failure. Rales up to } 50 \% \text { of } \\
\text { lung fields or S3 heart sound }\end{array}$ \\
\hline Class III & $\begin{array}{l}\text { Severe heart failure. Frank pulmonary edema with } \\
\text { rales more than } 50 \% \text { of lung fields }\end{array}$ \\
\hline Class IV & $\begin{array}{l}\text { Cardiogenic shock. Signs include hypotension } \\
\text { (systolic blood pressure }<90 \mathrm{mmHg} \text { ), oliguria, cyanosis, } \\
\text { cold and wet skin, and loss of consciousness }\end{array}$ \\
\hline
\end{tabular}

(Source: Prepared based on Killip T, et al. 1967453)

Table 49. Precipitating Factors of Heart Failure

- Acute coronary syndrome

- Tachyarrhythmia (e.g., atrial fibrillation, atrial flutter, and ventricular tachycardia)

- Bradyarrhythmia (e.g., complete atrioventricular block, and sick sinus syndrome)

- Infections (e.g., pneumonia, infective endocarditis, and sepsis)

- Poor adherence (e.g., insufficient salt/water restriction and noncompliance)

- Acute pulmonary thromboembolism

- Acute exacerbation of chronic obstructive pulmonary disease

- Drugs (e.g., nonsteroidal anti-inflammatory drugs [NSAIDs], negative inotropes, and cancer chemotherapy)

- Excessive stress or overwork

- Excessive blood pressure elevation

- Endocrine or metabolism disorders (e.g., hyperthyroidism hypothyroidism, adrenal dysfunction, and peripartum cardiomyopathy)

- Mechanical complications (e.g., cardiac rupture, acute mitral valve insufficiency, chest trauma, and acute aortic dissection)

\section{1.2.2 Pathophysiological Classification of Acute Heart} Failure

1) Acute pulmonary edema

2) Systemic fluid retention (congestion)

3) Low cardiac output/hypoperfusion (including cardiogenic shock)

\section{1.2.3 Classification by History of Hospitalization for Heart Failure}

1) De novo heart failure (patients with no history of hospitalization for heart failure)

2) Rehospitalization for heart failure (patients with history of hospitalization for heart failure)

\section{1.2.4 Killip Classification (Table 48) ${ }^{453}$}

Killip classification is a tool to classify patients after acute myocardial infarction according to their objective findings. It is also important to identify factors predicting prognosis of heart failure (Table 49).

\section{Diagnosis}

\section{2.1 Diagnosis (Table 50)}

The diagnosis of acute heart failure is based on signs and symptoms and the levels of natriuretic peptides (BNP or NT-proBNP). Biomarkers such as BNP and NT-proBNP are important indicators for diagnosis, treatment, and prognosis of patients with acute heart failure. Acute heart failure is unlikely in patients with BNP of $\leq 100 \mathrm{pg} / \mathrm{mL}$ or NT-proBNP of $\leq 400 \mathrm{pg} / \mathrm{mL} .{ }^{43}$

\subsection{Signs and Symptoms}

\section{2.2.1 Congestion}

Almost all patients with acute heart failure are hospitalized with congestion such as pulmonary edema and systemic fluid retention. Symptoms of congestion develop when intracardiac pressure abruptly increases from the baseline level.

\section{2.2.2 Low Cardiac Output/Hypoperfusion}

Symptoms of low cardiac output include fatigue, feeling of weakness, oliguria, cyanosis, cold extremities, and/or anorexia.

\begin{tabular}{|c|c|c|c|c|}
\hline & $\begin{array}{c}\text { Class of } \\
\text { Recommendation }\end{array}$ & $\begin{array}{l}\text { Level of } \\
\text { Evidence }\end{array}$ & \begin{tabular}{|c|} 
Grade of \\
Recommendation \\
(MINDS)
\end{tabular} & $\begin{array}{l}\text { Level of } \\
\text { Evidence } \\
\text { (MINDS) }\end{array}$ \\
\hline $\begin{array}{l}\text { Measurement of BNP or NT-proBNP levels at a clinic } \\
\text { visit for differential diagnosis }\end{array}$ & 1 & A & A & I \\
\hline $\begin{array}{l}\text { Evaluation of ECG, chest X-ray, troponin, blood urea } \\
\text { nitrogen, creatinine, electrolytes, blood glucose, blood } \\
\text { cell count, liver function test, and thyroid function test } \\
\text { at a clinic visit }\end{array}$ & 1 & $\mathrm{C}$ & B & VI \\
\hline Evaluation of cardiac function using echocardiography & I & C & B & VI \\
\hline $\begin{array}{l}\text { Evaluation of pulmonary edema and pleural fluid using } \\
\text { lung ultrasound }\end{array}$ & Ila & $\mathrm{B}$ & B & III \\
\hline
\end{tabular}

$\mathrm{BNP}$, brain (B-type) natriuretic peptide; ECG, electrocardiogram; NT-proBNP, N-terminal pro-brain (B-type) natriuretic peptide. 


\section{Treatment Strategies and Flowcharts}

During initial management including diagnosis of acute heart failure, patients should be evaluated carefully to clarify pathological characteristics and communicate the findings with healthcare professionals involved in acute phase treatment and ensure the earliest possible intervention. Clinical evaluation should be repeated whenever necessary to facilitate early improvement.

\subsection{Initial Management}

Table 51 lists the purpose of initial management for patients arriving at hospital. Arterial blood gas analysis should be performed whenever necessary, and appropriate oxygen therapy should be initiated promptly (Table 52).

Monitoring of vital signs, hemodynamics and respiratory function should be initiated immediately after hospitalization to examine whether peripheral circulation and organ perfusion are maintained (Figure 11). ${ }^{454}$ Oxygen saturation, blood pressure, body temperature, respiratory rate, and ECG must be monitored. Urine volume should be monitored whenever possible. In initial management, presence of cardiogenic shock and respiratory failure should be examined and treated appropriately. It is important to rule out specific conditions such as acute coronary syndrome (ACS) and acute thromboembolism. Table 53 lists patients indicated for CCU/ICU care.

Management strategies for the specific conditions are as follows:

1) Myocarditis: With the possibility of fulminant myocarditis in mind, patients should be monitored with ECG and echocardiography. Even in fulminant cases, prompt treatment may help improve the prognosis for many patients. Mechanical circulatory support including ventricular assist devices should be used when necessary. See the Guidelines for Diagnosis and Treatment of Myocarditis (JCS 2009) for detail.455

2) Right-sided heart failure: It is important to identify the cause of right-sided heart failure, and select appropriate treatment strategies accordingly. Patients diagnosed as having severe pulmonary arterial hypertension should be treated mainly with intravenous prostacyclin analogs, and the introduction or dose-escalation of the remaining two types of anti-pulmonary hypertension drugs should be considered. Other drugs such as dobutamine should be used whenever necessary to maintain or improve cardiac output. Right-sided heart failure due to constrictive pericarditis or other heart diseases should be differentiated from that due to pulmonary arterial hypertension.

3) Acute Coronary syndrome: Acute heart failure due to acute coronary syndrome should be diagnosed and treated according to the guidelines for the management of patients with ST-elevation acute myocardial infarction (JCS 2013) ${ }^{\mathbf{4 5 6}}$ and the Guidelines for Management of Acute Coronary Syndrome without Persistent ST Segment Elevation (JCS 2012). ${ }^{457}$

4) Hypertensive emergency: Vasodilators should be administered intravenously to reduce blood pressure promptly. Diuretics should be added to patients with systemic fluid retention.

5) Arrhythmias: Patients with acute heart failure due to ventricular tachycardia and other types of tachyarrhythmias should be treated with intravenous amiodarone or direct current defibrillation. Patients with acute heart

\begin{tabular}{l} 
Table 51. Purpose of Initial Management for Patients With \\
Acute Heart Failure \\
\hline 1. Rescue and stabilize vital signs \\
2. Improve hemodynamics and maintain oxygenation \\
3. Relieve dyspnea and other signs and symptoms of congestion \\
4. Diagnose acute heart failure and rule out acute coronary \\
syndrome or pulmonary thromboembolism \\
5. Prevent the progression of cardiac disorder and other organ \\
disorders \\
6. Shorten the duration of ICU/CCU treatment through early \\
intervention to achieve early improvement
\end{tabular}

$\mathrm{CCU}$, coronary care unit; ICU, intensive care unit.

\begin{tabular}{|c|c|c|c|c|}
\hline & $\begin{array}{c}\text { Class of } \\
\text { Recommendation }\end{array}$ & $\begin{array}{l}\text { Level of } \\
\text { Evidence }\end{array}$ & $\begin{array}{c}\text { Grade of } \\
\text { Recommendation } \\
\text { (MINDS) }\end{array}$ & $\begin{array}{l}\text { Level of } \\
\text { Evidence } \\
\text { (MINDS) }\end{array}$ \\
\hline $\begin{array}{l}\text { Measurement of } \mathrm{pH}, \mathrm{CO}_{2} \text {, and lactic acid levels in } \\
\text { venous blood in patients who also have pulmonary } \\
\text { edema or COPD. Measurement of } \mathrm{pH}, \mathrm{CO}_{2} \text {, and lactic } \\
\text { acid levels in arterial blood in patients with cardiogenic } \\
\text { shock }\end{array}$ & Ila & C & B & IVb \\
\hline $\begin{array}{l}\text { Oxygen therapy for patients with } \mathrm{SpO}_{2}<90 \% \text { or } \mathrm{PaO}_{2} \\
<60 \mathrm{mmHg} \text { to treat hypoxemia }\end{array}$ & I & C & B & VI \\
\hline $\begin{array}{l}\text { Prompt introduction of noninvasive positive pressure } \\
\text { ventilation (NPPV) in patients with dyspnea (respiratory } \\
\text { rate }>25 \text { breaths per minute, } \mathrm{SpO}_{2}<90 \% \text { ) to alleviate } \\
\text { difficult breathing and avoid tracheal intubation }\end{array}$ & I & A & A & 1 \\
\hline $\begin{array}{l}\text { Tracheal intubation for patients who cannot control the } \\
\text { following conditions despite above-described treatment: } \\
\text { - Hypoxemia }\left(\mathrm{PaO}_{2}<60 \mathrm{mmHg}\right) \\
\text { - } \mathrm{CO}_{2} \text { retention }\left(\mathrm{PaCO}_{2}>50 \mathrm{mmHg}\right) \\
\text { - Respiratory acidosis }(\mathrm{pH}<7.35)\end{array}$ & 1 & C & B & VI \\
\hline
\end{tabular}

COPD, chronic obstructive pulmonary disease; $\mathrm{PaCO}_{2}$, arterial partial pressure of carbon dioxide; $\mathrm{PaO}_{2}$, arterial partial pressure of oxygen; $\mathrm{SpO}_{2}$, oxygen saturation. 


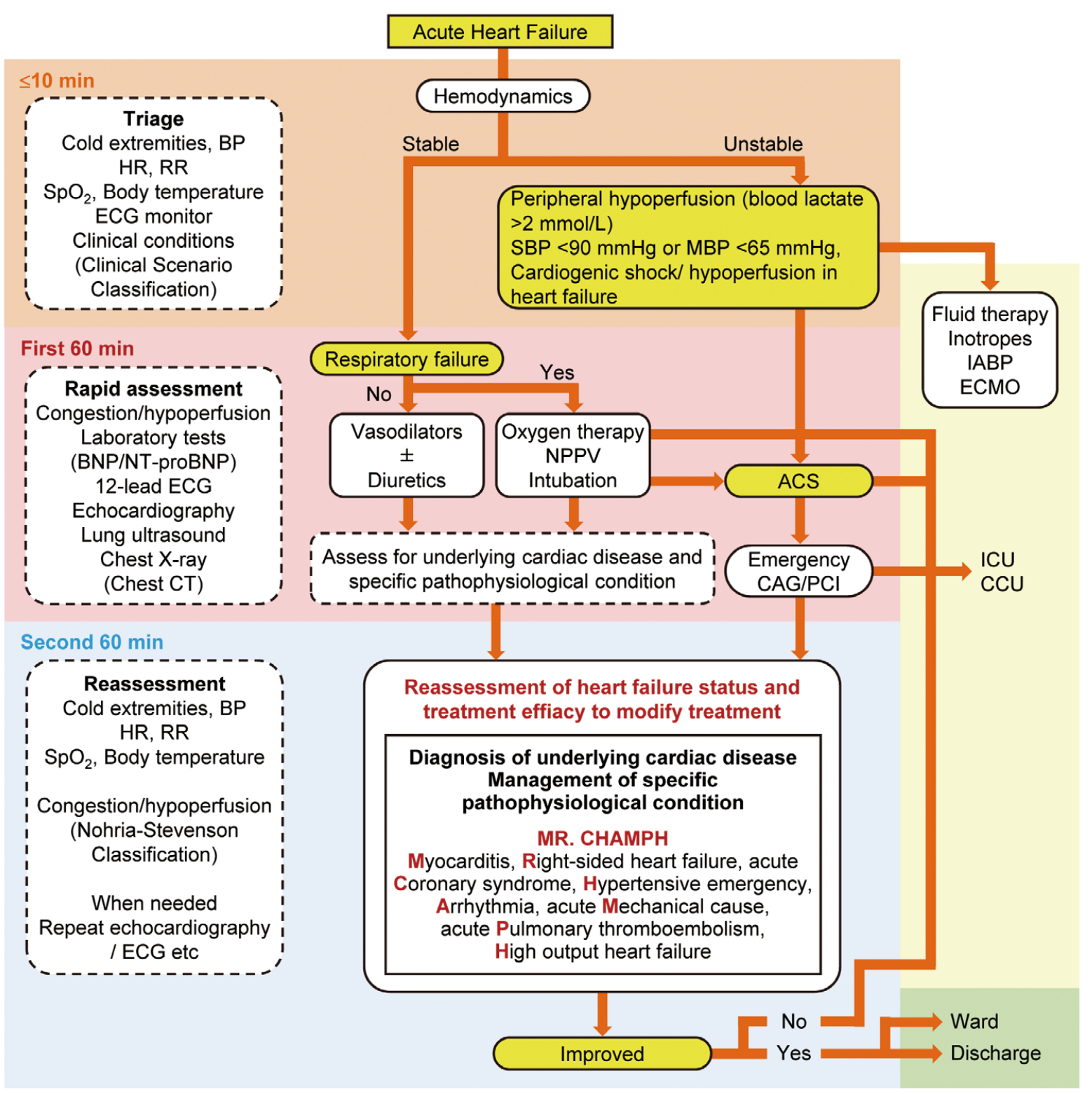

Figure 11. Flowchart from initial to acute phase management of acute heart failure. ACS, acute coronary syndrome; BNP, brain (B-type) natriuretic peptide; BP, blood pressure; CAG, coronary angiography; CCU, coronary care unit; CT, computed tomography; ECG, electrocardiography; ECMO, extracorporeal membrane oxygenation; HR, heart rate; IABP, intra-aortic balloon pumping; ICU, intensive care unit; NPPV, noninvasive positive pressure ventilation; NT-proBNP, N-terminal pro-brain (B-type) natriuretic peptide; $\mathrm{PCl}$, percutaneous coronary intervention; $\mathrm{RR}$, respiratory rate; $\mathrm{SpO}_{2}$, oxygen saturation. (Source: Prepared based on Mebazaa A, et al. 2016454)

Table 53. Indications for CCU/ICU Treatment for Acute Heart Failure

1. Patients who require or have already received tracheal intubation

2. Patients with hypotension (systolic blood pressure $<90 \mathrm{mmHg}$ or mean arterial pressure $<65 \mathrm{mmHg}$ ) or shock

3. Patients with oxygen saturation $<90 \%$ despite oxygen therapy

4. Patients with forced breathing and respiratory rate $>25 / \mathrm{min}$

5. Patients with uncontrolled dangerous arrhythmias failure due to severe bradycardia should be treated with external pacing.

6) Acute Mechanical causes: Acute mechanical causes include free wall rupture, ventricular septal perforation, or papillary muscle rupture associated with ACS, PCI complications such as coronary artery obstruction or perforation, acute aortic dissection, infective endocarditis, malfunctioning mechanical valves, and chest injuries. Echocardiography is essential for the diagnosis of these complications and emergency surgery is often needed. 


\begin{tabular}{|c|c|c|c|c|}
\hline & $\begin{array}{c}\text { Class of } \\
\text { Recommendation }\end{array}$ & $\begin{array}{l}\text { Level of } \\
\text { Evidence }\end{array}$ & $\begin{array}{l}\text { Grade of } \\
\text { Recommendation } \\
\text { (MINDS) }\end{array}$ & $\begin{array}{l}\text { Level of } \\
\text { Evidence } \\
\text { (MINDS) }\end{array}$ \\
\hline $\begin{array}{l}\text { Measurement of body weight and volume balance on } \\
\text { the day of hospitalization and daily during the hospital } \\
\text { stay }\end{array}$ & 1 & C & B & VI \\
\hline $\begin{array}{l}\text { Daily assessment for signs/symptoms of heart failure } \\
\text { (dyspnea, moist rales, peripheral edema, body weight) } \\
\text { on daily basis }\end{array}$ & 1 & B & B & IVb \\
\hline $\begin{array}{l}\text { Measurement of renal function (blood urea nitrogen } \\
\text { and creatinine), electrolytes ( } \mathrm{Na} \text { and } \mathrm{Cl}) \text { (especially in } \\
\text { patients receiving diuretics or renin-angiotensin- } \\
\text { aldosterone system inhibitors) }\end{array}$ & 1 & B & B & IVb \\
\hline $\begin{array}{l}\text { Echocardiography to estimate hemodynamics and } \\
\text { causative disease }\end{array}$ & 1 & C & B & VI \\
\hline $\begin{array}{l}\text { Arterial pressure monitoring in patients with unstable } \\
\text { hemodynamics }\end{array}$ & Ila & C & C1 & VI \\
\hline $\begin{array}{l}\text { Swan-Ganz catheterization to determine } \\
\text { hemodynamics } \\
\text { 1) In patients with cardiogenic shock not responding } \\
\text { promptly to appropriate fluid therapy } \\
\text { 2) In patients with pulmonary edema associated with } \\
\text { shock/near shock that does not respond to appropri- } \\
\text { ate treatment measures } \\
\text { 3) Use as a diagnostic measure to confirm whether the } \\
\text { cause of pulmonary edema is cardiogenic or } \\
\text { noncardiogenic }\end{array}$ & 1 & C & B & $\mathrm{IVb}$ \\
\hline $\begin{array}{l}\text { Swan-Ganz catheterization to determine } \\
\text { hemodynamics } \\
\text { in patients with repeated hypotension and hypoperfu- } \\
\text { sion despite drug therapy }\end{array}$ & Ila & C & B & IVa \\
\hline $\begin{array}{l}\text { Swan-Ganz catheterization to determine } \\
\text { hemodynamics } \\
\text { As routine procedure }\end{array}$ & III & B & D & II \\
\hline
\end{tabular}

7) Acute Pulmonary thromboembolism: Acute pulmonary thromboembolism should be diagnosed and treated according to the Guidelines for Diagnosis, Treatment and Prevention of Pulmonary Thromboembolism and Deep Vein Thrombosis (JCS 2009). ${ }^{458}$

8) High output heart failure: High output heart failure may be caused by sepsis, thyrotoxicosis, anemia, cardiac shunts, beriberi heart, or Paget's disease. Pathological assessment should be performed, and causative disease should be diagnosed and treated promptly.

\subsection{Basic Principle for Acute Phase Treatment (Table 54, Figure 12) (52,459 $^{4}$}

Patients who received initial management in the ICU/CCU should be reassessed for changes in pathological conditions including symptoms of heart failure and body weight, and their treatments should be modified whenever necessary.

\section{3.3 Pathological Conditions and Treatment Strategies in Acute Heart Failure (Figure 12) 452,459 $^{4}$}

Although there are various diseases that can cause acute heart failure, the conditions of acute heart failure may be generally classified into three categories: acute cardiogenic pulmonary edema, systemic fluid retention, and hypoperfusion due to low cardiac output.

\subsubsection{Acute Cardiogenic Pulmonary Edema}

Acute cardiogenic pulmonary edema is a CS 1 condition.
Patients often have orthopnea and an oxygen saturation $\left(\mathrm{SpO}_{2}\right)$ of $<90 \%$. Noninvasive positive pressure ventilation (NPPV) is effective in alleviating symptoms, increasing arterial blood oxygenation, and improving hemodynamics (Table 52). Before intravenous access is established, NPPV, sublingual nitrates, or nitrate spray should be used to treat dyspnea and improve oxygenation promptly. If pulmonary edema persists, vasodilators should be infused intravenously while avoiding an abrupt lowering in blood pressure. Physicians should keep in mind that about $50 \%$ of patients with CS 1 have low LVEF, ${ }^{\mathbf{4 6 0}}$ and are at risk of low cardiac output during treatment.

\section{3.3.2 Systemic Fluid Retention}

Systemic fluid retention is a CS 2 condition. Patients have excessive systemic fluid overload with peripheral edema. Their treatment should be mainly performed by diuretics.

\section{3.3.3 Low Cardiac Output/Hypoperfusion}

Low cardiac output or hypoperfusion is a CS 3 condition. The main symptoms are cold extremities, general fatigue, anorexia and reduced physical activity, but some patents may not complain of severe dyspnea or edema and thus treatment should be initiated carefully to avoid abrupt change in hemodynamics. Patients receiving $\beta$-blockers should continue treatment unless they present with shock. The use of phosphodiesterase (PDE) III inhibitors ${ }^{461}$ and dobutamine should be considered for such patients as needed. 


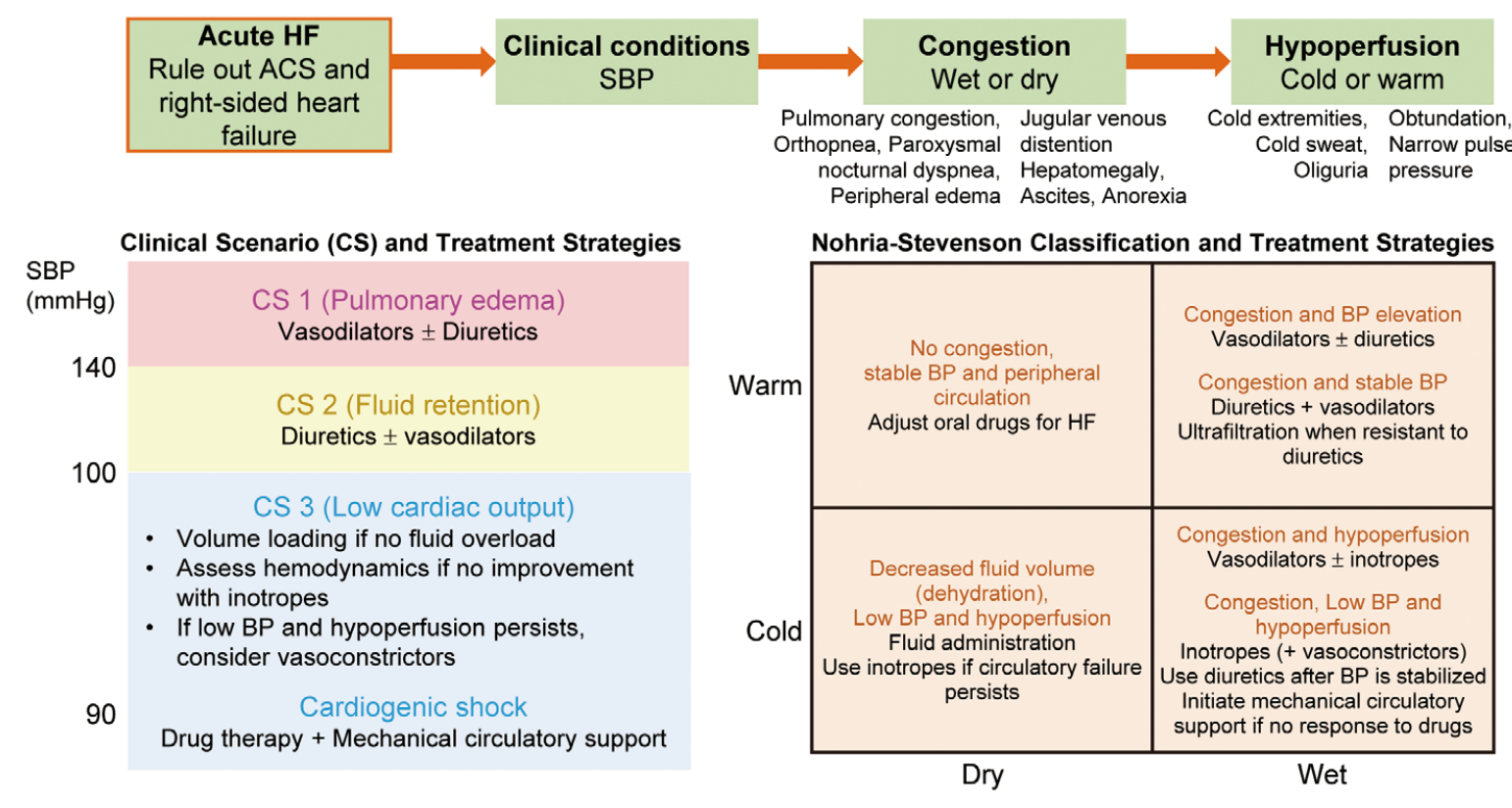

Figure 12. Basic treatment strategies from initial to acute phase management of acute heart failure. ACS, acute coronary syndrome; BP, blood pressure; SBP, systolic blood pressure. (Source: Prepared based on Mebazaa A, et al. 2008452 and Stevenson LW. 1999459)

\section{3.3.4 Cardiogenic Shock (Table 55)}

Cardiogenic shock is defined as a systolic blood pressure of $<90 \mathrm{mmHg}$ or a mean arterial blood pressure of $<65 \mathrm{mmHg}$ with signs of tissue hypoperfusion in the absence of decrease in circulatory plasma volume or lack of preload due to bleeding or dehydration. In addition to physical findings, an increase in blood lactate levels $(>2 \mathrm{mmol} / \mathrm{L}, 18 \mathrm{mg} / \mathrm{dL})$ suggests hypoperfusion. All patients with cardiogenic shock must undergo emergency 12-lead ECG and echocardiography to identify the causative condition and treat it accordingly. Rehydration should be attempted in patients without fluid retention. Dobutamine is a first-line drug for this patient population. Addition of PDE III inhibitors can be considered for patients with biventricular cardiac failure. Mechanical circulatory support should be considered in patients who do not respond well to these drugs. The prognosis of patients often depends on the cause and conditions of cardiogenic shock rather than the treatment itself.

\subsection{Management During Transition Period From Acute Heart Failure to Chronic Phase}

In patients transferred from the CCU/ICU to the general ward with stable condition, treatment for the causative conditions should be continued.

Table 56 summarizes the goal of in-hospital treatment for heart failure during transition from acute heart failure to chronic phase. Management to avoid worsening heart failure is important, and patients should be assessed accurately for symptomatic improvement in orthopnea, jugular venous distention, coarse crackles in the lung fields, peripheral edema, and general fatigue at discharge.

\subsection{From Discharge to Ambulatory Care}

As rehospitalization due to worsening heart failure often occurs during early period after discharge from hospital, early clinic visit should be scheduled after discharge whenever the patient's conditions permit. It is desirable to continue multidisciplinary heart failure team care after discharge.

Treatment goals after discharge are as follows:

1) To prevent worsening symptoms and decline in QOL, and improve prognosis.

2) To prevent rehospitalization early phase after discharge.

3) To develop a comprehensive clinical path to help the hospital and clinics collaborate to provide lifestyle modification intervention for each patient.

4) To try increasing the doses of standard treatments such as $\beta$-blockers to target levels, even after hospital discharge.

5) To consider for the indication of device therapy, whenever necessary.

\section{Pharmacological Therapy}

Tables 57 and $\mathbf{5 8}$ list the indications and recommended dosage regimens of drugs used for the treatment of acute heart failure in Japan.

\subsection{Sedation}

\subsubsection{Morphine Hydrochloride}

Through its central actions, morphine diminishes excessive sympathetic tone and thereby decreases myocardial oxygen demand. It reduces afterload by dilating arterioles, and 
Table 55. Recommendations and Levels of Evidence for the Treatment of Patients With Cardiogenic Shock

\begin{tabular}{|l|c|c||c|c|}
\hline & $\begin{array}{c}\text { Class of } \\
\text { Recommendation }\end{array}$ & $\begin{array}{c}\text { Level of } \\
\text { Evidence }\end{array}$ & $\begin{array}{c}\text { Grade of } \\
\text { Recommendation } \\
\text { (MINDS) }\end{array}$ & $\begin{array}{c}\text { Level of } \\
\text { Evidence } \\
\text { (MINDS) }\end{array}$ \\
\hline $\begin{array}{l}\text { Transfer to ICU/CCU where mechanical circulatory } \\
\text { support is available }\end{array}$ & I & C & B & VI \\
\hline $\begin{array}{l}\text { Continuous monitoring of ECG and arterial blood } \\
\text { pressure }\end{array}$ & I & C & B & VI \\
\hline $\begin{array}{l}\text { Rapid intravenous infusion of physiological saline or } \\
\text { Ringer solution ( } \geq 200 \text { mL over 15 to 30min) in patients } \\
\text { without fluid retention }\end{array}$ & I & C & B & V \\
\hline $\begin{array}{l}\text { Treatment with inotropic drugs (dobutamine) to } \\
\text { increase cardiac output }\end{array}$ & Ila & B & B & III \\
\hline $\begin{array}{l}\text { Treatment of vasoconstrictors (norepinephrine) to } \\
\text { maintain systolic blood pressure in patients with } \\
\text { persistent peripheral hypoperfusion }\end{array}$ & Ila & B & B & III \\
\hline $\begin{array}{l}\text { Routine use of IABP } \\
\text { Short-term use of mechanical circulatory support }\end{array}$ & III & B & D & II \\
\hline $\begin{array}{l}\text { considering the age, higher brain function, } \\
\text { complications and social factors }\end{array}$ & Ilb & C & C1 & VI \\
\hline
\end{tabular}

See the Guidelines for the Management of Patients with ST-Elevation Acute Myocardial Infarction (JCS 2013$)^{456}$ and the Guidelines for Management of Acute Coronary Syndrome without Persistent ST Segment Elevation (JCS $2012)^{457}$ for management of ACS.

ACS, acute coronary syndrome; CCU, coronary care unit; IABP, intra-aortic balloon pump; ICU, intensive care unit.

improves pulmonary congestion by dilating veins and thereby reducing venous return. ${ }^{462}$ Morphine should be administered carefully in patients with hypotension, bradycardia or high-grade atrioventricular block. In patients with intracerebral hemorrhage, decreased consciousness, bronchial asthma, or COPD, morphine should generally be avoided. Based on the reported effects of morphine on prognosis, ${ }^{463,464}$ morphine should not be used as a routine treatment.

\subsection{Diuretics}

\section{| 4.2.1 Loop Diuretics \\ a. Furosemide}

Loop diuretics alleviate symptoms of heart failure such as pulmonary congestion and edema, and decreases left ventricular end-diastolic pressure by reducing preload. Furosemide has a rapid onset of action in patients with acute heart failure. ${ }^{465}$ Western guidelines ${ }^{7,16}$ recommend diuretics for patients with symptomatic left ventricular systolic heart failure. Findings from an observational study in Japan have indicated the importance of early treatment of congestion to shorten the duration of congestion. 466

Patients with severe heart failure and renal dysfunction should receive diuretics at higher doses. ${ }^{467}$ A study has suggested that patients in whom adequate diuresis was not obtained with a single bolus dose of furosemide may respond well to continuous intravenous infusion of the drug. ${ }^{468}$

The dose of loop diuretics should be limited to minimum necessary. The method of administration, i.e., bolus injection vs. continuous infusion, should be selected based on the individual patient's condition. The dose should be adjusted based on LVEF or other pathological features.

Loop diuretics are less effective in patients with hypotension (systolic blood pressure: $<90 \mathrm{mmHg}$ ), hyponatremia, hypoalbuminemia, or acidosis. Patients who do not respond well to loop diuretics may respond to diuretics which have different site of action. However, non-loop diuretics should
Table 56. Treatment Goals for Hospitalized Patients During Transition From Acute to Chronic Heart Failure

1. Identify the cause of heart failure and complications and treat them accordingly

2. Treat the patient to alleviate signs/symptoms of heart failure and improve cardiac function (e.g., treatment with diuretics or vasodilators)

3. For patients with $\mathrm{HFrEF}$, start treatment with RAAS inhibitors and $\beta$-blockers and then increase the doses to the target levels. For patients with HFpEF, standard drug therapy has not been established and focus on the management of risk factors such as hypertension.

4. Consider device treatment such as ICD and CRT/CRT-D, if indicated.

ICD, implantable cardioverter defibrillator; CRT, cardiac resynchronization therapy; CRT-D, cardiac resynchronization therapy defibrillator; HFpEF, heart failure with preserved ejection fraction; HFrEF, heart failure with reduced ejection fraction; RAAS, renin-angiotensin-aldosterone system.

be used carefully as they may cause electrolyte imbalance and an increase in blood urea nitrogen more frequently than loop diuretics.

\section{4.2.2 Vasopressin $V_{2}$ Receptor Antagonists (AVP Antagonists)}

Tolvaptan is an oral drug that inhibits arginine vasopressin (AVP) type 2 receptors. In Japan, it is indicated for patients with heart failure who are resistant to other diuretics. AVP antagonists suppress hyponatremia and are beneficial in the treatment of patients with intractable heart failure, especially those with heart failure and hyponatremia. Although AVP antagonists are considered effective in fluid management in patients with diuretic-resistant heart failure and severe congestion, the dose should be limited to the minimum necessary. Patients should be observed carefully for adverse reactions such as thirst and hypernatremia. 
Table 57. Recommendations and Levels of Evidence for Drug Therapy for Patients With Acute Heart Failure

\begin{tabular}{|c|c|c|c|c|}
\hline & $\begin{array}{c}\text { Class of } \\
\text { Recommendation }\end{array}$ & $\begin{array}{l}\text { Level of } \\
\text { Evidence }\end{array}$ & \begin{tabular}{|c|} 
Grade of \\
Recommendation \\
(MINDS)
\end{tabular} & $\begin{array}{c}\text { Level of } \\
\text { Evidence } \\
\text { (MINDS) }\end{array}$ \\
\hline \multicolumn{5}{|l|}{ Diuretics } \\
\hline \multicolumn{5}{|l|}{ Loop diuretics } \\
\hline $\begin{array}{l}\text { Intravenous and oral administration to alleviate fluid retention in patients with } \\
\text { acute heart failure }\end{array}$ & I & C & B & II \\
\hline Continuous intravenous infusion to patients not responding to bolus injections & Ila & B & B & $\mathrm{IVb}$ \\
\hline \multicolumn{5}{|l|}{ Vasopressin $V_{2}$ receptor antagonists (tolvaptan) } \\
\hline $\begin{array}{l}\text { Use for the treatment of fluid retention in patients not responding well to other } \\
\text { diuretics including loop diuretics (Excluding patients with hypernatremia) }\end{array}$ & Ila & A & B & II \\
\hline Use for the treatment of fluid retention in patients with hyponatremia & Ila & C & $\mathrm{C} 1$ & II \\
\hline \multicolumn{5}{|l|}{ MRAs } \\
\hline $\begin{array}{l}\text { Use in combination with loop diuretics in patients in whom loop diuretics become } \\
\text { less effective }\end{array}$ & $\mathrm{llb}$ & $\mathrm{C}$ & C1 & III \\
\hline Use in patients with hypokalemia and normal renal function & Ila & B & B & II \\
\hline Use in patients with renal dysfunction and hyperkalemia & III & C & $\mathrm{D}$ & VI \\
\hline \multicolumn{5}{|l|}{ Thiazide diuretics } \\
\hline $\begin{array}{l}\text { Use in combination with furosemide in patients in whom furosemide becomes } \\
\text { less effective }\end{array}$ & Ilb & C & $\mathrm{C} 1$ & III \\
\hline \multicolumn{5}{|l|}{ Vasodilators } \\
\hline \multicolumn{5}{|l|}{ Nitrates } \\
\hline $\begin{array}{l}\text { Use for the treatment of pulmonary congestion in patients with acute heart failure } \\
\text { or acute worsening chronic heart failure }\end{array}$ & I & B & A & II \\
\hline \multicolumn{5}{|l|}{ Nicorandil } \\
\hline $\begin{array}{l}\text { Use for the treatment of pulmonary congestion in patients with acute heart failure } \\
\text { or acute worsening chronic heart failure }\end{array}$ & Ilb & C & C1 & II \\
\hline \multicolumn{5}{|l|}{ Carperitide } \\
\hline $\begin{array}{l}\text { Use for the treatment of pulmonary congestion in patients with decompensated } \\
\text { heart failure }\end{array}$ & Ila & B & B & II \\
\hline Use in combination with inotropes in patients with intractable heart failure & Ila & B & C1 & II \\
\hline $\begin{array}{l}\text { Use in patients with serious hypotension, cardiogenic shock, acute right ventricular } \\
\text { infarction, or dehydration }\end{array}$ & III & C & $\mathrm{C} 2$ & VI \\
\hline \multicolumn{5}{|l|}{ Calcium channel blockers } \\
\hline Sublingual administration of nifedipine to patients with hypertensive emergency & III & C & $\mathrm{D}$ & $\mathrm{IVb}$ \\
\hline \multicolumn{5}{|l|}{ Inotropes/vasopressors } \\
\hline \multicolumn{5}{|l|}{ Dobutamine } \\
\hline Use in patients with pump dysfunction and pulmonary congestion & Ila & C & B & II \\
\hline \multicolumn{5}{|l|}{ Dopamine } \\
\hline Use in expectation of increase in urine volume and renal protective effect & $\mathrm{Ilb}$ & A & $\mathrm{C} 2$ & II \\
\hline \multicolumn{5}{|l|}{ Norepinephrine } \\
\hline $\begin{array}{l}\text { Use in combination with catecholamines in patients with pulmonary congestion } \\
\text { and hypotension }\end{array}$ & Ila & B & B & III \\
\hline \multicolumn{5}{|l|}{ PDE III inhibitors } \\
\hline Use in patients with non-ischemic pump dysfunction and pulmonary congestion & Ila & A & B & II \\
\hline Use in patients with ischemic pump dysfunction and pulmonary congestion & $\mathrm{Ilb}$ & A & B & II \\
\hline $\begin{array}{l}\text { Use in combination with dobutamine in patients with a severe reduction in } \\
\text { cardiac output }\end{array}$ & Ilb & C & C1 & IVb \\
\hline \multicolumn{5}{|l|}{ Rate controllers } \\
\hline \multicolumn{5}{|l|}{ Digitalis } \\
\hline $\begin{array}{l}\text { Use for rate control of atrial fibrillation in patients with tachycardia-induced heart } \\
\text { failure }\end{array}$ & 1 & A & B & II \\
\hline \multicolumn{5}{|l|}{ Landiolol } \\
\hline $\begin{array}{l}\text { Use for rate control of atrial fibrillation in patients with tachycardia-induced heart } \\
\text { failure }\end{array}$ & 1 & $\mathrm{C}$ & B & II \\
\hline
\end{tabular}

MRA, mineralocorticoid receptor antagonist; PDE, phosphodiesterase. 


\subsection{Vasodilators}

Vasodilators, like diuretics, are effective in the treatment of acute cardiogenic pulmonary edema. In general, vasodilators are the first choice, but diuretics should mainly be used in patients with severe congestion due to fluid retention such as those with acute exacerbation of chronic heart failure. On the other hand, vasodilators may be preferred for patients with high blood pressure, those with myocardial ischemia, and those with mitral valve regurgitation, among others. Vasodilators should not be used for patients with cardiogenic shock with a systolic blood pressure of $<90 \mathrm{mmHg}$. Since excessive hypotension may worsen renal function, the dose of vasodilators should be titrated carefully, and careful monitoring after dosing is crucial. Especially, patients with renal dysfunction, elderly patients, and patients with aortic valve stenosis should be carefully observed for hypotension.

\subsubsection{Nitrates}

Sublingual, spray or intravenous administration of nitroglycerin or isosorbide dinitrate are effective in alleviating pulmonary congestion in patients with acute heart failure and patients with acute exacerbation of chronic heart failure (Table 57). Nitrates dilate venous capacitance vessels at low doses and arterial resistance vessels at high doses, reducing preload (pulmonary capillary pressure) and afterload (a slight increase in cardiac output associated with reduced peripheral vascular resistance). As nitrates dilate coronary arteries, they are often used for the treatment of acute heart failure due to ischemic heart disease.

Adverse drug reactions to nitrates include hypotension, and decrease in arterial oxygen saturation due to increased intrapulmonary shunting. Physicians should be aware that nitrate tolerance may develop rapidly when administered intravenously.

\subsubsection{Nicorandil}

Nicorandil dilates both veins and arteries, and, like nitrates, reduces pulmonary artery wedge pressure. Nicorandil is less likely to develop tolerance ${ }^{\mathbf{4 6 9 , 4 7 0}}$ and cause excessive hypotension than nitrates. ${ }^{471}$

\section{| 4.3.3 Carperitide}

Carperitide, a recombinant human atrial natriuretic peptide (hANP), reduce cardiac load by vasodilation, sodium diuresis, and inhibition of renin and aldosterone synthesis. The drug is indicated for the treatment of pulmonary congestion and is also used in combination of catecholamines or other inotropic drugs for the treatment of refractory heart failure. As with other vasodilators, carperitide have not been demonstrated to improve the prognosis of patients with acute heart failure and further studies are needed to identify patients in whom the drug may improve prognosis.

Carperitide may cause hypotension at the beginning of treatment, carperitide should be administered by continuous intravenous infusion at a low dose, i.e., 0.025 to $0.05 \mu \mathrm{g} / \mathrm{kg} /$ $\mathrm{min}$, and $0.0125 \mu \mathrm{g} / \mathrm{kg} / \mathrm{min}$ for some cases. A prospective study in Japan has reported that carperitide is often administered at a dose of 0.05 to $0.1 \mu \mathrm{g} / \mathrm{kg} / \mathrm{min}$ (maximum recommended dose is $0.2 \mu \mathrm{g} / \mathrm{kg} / \mathrm{min}$ ), and improves clinical conditions in $82 \%$ of patients. ${ }^{472}$ The efficacy is especially high in patients with decompensated heart failure due to cardiomyopathy, hypertensive heart disease, or valvular diseases. Carperitide is contraindicated for patients with

\begin{tabular}{|c|c|}
\hline \multicolumn{2}{|c|}{$\begin{array}{l}\text { Table 58. Intravenous Drugs and Dosage Regimens for } \\
\text { Patients in the Acute Phase of Acute Heart Failure }\end{array}$} \\
\hline Drugs & Dosage regimens \\
\hline Morphine & $\begin{array}{l}\text { Dilute an ampule of } 5 \text { to } 10 \mathrm{mg} \text {, and administer } \\
2 \text { to } 5 \mathrm{mg} \text { intravenously over } 3 \text { minutes. }\end{array}$ \\
\hline Furosemide & $\begin{array}{l}\text { Start treatment with a bolus dose of } 10 \text { to } \\
120 \mathrm{mg} \text { or an infusion at } 1 \text { to } 2 \mathrm{mg} / \mathrm{hr} \text {, then } \\
\text { infuse continuously at } 1 \text { to } 5 \mathrm{mg} / \mathrm{hr} \text {. }\end{array}$ \\
\hline $\begin{array}{l}\text { Potassium } \\
\text { canrenoate }\end{array}$ & $\begin{array}{l}\text { Dissolve } 100 \text { to } 200 \mathrm{mg} \text { in } 10 \text { to } 20 \mathrm{~mL} \text { solution } \\
\text { to administer by slow intravenous injection. Do } \\
\text { not continue treatment unnecessarily. Limit the } \\
\text { daily dose to } 600 \mathrm{mg} \text {. }\end{array}$ \\
\hline Digoxin & $\begin{array}{l}\text { Administer } 0.125 \text { to } 0.25 \mathrm{mg} \text { by slow intravenous } \\
\text { injection. }\end{array}$ \\
\hline Dopamine & $\begin{array}{l}\text { Start infusion at } 0.5 \text { to } 5 \mu \mathrm{g} / \mathrm{kg} / \mathrm{min} \text { and maintain } \\
\text { at } 0.5 \text { to } 20 \mu \mathrm{g} / \mathrm{kg} / \mathrm{min} \text {. When discontinuing the } \\
\text { infusion, reduce the dose gradually. Limit the } \\
\text { dose and treatment duration to minimum } \\
\text { necessary. }\end{array}$ \\
\hline Dobutamine & $\begin{array}{l}\text { Start infusion at } 0.5 \text { to } 5 \mu \mathrm{g} / \mathrm{kg} / \mathrm{min} \text { and maintain } \\
\text { at } 0.5 \text { to } 20 \mu \mathrm{g} / \mathrm{kg} / \mathrm{min} \text {. When discontinuing the } \\
\text { infusion, reduce the dose gradually. Limit the } \\
\text { dose and treatment duration to minimum } \\
\text { necessary. }\end{array}$ \\
\hline Norepinephrine & $\begin{array}{l}\text { Start and continue infusion at } 0.03 \text { to } 0.3 \mu \mathrm{g} / \\
\mathrm{kg} / \mathrm{min} \text {. }\end{array}$ \\
\hline Milrinone & $\begin{array}{l}\text { Start infusion at } 0.05 \text { to } 0.25 \mu \mathrm{g} / \mathrm{kg} / \mathrm{min} \text { and } \\
\text { maintain at } 0.05 \text { to } 0.75 \mu \mathrm{g} / \mathrm{kg} / \mathrm{min} \text {. }\end{array}$ \\
\hline Olprinone & $\begin{array}{l}\text { Start infusion at } 0.05 \text { to } 0.2 \mu \mathrm{gg} / \mathrm{kg} / \mathrm{min} \text { and } \\
\text { maintain at } 0.05 \text { to } 0.5 \mu \mathrm{g} / \mathrm{kg} / \mathrm{min} \text {. }\end{array}$ \\
\hline $\begin{array}{l}\text { Colforsin } \\
\text { daropate }\end{array}$ & $\begin{array}{l}\text { Start and continue infusion at } 0.1 \text { to } 0.25 \mu \mathrm{g} / \\
\mathrm{kg} / \mathrm{min} \text {. }\end{array}$ \\
\hline Nitroglycerin & $\begin{array}{l}\text { Start and continue infusion at } 0.5 \text { to } 10 \mu \mathrm{g} / \mathrm{kg} / \\
\text { min. }\end{array}$ \\
\hline $\begin{array}{l}\text { Isosorbide } \\
\text { dinitrate }\end{array}$ & Start and continue infusion at 1 to $8 \mathrm{mg} / \mathrm{hr}$. \\
\hline Nicorandil & $\begin{array}{l}\text { Start and continue infusion at } 0.05 \text { to } 0.2 \mathrm{mg} / \\
\mathrm{kg} / \mathrm{min} \text {. }\end{array}$ \\
\hline Nitroprusside & $\begin{array}{l}\text { Start and continue infusion at } 0.5 \text { to } 3 \mu \mathrm{g} / \mathrm{kg} / \\
\text { min. }\end{array}$ \\
\hline Carperitide & $\begin{array}{l}\text { Start infusion at } 0.0125 \text { to } 0.05 \mu \mathrm{g} / \mathrm{kg} / \mathrm{min} \text { and } \\
\text { maintain at } \leq 0.2 \mu \mathrm{g} / \mathrm{kg} / \mathrm{min} \text {. }\end{array}$ \\
\hline Landiolol & $\begin{array}{l}\text { Start infusion at } 1 \mu \mathrm{g} / \mathrm{kg} / \mathrm{min} \text {, adjust the dose } \\
\text { according to heart rate and blood pressure, } \\
\text { and maintain at } 1 \text { to } 10 \mu \mathrm{g} / \mathrm{kg} / \mathrm{min} \text {. }\end{array}$ \\
\hline
\end{tabular}

serious hypotension, cardiogenic shock, acute right ventricular infarction, or dehydration.

\subsection{Inotropes and Vasopressors}

Drugs with inotropic action are indicated for patients with hypotension, patients with peripheral circulatory failure, and patients not responding to treatment to optimize circulating volume. Inotropes are effective in improving hemodynamics and clinical conditions in the short term, and are often administered to patients with left ventricular enlargement and reduced LVEF. However, these drugs increase myocardial oxygen demand and cause myocardial calcium loading, which may result in arrhythmias, myocardial ischemia or myocardial injury and poor prognosis. Accordingly, it is desirable that dose and duration of inotropic treatment should be limited to minimum necessity.

\section{4.4.1 Catecholamine Inotropes}

Catecholamines bind to adrenergic receptors (e.g., $\alpha_{1}, \alpha_{2}$, 
$\beta_{1}$, and $\beta_{2}$ ) and exerts various physiological effects. $\beta$-receptors on myocytes are mainly $\beta_{1}$ receptors, and catecholamines enhance myocardial contraction, accelerate myocardial relaxation, increase heart rate, and increase myocardial conduction velocity via $\beta_{1}$ receptors. On the other hand, catecholamines dilate peripheral vessels by stimulating $\beta_{2}$ receptors on vascular smooth muscle cells, exert vasoconstriction through $\alpha_{1}$ receptors mainly located in the vascular smooth muscle, and enhance cardiac contraction mildly through the $\alpha_{1}$ receptors on myocytes.

\section{a. Dobutamine}

Dobutamine is a synthetic catecholamine that stimulates $\beta_{1}, \beta_{2}$, and $\alpha_{1}$ receptors. As a $\beta_{2}$ receptor stimulant, dobutamine at $5 \mu \mathrm{g} / \mathrm{kg} / \mathrm{min}$ or lower doses acts as a mild vasodilator to decrease systemic peripheral vascular resistance and pulmonary capillary pressure. As dobutamine does not increase heart rate or myocardial oxygen demand substantially at $10 \mu \mathrm{g} / \mathrm{kg} / \mathrm{min}$ or lower doses, the drug can be used for the treatment of ischemic heart disease. Dobutamine reduces pulmonary artery diastolic pressure more substantially than dopamine does, and is effective in the treatment of pulmonary congestion. ${ }^{473}$ In patients with unstable blood pressure, consideration for addition of dopamine or noradrenaline is necessary. Dobutamine may increase the number of eosinophils in the myocardium and blood. ${ }^{\mathbf{4 7 4}}$ When dobutamine therapy is discontinued, the dose should be tapered gradually. A study evaluated the effect of dobutamine on long-term prognosis have suggested that dobutamine may increase the risk of cardiac accidents. ${ }^{475}$ The dose and duration of dobutamine therapy should be limited to minimum necessity.

\section{b. Dopamine}

Dopamine is an endogenous catecholamine and a precursor of noradrenaline. Studies with animal model and healthy subjects show that at low doses $(\leq 2 \mu \mathrm{g} / \mathrm{kg} / \mathrm{min})$, dopamine induces diuresis through its vasodilative effects on renal arteries and direct action to renal tubules. At intermediate doses ( 2 to $10 \mu \mathrm{g} / \mathrm{kg} / \mathrm{min}$ ), dopamine exerts positive inotropic effects, increases heart rate, and constricts vessels and at high doses (10 to $20 \mu \mathrm{g} / \mathrm{kg} / \mathrm{min}$ ), increase vascular resistance.

It is unclear whether low-dose dopamine is beneficial in patients with heart failure in terms of increasing urine volume or protecting renal function. ${ }^{476-479}$

\section{c. Norepinephrine}

Norepinephrine is an endogenous catecholamine, and enhances myocardial contraction and increases heart rate by stimulating $\beta_{1}$ receptors and also acts as a potential vasoconstrictor by $\alpha$ receptors located on peripheral veins. Patients in refractory cardiogenic shock should be treated with continuous intravenous infusion of noradrenaline starting at a dose of 0.03 to $0.3 \mu \mathrm{g} / \mathrm{kg} / \mathrm{min}$. Norepinephrine is well indicated for patients with septic shock. As the drug increases afterload and myocardial oxygen consumption and reduces blood flow to the kidneys, brain and other organs, monotherapy with norepinephrine as an inotrope should be avoided, and the dose and duration of noradrenaline therapy should be limited to minimum necessity. In patients who require large doses of noradrenaline, mechanical support such as intra-aortic balloon pump (IABP) and percutaneous cardiopulmonary support (PCPS) should be introduced to decrease the dose of noradrenaline.

\section{| 4.4.2 Digitalis}

Digoxin is beneficial in improving hemodynamics in a short period of time. ${ }^{480}$ Digoxin is not expected to improve long term prognosis, but will reduce the frequency of rehospitalizations in keeping attentions to blood concentration. ${ }^{207}$ In patients with acute heart failure, digitalis is indicated for the treatment of heart failure induced by tachycardias such as atrial fibrillation. Treatment with digitalis is not recommended for patients with acute heart failure due to acute myocardial infarction or myocarditis.

In general, digoxin is administered slowly intravenously to control heart rate in patients with atrial fibrillation or other conditions at a dose of 0.125 to $0.25 \mathrm{mg}$ while avoiding digitalis toxicity.

Digitalis is contraindicated for patients with bradycardia, second or third degree atrioventricular block, sick sinus syndrome, Wolff-Parkinson-White (WPW) syndrome, hypertrophic obstructive cardiomyopathy, hypokalemia, or hypercalcemia.

\subsubsection{PDE III Inhibitors}

Strengths of PDE III inhibitors include: 1) they are effective even in patients not responding to catecholamines; 2) they possess both vasodilative and positive inotropic effects and are associated with a smaller increase in myocardial oxygen consumption as compared with catecholamines; 3) and they are less likely to develop tolerance than nitrates. PDE III inhibitors exert rapid onset of action after the initiation of intravenous administration and improve hemodynamics almost in a dose-dependent manner. ${ }^{481}$

For acute worsening heart failure in patients who are receiving $\beta$-blockers, PDE inhibitors and adenylate cyclase activators favorably increase cardiac output and decrease pulmonary capillary pressure because their actions are not mediated by $\beta$-receptors. ${ }^{\mathbf{4 8 2}}$

As with the catecholamine inotropes, PDE III inhibitors should be carefully used for the treatment of appropriate conditions, and the dose and duration of treatment should be limited to minimum necessity. In general, treatment with PDE III should be initiated with continuous intravenous infusion, and patients should be observed carefully for hypotension and arrhythmias.

I 4.4.4 Adenylate Cyclase Activators (Colforsin Daropate) Adenylate cyclase activators are inotropes available only in Japan. They act as inodilators, but have slower onset of action and induce a larger increase in heart rate as compared with PDE inhibitors. Physicians should be aware that they may induce arrhythmias.

\section{| 4.4.5 Calcium Sensitizers (Pimobendan)}

Although pimobendan increases the myocardial contractility and dilates vessels to increase cardiac output and decrease pulmonary capillary pressure, no clear evidence has been obtained about the efficacy of this drug in the treatment of acute heart failure.

\subsection{Myocardial Protective Agents}

Survival should be prioritized in the treatment of acute heart failure. Once survival is ensured, then improvement of long-term prognosis and QOL should be aimed. Considering the fact that many cases of acute heart failure are acute worsening of chronic heart failure, physicians should try to protect the myocardium while taking into account 


\begin{tabular}{|l|}
\hline Table 59. Indications and Contraindications of Noninvasive \\
Positive Pressure Ventilation (NPPV) in Patients \\
With Acute Heart Failure and the Criteria for \\
Conversion to Tracheal Intubation
\end{tabular}

the management during transition period from the acute to chronic phases.

For details, see Chapter "VI. Drug Therapy".

\section{Nonpharmacological Therapy}

\subsection{Mechanical Ventilation}

\section{5.1.1 Pathophysiology of Pulmonary Edema and Oxygen Therapy}

Patients with acute left-sided heart failure have high pulmonary capillary pressure, severe pulmonary congestion or pulmonary edema. In patients with normal plasma protein levels, an increase in pulmonary capillary pressure to $\geq 24 \mathrm{mmHg}$ causes leakage of plasma components into alveoli. As pulmonary capillary pressure increases the severity of pulmonary edema increases in a linear manner. In patients in whom plasma protein levels decrease to half of the lower normal limit, pulmonary edema develops when pulmonary capillary pressure is $11 \mathrm{mmHg}$ or higher. 483 Treatment of pulmonary edema should prioritize the management of dyspnea and hypoxemia to improve oxygen supply to peripheral tissues.

\subsubsection{Oxygen Therapy and Non-Invasive Positive-Pressure Ventilation (NPPV)}

In patients with acute heart failure, oxygen administration should be started with a nasal cannula or face mask at 2 to $6 \mathrm{~L} / \mathrm{min}$. In patients with a $\mathrm{PaO}_{2}$ of less than $80 \mathrm{mmHg}$ (oxygen saturation $\left[\mathrm{SpO}_{2}\right]$ of less than $95 \%$ ) or an arterial partial pressure of carbon dioxide $\left(\mathrm{PaCO}_{2}\right)$ of $50 \mathrm{mmHg}$ or more, or patients in whom symptoms such as tachypnea, forced respiration, and orthopnea are not improved or are worsening, NPPV should be initiated promptly using a mask or bag-mask device (Table 59).

Continuous positive airway pressure (CPAP) is the firstchoice treatment for patients with acute heart failure, but

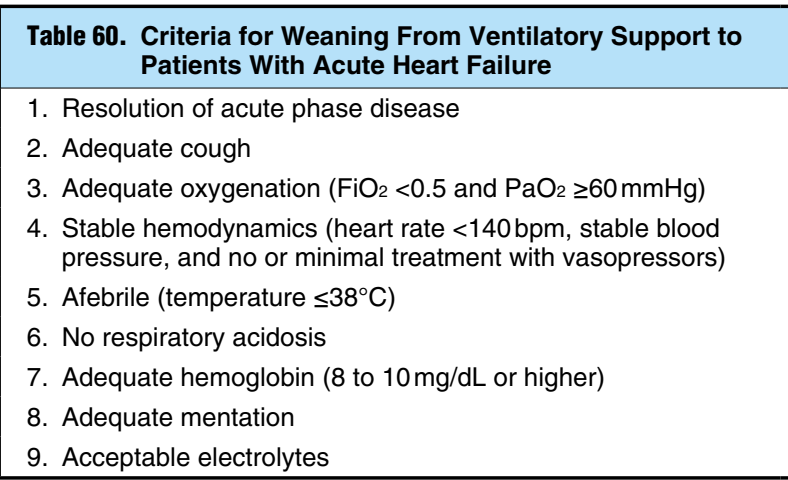

$\mathrm{FiO}_{2}$, fraction of inspiratory oxygen; $\mathrm{PaO}_{2}$, arterial partial pressure of oxygen. (Source: Prepared based on Maclntyre NR, et al. 2001486)

patients who still have high $\mathrm{CO}_{2}$ levels or dyspnea during CPAP should receive bi-level PAP. Patients who do not respond well to NPPV should be intubated promptly to receive artificial respiration. Table 59 summarize how switch from NPPV to endotracheal intubation. In order to ensure the success of ventilation in patients with acute cardiogenic pulmonary edema, oxygen therapy should not be continued aimlessly. Patients who still have hypoxemia and dyspnea despite oxygen therapy should start receiving NPPV without delay. ${ }^{\mathbf{4 8 4}, 485}$

\subsubsection{Mechanical Ventilation With Endotracheal Intubation}

In patients with no improvement of respiratory condition or arterial blood gasses during NPPV, or patients who have a consciousness disorder, loss of cough reflex, or difficulty in expectoration, artificial respiration under endotracheal intubation is indicated (Table 59).

Patients with acute decompensated heart failure associated with pulmonary congestion or pulmonary edema should receive positive end-expiratory pressure (PEEP) at around 2 to $10 \mathrm{cmH}_{2} \mathrm{O}$ to maximize oxygen delivery to peripheral tissues unless contraindicated. Typical ventilation conditions include a tidal volume of 10 to $15 \mathrm{~mL} / \mathrm{kg}$, a respiratory rate of 10 to 20 breaths per minute (target $\mathrm{PaCO}_{2}: 30$ to $40 \mathrm{mmHg}$ ), and an inhale: exhale ratio of 1 to 1.5:2. These settings should be individualized based on the results of arterial blood gas analysis. Immediately after intubation, the fraction of inspiratory oxygen $\left(\mathrm{FiO}_{2}\right)$ should be set at 1.0, and then should be adjusted to maintain a $\mathrm{PaO}_{2}$ of $\geq 80 \mathrm{mmHg}$. It is desirable that $\mathrm{FiO}_{2}$ be set at $\leq 0.5$ to prevent oxygen toxicity.

D.1.4 Weaning From Artificial Respiration and Extubation When the condition required artificial respiration has been corrected with a $\mathrm{FiO}_{2}$ of $<0.5$, a PEEP of $<5$ to $10 \mathrm{cmH}_{2} \mathrm{O}$, and $\mathrm{PaO}_{2}$ of $\geq 60 \mathrm{mmHg}$, weaning from artificial ventilation should be considered (Table 60). ${ }^{486}$ Recently, highflow nasal cannula oxygen therapy has been tried after extubation. ${ }^{487}$

\subsection{Management With Pacing (Cardiac Resynchronization Therapy and Other Types of Pacing)}

I 5.2.1 Cardiac Resynchronization Therapy (CRT)

No studies have investigated the effects of CRT during the acute phase of acute heart failure. Patients with acute heart 


\begin{tabular}{|c|c|c|c|c|}
\hline & $\begin{array}{c}\text { Class of } \\
\text { Recommendation }\end{array}$ & $\begin{array}{l}\text { Level of } \\
\text { Evidence }\end{array}$ & $\begin{array}{l}\text { Grade of } \\
\text { Recommendation } \\
\text { (MINDS) }\end{array}$ & $\begin{array}{l}\text { Level of } \\
\text { Evidence } \\
\text { (MINDS) }\end{array}$ \\
\hline $\begin{array}{l}\text { Prompt initiation of emergency temporary } \\
\text { pacing in patients with bradycardia that } \\
\text { worsens hemodynamics and causes } \\
\text { transient cerebral ischemia, and who do } \\
\text { not respond well to atropine }\end{array}$ & I & C & C1 & VI \\
\hline $\begin{array}{l}\text { Cardiac resynchronization therapy in the } \\
\text { very early phase of acute heart failure }\end{array}$ & Ilb & C & C2 & VI \\
\hline
\end{tabular}

\begin{tabular}{|c|c|c|c|c|}
\hline & $\begin{array}{c}\text { Class of } \\
\text { Recommendation }\end{array}$ & $\begin{array}{l}\text { Level of } \\
\text { Evidence }\end{array}$ & $\begin{array}{l}\text { Grade of } \\
\text { Recommendation } \\
\text { (MINDS) }\end{array}$ & $\begin{array}{l}\text { Level of } \\
\text { Evidence } \\
\text { (MINDS) }\end{array}$ \\
\hline \multicolumn{5}{|l|}{ Hemofiltration } \\
\hline Extracorporeal ultrafiltration method (ECUM) & $\mathrm{Ilb}$ & B & $\mathrm{C} 2$ & II \\
\hline $\begin{array}{l}\text { Continuous venovenous hemofiltration (CVVH) for } \\
\text { patients with volume overload and stable hemodynamics }\end{array}$ & $\mathrm{llb}$ & B & $\mathrm{C} 2$ & II \\
\hline \multicolumn{5}{|l|}{ Hemodialysis } \\
\hline Hemodialysis & Ilb & B & $\mathrm{C} 2$ & II \\
\hline Peritoneal dialysis & Ilb & B & $\mathrm{C} 2$ & II \\
\hline \multicolumn{5}{|l|}{ Hemodiafiltration } \\
\hline Continuous hemodiafiltration (CHDF) & $\mathrm{Ilb}$ & B & $\mathrm{C} 2$ & II \\
\hline
\end{tabular}

failure should receive pharmacotherapy first, and should then be considered for the indication of CRT during the chronic phase of heart failure (See Section "2. Cardiac Resynchronization Therapy" in Chapter "VII. Nonpharmacologic Therapy").

\subsubsection{Emergency Temporary Pacing}

Emergency temporary pacing should be performed promptly in patients with bradycardia leading to compromised hemodynamics or transient cerebral ischemia who do not respond to atropine regardless of type of causative conditions (Table 61).

\subsection{Acute Hemofiltration}

In patients with acute decompensated congestive heart failure, hepatic congestion and edema may develop in association with pulmonary congestion and excessive fluid retention. During the acute phase treatment, excessive fluid should be rapidly corrected. Patients with renal dysfunction in whom diuresis cannot be achieved require acute hemofiltration (Table 62).

At present, ultrafiltration should be reserved for patients in whom fluid removal is difficult or impossible with any drug therapies.

\subsection{Indications and Methods of Surgical Treatment in Patients With Acute Heart Failure (Cardiac Tamponade and Acute Valvular Disease)}

\section{5.4.1 Cardiac Tamponade}

Cardiac tamponade is a condition of elevated pericardial pressure caused by pericardial effusion, resulting in decreased venous return during the diastolic phase and impaired ventricular filling.

In cases of urgency, echocardiography-guided pericardiocentesis and drainage are conducted. Inotropes are not effective in urgent situations. In patients with hemorrhagic cardiac tamponade with hypovolemia, drainage is effective in maintaining hemodynamics on a temporary basis. In patients with unsuccessful pericardiocentesis or patients with recurrent pericardial effusion due to hemorrhagic cardiac tamponade, surgical drainage by pericardiotomy through a subxiphoid approach or pericardiotomy should be performed.

\subsubsection{Acute Valvular Disease \\ a. Acute Aortic Regurgitation 488}

Acute aortic regurgitation is an emergent condition that may lead to cardiogenic shock unless prompt surgical intervention is undertaken. Causes of acute aortic regurgitation include aortic dissection, infective endocarditis, injuries, and iatrogenic aortic valve injury. Indication for surgery should be considered promptly for patients with acute aortic regurgitation. Echocardiography is essential for confirmatory diagnosis and severity assessment, and provides information that helps physicians specify the cause and assess the severity of pulmonary hypertension. IABP is contraindicated for patients with acute aortic regurgitation.

\section{b. Acute Mitral Valve Insufficiency ${ }^{488}$}

Acute mitral valve insufficiency (mitral valve regurgitation) causes acute volume overload of the left ventricle and left 


$\begin{aligned} & \text { Table 63. Recommendations and Levels of Evidence for Invasive Treatment of Acute Mitral Regurgitation in } \\
& \text { Patients With Acute Myocardial Infarction }\end{aligned}$
\begin{tabular}{|l|c|c||c|c|}
\hline & $\begin{array}{c}\text { Class of } \\
\text { Recommendation }\end{array}$ & $\begin{array}{c}\text { Level of } \\
\text { Evidence }\end{array}$ & $\begin{array}{c}\text { Grade of } \\
\text { Recommendation } \\
\text { (MINDS) }\end{array}$ & $\begin{array}{c}\text { Level of } \\
\text { Evidence } \\
\text { (MINDS) }\end{array}$ \\
\hline Surgical repair through prompt IABP insertion & I & B & C1 & IVa \\
\hline Addition of CABG & I & B & C1 & IVa \\
\hline
\end{tabular}

CABG, coronary artery bypass grafting; IABP, intra-aortic balloon pump.

atrium, which results in pulmonary edema and cardiogenic shock. Patients with no improvement in hemodynamics after treatment with vasodilators and catecholamines are indicated for emergency surgery. IABP is used to maintain hemodynamics in patients who are waiting for surgery. Accurate color Doppler examination can be performed with transesophageal echocardiography. IABP may stabilize the hemodynamics of patients in preparation for surgery.

\subsection{Treatment of Mechanical Complications Associated With Acute Myocardial Infarction}

\section{5.5.1 Left Ventricular Free Wall Rupture}

Left ventricular free wall rupture develops in 4 to $24 \%$ of patients with acute myocardial infarction. Treatment often fails, and deaths due to this condition account for $20 \%$ of early deaths from acute myocardial infarction. ${ }^{489}$ Left ventricular free wall rupture often develops in 1 to 7 days after the onset of acute myocardial infarction. It is classified by mode of onset into oozing (slow rupture) type, which develops as cardiac tamponade caused by gradual accumulation of bloody pericardial effusion, and blow-out type, which develops as an abrupt rupture of the myocardial wall. Oozing cases can be diagnosed before shock develops, and should be treated with pericardial drainage followed by surgery. However, in blow-out cases, pulseless electrical activity develops rapidly, and leads to death. Patients should be diagnosed immediately after onset, receive percutaneous cardiopulmonary support (PCPS) promptly to maintain systemic circulation before undergoing emergency surgery.

\subsubsection{Ventricular Septal Perforation}

The incidence of ventricular septal perforation has been reported about half the incidence of free wall rupture. Ventricular septal perforation often develops on the third to fifth day after the onset of acute myocardial infarction. Patients with ventricular septal perforation often experience abrupt hemodynamic decompensation, hypotension, bilateral cardiac failure (right-sided heart failure is prominent in some cases), and newly developed holosystolic murmur. Patients with cardiogenic shock should undergo emergency surgery.

\section{5.5.3 Mitral Papillary Muscle Dysfunction ${ }^{490}$ (Table 63)}

Acute mitral regurgitation in patients with acute myocardial infarction is mainly caused by rupture of papillary muscle or chordae. Mitral regurgitation develops in about 14\% of patients after acute myocardial infarction as mild to moderate in severity in almost all cases. Severe mitral regurgitation develops in 3\% of patients after acute myocardial infarction, and the mortality is high. The prognosis depends on whether patients are diagnosed, and start receiving medical treatment without delay and promptly undergo emergency surgery. Effective medical treatment includes afterload reduction through intense vasodilation and diuresis. IABP is effective as well. Patients should receive medical treatment to stabilize hemodynamics, and undergo surgical treatment as soon as it is ready.

\subsection{Cardiac Rehabilitation in Patients With Acute Heart Failure}

\subsubsection{Significance of Cardiac Rehabilitation in Patients With Acute Heart Failure}

The goals of cardiac rehabilitation in patients with acute heart failure are

(1) facilitating early ambulation to prevent consequences of prolonged bed rest (e.g., physical/mental deconditioning, bedsores, and pulmonary embolism);

(2) establishing/sharing plans for prompt and safe discharge from hospital and return to society;

(3) improving QOL by increasing exercise capacity; and

(4) preventing recurrent heart failure and rehospitalization through comprehensive patient education and disease management.

As patients with heart failure are prone to have physical/ mental deconditioning or disuse syndrome due to prolonged bed rest, and skeletal muscle atrophy due to malnutrition or increased proinflammatory cytokine levels ("cardiac cachexia"), it is important to start cardiac rehabilitation, consisting of physical therapy, exercise therapy and education/counseling, in the early phase of acute heart failure.

After the disease is stabilized, a comprehensive cardiac rehabilitation program should be initiated. The program should be shifted to an ambulatory cardiac rehabilitation program to continue disease management. ${ }^{148}$

Cardiac rehabilitation only during hospitalization has not been demonstrated to improve long-term prognosis in patients with acute heart failure. However, comprehensive ambulatory cardiac rehabilitation programs have been reported to be effective in preventing rehospitalizations of patients with heart failure. In-hospital cardiac rehabilitation programs should aim for not only early ambulation and early discharge but also encouraging patients to participate and continue ambulatory cardiac rehabilitation after discharge.

Patients hospitalized in the ICU for the treatment of acute heart failure tend to have strong anxiety and unstable mental state because they are often overwhelmed with the abrupt onset of the disease, emergency hospitalization, invasive treatment procedures, fear of death, anxiety about the future, and unfamiliar environment apart from the family. They also have physical stress caused by invasive 


\begin{tabular}{|c|c|c|c|c|}
\hline & $\begin{array}{c}\text { Class of } \\
\text { Recommendation }\end{array}$ & $\begin{array}{l}\text { Level of } \\
\text { Evidence }\end{array}$ & $\begin{array}{l}\text { Grade of } \\
\text { Recommendation } \\
\text { (MINDS) }\end{array}$ & $\begin{array}{l}\text { Level of } \\
\text { Evidence } \\
\text { (MINDS) }\end{array}$ \\
\hline $\begin{array}{l}\text { Educational programs on the prevention of recurrence } \\
\text { and self-management for all patients }\end{array}$ & I & C & C1 & VI \\
\hline $\begin{array}{l}\text { Rehabilitation for patients with heart failure who are } \\
\text { treated with intravenous inotropic drugs and have } \\
\text { stable hemodynamics, including low-intensity resistance } \\
\text { training under strict supervision }\end{array}$ & IIb & C & C1 & V \\
\hline $\begin{array}{l}\text { Comprehensive cardiac rehabilitation programs for all } \\
\text { patients with heart failure after stabilization }\end{array}$ & Ila & C & C1 & VI \\
\hline
\end{tabular}

procedures and prolonged bed rest as well as mental stress and shame of receiving nursing care. Therefore, mental support for patients in the early stage of acute heart failure is important to alleviate patients' mental stress and improve the QOL of patients during hospital stay. Healthcare professionals should try to detect mental health problems early, provide appropriate mental counseling, prescribe drug therapy, and consider for cognitive behavioral therapy, if necessary. ${ }^{\mathbf{1 4 8}}$

\subsubsection{Early-Phase Cardiac Rehabilitation in Patients With Severe Heart Failure in the ICU (Table 64)}

Exercise therapy is not recommended for patients with unstable hemodynamics due to acute heart failure or severe heart failure and patients with dyspnea at rest due to pulmonary congestion or fever. However, it has been reported that even patients with severe heart failure on mechanical ventilation, IABP or CHDF or those who are receiving continuous infusion of cardiovascular drugs can safely receive early-phase cardiac rehabilitation including low-strength physical or exercise therapy when they have stable hemodynamics and no symptoms at rest. ${ }^{491}$ For example, rhythmic low-strength resistance training using a rubber tube or ball can be conducted under the monitoring by ECG and vital signs in the bed or at the bedside. When unsupported sitting becomes possible, patients should prolong sitting time gradually, and then should try to stand. When standing at the bedside becomes possible, patients should try to stand on their tiptoes, among other training.

\section{Surgical Treatment}

\section{Surgical Procedures and TAVI}

\subsection{Left Ventricular Reconstruction}

Left ventricular reconstruction was initially introduced as a surgical procedure for the treatment of left ventricular aneurysm in $1980 \mathrm{~s}$. As the resection of left ventricular aneurysm, which increases in size during cardiac constriction, increases cardiac output by increasing the effective left ventricular volume and thereby improves cardiac function and symptoms. On the other hand, as prompt reperfusion therapy for the treatment of myocardial infarction has become a common procedure, cases of left ventricular aneurysm due to transmural infarction have become less common, while cases of ischemic cardiomyopathy with akinesis due to post-reperfusion extensive subendocardial infarction have become more common. Since Dor et al ${ }^{492}$ have reported that left ventricular reconstruction may improve the long-term prognosis of patients with ischemic myocardiopathy and akinesis, diverse procedures have been developed. In 2009, the results of the Surgical Treatment for Ischemic Heart Failure (STICH) trial, a randomized controlled trial to assess the effects of adding left ventricular reconstruction to coronary-artery bypass grafting (CABG), were published. ${ }^{493}$ This study had unexpected results that adding left ventricular restoration to $\mathrm{CABG}$ are not effective in exercise capacity, symptoms, or prognosis in patients with ischemic cardiomyopathy and $\mathrm{LVEF} \leq 35 \%$. A considerable number of objections have been published, but it is still unclear how surgical left ventricular resizing decreases wall tension against the remodeling myocardium, and thereby reverse the remodeling process. In a study in Japan, adding left ventricular reconstruction to mitral annuloplasty was beneficial in patients with ischemic cardiomyopathy with a left ventricular end-systolic volume index (LVESVI) of 105 to $150 \mathrm{~mL} / \mathrm{m}^{2} .494$ While in the $\mathrm{J}-\mathrm{STICH}$ registry in patients undergoing left ventricular reconstruction, the one-year survival of patients with ischemic cardiomyopathy and severe mitral regurgitation was $60 \% .{ }^{495}$ Myocardial viability should be considered to determine whether surgery is indicated or not. The efficacy of Batista procedure and other left ventricular reconstructive procedures for the treatment of non-ischemic cardiomyopathy has not been established. In 2005, the ACC/AHA guidelines for the diagnosis and treatment of chronic heart failure dropped the use of left ventricular reconstruction for this patient population to a Class III recommendation. ${ }^{4}$ In Japan, these procedures are conducted only in limited cases.

\section{I1.2 Transcatheter Aortic Valve Implantation (TAVI)}

At present, transcatheter aortic valve implantation (TAVI) or transcatheter aortic valve replacement (TAVR) are indicated for the treatment of severe aortic stenosis. The indications and timing of these procedures are in accordance of those of aortic valve replacement (Table 65). For details, refer to latest guidelines for the treatment of valvular heart diseases. ${ }^{370,371,496}$

TAVI is recommended for patients with severe aortic stenosis who are not indicated for surgery and are expected 


\begin{tabular}{|c|c|c|c|c|}
\hline & $\begin{array}{c}\text { Class of } \\
\text { Recommendation }\end{array}$ & $\begin{array}{l}\text { Level of } \\
\text { Evidence }\end{array}$ & $\begin{array}{l}\text { Grade of } \\
\text { Recommendation } \\
\text { (MINDS) }\end{array}$ & $\begin{array}{l}\text { Level of } \\
\text { Evidence } \\
\text { (MINDS) }\end{array}$ \\
\hline TAVI conducted by the multidisciplinary heart team & 1 & C & C1 & VI \\
\hline $\begin{array}{l}\text { TAVI conducted only at medical institutions which have } \\
\text { a department of cardiovascular surgery }\end{array}$ & I & C & C1 & VI \\
\hline $\begin{array}{l}\text { TAVI for patients with aortic valve stenosis who cannot } \\
\text { undergo cardiotomy and are expected to survive for at } \\
\text { least } 12 \text { months after the procedure }\end{array}$ & 1 & A & A & II \\
\hline $\begin{array}{l}\text { TAVI as an alternative procedure for patients who are } \\
\text { indicated for aortic valve replacement but in whom } \\
\text { surgery risk is high }\end{array}$ & Ila & A & B & II \\
\hline $\begin{array}{l}\text { TAVI for patients with aortic valve stenosis in whom } \\
\text { treatment is not expected to improve QOL or prognosis }\end{array}$ & III & A & D & II \\
\hline $\begin{array}{l}\text { TIVI for patients with aortic valve stenosis and low } \\
\text { LVEF }\end{array}$ & III & C & C2 & IVa \\
\hline
\end{tabular}

LVEF, left ventricular ejection fraction; QOL, quality of life; TAVI, transcatheter aortic valve implantation.

\begin{tabular}{|c|c|c|c|}
\hline \multirow{2}{*}{ Profile } & INTERMACS & \multirow{2}{*}{ Status } & \multirow{2}{*}{ Options of device therapy } \\
\hline & J-MACS & & \\
\hline 1 & $\begin{array}{l}\text { Critical cardiogenic } \\
\text { shock } \\
\text { "Crash and burn" }\end{array}$ & $\begin{array}{l}\text { Patients with compromised hemodynamics } \\
\text { and peripheral hypoperfusion despite rapid } \\
\text { escalation of intravenous inotropes and/or } \\
\text { introduction of mechanical circulatory } \\
\text { support }\end{array}$ & $\begin{array}{l}\text { IABP, peripheral VA-ECMO, } \\
\text { percutaneous VAD, centrifugal } \\
\text { pumps for extracorporeal circulation, } \\
\text { and paracorporeal VADs }\end{array}$ \\
\hline 2 & $\begin{array}{l}\text { Progressive decline } \\
\text { despite inotropic } \\
\text { support } \\
\text { "Sliding on inotropes" }\end{array}$ & $\begin{array}{l}\text { Patients with declining renal function, } \\
\text { nutritional status, and signs of congestion } \\
\text { despite intravenous inotropes and } \\
\text { required incremental doses of them }\end{array}$ & $\begin{array}{l}\text { IABP, peripheral VA-ECMO, } \\
\text { percutaneous VAD, centrifugal } \\
\text { pumps for extracorporeal circulation, } \\
\text { paracorporeal VADs, implantable } \\
\text { LVADs }\end{array}$ \\
\hline 3 & $\begin{array}{l}\text { Stable but inotrope- } \\
\text { dependent } \\
\text { "Dependent stability" }\end{array}$ & $\begin{array}{l}\text { Patients with stable hemodynamics on } \\
\text { intravenous inotropes at relatively low } \\
\text { doses, but physicians are not able to } \\
\text { discontinue the intravenous treatment } \\
\text { because of the risk of hypotension, } \\
\text { worsening symptoms of heart failure, or } \\
\text { worsening renal function }\end{array}$ & Implantable LVADs \\
\hline 4 & $\begin{array}{l}\text { Resting symptoms } \\
\text { "Frequent flyer" }\end{array}$ & $\begin{array}{l}\text { Patients who can be weaned from } \\
\text { intravenous inotropic support temporarily } \\
\text { and be discharged from hospital, but may } \\
\text { soon repeat hospitalizations for worsening } \\
\text { heart failure }\end{array}$ & $\begin{array}{l}\text { Consider implantable LVADs } \\
\text { (especially patients with modifier } A^{*} \text { ) }\end{array}$ \\
\hline 5 & $\begin{array}{l}\text { Exertion intolerant } \\
\text { "House-bound" }\end{array}$ & $\begin{array}{l}\text { Patients who can do daily routines in the } \\
\text { house, but have significant limitations in } \\
\text { activities of daily livings, and hardly go out }\end{array}$ & $\begin{array}{l}\text { Consider implantable LVADs for } \\
\text { patients with modifier } \mathrm{A}^{*}\end{array}$ \\
\hline 6 & $\begin{array}{l}\text { Exertion limited } \\
\text { "Walking wounded" }\end{array}$ & $\begin{array}{l}\text { Patients who can go out, but are difficult } \\
\text { in doing anything other than light activities, } \\
\text { and have symptoms during walk less than } \\
100-\text { meter }\end{array}$ & $\begin{array}{l}\text { Consider implantable LVADs for } \\
\text { patients with modifier } A^{*}\end{array}$ \\
\hline 7 & $\begin{array}{l}\text { Advanced NYHA III } \\
\text { "Placeholder" }\end{array}$ & $\begin{array}{l}\text { Patients can walk more than } 100 \text { meters } \\
\text { without fatigue, and have had no } \\
\text { hospitalizations in the recent } 6 \text { months }\end{array}$ & $\begin{array}{l}\text { Consider implantable LVADs for } \\
\text { patients with modifier } \mathrm{A}^{*}\end{array}$ \\
\hline
\end{tabular}

${ }^{*}$ Recurrent appropriate ICD shocks due to life-threatening ventricular arrhythmias. IABP, intra-aortic balloon pump; LVAD, left ventricular assist device; PCPS, percutaneous cardiopulmonary support; VAD, ventricular assist device; VA-ECMO, veno-arterial extracorporeal membrane oxygenation. (Source: Prepared based on Stevenson LW, et al. 2009511 and the Japanese Association for Thoracic Surgery ${ }^{512}$ )

to live more than 1 year after surgery by the heart team. ${ }^{497-500}$ TAVI should also be considered for high-risk patients who are indicated for surgery when the heart team considers that TAVI is a more preferable treatment option according to the patient's risk factors and anatomical conditions. ${ }^{499-502}$
Patients in whom TAVI is not expected to improve symptoms and QOL are not indicated for the procedure. ${ }^{497,500-503}$

Among patients with severe aortic stenosis and left ventricular dysfunction, those with low-flow/low-gradient aortic stenosis (defined as a valve area of $<1 \mathrm{~cm}^{2}$, LVEF 


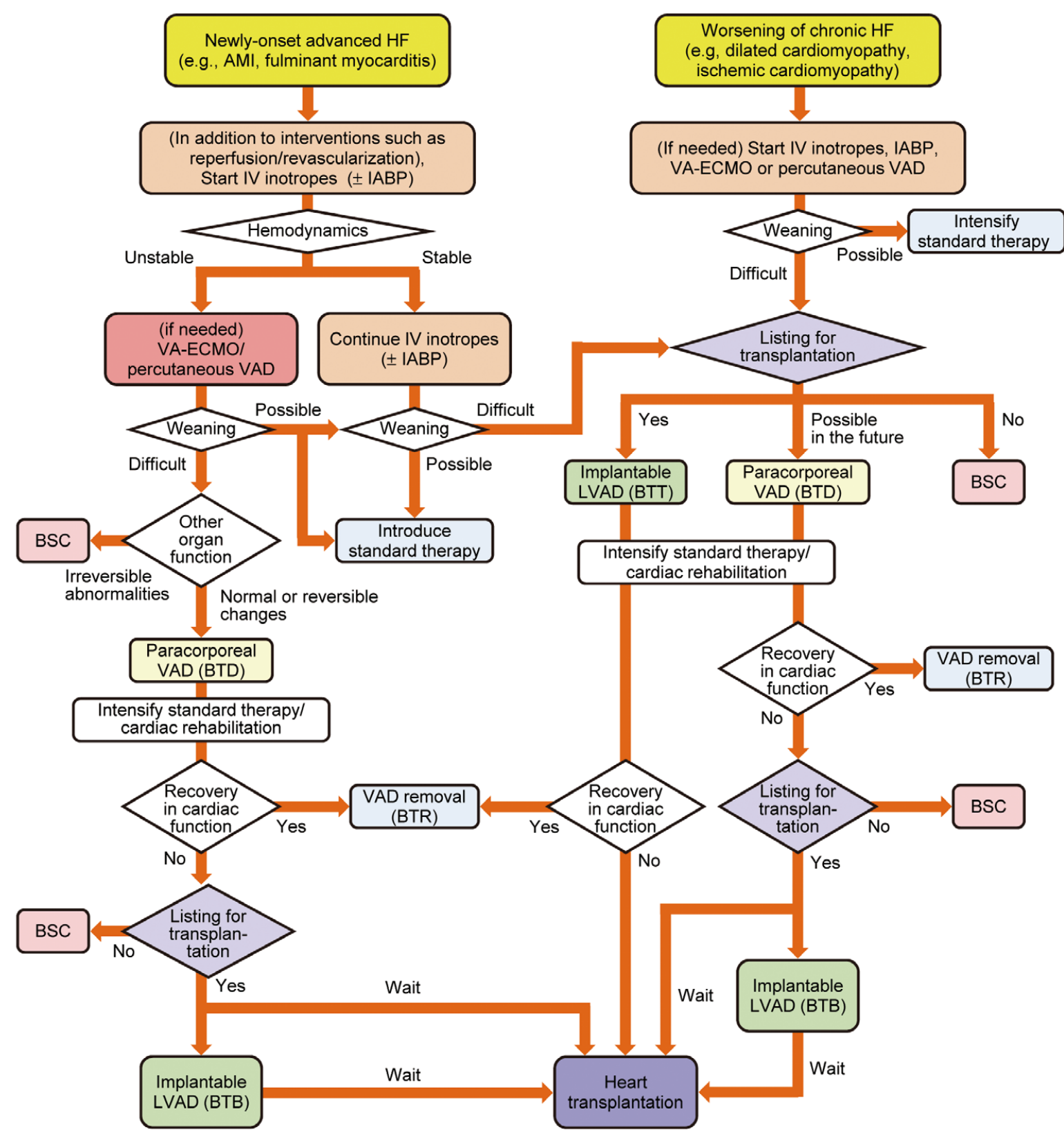

Note: This algorism describes therapeutic strategies for patients with advanced heart failure due to systolic dysfunction. Refer to the text for the contents of standard therapy.

Figure 13. Algorithm of VAD therapy for patients with advanced heart failure. AMI, acute myocardial infarction; BSC, best supportive care; BTB, bridge to bridge; BTD, bridge to decision; BTR, bridge to recover; BTT, bridge to transplant; HF, heart failure; IABP, intra-aortic balloon pump; IV, intravenous; LVAD, left ventricular assist device; VA-ECMO, veno-arterial extracorporeal membrane oxygenation; VAD, ventricular assist device.

$<40 \%$, and a mean aortic transvalvular gradient of $<40 \mathrm{mmHg}$ ) are known to be associated with worse outcomes, and dobutamine stress echocardiography is useful in identifying such patients..$^{\mathbf{5 0 4 5 0 5}}$ When the cause of left ventricular dysfunction cannot be determined to be excessive afterload, TAVI may not substantially improve left ventricular function or clinical symptoms, but does improve life expectancy.506 In patients with low cardiac function, some studies have reported favorable early postoperative results, ${ }^{\mathbf{5 0 7 , 5 0 8}}$ while other studies have pointed out that low cardiac function predicts poor prognosis after TAVI. ${ }^{\mathbf{5 0 9 , 5 1 0}}$ No consensus has been achieved regarding the efficacy of TAVI in patients with cardiac dysfunction. Careful consideration should be given to determine whether TAVI should be conducted or not in patients with cardiac dysfunction. 


\begin{tabular}{|l|l|l|}
\hline \multicolumn{2}{|c|}{ Table 67. Various Strategies for VAD Therapy } \\
\hline Abbreviation & \multicolumn{1}{|c|}{ Strategy } & \multicolumn{1}{c|}{ Definition } \\
\hline BTD & $\begin{array}{l}\text { Bridge to } \\
\text { decision }\end{array}$ & $\begin{array}{l}\text { Temporal use of VADs for the } \\
\text { treatment of acute-onset cardiogenic } \\
\text { shock before deciding the next } \\
\text { treatment options }\end{array}$ \\
\hline BTR & $\begin{array}{l}\text { Bridge to } \\
\text { recovery }\end{array}$ & $\begin{array}{l}\text { Use of VADs to support circulation } \\
\text { and thereby promote the recovery } \\
\text { of cardiac function aiming for } \\
\text { removal of VADs }\end{array}$ \\
\hline BTB & $\begin{array}{l}\text { Bridge to } \\
\text { bridge }\end{array}$ & $\begin{array}{l}\text { Conversion from a paracorporeal } \\
\text { LVAD to an implantable LVAD }\end{array}$ \\
\hline BTC & $\begin{array}{l}\text { Bridge to } \\
\text { candidacy }\end{array}$ & $\begin{array}{l}\text { LVAD therapy to reverse organ } \\
\text { dysfunction to obtain the eligibility } \\
\text { for heart transplantation }\end{array}$ \\
\hline BTT & $\begin{array}{l}\text { Bridge to } \\
\text { transplant }\end{array}$ & $\begin{array}{l}\text { LVAD therapy as a bridge to } \\
\text { transplant in patients who have } \\
\text { been listed for heart transplantation } \\
\text { but cannot maintain hemodynamics } \\
\text { with medical treatment }\end{array}$ \\
\hline DT & $\begin{array}{l}\text { Destination } \\
\text { therapy }\end{array}$ & $\begin{array}{l}\text { Permanent LVAD therapy as an } \\
\text { alternative to heart transplantation } \\
\text { in patients who are ineligible for } \\
\text { transplantation }\end{array}$ \\
\hline
\end{tabular}

LVAD, left ventricular assist device; VAD, ventricular assist device.

\section{Mechanical Circulatory Support}

\subsection{Classification of Advanced Heart Failure}

Advanced heart failure is classified by the Interagency Registry for Mechanically Assisted Circulatory Support (INTERMACS) profiles ${ }^{511}$ or the Japanese registry for Mechanically Assisted Circulatory Support (J-MACS) profiles $^{\mathbf{5 1 2}}$ (Table 66). In the INTERMACS profile, modifier A (arrhythmia) is defined as recurrent appropriate ICD shocks due to life-threatening ventricular arrhythmias.

\subsection{Percutaneous Circulatory Support for Patients With Acute Heart Failure}

\subsubsection{Intra-Aortic Balloon Pump (IABP)}

IABP has been traditionally indicated for patients with acute myocardial infarction/complex coronary lesions who need hemodynamic support during reperfusion/revascularization or until surgical repair of mechanical complications, although its routine use is not recommended. IABP also has become indicated for patients with advanced heart failure who are categorized as INTERMACS profile 1 or 2. IABP is contraindicated for patients with moderate or severe aortic regurgitation or patients with aortic dissection.

\section{2.2.2 Peripheral Veno-Arterial Extracorporeal Membrane Oxygenation (VA-ECMO)}

The use of peripheral VA-ECMO (also called percutaneous cardiopulmonary support [PCPS] in Japan) is considered for patients with INTERMACS profile 1 or 2 often in combination with IABP. VA-ECMO is used as a temporal flow support system aiming for hemodynamic stabilization or bailing out of multiple organ failure, which sometimes works as a bridging device towards listing for heart transplant or converting to durable ventricular assist devices (VADs). Since it does not unload left ventricle in itself, an improvement in pulmonary congestion may not be expected.

\begin{tabular}{|c|c|c|}
\hline \multicolumn{3}{|c|}{$\begin{array}{l}\text { Table 68. Criteria for Implantable LVAD Under the Bridge-to- } \\
\text { Transplant Policy }\end{array}$} \\
\hline \multirow{5}{*}{$\begin{array}{l}\text { Selection } \\
\text { criteria }\end{array}$} & Patient status & $\begin{array}{l}\text { Patient has advanced heart failure } \\
\text { with progressive symptoms } \\
\text { (generally NYHA class IV) despite } \\
\text { standard therapy recommended in } \\
\text { the relevant guidelines (stage D), } \\
\text { who is listed or being listed for } \\
\text { heart transplantation }\end{array}$ \\
\hline & Age & $<65$ years \\
\hline & $\begin{array}{l}\text { Body surface } \\
\text { area }\end{array}$ & $\begin{array}{l}\text { Refer to the criterion specified for } \\
\text { each device }\end{array}$ \\
\hline & Severity & $\begin{array}{l}\text { Patient depending on intravenous } \\
\text { inotropes (INTERMACS profile } 2 \\
\text { or 3), IABP or paracorporeal } \\
\text { LVAD, or with modifier A } \\
\text { (especially for patients with } \\
\text { INTERMACS profile 4) }\end{array}$ \\
\hline & $\begin{array}{l}\text { Social } \\
\text { indications }\end{array}$ & $\begin{array}{l}\text { Patient and his/her caregivers } \\
\text { understand the characteristics of } \\
\text { VAD therapy in Japan as a long- } \\
\text { term home-based treatment, and } \\
\text { the patient is highly expected to } \\
\text { return to society }\end{array}$ \\
\hline \multirow{6}{*}{$\begin{array}{l}\text { Exclusion } \\
\text { criteria }\end{array}$} & $\begin{array}{l}\text { Systemic } \\
\text { diseases }\end{array}$ & $\begin{array}{l}\text { Patient has malignancy, collagen } \\
\text { disease or other refractory } \\
\text { systemic diseases that have poor } \\
\text { prognosis }\end{array}$ \\
\hline & $\begin{array}{l}\text { Respiratory } \\
\text { diseases }\end{array}$ & $\begin{array}{l}\text { Severe respiratory failure, } \\
\text { irreversible pulmonary hypertension }\end{array}$ \\
\hline & $\begin{array}{l}\text { End-organ } \\
\text { dysfunction }\end{array}$ & $\begin{array}{l}\text { Irreversible hepatic or renal } \\
\text { dysfunction, insulin-dependent } \\
\text { diabetes mellitus }\end{array}$ \\
\hline & $\begin{array}{l}\text { Cardiovascular } \\
\text { disorders }\end{array}$ & $\begin{array}{l}\text { Difficult-to-treat aortic aneurysm, } \\
\text { untreatable moderate or severe } \\
\text { aortic valve insufficiency, } \\
\text { mechanical aortic valve that } \\
\text { cannot be replaced by a } \\
\text { bioprosthetic valve, severe } \\
\text { peripheral vascular disease }\end{array}$ \\
\hline & Pregnancy & $\begin{array}{l}\text { Women being pregnant or planning } \\
\text { to become pregnant }\end{array}$ \\
\hline & Others & Severe obesity \\
\hline
\end{tabular}

IABP, intra-aortic balloon pump; LVAD, left ventricular assist device; NYHA, New York Heart Association.

\section{2.2.3 Percutaneous VAD}

In Japan, catheter-based transaortic microaxial pumps (Impella ${ }^{\circledR} 2.5$ and 5.0) have been approved as percutaneous VADs for the treatment of cardiogenic shock. These devices are expected to improve pulmonary congestion through unloading left ventricle.

\subsection{Mechanical Circulatory Support Requiring Thoracotomy}

\section{2.3.1 Centrifugal Pumps for Extracorporeal Circulation}

VA-ECMO with central cannulation using centrifugal pumps for extracorporeal circulation can be used for patients who do not respond well to peripheral VA-ECMO and require stronger circulatory support, or who cannot continue peripheral VA-ECMO due to complications such as bleeding from the access site.

The reimbursement of these pumps as VADs is not covered by the Japanese National Health Insurance, and these pumps are often switched to durable VADs approved 


Table 69. Recommendations and Levels of Evidence on the Use of Implantable Left Ventricular Assist
Devices (LVADs)

HFrEF, heart failure with reduced ejection fraction; LVAD, left ventricular assist device; QOL, quality of life.

Table 70. Indications for Heart Transplantation

\section{Indications}

Heart transplantation is indicated for patients with the following severe heart diseases in whom conventional treatment is not expected to save or prolong life:

1) Dilated cardiomyopathy, and dilated phase hypertrophic cardiomyopathy

2) Ischemic myocardial disease

3) Others (Conditions approved by the Heart Transplantation Indication Review Committee of the Japanese Circulation Society and the Japanese Society of Pediatric Cardiology and Cardiac Surgery)

\section{Eligibility Criteria}

1) Patients with an intractable end-stage heart disease that meet at least one of the following conditions:

a) Heart failure requiring long-term or repeated hospitalization

b) Patients with heart failure that remains in NYHA Class III or IV despite conventional treatment including $\beta$-blockers and ACE inhibitors

c) Patients with life-threatening severe arrythmias not responding to any currently available treatments

2) It is desirable that patients be $<65$ years of age

3) Patients and their family members should fully understand heart transplantation and can cooperate to the treatment

\section{Exclusion criteria}

A) Absolute exclusion criteria

1) Irreversible renal or hepatic dysfunction

2) Active infection (including cytomegalovirus infection)

3) Pulmonary hypertension (with pulmonary vascular resistance of $\geq 6$ Wood units despite treatment with vasodilators)

4) Drug and substance abuse (including alcoholic myocardial disease)

5) Malignant tumor

6) Human immunodeficiency virus (HIV) antibody positive

B) Relative exclusion criteria

1) Renal or hepatic dysfunction

2) Active peptic ulcer

3) Insulin-dependent diabetes mellitus

4) Mental disorders/neurosis (may be listed as exclusion criterion if no improvement is seen despite efforts to eliminate anxiety about the patient's own disease or condition)

5) History of pulmonary infarction, pulmonary vascular obstructive disease

6) Collagen disorder or other systemic diseases

\section{Determination of eligibility for heart transplantation}

- For the time being, the institutional review committee and the Heart Transplantation Indication Review Subcommittee of the Japanese Circulation Society will review patients in two stages to determine who are indicated for heart transplantation. After the selection of patients indicated for heart transplantation, the patients and family members provide informed consent and are included in the waiting list. Transplantation is conducted for patients on the list.

- The indications and the eligibility criteria listed above will be revised according to the advancement of medical/surgical treatment.

- Other organ disorders should be considered carefully to determine medical urgency.

$\mathrm{ACE}$, angiotensin converting enzyme; IABP, intra-aortic balloon pump; LVAD, left ventricular assist device; NYHA, New York Heart Association. (Excerpted from the Heart Transplantation Committee of the Japanese Circulation Society. 2013522) in patients who require longer circulatory support (see below).

\section{2.3.2 Types and Features of VADs}

Among VADs currently available in Japan, paracorporeal VADs are pulsatile pumps, while implantable VADs are non-pulsatile (continuous flow) pumps. As these devices support the left ventricle in most cases, they are called left ventricular assist devices (LVADs). Paracorporeal VADs that support the right ventricle are called right ventricular assist devices (RVADs). Implantable RVADs are not approved in Japan.

In Japan, paracorporeal VADs are available only for in-hospital setting. The use of paracorporeal VADs may increase the risk of serious complications such as cerebrovascular disorder and infections, and pump exchanges due to pump thrombosis or device malfunctions are common. Although implantable LVADs are superior to paracorporeal ones in terms of QOL improvement and the risk of complications, the implantable LVADs are reimbursed only in patients listed (or being listed) for heart transplantation.

\subsubsection{Therapeutic Strategies With VADs}

As indicated in the algorithms (Figure 13) and strategies (Table 67) in the VAD therapy, indications should be carefully evaluated to achieve the goal of an individual patient. ${ }^{513}$

\section{2.3.4 Indications and Outcomes of Paracorporeal VADs}

Paracorporeal VADs are used as "bridge to decision" (BTD) in patients with INTERMACS profile 1 who cannot maintain hemodynamics even under mechanical circulatory support such as peripheral VA-ECMO, and as "bridge to candidacy" (BTC) in patients with INTERMACS profile 2 who are not immediate candidates for heart transplantation. Studies have reported that one-year survival rate in patients who received paracorporeal VADs implantation at high volume centers in Japan ranged between about 50 to $80 \% .514516$

\subsubsection{Indications and Outcomes of Implantable LVADs}

Table 68 outlines the indication/exclusion criteria for implantable LVADs in Japan. ${ }^{517}$ According to the J-MACS registry, one-year and two-year survival rates of patients with implantable LVADs were $93.6 \%$ and $89.8 \%$, respectively, which were higher than the corresponding rates in patients with paracorporeal LVADs. ${ }^{518}$ Complications requiring re-hospitalizations reported in patients with implantable LVADs include cerebrovascular disorder, device thrombosis, and drive-line infection. ${ }^{519}$ Several complications such as gastrointestinal arteriovenous malformation, gastrointestinal bleeding, late-onset rightsided heart failure, and aortic regurgitation are rare among 


\begin{tabular}{|l|c|c||c|c|}
\hline Table 71. Recommendations and Levels of Evidence for Heart Transplantation \\
\hline & $\begin{array}{c}\text { Class of } \\
\text { Recommendation }\end{array}$ & $\begin{array}{c}\text { Level of } \\
\text { Evidence }\end{array}$ & $\begin{array}{c}\text { Grade of } \\
\text { Recommendation } \\
\text { (MINDS) }\end{array}$ & $\begin{array}{c}\text { Level of } \\
\text { Evidence } \\
\text { (MINDS) }\end{array}$ \\
\hline $\begin{array}{l}\text { Heart transplantation for patients with severe HFrEF } \\
\text { resistant to appropriate drug therapies and device } \\
\text { treatments }\end{array}$ & Ila & $\mathrm{C}$ & $\mathrm{B}$ & IVa \\
\hline
\end{tabular}

$\mathrm{HFrEF}$, heart failure with reduced ejection fraction.

patients using pulsatile LVADs but have been known to be more common in patients using continuous-flow LVADs.

\subsubsection{Recommendations for and Evidence of LVADs (Table 69)}

No controlled clinical studies of paracorporeal LVADs have been conducted. The use of implantable LVADs for bridge to transplant (BTT) is recommended, although their benefits have not been proven in randomized clinical trials. For the purpose of destination therapy (DT), the Randomized Evaluation of Mechanical Assistance for the Treatment of Congestive Heart Failure (REMATCH) trial, a randomized controlled trial of a pulsatile implantable LVAD vs. medical therapy has concluded that the device has a survival benefit. ${ }^{520}$ Combined with the result of another randomized clinical trial that reported the superiority of continuous-flow device over the pulsatile device, ${ }^{521}$ continuous-flow implantable LVADs are most effective to improve prognosis and is widely recommended.

\section{Heart Transplantation}

Heart transplantation is performed for patients with underlying cardiovascular disease such as dilated cardiomyopathy or dilated-phase hypertrophic cardiomyopathy, ischemic myocardial disease, and congenital heart disease. Criteria for indication of heart transplantation include lack of effective treatment other than heart transplantation; understanding of heart transplantation by patients and family; and ability to continue lifelong treatment such as immunosuppressive therapy and examinations such as myocardial biopsy (Table 70). ${ }^{522}$ Additional conditions for application are patients with heart failure who require long-term or frequent hospitalizations and remain in NYHA Class III or IV despite conventional drug therapy including $\beta$-blockers and ACE inhibitors, and those with potentially fatal severe arrhythmia that does not respond to conventional treatment. Both types of patients are preferably under 65 years of age. Absolute exclusion criteria include severe irreversible organ failure, active infection, severe pulmonary hypertension, drug and substance abuse, including tobacco and alcohol, malignant tumor and positive results of human immunodeficiency virus (HIV) antibody test. Patients with irreversible pulmonary hypertension with pulmonary vessel resistance of $>6$ Wood units despite available treatments are not indicated for heart transplantation, and should be considered for heart-lung transplantation. When heart failure progresses during the waiting period, VAD implantation should be considered before other organ dysfunctions occur. By June 2016, a total of 284 patients underwent heart transplantation, ${ }^{523}$ and the survival rates at 5 and 10 years after the transplantation were $92.7 \%$ and $89.6 \%$, respectively, which are among the highest in the world. According to an annual report of the heart and lung registries by the International Society for Heart and Lung Transplantation, ${ }^{\mathbf{5 2 4}}$ heart transplantation is proved to be the most favorable for treatment of advanced heart failure compared to other treatment modalities. Table 71 summarizes recommendations and levels of evidence for heart transplantation in patients with heart failure.

\section{Disease Management}

\section{Disease Management Programs (e.g., Educational Programs) and Team Medical Care}

\subsection{Disease Management Programs by Multidisciplinary Teams}

Table 72 summarizes features and components of disease management for patients with heart failure. It is desirable that disease management for each patient should be operated by a multidisciplinary team of diverse healthcare professionals, including physicians, nurses, pharmacists and dieticians, and the team should contain two or more members who have expertise in the treatment, management and care of heart failure. In order to operate the disease management team efficiently, comprehensive cardiac rehabilitation programs should be utilized proactively. Disease management for patients with heart failure include guideline-based standard drug therapy, nonpharmacologic therapy and exercise therapy, patient education and counseling emphasizing the importance of treatment adherence and selfcare, symptom monitoring, preparation for and support of hospital discharge, appropriate use of social resources, follow-up examinations of patients, periodic assessment of physical, mental, and social functions, and mental support.

\subsection{Contents of Disease Management Programs for Patients With Heart Failure (Tables 73 and 74) \\ I1.2.1 Patient Education Emphasizing the Importance of Adherence and Self-Care}

Appropriate self-care behaviors play an important role in preventing worsening heart failure, and patient education to prove their self-care capabilities is expected to improve prognosis and QOL. ${ }^{525-527}$ Healthcare professionals should 


\begin{tabular}{|c|c|}
\hline $\begin{array}{l}\text { ble 72. } \mathrm{Fe} \\
\mathrm{Pr}\end{array}$ & $\begin{array}{l}\text { s and Components of Disease Management } \\
\text { ns for Patients With Heart Failure }\end{array}$ \\
\hline Features & $\begin{array}{l}\text { - Multidisciplinary team approaches by cardiolo- } \\
\text { gists, cardiovascular surgeons, nurses, } \\
\text { pharmacists, physical therapists, nutritionists, } \\
\text { social workers, and psychologists, etc. } \\
\text { - Patient education, consultation and support } \\
\text { by specially trained healthcare professionals } \\
\text { - Implementation of comprehensive cardiac } \\
\text { rehabilitation programs }\end{array}$ \\
\hline Components & $\begin{array}{l}\text { - Drug and nonpharmacologic therapy } \\
\text { - Exercise therapy } \\
\text { - Patient education focused on adherence and } \\
\text { self-care } \\
\text { - Symptoms monitoring by patients, family } \\
\text { members, caregivers, or healthcare } \\
\text { professionals } \\
\text { - Discharge planning and support and utilization } \\
\text { of social resources } \\
\text { - Post-discharge follow-up } \\
\text { - Continuous assessment of patients' physical, } \\
\text { mental and social functions (e.g., body weight, } \\
\text { nutritional status, laboratory findings, ADL, } \\
\text { mental status, and QOL changes) } \\
\text { - Provide mental support to patients, family } \\
\text { members, and caregivers }\end{array}$ \\
\hline
\end{tabular}

$A D L$, activities of daily living; $Q O L$, quality of life.

evaluate appropriateness of patients' self-care, and educate and consult patients and their family members to improve the quality of self-care behaviors. ${ }^{528,529}$ In patient education, healthcare professionals should consider their health literacy, the ability to access, understand, and utilize appropriate information on the disease, ${ }^{\mathbf{5 3 0}}$ and should provide materials suitable for individual patients according to the level of health literacy. ${ }^{\mathbf{5 3 1}}$ For patients with limited self-care capabilities such as elderly, people living alone, and patients also suffering from cognitive disorder, healthcare professionals should educate and support their family members, and utilize social resources such as sending home visiting physicians, nurses or caregivers in a more proactive way.

\section{Comprehensive Cardiac Rehabilitation}

\subsection{Significance of Ambulatory Cardiac Rehabilitation in Disease Management Programs}

The most common reasons for rehospitalization in patients with heart failure are 1) worsening congestion (fluid retention), 2) non-cardiac comorbidities, 3) poor adherence. ${ }^{532}$ It has also been pointed out that sarcopenia and frailty predict the long-term prognosis of elderly patients with heart failure. ${ }^{14}$ Accordingly, out-patient and home-based interventions are essential for elderly patients with heart failure and noncardiac comorbidities with a high risk of rehospitalization to improve QOL and exercise capacity and prevent rehospitalization and conditions requiring nursing care. These interventions should include systemic disease management covering both heat failure and noncardiac comorbidities and exercise interventions to prevent sarcopenia and frailty. ${ }^{\mathbf{5 3 3}}$

Although many studies have reported the efficacy of multidisciplinary intervention/disease management programs in patients with heart failure, ${ }^{\mathbf{5 3 4}}$ and a systematic review $^{\mathbf{5 3 5}}$ has concluded that multidisciplinary interventions significantly reduce rehospitalization rates and all-cause mortality in patients with heart failure, there are many unsolved issues, such that the program contents have not been standardized. ${ }^{\text {536-539 }}$ In contrast, comprehensive ambulatory cardiac rehabilitation programs, which include lifestyle interventions to prevent recurrent heart failure and clinical monitoring of heart failure, are expected to serve as disease management programs for heart failure, and their benefits have been demonstrated..$^{\mathbf{5 4 0 , 5 4 1}}$

\subsection{Practical Examples of Ambulatory Cardiac Rehabilitation as a Disease Management Program (Table 75)}

Figure 14 outlines a typical flowchart of exercise therapy and heart failure monitoring in an ambulatory cardiac rehabilitation program. ${ }^{\mathbf{5 4 2}}$ Every time when a patient visits the clinic for a rehabilitation session, he/she is checked for physical condition before, during and after the session, and periodically for improvement in exercise capacity (Table 76). When findings suggestive of worsening heart failure are observed, the patient is referred to his or her physician, who may modify the exercise prescription, limit water intake or increase the dose of diuretics, among other measures, to prevent worsening heart failure. ${ }^{\mathbf{5 4 3}}$ Comprehensive ambulatory cardiac rehabilitation sessions as a disease management program for patients with heart failure is superior to medical consultations at clinic in terms of identifying early signs of worsening heart failure through symptoms, signs and ECG changes during exercise.

\section{Palliative Care}

The World Health Organization (WHO) describes palliative care as services that must be considered for all patients with life-threatening conditions such as cardiovascular diseases and respiratory diseases. Many patients with heart failure are suffering from total pain and healthcare professionals should support patients with heart failure and their family members from early stages of the disease in a multidisciplinary setting to improve their QOL. In 2014, WHO has reported that nearly $40 \%$ of adults who need palliative care has cardiovascular diseases..$^{\mathbf{5 4 4}}$

\section{Advance Care Planning and Decision-Making Support}

Although the number of elderly patients with heart failure, are increasing year by year, their recognition about prognosis is substantially more optimistic than the real situation. ${ }^{545}$ Also, it is often difficult to introduce palliative care in a timely manner. Advance care planning (ACP) is an important step to help individual patients prepare for future changes in their disease condition. ACP is a process 
Table 73. Contents of Treatment/Lifestyle Education and Support for Patients With Heart Failure, Family Members, and Caregivers

\begin{tabular}{|c|c|}
\hline $\begin{array}{l}\text { Contents of } \\
\text { education }\end{array}$ & $\begin{array}{l}\text { Specific education/support } \\
\text { methods }\end{array}$ \\
\hline \multicolumn{2}{|l|}{ Knowledge on heart failure } \\
\hline $\begin{array}{l}\text { - Definition, causes, symptoms, } \\
\text { and clinical course } \\
\text { - Severity assessment } \\
\text { (laboratory findings) } \\
\text { - Factors of worsening heart } \\
\text { failure } \\
\text { - Comorbidities } \\
\text { - Drug and nonpharmacologic } \\
\text { therapy }\end{array}$ & $\begin{array}{l}\text { - Provide information using } \\
\text { appropriate materials } \\
\text { suitable for individual } \\
\text { patient's comprehension and } \\
\text { health literacy }\end{array}$ \\
\hline \multicolumn{2}{|l|}{ Self-monitoring } \\
\hline $\begin{array}{l}\text { - Necessity and importance of } \\
\text { symptom monitoring by } \\
\text { patients themselves } \\
\text { - Self-monitoring skills } \\
\text { - Utilizing patient diaries }\end{array}$ & $\begin{array}{l}\text { - Encourage patients to } \\
\text { recording in their diaries and } \\
\text { utilize recorded information } \\
\text { for better practice and } \\
\text { patient education }\end{array}$ \\
\hline \multicolumn{2}{|c|}{ Management of disease worsening } \\
\hline $\begin{array}{l}\text { - Symptoms of worsening } \\
\text { heart failure and assess- } \\
\text { ment } \\
\text { - How to contact healthcare } \\
\text { professionals when disease } \\
\text { worsens }\end{array}$ & $\begin{array}{l}\text { - Instruct patients to visit clinic } \\
\text { when symptoms of worsening } \\
\text { heart failure (e.g., dyspnea, } \\
\text { swelling, body weight gain } \\
\text { by }>2 \mathrm{~kg} \text { in } 3 \text { days) develop, } \\
\text { and explain how to contact } \\
\text { the clinic }\end{array}$ \\
\hline \multicolumn{2}{|l|}{ Adherence to treatment } \\
\hline $\begin{array}{l}\text { - Name of drugs, expected } \\
\text { effects, how to take drugs, } \\
\text { adverse drug reactions } \\
\text { - Importance of taking drugs } \\
\text { as directed } \\
\text { Purpose of device therapy, } \\
\text { and how to handle devices } \\
\text { during daily life }\end{array}$ & $\begin{array}{l}\text { - Provide information using } \\
\text { appropriate materials } \\
\text { suitable for individual } \\
\text { patient's comprehension and } \\
\text { health literacy } \\
\text { - Evaluate adherence to } \\
\text { treatment periodically } \\
\text { - Patients with poor adherence } \\
\text { should be educated and } \\
\text { supported by healthcare } \\
\text { professionals }\end{array}$ \\
\hline \multicolumn{2}{|l|}{ Infection control and vaccination } \\
\hline $\begin{array}{l}\text { - Infections as factors } \\
\text { worsening heart failure } \\
\text { - Necessity of vaccinations } \\
\text { against influenza and } \\
\text { pneumonia }\end{array}$ & $\begin{array}{l}\text { - Provide knowledge on how } \\
\text { to prevent infections during } \\
\text { daily life } \\
\text { - Provide information on the } \\
\text { timing of vaccinations }\end{array}$ \\
\hline \multicolumn{2}{|l|}{ Salt and water management } \\
\hline $\begin{array}{l}\text { - Risk of excessive water } \\
\text { intake } \\
\text { - Limit water intake in patients } \\
\text { with severe heart failure } \\
\text { - Appropriate salt intake } \\
\text { (<6g/day) } \\
\text { - Importance of maintaining } \\
\text { an appropriate body weight }\end{array}$ & $\begin{array}{l}\text { - Explain how to measure } \\
\text { water intake in detail } \\
\text { - Explain how to reduce salt } \\
\text { intake efficacy using educa- } \\
\text { tional materials } \\
\text { - Observe patients for } \\
\text { symptoms of decreased } \\
\text { appetite due to salt restriction }\end{array}$ \\
\hline \multicolumn{2}{|l|}{ Nutritional management } \\
\hline $\begin{array}{l}\text { - Importance of well-balanced } \\
\text { diet } \\
\text { - Menus considering the } \\
\text { nature of complications }\end{array}$ & $\begin{array}{l}\text { - Observe patients periodically } \\
\text { for nutritional status } \\
\text { - Provide nutritional guidance } \\
\text { based on the individual } \\
\text { patient's physical status (e.g. } \\
\text { swallowing function) and life } \\
\text { style } \\
\text { - Explain that reduced meal } \\
\text { size and appetite may be } \\
\text { signs of worsening heart } \\
\text { failure }\end{array}$ \\
\hline
\end{tabular}

(Table $\mathbf{7 3}$ continued the next column.)

\begin{tabular}{|c|c|}
\hline $\begin{array}{l}\text { Contents of } \\
\text { education }\end{array}$ & $\begin{array}{l}\text { Specific education/support } \\
\text { methods }\end{array}$ \\
\hline \multicolumn{2}{|l|}{ Alcohol } \\
\hline $\begin{array}{l}\text { - Risk of excessive alcohol } \\
\text { consumption }\end{array}$ & $\begin{array}{l}\text { - Suggest appropriate alcohol } \\
\text { consumption based on the } \\
\text { individual patient's causes of } \\
\text { heart failure }\end{array}$ \\
\hline \multicolumn{2}{|l|}{ Smoking cessation } \\
\hline - Importance of quit smoking & $\begin{array}{l}\text { - See the "Guidelines for } \\
\text { Smoking Cessation (JCS } \\
\text { 2010)" }\end{array}$ \\
\hline \multicolumn{2}{|l|}{ Physical activity } \\
\hline $\begin{array}{l}\text { - Importance of appropriate } \\
\text { physical activity during } \\
\text { stable conditions } \\
\text { - Importance of bed rest and } \\
\text { activity restrictions during } \\
\text { worsening heart failure } \\
\text { - Negative effects of excessive } \\
\text { bed rest (e.g. decreased } \\
\text { exercise capacity) }\end{array}$ & $\begin{array}{l}\text { - Evaluate exercise capacity } \\
\text { and skeletal muscles } \\
\text { - Evaluate activities of daily } \\
\text { living regularly } \\
\text { - Considering the individual } \\
\text { patient's physical function } \\
\text { and living environment, } \\
\text { assess the risk of fall and } \\
\text { provide detailed guidance on } \\
\text { physical activities during } \\
\text { daily life }\end{array}$ \\
\hline \multicolumn{2}{|l|}{ Bath } \\
\hline $\begin{array}{l}\text { - How to take a bath } \\
\text { appropriately }\end{array}$ & $\begin{array}{l}\text { - Instruct appropriate methods } \\
\text { according to the severity of } \\
\text { heart failure and living } \\
\text { environment }\end{array}$ \\
\hline \multicolumn{2}{|l|}{ Travel } \\
\hline $\begin{array}{l}\text { - Precautions during travel } \\
\text { (drug therapy, water intake, } \\
\text { meals, and physical activity) } \\
\text { - Risk of worsening heart } \\
\text { failure during travel } \\
\text { - How to manage worsening } \\
\text { heart failure during travel }\end{array}$ & $\begin{array}{l}\text { - Explain possible effects of } \\
\text { changes in contents and } \\
\text { timing of meals, weather and } \\
\text { climates, and physical } \\
\text { activities, etc. during travel } \\
\text { on the condition of heart } \\
\text { failure } \\
\text { - Provide information on pre- } \\
\text { travel preparation }\end{array}$ \\
\hline \multicolumn{2}{|l|}{ Sex life } \\
\hline $\begin{array}{l}\text { - Effects on sexual activity on } \\
\text { heart failure } \\
\text { - Relationship between heart } \\
\text { failure mediations and sexual } \\
\text { function } \\
\text { - Precautions for using erectile } \\
\text { dysfunction medications }\end{array}$ & $\begin{array}{l}\text { - Explain that sexual activity } \\
\text { may worsen heart failure } \\
\text { - Refer to specialist physi- } \\
\text { cians whenever necessary }\end{array}$ \\
\hline \multicolumn{2}{|l|}{ Mental support } \\
\hline $\begin{array}{l}\text { - Heart failure and mental/ } \\
\text { psychological changes } \\
\text { - Stress management during } \\
\text { daily life }\end{array}$ & $\begin{array}{l}\text { - Evaluate psychiatric } \\
\text { symptoms periodically } \\
\text { - Explain the importance and } \\
\text { methods of stress } \\
\text { management during daily life } \\
\text { - When worsening psychiatric } \\
\text { symptoms are suspected, } \\
\text { consult the patient to } \\
\text { psychiatrists, psychosomatic } \\
\text { medicine specialists, and } \\
\text { clinical psychotherapists }\end{array}$ \\
\hline \multicolumn{2}{|l|}{ Periodic hospital visits } \\
\hline $\begin{array}{l}\text { - Importance of periodical clinic } \\
\text { visits }\end{array}$ & $\begin{array}{l}\text { - Before discharge, confirm } \\
\text { appoints for out-patient clinic } \\
\text { visits after discharge } \\
\text { - Instruct patients to contact } \\
\text { medical institutions promptly } \\
\text { when symptoms worsen } \\
\text { regardless of visit schedule } \\
\text { - Ensure easy access to } \\
\text { healthcare professionals } \\
\text { (e.g., Telephone consultation, } \\
\text { and utilization of social } \\
\text { resources) }\end{array}$ \\
\hline
\end{tabular}




\begin{tabular}{|c|c|c|c|c|}
\hline & $\begin{array}{c}\text { Class of } \\
\text { Recommendation }\end{array}$ & $\begin{array}{l}\text { Level of } \\
\text { Evidence }\end{array}$ & $\begin{array}{l}\text { Grade of } \\
\text { Recommendation } \\
\text { (MINDS) }\end{array}$ & $\begin{array}{l}\text { Level of } \\
\text { Evidence } \\
\text { (MINDS) }\end{array}$ \\
\hline $\begin{array}{l}\text { Multidisciplinary team-based education and support to } \\
\text { improve treatment adherence and self-care for } \\
\text { patients, family members, and caregivers }\end{array}$ & 1 & A & A & I \\
\hline Discharge support and continuous follow-up & 1 & A & B & 1 \\
\hline Smoking cessation & 1 & C & B & $\mathrm{IVb}$ \\
\hline Symptom monitoring & 1 & C & $\mathrm{C} 1$ & VI \\
\hline $\begin{array}{l}\text { Monitoring and specialists' treatment for psychiatric } \\
\text { symptoms }\end{array}$ & 1 & B & B & II \\
\hline $\begin{array}{l}\text { Educational support for patients at a high risk of } \\
\text { worsening heart failure and use of social resources for } \\
\text { people living alone, elderly patients, and people who } \\
\text { also have dementia }\end{array}$ & I & A & A & I \\
\hline Low-salt diet (ca. $6 \mathrm{~g} /$ day) & Ila & C & $\mathrm{C} 1$ & VI \\
\hline Restriction of alcohol & Ila & C & $\mathrm{C} 1$ & VI \\
\hline Vaccinations to prevent infections & Ila & C & B & $\mathrm{IVb}$ \\
\hline
\end{tabular}

\begin{tabular}{|l|c|c||c|c|}
\hline \multicolumn{1}{|c|}{ Table 75. Recommendations and Levels of Evidence for Comprehensive Ambulatory Cardiac Rehabilitation } \\
for Patients with Heart Failure
\end{tabular}

HFrEF, heart failure with reduced ejection fraction; QOL, quality of life.

to share decisions what the patient and his or her family members decided about what treatment they want and what way of life they want to lead in advance, before the patient becomes difficult to make his or her own decisions. It has been recommended that ACP should be conducted at an annual heart failure review and at the end of hospitalization during which clinical milestones that trigger review of treatment strategies occurred (Table 77). ${ }^{546}$ The aim of ACP is to avoid unwanted, invasive treatments near death and improve the quality of death. A randomized controlled in ACP in non-cancer patients has reported its benefits..$^{547}$

ACP may include completion of an advance directive, a document that describes the patient's preferences about end-of-life care. Specifically, the patient may make shared decision making, with support from a multidisciplinary team, about Do Not Attempt Resuscitation (DNAR) orders and policies on whether or not to discontinue device therapy such as implantable cardioverter defibrillators (ICDs), cardiac resynchronization therapy (CRT), and left ventricular assist device (LVADs), and prepare an advance directive. At this time, the patient should be informed that he or she can change the contents of the advance directive at any time. When necessary, the patient may designate another person to make health care decisions for him or her when the patient becomes unable to make health care decisions. In the guidelines for decision making with endof-life care published by the Ministry of Health, Labor and Welfare in 2007, a flow process to determine medical and care policies at the end of life is described (Figure 15). ${ }^{548}$

"The statement on the treatment of elderly patients with heart failure" published by the Japanese Heart Failure Society in 2016 describes the importance of pain-relieving treatment in end-of-life care for elderly patients and the roles of multidisciplinary conferences and ACP. ${ }^{549}$ In 2016, the Japanese Society of Intensive Care Medicine published "Advice on Do Not Attempt Resuscitation (DNAR) Order" 550 to describe that ACR is not a procedure just to determine DNAR policies but is an important process to share the patient's values and philosophy on life and death with healthcare professionals. 


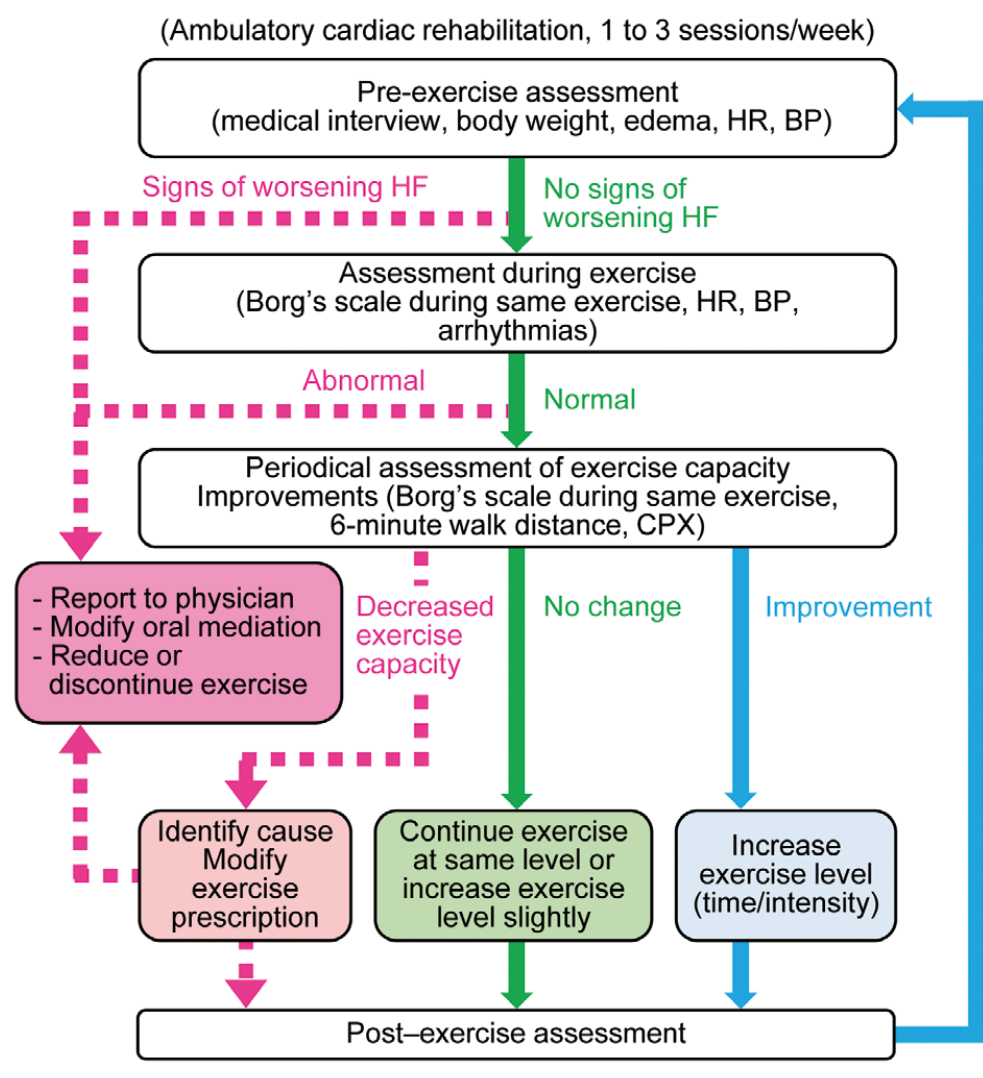

Figure 14. Exercise therapy and disease management for heart failure in ambulatory cardiac rehabilitation programs. BP, blood pressure; CPX, cardiopulmonary exercise testing; HF, heart failure; HR, heart rate. (Adapted from Goto Y. 2014542 with modifications)

\section{End-Stage Heart Failure and Indication for Palliative Care}

End-stage heart failure is defined as a heart condition that doesn't respond to maximal medical or on-pharmaceutical treatments. End of life is defined as the period in which death is imminent due to repeated or rapid worsening of an illness and there is little likelihood of cure. ${ }^{551}$ However, patients with advanced chronic heart failure show a clinical course different from that of patients with cancer. If is often difficult to know the end of life is approaching in patients with advanced heart failure (Figure 16). ${ }^{552}$ The 2013 ACCF/ AHA guideline for the management of heart failure described end-stage heart failure as Stage D heart failure, defined as "patients with truly refractory heart failure who might be eligible for specialized, advanced treatment strategies, such as mechanical circulatory support, procedures to facilitate fluid removal, continuous inotropic infusions, or cardiac transplantation or other innovative or experimental surgical procedures, or for end-of-life care, such as hospice". ${ }^{553}$ The 2016 ESC guidelines for the diagnosis of treatment of acute and chronic heart failure defined heart failure requiring end-of-life care as the conditions, including: - progressive functional decline (physical and mental) and dependence in most activities of daily living

- severe heart failure symptoms with poor quality of life despite optimal pharmacological and nonpharmacologic therapies

- frequent admissions to hospital or other serious episodes of decompensation despite optimal treatment
- heart transplantation and mechanical circulatory support ruled out

- cardiac cachexia

- clinically judged to be close to end of life. ${ }^{\mathbf{1 4}}$

In Japan, the Japanese Circulation Society published the "Statement for End-stage Cardiovascular Care" in 2010.554 All of these guidelines assume that patients with heart failure receive appropriate treatment throughout the disease course, which clearly differs from the situation of cancer treatment where end-stage patients often do not receive aggressive treatment. To alleviate their signs and symptoms, patients should be treated for heart failure and its complications throughout the life. Moreover, palliative care is not the same as end-of-life care, and is not indicated only for patients nearing the end of life (Figure 17). ${ }^{555}$ Palliative care should be initiated in the early phase of heart failure where symptoms begin. ACP should be conducted in the early phase as well, and a multidisciplinary team should repeatedly assess the physical, psychological, and mental needs of patients (Table 78).

\section{Importance of Multidisciplinary Approaches}

In order to prevent and remove total pain in patients with heart failure, a multidisciplinary approach is essential. A team of physicians, nurses, pharmacists, clinical psychotherapists, physical therapists, registered dieticians, medical social workers, clinical engineers and other health care experts should address this issue. 


Table 76. Points to Be Examined During Ambulatory Cardiac
Rehabilitation Sessions for Patients With Heart
Failure, and Signs of Worsening Heart Failure or
Excessive Exercise

ECG, electrocardiogram; $\mathrm{SpO}_{2}$, oxygen saturation

\section{Symptoms and Treatment of End-Stage Heart Failure}

Typical symptoms of end-stage heart failure include dyspnea, generalized malaise, pain, anorexia, and depression.
Table 77. Triggers for Formally Assessing Prognosis and Having Conversations About Goals of Care and Voluntary Advance Care Planning (ACP)

\section{Routine}

- "Annual Heart Failure Review" with a scheduled clinic visit

Event-driven "milestones" that should prompt reassessment

- Increased symptom burden and/or decreased quality of life

- Significant decrease in functional capacity

Loss of ADLs

Falls

Transition in living situation (independent to assisted or LTC)

- Worsening heart failure prompting hospitalization, particularly if recurrent

- Serial increases of maintenance diuretic dose

- Symptomatic hypotension, azotemia, or refractory fluid retention necessitating neurohormonal medication underdosing or withdrawal

Circulatory-renal limitations to ACEI/ARB

Decrease or discontinuation of $\beta$-blockers because of hypotension

- First or recurrent ICD shock for VT/VF

- Initiation of intravenous inotropic support

- Consideration of renal replacement therapy

- Other important comorbidities: new cancer, etc

- Major "life events": death of a spouse

ADL indicates activities of daily living; LTC, long-term care; ACEI, angiotensin-converting enzyme inhibitor; ARB, angiotensin II receptor blocker; ICD, implantable cardioverter-defibrillator; VT, ventricular tachycardia; and VF, ventricular fibrillation. (Adapted from Allen LA, et al. 2012 ${ }^{546}$ )

It has been reported that 60 to $88 \%$ of patients with endstage heart failure have dyspnea, 69 to $92 \%$ have generalized malaise, and 35 to $68 \%$ have pain. ${ }^{556-558}$ It has also been reported that $70 \%$ of patients hospitalized for end-stage heart failure have depression. ${ }^{559}$ As heart failure itself is considered to lease these problems through causing fluid retention and low cardiac output, heart failure treatment in Stage D should be continued in combination with the following treatments to control these symptoms.

\subsection{Dyspnea}

It has been reported that low-dose morphine and other opioids are safe and effective in releasing intractable dyspnea. ${ }^{\mathbf{5 6 0 5 6 1}}$ However, opioids may cause adverse drug reactions such as nausea, vomiting and constipation. Careful dose adjustment is required especially in elderly patients and patients with renal dysfunction to prevent overdosage, which may lead to respiratory depression in some patients.

\section{4.2 Pain}

A study has reported that the prevalence of pain increases as NYHA functional class worsens. ${ }^{\mathbf{5 6 2}}$ Nonsteroidal antiinflammatory drugs (NSAIDs) should be avoided whenever possible as they may worsen renal dysfunction and fluid retention in patients with end-stage heart failure. It is recommended that acetaminophen, a non-opioid analgesic, should be tried first and then opioids should be added if pain in difficult to control. 


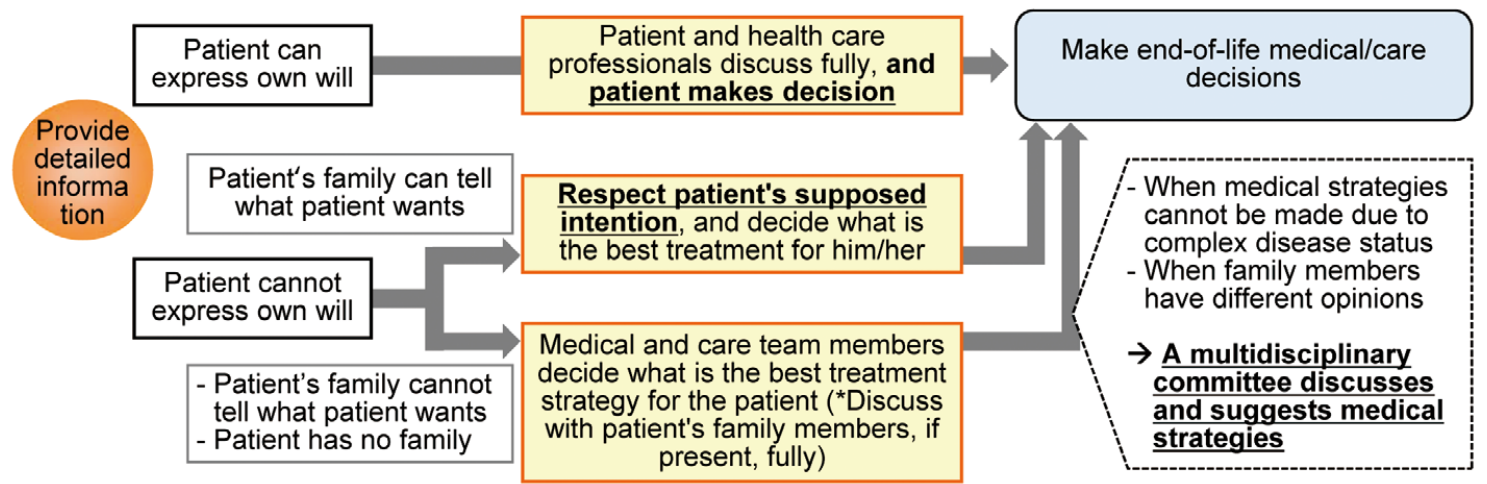

Figure 15. Process of end-of-life medical/care planning. (Adapted from The Ministry of Health, Labor and Welfare. 2017548)
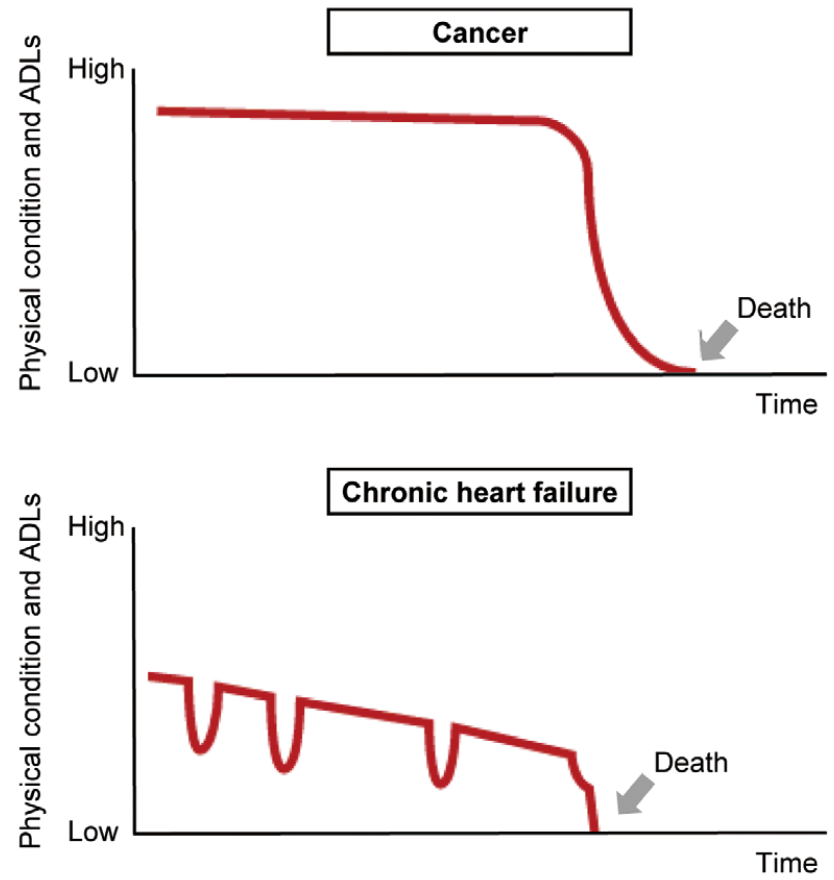

Patients with chronic heart failure show a clinical course different from that of patients with cancer. As patients repeat hospitalizations for worsening heart failure and experience an abrupt worsening of symptoms before death, it is often difficult to determine when the end of life is approaching.
Figure 16. Models of end-stage treatment in chronic heart failure and cancer. ADL, activities of daily livings. (Adopted from: Lynn J. $2001^{552}$ with modification)

\subsection{Generalized Malaise}

Patients should be examined not only for low cardiac output but also for depression, hypothyroidism, anemia, overuse of diuretics, electrolyte imbalance, sleep apnea, and occult infections, and should be treated accordingly. As pharmacotherapy is often ineffective in alleviating this condition, and nonpharmacologic therapy such as energy-conservation techniques may work in some patients. ${ }^{563}$

\subsection{Depression and Anxiety}

In patients with heart failure, depression predicts poor prognosis and is also associated with poor QOL. ${ }^{564}$ Depression is commonly treated with selective serotonin reuptake inhibitors (SSRIs), serotonin-noradrenaline reuptake inhibitors, and noradrenergic and specific serotonergic antidepressants, but it has been recently reported that concomitant use of $\beta$-blockers and SSRIs may increase the risk of death, ${ }^{565}$ and antidepressants may not always improve the prognosis of patients with heart failure. ${ }^{566-568}$ 


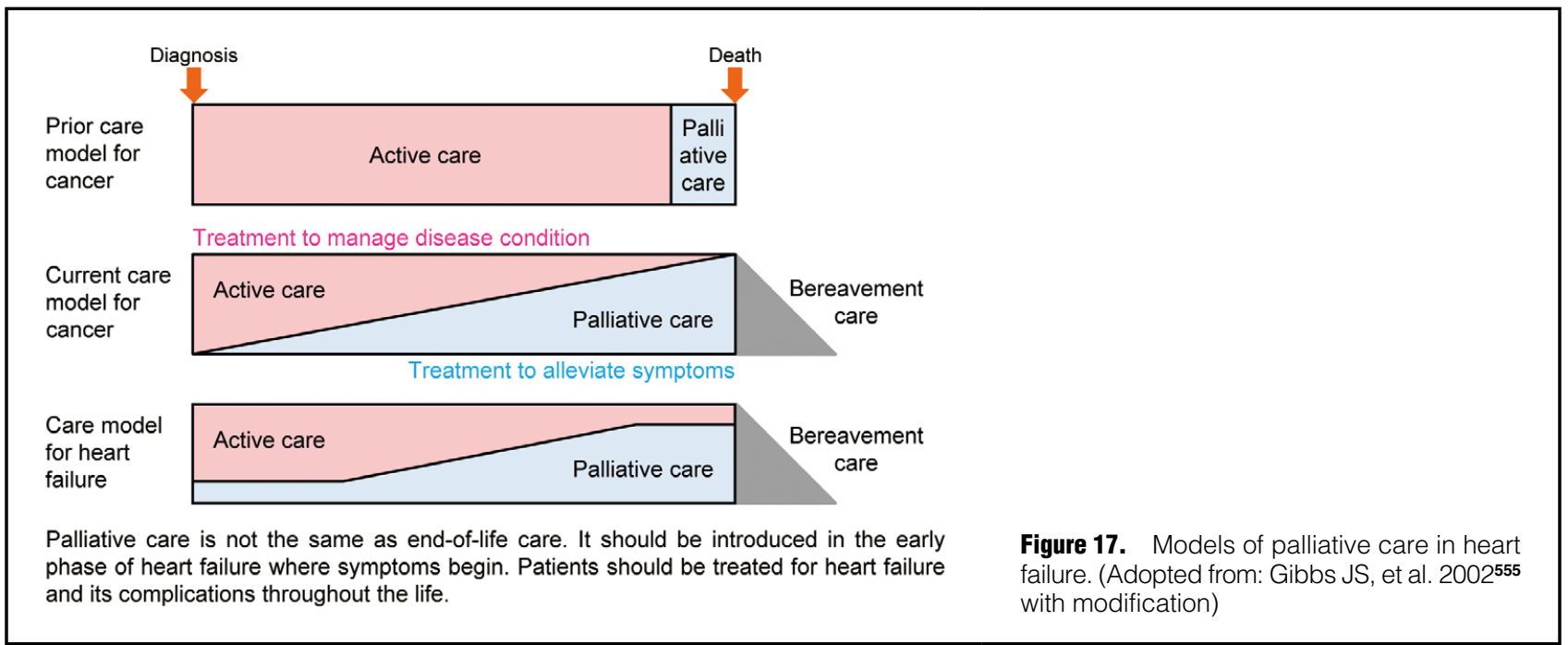

\begin{tabular}{|l|l|c||c|c|}
\hline \multicolumn{1}{|l|}{ Table 78. Recommendations and Levels of Evidence for Palliative Care for Patients With End-Stage Heart } \\
Failure
\end{tabular}

Tricyclic antidepressants should be used with caution as they may prolong QT intervals and cause anticholinergic effects. Benzodiazepines are the first-line treatment for anxiety. Nonpharmacologic therapy such as cardiac rehabilitation and expert counseling are beneficial as well.569,570

\subsection{Delirium}

Delirium often develops in patients with end-stage heart failure, especially in elderly. Delirium should be differentiated from dementia and depression, and early intervention should be offered to prevent severe delirium. When delirium develops in a patient with heart failure, the physician should review his/her treatment and environment for whether or not he/she uses drugs that may induce or worsen delirium (e.g. antihypertensives, $\beta$-blockers, antiarrhythmics, sympathomimetics, anticholinergics, hypnotics, and antianxiety drugs), take appropriate safety measures, and, if the condition is severe, consult him/her to a psychiatrist and consider for antipsychotic therapy.

\subsection{End-of-Life Pain}

As the final measure for patients suffering from uncontrollable pain, an appropriate amount of midazolam, a benzodiazepine drug, may be administered.

\subsection{Deactivation of Medical Devices}

When the patient's clinical status reaches the end-of-life stage, the patient, his/her family members and the palliative care team should discuss fully to determine whether to deactivate his/her ICD, pacemaker or CRT. ${ }^{571}$ In the "Concept of optimizing the indications for ventricular assist devices in Japan: Destination therapy (DT),"572 the Japan VAD Council has recommended that the physician should explain about end-stage cardiovascular care to the patient and his or her family members before implanting cardiac devices, inform that he/she has an option to deactivate his/ her implantable LVAD at the end-of-life stage, and recommend him/her to describe his/her preferences in an advance directive. Healthcare professionals should explain to patients about potential problems of DT (e.g., device malfunction, serious LVAD-related complications, status of comorbidities, and poor QOL after LVAD implantation) fully in advance, and help them plan how to address such problems in future according to the patients' own life philosophy and values. This process is called "preparedness planning." 573 The guidelines on the use of implantable LVADs proposed by the Japanese Circulation Society and the Japanese Society for Cardiovascular Surgery in 2013,517 and the guidelines on end-stage care for patients in emergency room or ICU proposed by the Japanese Association for Acute Medicine, the Japanese Society of Intensive Care 
Medicine, and the Japanese Circulation Society in 2014574 recommend multidisciplinary process-oriented approaches based on the advance directives and family's wishes.

\section{Early Introduction of Palliative Care for Heart Failure}

The introduction of palliative care for heart failure does not mean abandoning hope for cure. Palliative care is conducted to improve the QOL of the patient and his or her family members, and is continued together with standard heart failure treatment. Accordingly, palliative care should be initiated in the early phase of the disease rather than considering near the end of life.

\section{Future Treatment}

\section{Ivabradine (If-Channel Blocker)}

Ivabradine decreases heart rate by blocking If channels of sinus node cells. It is indicated only for patients with sinus rhythm. In a randomized, double-blind, placebo-controlled trial of ivabradine in patients who had HFrEF (LVEF $<35 \%$ ), were in sinus rhythm with a heart rate $\geq 70 \mathrm{bpm}$, had been admitted to hospital for heart failure within the previous year, and were receiving a $\beta$-blocker at the recommended or maximum tolerated dose, an angiotensin converting enzyme (ACE) inhibitor (or an ARB), and/or a mineralocorticoid receptor antagonist, ivabradine significantly reduced the composite of cardiovascular death or hospital admission for worsening heart failure. ${ }^{575}$ This study revealed that increased heart rate is a risk factor in patients with HFrEF in sinus rhythm, and lowering heart rate is an important target for treatment of heart failure. ${ }^{576}$

\section{Sacubitril/Valsartan (ARNI)}

Sacubitril/valsartan (LCZ696) is a new class of drug named as an angiotensin receptor neprilysin inhibitor (ARNI), and consists of valsartan, an ARB, and sacubitril (AHU377), a prodrug of a neprilysin inhibitor, in a 1:1 mixture. Sacubitril is converted to the active form LBQ657, which exerts an inhibitory effect on neprilysin 3 to 4 hours after absorption. LBQ657 mainly inhibits the degradation of endogenous natriuretic peptide but does not inhibit ACE or aminopeptidase P. Therefore, it does not enhance the degradation of bradykinin, and the risk of angioedema is expected to be low. The half-life of LBQ657 is 12 hours and that of valsartan is 14 hours. Sacubitril/valsartan is administered twice daily.

The Prospective Comparison of ARNI with ACEI to Determine Impact on Global Mortality and Morbidity in Heart Failure (PARADIGM-HF) trial has revealed that sacubitril/valsartan is superior to ACE inhibitor enalapril in improving prognosis. ${ }^{577} \mathrm{ESC}$ and ACC/AHA Guidelines recommended the replacement from ACE inhibitor to ARNI for $\mathrm{HFrEF}$ and the inhibition of the renin-angiotensin system with ACE inhibitors, ARBs, or ARNI in patients with HFrEF as Class I recommendations with Level of Evidence B. ${ }^{14,578}$

In Japan, the Prospective comparison of ARNI with ACE inhibitor to determine the novel beneficial treatment value in Japanese Heart Failure patients (PARALLELHF), a phase III randomized double-blind trial to obtain the approval from the government, is underway. ${ }^{579} \mathrm{Sacu}-$ bitril/valsartan reduced plasma NT-proBNP levels to a greater extent than did valsartan at 12 weeks in heart failure with preserved ejection fraction (HFpEF) in the Prospective Comparison of ARNI With ARB on Management of Heart Failure With Preserved Ejection Fraction (PARAMOUNT) trial. 580 The Prospective Comparison of ARNI with ARB Global Outcomes in HF With Preserved Ejection Fraction (PARAGON-HF) trial, a large-scale clinical trial to investigate the effects of sacubitril/valsartan on clinical outcomes is underway in countries including Japan. These large-scale clinical trials are expected to provide further evidence on the benefits of ARNI in patients with heart failure.

\section{Vericiguat (cGS Activator)}

In patients with heart failure, endothelial dysfunction and increased production of reactive oxygen species (ROS) reduce the production and bioavailability of nitric oxide (NO) and activity of the NO receptor, soluble guanylate cyclase (sGC), resulting in decreased activation of cyclic guanosine monophosphate (cGMP), as well as conversion to the NO-insensitive (inactive) sGC by ROS. Accordingly, cGMP-mediated intracellular signaling has attracted attention as a potential treatment target in HFrEF and HFpEF. ${ }^{581-583}$

Vericiguat is a novel sGC stimulator that directly stimulates sGC to promote NO production in a NO-independent manner via a site other than the NO binding site and also synergizes with NO. ${ }^{581,583}$

In a dose-finding phase II randomized controlled study of vericiguat in patients with $\mathrm{HFrEF}$ with a LVEF of $<45 \%$ (the SOCRATES-REDUCED trial in the Soluble guanylate Cyclase stimulator in heart failure Study [SOCRATES] program), ${ }^{584}$ patients who were clinically stable with LVEF $<45 \%$ within 4 weeks of a worsening chronic heart failure event received placebo $(n=92)$ or 1 of 4 daily target doses of oral vericiguat $(1.25 \mathrm{mg}, 2.5 \mathrm{mg}, 5 \mathrm{mg}$, or $10 \mathrm{mg}$; $n=91$ for each dose) for 12 weeks. The primary endpoint, change from baseline to week 12 in log-transformed NT-proBNP level, was not significantly different between the pooled 3-highest-dose vericiguat group and placebo group, but a secondary analysis revealed that higher vericiguat doses were significantly associated with greater reductions in NT-proBNP level. ${ }^{585}$

As vericiguat was shown to tolerable in patients with HFrEF in phase II studies, the drug is currently being evaluated in a global phase III placebo-controlled randomized clinical trial called the Vericiguat Global Study in Subjects With Heart Failure With Reduced Ejection Fraction (VICTRIA) trial. ${ }^{586}$ The VICTRIA trial plans to 
The tip of MitraClip ${ }^{\circledR}$ device

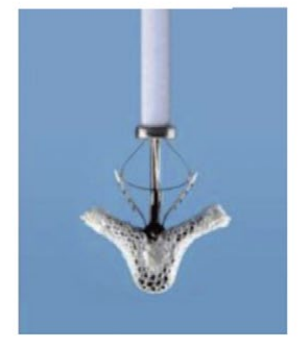

MitraClip ${ }^{\circledR}$ grasping the anterior and posterior mitral leaflets

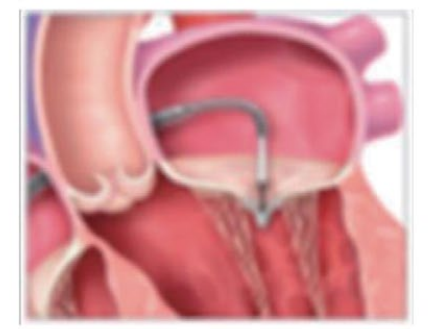

A view from the left atrium of mitral valves after a clip procedure

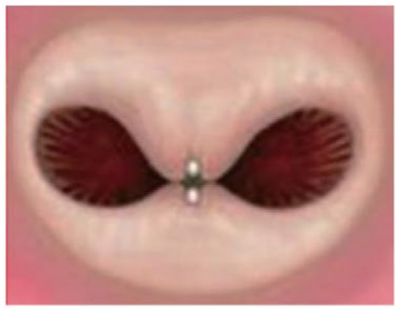

Figure 18. Treatment of mitral valve insufficiency with MitraClip ${ }^{\circledR}$. (Figures courtesy of Abbott Vascular Japan Co., Ltd.) enroll a total of 4,872 patients with NYHA class II to IV heart failure and LVEF $>45 \%$ by the end of 2020 , and will follow them for approximately 3.5 years. The primary endpoint is time to first occurrence of composite endpoint of cardiovascular death or heart failure hospitalization. The trial is conducted in many countries including Japan.

Phase III trials of vericiguat are expected to generate evidence that help position this drug in the treatment of heart failure, which will be described in the relevant guidelines including Western guidelines in the future.

\section{Omecamtiv Mecarbil (Cardiac Myosin Activator)}

As omecamtiv mecarbil increase the transition rate of myosin from weakly to strongly actin-bound force-generating state and thereby increase myocardial contractility, ${ }^{\mathbf{5 8 7}}$ this drug is expected to increase cardiac function without increasing intracellular calcium concentration and worsening prognosis.

In phase II clinical trial of intravenous omecamtiv mecarbil in patients with $\mathrm{HFrEF},{ }^{\mathbf{5 8 8}}$ left ventricular ejection time and stroke volume increased proportionally with plasma concentration of omecamtiv mecarbil, and higher plasma concentrations were also associated with reductions in left ventricular end-systolic and end-diastolic volumes. Heart rate decreased slightly but significantly. Cardiac ischemia developed in some patients receiving higher doses of the drug.

In a following large-scale randomized controlled trial, the Acute Treatment with Omecamtiv Mecarbil to Increase Contractility in Acute Heart Failure (ATOMIC-AHF), ${ }^{\mathbf{8 8 9}}$ 606 patients with acute heart failure who had LVEF $\leq 40 \%$, elevated natriuretic peptide level, and persistent dyspnea received omecamtiv mecarbil at 3 escalating intravenous doses. Omecamtiv mecarbil resulted in significantly greater dyspnea relief in the higher-dose group as compared with the control group, but plasma troponin levels were significantly higher in patients treated with omecamtiv mecarbil compared with placebo.

In the Chronic Oral Study of Myosin Activation to Increase Contractility in Heart Failure (COSMIC-HF) trial, ${ }^{590}$ a clinical study of oral omecamtiv mecarbil in 448 patients with $\mathrm{HFrEF}$, patients receiving the drug at $25 \mathrm{mg}$ twice daily titrated to $50 \mathrm{mg}$ twice daily guided by pharmacokinetics had longer systolic ejection time, larger cardiac output, smaller left ventricular end-systolic diameter, and lower heart rate than the control group.

A phase III study in about 8,000 patients with HFrEF to evaluate the effect of omecamtiv mecarbil on the risk of cardiovascular death or heart failure events, the Global Approach to Lowering Adverse Cardiac Outcomes Through Improving Contractility in Heart Failure (GALACTIC-HF) trial, is currently ongoing. .591 


\section{Percutaneous Mitral Valve Repair System (MitraClip ${ }^{\circledR}$ )}

Percutaneous mitral valve repair should be considered for patients with mitral valve insufficiency for whom mitral repair is expected to reduce symptoms and improve QOL but surgical risk is high. In Japan, MitraClip ${ }^{\circledR}$ has become available recently (Figure 18). This system facilitates early ambulation after surgery. Symptomatic improvement reported by patients receiving this procedure on day 30 after the procedure is better than those undergoing thoracotomy.

\section{Human (Autologous) Skeletal Muscle-Derived Cell Sheet (HeartSheet ${ }^{\circledR}$ )}

Myoblast sheet is a cell therapy technology for severe heart failure, and five sheets, each contains $6 \times 10^{7}$ myoblasts, are applied on the epicardium to cover the anterior and lateral walls of the left ventricle through a left lateral thoracotomy. The implanted myoblast sheets secrete cytokines such as hepatocyte growth factor, vascular endothelial growth factor (VEGF), basic fibroblast growth factor (bFGF), and stromal derived factor-1 that are considered to promote neovascularization, induce stem cells, and inhibit fibrosis, and thereby improve cardiac function. ${ }^{\mathbf{5 9 2}}$ In animal models of heart failure, the sheet improved cardiac function and prolonged survival.

It has been reported that among 4 patients with dilated cardiomyopathy supported by a LVAD who received the autologous myoblast sheet implantation, two patients showed an improvement in cardiac function and could remove the LVAD. ${ }^{593}$ Safety and efficacy of the myoblast sheet technology for treatment of ischemic cardiomyopathy were demonstrated in clinical research ${ }^{594}$ and a multi-center company-sponsored study, ${ }^{\mathbf{5 9 5}}$ and the sheet was approved as the world's first tissue-engineered medical product, HeartSheet ${ }^{\circledR}$, under the fast-track designation and reimbursed by the National health Insurance.

Investigator-initiated studies are now underway to assess the efficacy and safety of the product in the treatment of children and adults with dilated cardiomyopathy.

\section{Waon Therapy}

In Waon therapy, ${ }^{\mathbf{5 9 6}}$ a thermal therapy developed in Japan, patients stay in a far-infrared dry sauna at $60^{\circ} \mathrm{C}$ for 15 minutes, and then maintain body temperature for 30 minutes after sauna bath.

It has been reported that Waon therapy is beneficial in improving hemodynamics, ${ }^{597}$ left ventricular function, ${ }^{598} \mathbf{6 0 1}$ heart failure symptoms, ${ }^{\mathbf{5 8 8 , 6 0 0 , 6 0 2}} \mathrm{QOL}$ and exercise capacity, ${ }^{600}$ and peripheral vascular endothelial function, ${ }^{\mathbf{6 0 0}, 602}$ and reducing heart rate variability in patients with heart failure. ${ }^{603,604}$ A retrospective study has revealed that Waon therapy significantly reduced the risk of death and rehospitalization for worsening heart failure, and improved the prognosis of patients with chronic heart failure. ${ }^{65}$ In the WAON-CHF trial, a multicenter prospective randomized trial in 149 patients treated in 19 medical institutions, ${ }^{606}$ patients receiving Waon therapy once daily for 10 days showed improvement in BNP levels, NYHA functional class, 6-minute walk distance, and cardiothoracic ratio and a favorable safety profile. However, no significant difference between the Waon therapy group and the control group was found in the change in BNP from before and after treatment, which was the primary endpoint of the study.

At present, Waon therapy in the treatment of heart failure is not covered by the National Health Insurance in Japan. 
Supplement 1. A Statement on Appropriate Use of Adaptive Servo-Ventilation (ASV) by the Japanese Circulation Society and the Japanese Heart Failure Society (the Second Statement)

1) Adaptive Servo-Ventilation (ASV) for patients whose conditions are similar to the participants in the SERVE-HF trial (patients with heart failure who have predominant central sleep apnea and stable left ventricular systolic dysfunction with left ventricular ejection fraction [LVEF] $\leq 45 \%)$

The introduction and continuation of ASV in these patients are not contraindicated, but careful consideration is required. In the clinical practice, it is desirable that, as described in the relevant guidelines in Japan, ${ }^{1,2}$ patients should be first considered for continuous positive airway pressure (CPAP) and then ASV should be considered only for patients who still have sleep apnea despite CPAP or are intolerable to CPAP. After initiating ASV, patients should be observed carefully for clinical conditions, and should be considered for switching to CPAP whenever possible. Healthcare professional should fully inform patients and their family members of the advantages and disadvantages of ASV on the basis not only the relevant guidelines in Japan but also the results of small-scale clinical studies, ${ }^{3}$ the SERVE-HF study, ${ }^{4}$ and SAVIOR-C trial, ${ }^{5}$ Western guidelines, and regulations for use of ASV by regulatory authorities to obtain informed consent from patients to introduce and continue taking ASV.

2) ASV for patients who do not meet the above criteria 1 but have heart failure and sleep apnea (e.g. those with predominant obstructive sleep apnea, and those with sleep apnea and heart failure with preserved ejection fraction [LVEF $>45 \%$ ])

At present, there are no reasons to limit the introduction and continuation of ASV in these patients. However, patients should be observed carefully for their clinical course during the introduction and continuation of ASV to ensure safety of treatment. Patients should first be considered for CPAP, and receive ASV only when it is necessary (the coverage with the National Health Insurance should be reviewed individually).

3) ASV for patients with or without sleep apnea in whom ASV has been effective in the treatment of severe congestion

ASV may be continued in patients with heart failure in whom severe congestion was not alleviated with conventional medical treatment but was successfully treated with ASV when physicians consider that discontinuing ASV would worsen heart failure, regardless of whether sleep apnea is present or not. However, it should be considered whether patients can withdraw from ASV or switch from ASV to other procedures when they become clinically stable or when 6 months has passed since the introduction of ASV. At this time, patients should be assessed for sleep apnea and those with sleep apnea should be treated according to the criteria 1 and 2 above.

4) ASV for patients who do not meet any of the criteria 1 to 3

This statement does not describe the use or appropriateness of ASV for patients who do not meet any of the criteria 1 to 3 .

5) ASV in clinical research

No restrictions are placed on the use of ASV in clinical research that is conducted according to the ethical standard at the medical institution even when participating patients have conditions similar to those in the SERVE-HF trial. However, investigators must fully explain to participants and their family members the usage of ASV in non-research settings, as well as the results of small-scale studies, the SERVE-HF trial, and the SAVIOR-C trial before obtaining informed consent. Investigators of ongoing clinical research of ASV must share the results of the SERVE$\mathrm{HF}$ trial as new safety guidelines with all relevant healthcare professionals at participating medical institutions.

6) Other remarks

The above criteria 1 to 5 will be revised and updated when new information is available in the SERVE-HF trial or other studies.

1) The Japanese Circulation Society. Circ J 2010; 74 (suppl. II): 963-1051.

2) Guidelines on Positive Pressure Ventilation (NPPV), Second Revision Nankodo 2015.

3) Aurora RN, et al. J Clin Sleep Med 2016; 12: 757-761.

4) Cowie MR, et al. N Engl J Med 2015; 373: 1095-1105.

5) Momomura S, et al. Circ J 2015; 79: 981-990.

(Adapted from The Japanese Circulation Society ${ }^{271}$ )

\section{Supplement 2. Effects of Exercise Therapy in Heart Failure}

1) Exercise capacity: Improvement

2) Effects on the heart

a) Left ventricular function: No change or slight improvement in LVEF at rest, increase in the increment of cardiac output during exercise, and improvement in left ventricular early diastolic function

b) Coronary circulation: Improvement in coronary endothelial function, improvement in myocardial perfusion during exercise, and increase in coronary collateral flow

c) Left ventricular remodeling: Prevention (or inhibition) of progression, decrease in BNP

\section{3) Peripheral effects}

a) Skeletal muscle: Increase in muscle mass/strength, improvement in aerobic metabolism, and increase in expression of antioxidant enzymes

b) Respiratory muscles: Improvement in respiratory muscle function

c) Vascular endothelium: Improvement in endothelium-dependent vasodilation responses, and increase in expression of eNOS

4) Neurohumoral factors

a) Autonomic nervous system function: Suppression of sympathetic nervous activity, increase in parasympathetic activity, and improvement in heart rate variability

b) Ventilatory response: Improvement in ventilatory response and $\mathrm{CO}_{2}$ sensitivity of the respiratory center

c) Inflammatory markers: Decreases in inflammatory cytokines (e.g., TNF- $\alpha$ ) and CRP

5) QOL: Improvement in health-related QOL

6) Long-term prognosis: Decrease in hospitalizations due to heart failure

BNP: brain (B-type) natriuretic peptide; CRP, C-reactive protein; eNOS, endothelial nitric oxide synthase; LVEF, left ventricular ejection fraction; $\mathrm{QOL}$, quality of life; TNF, tumor necrosis factor. (Adapted from The Japanese Circulation Society ${ }^{148}$ with modification) 


\section{Supplement 3. Contraindications in Exercise Therapy for Patients With Heart Failure}
I. Absolute contraindications
1) Exacerbation of heart failure symptoms (e.g., dyspnea, easy fatigability) during the last 3 days
2) Unstable angina or low-threshold myocardial ischemia that is induced by slow walking on a flat surface (2 METs)
3) Severe valvular disease indicated for surgery, especially aortic stenosis
4) Severe left ventricular outflow tract stenosis (hypertrophic obstructive cardiomyopathy)
5) Untreated severe exercise-induced arrhythmia (ventricular fibrillation, sustained ventricular tachycardia)
6) Active myocarditis/pericarditis
7) Acute systemic disease or fever
8) Other diseases in which exercise therapy is contraindicated (moderate or severe aortic aneurysm, severe hypertension, thrombophlebitis, embolism within past 2 weeks, and serious organ diseases)

\section{Relative contraindications}

1) NYHA Class IV or hemodynamically unstable heart failure

2) Heart failure with an increase in body weight by $\geq 2 \mathrm{~kg}$ during the last week

3) Exercise-induced decrease in systolic blood pressure

4) Moderate left ventricular outflow tract stenosis

5) Exercise-induced moderate arrhythmia (e.g., nonsustained ventricular tachycardia, tachycardiac atrial fibrillation)

6) Advanced atrioventricular block, exercise-induced Mobitz type II atrioventricular block

7) Occurrence or exacerbation of exercise-induced symptoms (e.g., fatigue, dizziness, excessive sweating, dyspnea)

\section{Not contraindicated}

1) Elderly patients

2) Decreased LVEF

3) Use of ventricular assist devices (LVADs)

4) Use of implantable cardiac devices (e.g., ICDs, CRT-D)

CRT-D, cardiac resynchronization therapy defibrillator; ICD, implantable cardioverter defibrillator; LVEF, left ventricular ejection fraction LVAD, left ventricular assist device; METs, metabolic equivalents; NYHA, New York Heart Association. (Adapted from The Japanese Circulation Society ${ }^{148}$ with modification)

Supplement 4. Exercise Prescriptions for Patients With Heart Failure

\begin{tabular}{|c|c|}
\hline Type of exercise & $\begin{array}{l}\text { - Walking (begin with supervised indoor walking), cycle ergometer, light aerobics, low-intensity resistance training (for } \\
\text { patients with muscle weakness) } \\
\text { - Jogging, swimming, and vigorous aerobics are not recommended }\end{array}$ \\
\hline \multirow{2}{*}{ Exercise intensity } & $\begin{array}{l}\text { [Early phase] } \\
\text { - Indoor walking at } 50 \text { to } 80 \mathrm{~m} / \mathrm{min} \text { for } 5 \text { to } 10 \mathrm{~min} \text { or a cycle ergometer at } 10 \text { to } 20 \mathrm{~W} \text { for } 5 \text { to } 10 \mathrm{~min} \\
\text { - The duration and intensity of exercise should be increased gradually over } 1 \text { month as guided by signs/symptoms } \\
\text { during exercise }\end{array}$ \\
\hline & $\begin{array}{l}\text { [Goal in the stable phase] } \\
\text { - The target heart rate }(\mathrm{HR}) \text { is set at } 40 \text { to } 60 \% \text { of the peak } \dot{\mathrm{VO}}_{2} \text { or at anaerobic threshold level } \\
\text { - The target } \mathrm{HR} \text { is set at } 30 \text { to } 50 \% \text { of } \mathrm{HR} \text { reserve, or } 50 \text { to } 70 \% \text { of the maximum } \mathrm{HR} \\
\text { - Target rating of perceived exertion (RPE) is set at Borg scale } 11 \text { (fairly light) to } 13 \text { (somewhat hard) }\end{array}$ \\
\hline Duration & - Start with 5 to $10 \mathrm{~min} / \mathrm{session}, 2$ sessions a day, and then increase gradually from 30 to $60 \mathrm{~min} / \mathrm{day}$ \\
\hline Frequency & $\begin{array}{l}\text { - } 3 \text { to } 5 \text { days/week ( } 3 \text { days/week for patients with severe heart failure, and may be increased up to } 5 \text { days/week for } \\
\text { those with stable condition) } \\
\text { - Low-intensity resistance training may be added at a frequency of } 2 \text { to } 3 \text { days/week }\end{array}$ \\
\hline Precautions & $\begin{array}{l}\text { - Exercise during the first month should be light in intensity and careful monitoring for worsening heart failure should } \\
\text { be made } \\
\text { Start with supervised training and then combine with non-supervised (home-based) exercise training during the } \\
\text { stable phase } \\
\text { - Changes in subjective symptoms, physical findings, body weight, and blood BNP or NT-proBNP levels should be } \\
\text { observed carefully }\end{array}$ \\
\hline
\end{tabular}

BNP, brain (B-type) natriuretic peptide; NT-proBNP, N-terminal pro-brain (B-type) natriuretic peptide. (Adapted from The Japanese Circulation Society ${ }^{148}$ with modification) 


\begin{tabular}{|c|c|c|c|}
\hline \multicolumn{4}{|c|}{ Supplement 5: CHADS $_{2}$ Score } \\
\hline & \multicolumn{2}{|c|}{ Clinical characteristics } & Score \\
\hline $\mathrm{C}$ & \multicolumn{2}{|c|}{ Heart Failure } & 1 \\
\hline $\mathrm{H}$ & \multicolumn{2}{|c|}{ Hypertension } & 1 \\
\hline A & \multicolumn{2}{|c|}{ Age $\geq 75$ years } & 1 \\
\hline $\mathrm{D}$ & \multicolumn{2}{|c|}{ Diabetes mellitus } & 1 \\
\hline $\mathrm{S}$ & \multicolumn{2}{|c|}{ History of cerebral infarction or transient ischemic attack } & 2 \\
\hline \multicolumn{2}{|c|}{ CHADS $_{2}$ Score } & Stroke rate per 100 patien & \\
\hline \multicolumn{2}{|r|}{0} & 1.9 & \\
\hline \multicolumn{2}{|r|}{1} & 2.8 & \\
\hline \multicolumn{2}{|r|}{2} & 4.0 & \\
\hline \multicolumn{2}{|r|}{3} & 5.9 & \\
\hline \multicolumn{2}{|r|}{4} & 8.5 & \\
\hline \multicolumn{2}{|r|}{5} & 12.5 & \\
\hline \multicolumn{2}{|r|}{6} & 18.2 & \\
\hline
\end{tabular}

(Source: Prepared based on Gage BF, et al. 2001328)

\section{References}

1. McMurray JJ, Adamopoulos S, Anker SD, et al. ESC guidelines for the diagnosis and treatment of acute and chronic heart failure 2012: The Task Force for the Diagnosis and Treatment of Acute and Chronic Heart Failure 2012 of the European Society of Cardiology. Developed in collaboration with the Heart Failure Association (HFA) of the ESC. Eur J Heart Fail 2012; 14: 803-869. PMID: 22828712

2. Guidelines for the evaluation and management of heart failure. Report of the American College of Cardiology/American Heart Association Task Force on Practice Guidelines (Committee on Evaluation and Management of Heart Failure). J Am Coll Cardiol 1995; 26: 1376-1398. PMID: 7594057

3. Hunt SA, Baker DW, Chin MH, et al. ACC/AHA Guidelines for the Evaluation and Management of Chronic Heart Failure in the Adult: Executive Summary A Report of the American College of Cardiology/American Heart Association Task Force on Practice Guidelines (Committee to Revise the 1995 Guidelines for the Evaluation and Management of Heart Failure): Developed in Collaboration With the International Society for Heart and Lung Transplantation; Endorsed by the Heart Failure Society of America. Circulation 2001; 104: 2996-3007. PMID: 11739319

4. Hunt SA, Abraham WT, Chin MH, et al. ACC/AHA 2005 Guideline Update for the Diagnosis and Management of Chronic Heart Failure in the Adult: A report of the American College of Cardiology/American Heart Association Task Force on Practice Guidelines (Writing Committee to Update the 2001 Guidelines for the Evaluation and Management of Heart Failure): Developed in collaboration with the American College of Chest Physicians and the International Society for Heart and Lung Transplantation: Endorsed by the Heart Rhythm Society. Circulation 2005; 112: e154-e235. PMID: 16160202

5. Hunt SA, Abraham WT, Chin MH, et al. 2009 focused update incorporated into the ACC/AHA 2005 Guidelines for the Diagnosis and Management of Heart Failure in Adults: A report of the American College of Cardiology Foundation/American Heart Association Task Force on Practice Guidelines: Developed in collaboration with the International Society for Heart and Lung Transplantation. Circulation 2009; 119: e391-e479. PMID: 19324966

6. Dickstein K, Cohen-Solal A, Filippatos G, et al. ESC Committee for Practice Guidelines (CPG). ESC guidelines for the diagnosis and treatment of acute and chronic heart failure 2008: The Task Force for the diagnosis and treatment of acute and chronic heart failure 2008 of the European Society of Cardiology. Developed in collaboration with the Heart Failure Association of the ESC (HFA) and endorsed by the European Society of Intensive Care Medicine (ESICM). Eur J Heart Fail 2008; 10: 933-989. PMID: 18826876

7. Yancy CW, Jessup M, Bozkurt B, et al. 2013 ACCF/AHA guideline for the management of heart failure: A report of the
American College of Cardiology Foundation/American Heart Association Task Force on practice guidelines. Circulation 2013; 128: e240-e327. PMID: 23741058

8. Yancy CW, Jessup M, Bozkurt B, et al. 2017 ACC/AHA/HFSA Focused Update of the 2013 ACCF/AHA Guideline for the Management of Heart Failure: A Report of the American College of Cardiology/American Heart Association Task Force on Clinical Practice Guidelines and the Heart Failure Society of America. Circulation 2017; 136: e137-e161. PMID: 28455343

9. Guidelines for the diagnosis of heart failure. The Task Force on Heart Failure of the European Society of Cardiology. Eur Heart J 1995; 16: 741-751. PMID: 7588917

10. The treatment of heart failure. Task Force of the Working Group on Heart Failure of the European Society of Cardiology. Eur Heart J 1997; 18: 736-753. PMID: 9152644

11. Remme WJ, Swedberg K. Task Force for the Diagnosis and Treatment of Chronic Heart Failure, European Society of Cardiology. Guidelines for the diagnosis and treatment of chronic heart failure. Eur Heart J 2001; 22: 1527-1560. PMID: 11492984

12. Swedberg K, Cleland J, Dargie H, et al. Guidelines for the diagnosis and treatment of chronic heart failure: Executive summary (update 2005): The Task Force for the Diagnosis and Treatment of Chronic Heart Failure of the European Society of Cardiology. Eur Heart J 2005; 26: 1115-1140. PMID: 15901669

13. Nieminen MS, Böhm M, Cowie MR, et al. ESC Committe for Practice Guideline (CPG). Executive summary of the guidelines on the diagnosis and treatment of acute heart failure: The Task Force on Acute Heart Failure of the European Society of Cardiology. Eur Heart J 2005; 26: 384-416. PMID: 15681577

14. Ponikowski P, Voors AA, Anker SD, et al. Authors/Task Force Members. 2016 ESC Guidelines for the diagnosis and treatment of acute and chronic heart failure: The Task Force for the diagnosis and treatment of acute and chronic heart failure of the European Society of Cardiology (ESC) Developed with the special contribution of the Heart Failure Association (HFA) of the ESC. Eur Heart J 2016; 37: 2129-2200. PMID: 27206819

15. Mind Treatment Guideline Selection Committee, supervisor. Fukui T, Yoshida M, Yamaguchi N, editors. Minds handbook for clinical practice guideline development, 2007. Tokyo: Igaku Shoin, 2007.

16. Ponikowski P, Voors AA, Anker SD, et al. Authors/Task Force Members. 2016 ESC Guidelines for the diagnosis and treatment of acute and chronic heart failure: The Task Force for the diagnosis and treatment of acute and chronic heart failure of the European Society of Cardiology (ESC). Developed with the special contribution of the Heart Failure Association (HFA) of the ESC. Eur J Heart Fail 2016; 18: 891 -975. PMID: 27207191

17. Owan TE, Hodge DO, Herges RM, et al. Trends in prevalence and outcome of heart failure with preserved ejection fraction. $N$ Engl J Med 2006; 355: 251-259. PMID: 16855265

18. Lee DS, Gona P, Vasan RS, et al. Relation of disease pathogenesis 
and risk factors to heart failure with preserved or reduced ejection fraction: Insights from the framingham heart study of the national heart, lung, and blood institute. Circulation 2009; 119: 3070-3077. PMID: 19506115

19. Punnoose LR, Givertz MM, Lewis EF, et al. Heart failure with recovered ejection fraction: A distinct clinical entity. J Card Fail 2011; 17: 527-532. PMID: 21703523

20. The Ministry of Health, Labour and Welfare. Committee on collaborative clinical practice for the treatment of stroke, heart disease and other cardiovascular disorders. What collaborative clinical practice for the treatment of stroke, heart disease and other cardiovascular disorders should be (July 2017). http://www. mhlw.go.jp/file/05-Shingikai-10901000-Kenkoukyoku-Soumuka/ 0000173149.pdf

20a. Criteria Committee of the New York Heart Association. Diseases of the Heart and Blood Vessels: Nomenclature and Criteria for diagnosis, 6th edition. Little, Brown and Co., 1964: $112-113$.

21. Forrester JS, Diamond G, Chatterjee K, et al. Medical therapy of acute myocardial infarction by application of hemodynamic subsets (second of two parts). N Engl J Med 1976; 295: 1404 1413. PMID: 790194

22. Nohria A, Tsang SW, Fang JC, et al. Clinical assessment identifies hemodynamic profiles that predict outcomes in patients admitted with heart failure. J Am Coll Cardiol 2003; 41: 1797 1804. PMID: 12767667

23. The Ministry of Health, Labour and Welfare. Population survey summary report in 2014 (definitive values). http://www.mhlw. go.jp/toukei/saikin/hw/jinkou/kakutei14/index.html

24. The Japanese Circulation Society. Japanese registry of all cardiac and vascular diseases (JROAD) survey report (Conducted and published in 2016). http://www.j-circ.or.jp/jittai_chosa/jittai_ chosa2015web.pdf

25. Okura Y, Ramadan MM, Ohno Y, et al. Impending epidemic: Future projection of heart failure in Japan to the year 2055. Circ J 2008; 72: 489-491. PMID: 18296852

26. American Heart Association: Heart Disease and Stroke Statistics - 2005 Update. Dallas, Tex; American Heart Association; 2005.

27. Vasan RS, Larson MG, Benjamin EJ, et al. Congestive heart failure in subjects with normal versus reduced left ventricular ejection fraction: Prevalence and mortality in a population-based cohort. J Am Coll Cardiol 1999; 33: 1948-1955. PMID: 10362198

28. Tsutsui H, Tsuchihashi-Makaya M, Kinugawa S, et al. JCARECARD Investigators. Clinical characteristics and outcome of hospitalized patients with heart failure in Japan. Circ J 2006; 70: 1617-1623. PMID: 17127810

29. Shiba N, Watanabe J, Shinozaki T, et al. CHART Investigators. Analysis of chronic heart failure registry in the Tohoku district: Third year follow-up. Circ J 2004; 68: 427-434. PMID: 15118283

30. Shiba N, Nochioka K, Miura M, et al. CHART-2 Investigators. Trend of westernization of etiology and clinical characteristics of heart failure patients in Japan: First report from the CHART-2 study. Circ J 2011; 75: 823-833. PMID: 21436596

31. Ushigome R, Sakata Y, Nochioka K, et al. CHART-2 Investigators. Temporal trends in clinical characteristics, management and prognosis of patients with symptomatic heart failure in Japan: Report from the CHART Studies. Circ J 2015; 79: 2396-2407. PMID: 26356834

32. Tsuchihashi-Makaya M, Hamaguchi S, Kinugawa S, et al. JCARE-CARD Investigators. Characteristics and outcomes of hospitalized patients with heart failure and reduced vs preserved ejection fraction: A report from the Japanese Cardiac Registry of Heart Failure in Cardiology (JCARE-CARD). Circ J 2009; 73: 1893-1900. PMID: 19644216

33. Berry C. Meta-analysis Global Group in Chronic Heart Failure (MAGGIC). The survival of patients with heart failure with preserved or reduced left ventricular ejection fraction: An individual patient data meta-analysis. Eur Heart J 2012; 33: 1750-1757. PMID: 21821849

34. Tsuji K, Sakata Y, Nochioka K, et al. CHART-2 Investigators. Characterization of heart failure patients with mid-range left ventricular ejection fraction-a report from the CHART-2 Study. Eur J Heart Fail 2017; 19: 1258-1269. PMID: 28370829

35. Kawashiro N, Kasanuki H, Ogawa H, et al. Heart Institute of Japan--Department of Cardiology (HIJC) Investigators. Clinical characteristics and outcome of hospitalized patients with congestive heart failure: Results of the HIJC-HF registry. Circ $J$ 2008; 72: 2015-2020. PMID: 18931450

36. Sato N, Kajimoto K, Keida T, et al. ATTEND Investigators.
Clinical features and outcome in hospitalized heart failure in Japan (from the ATTEND Registry). Circ J 2013; 77: 944-951. PMID: 23502987

37. Adams KF, Fonarow GC, Emerman CL, et al. ADHERE Scientific Advisory Committee and Investigators. Characteristics and outcomes of patients hospitalized for heart failure in the United States: Rationale, design, and preliminary observations from the first 100,000 cases in the Acute Decompensated Heart Failure National Registry (ADHERE). Am Heart J 2005; 149: 209-216. PMID: 15846257

38. Nieminen MS, Brutsaert D, Dickstein K, et al. EuroHeart Survey Investigators. EuroHeart Failure Survey II (EHFS II): A survey on hospitalized acute heart failure patients: Description of population. Eur Heart J 2006; 27: 2725-2736. PMID: 17000631

39. Ho KK, Anderson KM, Kannel WB, et al. Survival after the onset of congestive heart failure in Framingham Heart Study subjects. Circulation 1993; 88: 107-115. PMID: 8319323

40. Lloyd-Jones DM, Larson MG, Leip EP, et al. Framingham Heart Study. Lifetime risk for developing congestive heart failure: The Framingham Heart Study. Circulation 2002; 106: $3068-$ 3072. PMID: 12473553

41. Bleumink GS, Knetsch AM, Sturkenboom MC, et al. Quantifying the heart failure epidemic: Prevalence, incidence rate, lifetime risk and prognosis of heart failure The Rotterdam Study. Eur Heart J 2004; 25: 1614-1619. PMID: 15351160

42. Sakata Y, Miyata S, Nochioka K, et al. Gender differences in clinical characteristics, treatment and long-term outcome in patients with stage C/D heart failure in Japan: Report from the CHART-2 study. Circ J 2014; 78: 428 -435. PMID: 24317114

43. Preventive Committee for Japanese Heart Failure Society. Points to consider when using BNP and NT-pro BNP levels in the blood for the diagnosis and treatment of heart failure. http://www.asas.or.jp/jhfs/topics/bnp201300403.html

44. McKee PA, Castelli WP, McNamara PM, et al. The natural history of congestive heart failure: The Framingham study. $N$ Engl J Med 1971; 285: 1441 -1446. PMID: 5122894

45. Cohn JN, Levine TB, Olivari MT, et al. Plasma norepinephrine as a guide to prognosis in patients with chronic congestive heart failure. $N$ Engl J Med 1984; 311: 819-823. PMID: 6382011

46. Kawaguchi $\mathrm{H}$, Kitabatake A. Renin-angiotensin system in failing heart. J Mol Cell Cardiol 1995; 27: 201 -209. PMID: 7760344

47. Iwai N, Shimoike H, Kinoshita M. Cardiac renin-angiotensin system in the hypertrophied heart. Circulation 1995; 92: 26902696. PMID: 7586374

48. Mizuno Y, Yoshimura M, Yasue H, et al. Aldosterone production is activated in failing ventricle in humans. Circulation 2001; 103: 72-77. PMID: 11136688

49. Young M, Fullerton M, Dilley R, et al. Mineralocorticoids, hypertension, and cardiac fibrosis. J Clin Invest 1994; 93: 2578 2583. PMID: 8200995

50. Struthers AD, MacDonald TM. Review of aldosterone- and angiotensin II-induced target organ damage and prevention. Cardiovasc Res 2004; 61: 663-670. PMID: 14985063

51. Yamamuro M, Yoshimura M, Nakayama M, et al. Direct effects of aldosterone on cardiomyocytes in the presence of normal and elevated extracellular sodium. Endocrinology 2006; 147: 1314-1321. PMID: 16373419

52. Sudoh T, Kangawa K, Minamino N, et al. A new natriuretic peptide in porcine brain. Nature 1988; 332: 78-81. PMID: 2964562

53. Mukoyama M, Nakao K, Hosoda K, et al. Brain natriuretic peptide as a novel cardiac hormone in humans: Evidence for an exquisite dual natriuretic peptide system, atrial natriuretic peptide and brain natriuretic peptide. J Clin Invest 1991; 87: 1402-1412. PMID: 1849149

54. Nakao K, Ogawa Y, Suga S, et al. Molecular biology and biochemistry of the natriuretic peptide system. I: Natriuretic peptides. J Hypertens 1992; 10: 907-912. PMID: 1328371

55. Yoshimura M, Yasue H, Okumura K, et al. Different secretion patterns of atrial natriuretic peptide and brain natriuretic peptide in patients with congestive heart failure. Circulation 1993; 87: 464-469. PMID: 8425293

56. Yasue $\mathrm{H}$, Yoshimura $\mathrm{M}$, Sumida $\mathrm{H}$, et al. Localization and mechanism of secretion of B-type natriuretic peptide in comparison with those of A-type natriuretic peptide in normal subjects and patients with heart failure. Circulation 1994; 90: 195-203. PMID: 8025996

57. Maisel AS, Nakao K, Ponikowski P, et al. Japanese-Western consensus meeting on biomarkers. Int Heart J 2011; 52: 253 - 


\section{PMID: 22008432}

58. Yamamoto K, Burnett JC, Jougasaki M, et al. Superiority of brain natriuretic peptide as a hormonal marker of ventricular systolic and diastolic dysfunction and ventricular hypertrophy. Hypertension 1996; 28: 988-994. PMID: 8952587

59. Tsutamoto T, Wada A, Maeda K, et al. Attenuation of compensation of endogenous cardiac natriuretic peptide system in chronic heart failure: Prognostic role of plasma brain natriuretic peptide concentration in patients with chronic symptomatic left ventricular dysfunction. Circulation 1997; 96: 509-516. PMID: 9244219

60. Omland T, Persson A, Ng L, et al. N-terminal pro-B-type natriuretic peptide and long-term mortality in acute coronary syndromes. Circulation 2002; 106: 2913-2918. PMID: 12460871

61. Anand IS, Fisher LD, Chiang YT, et al. Val-HeFT Investigators. Changes in brain natriuretic peptide and norepinephrine over time and mortality and morbidity in the Valsartan Heart Failure Trial (Val-HeFT). Circulation 2003; 107: 1278-1283. PMID: 12628948

62. Suzuki S, Yoshimura M, Nakayama M, et al. Plasma level of B-type natriuretic peptide as a prognostic marker after acute myocardial infarction: A long-term follow-up analysis. Circulation 2004; 110: 1387-1391. PMID: 15353502

63. Price JF, Thomas AK, Grenier M, et al. B-type natriuretic peptide predicts adverse cardiovascular events in pediatric outpatients with chronic left ventricular systolic dysfunction. Circulation 2006; 114: 1063-1069. PMID: 16940194

64. Nishii M, Inomata T, Takehana H, et al. Prognostic utility of B-type natriuretic peptide assessment in stable low-risk outpatients with nonischemic cardiomyopathy after decompensated heart failure. J Am Coll Cardiol 2008; 51: 2329-2335. PMID: 18549918

65. Seino Y, Ogawa A, Yamashita T, et al. Application of NTproBNP and BNP measurements in cardiac care: A more discerning marker for the detection and evaluation of heart failure. Eur J Heart Fail 2004; 6: 295-300. PMID: 14987579

66. Kawai M, Yoshimura M, Harada M, et al. Determination of the B-type natriuretic peptide level as a criterion for abnormalities in Japanese individuals in routine clinical practice: The J-ABS Multi-Center Study (Japan Abnormal BNP Standard). Intern Med 2013; 52: 171-177. PMID: 23318845

67. Sato Y, Yamada T, Taniguchi R, et al. Persistently increased serum concentrations of cardiac troponin $t$ in patients with idiopathic dilated cardiomyopathy are predictive of adverse outcomes. Circulation 2001; 103: 369-374. PMID: 11157687

68. Ishii J, Cui W, Kitagawa F, et al. Prognostic value of combination of cardiac troponin $\mathrm{T}$ and B-type natriuretic peptide after initiation of treatment in patients with chronic heart failure. Clin Chem 2003; 49: 2020-2026. PMID: 14633873

69. Keller T, Zeller T, Peetz D, et al. Sensitive troponin I assay in early diagnosis of acute myocardial infarction. $N$ Engl J Med 2009; 361: 868-877. PMID: 19710485

70. Reichlin T, Hochholzer W, Bassetti S, et al. Early diagnosis of myocardial infarction with sensitive cardiac troponin assays. $N$ Engl J Med 2009; 361: 858-867. PMID: 19710484

71. Latini R, Masson S, Anand IS, et al. Val-HeFT Investigators. Prognostic value of very low plasma concentrations of troponin T in patients with stable chronic heart failure. Circulation 2007; 116: $1242-1249$. PMID: 17698733

72. Tsutamoto T, Kawahara C, Nishiyama K, et al. Prognostic role of highly sensitive cardiac troponin I in patients with systolic heart failure. Am Heart J 2010; 159: 63-67. PMID: 20102868

73. Levine B, Kalman J, Mayer L, et al. Elevated circulating levels of tumor necrosis factor in severe chronic heart failure. $N$ Engl J Med 1990; 323: 236-241. PMID: 2195340

74. Ferrari R, Bachetti T, Confortini R, et al. Tumor necrosis factor soluble receptors in patients with various degrees of congestive heart failure. Circulation 1995; 92: 1479-1486. PMID: 7664430

75. Tsutamoto T, Hisanaga T, Wada A, et al. Interleukin-6 spillover in the peripheral circulation increases with the severity of heart failure, and the high plasma level of interleukin-6 is an important prognostic predictor in patients with congestive heart failure. $J$ Am Coll Cardiol 1998; 31: 391 - 398. PMID: 9462584

76. Anand IS, Latini R, Florea VG, et al. Val-HeFT Investigators C-reactive protein in heart failure: Prognostic value and the effect of valsartan. Circulation 2005; 112: 1428-1434. PMID: 16129801

77. Pascual-Figal DA, Ordoñez-Llanos J, Tornel PL, et al. MUSIC Investigators. Soluble ST2 for predicting sudden cardiac death in patients with chronic heart failure and left ventricular systolic dysfunction. J Am Coll Cardiol 2009; 54: 2174-2179. PMID:
19942089

78. Tsutamoto T, Wada A, Matsumoto T, et al. Relationship between tumor necrosis factor-alpha production and oxidative stress in the failing hearts of patients with dilated cardiomyopathy. J Am Coll Cardiol 2001; 37: 2086-2092. PMID: 11419892

79. Tsutsui T, Tsutamoto T, Wada A, et al. Plasma oxidized low-density lipoprotein as a prognostic predictor in patients with chronic congestive heart failure. J Am Coll Cardiol 2002; 39: 957-962. PMID: 11897436

80. Watanabe E, Matsuda N, Shiga T, et al. Significance of 8-hydroxy-2'-deoxyguanosine levels in patients with idiopathic dilated cardiomyopathy. J Card Fail 2006; 12: 527-532. PMID: 16952786

81. Anker SD, Doehner W, Rauchhaus M, et al. Uric acid and survival in chronic heart failure: Validation and application in metabolic, functional, and hemodynamic staging. Circulation 2003; 107: 1991-1997. PMID: 12707250

82. Sakai H, Tsutamoto T, Tsutsui T, et al. Serum level of uric acid, partly secreted from the failing heart, is a prognostic marker in patients with congestive heart failure. Circ $J$ 2006; 70: 10061011. PMID: 16864933

83. Kittleson MM, Bead V, Fradley M, et al. Elevated uric acid levels predict allograft vasculopathy in cardiac transplant recipients. J Heart Lung Transplant 2007; 26: 498-503. PMID: 17449420

84. Hamaguchi S, Furumoto T, Tsuchihashi-Makaya M, et al. JCARE-CARD Investigators. Hyperuricemia predicts adverse outcomes in patients with heart failure. Int J Cardiol 2011; 151: 143-147. PMID: 20542341

85. Neuhold S, Huelsmann M, Strunk G, et al. Comparison of copeptin, B-type natriuretic peptide, and amino-terminal pro-B-type natriuretic peptide in patients with chronic heart failure: Prediction of death at different stages of the disease. $J$ Am Coll Cardiol 2008; 52: 266-272. PMID: 18634981

86. Kistorp C, Faber J, Galatius S, et al. Plasma adiponectin, body mass index, and mortality in patients with chronic heart failure. Circulation 2005; 112: 1756-1762. PMID: 16157772

87. George J, Patal S, Wexler D, et al. Circulating adiponectin concentrations in patients with congestive heart failure. Heart 2006; 92: 1420-1424. PMID: 16621874

88. Tsutamoto T, Tanaka T, Sakai H, et al. Total and high molecular weight adiponectin, haemodynamics, and mortality in patients with chronic heart failure. Eur Heart $J$ 2007; 28: 1723-1730. PMID: 17507366

89. Yanagisawa M, Kurihara H, Kimura S, et al. A novel potent vasoconstrictor peptide produced by vascular endothelial cells. Nature 1988; 332: 411-415. PMID: 2451132

90. Tsutamoto T, Hisanaga T, Fukai D, et al. Prognostic value of plasma soluble intercellular adhesion molecule-1 and endothelin-1 concentration in patients with chronic congestive heart failure. Am J Cardiol 1995; 76: 803-808. PMID: 7572659

91. Van Beneden R, Gurné O, Selvais PL, et al. Superiority of big endothelin-1 and endothelin-1 over natriuretic peptides in predicting survival in severe congestive heart failure: A 7-year follow-up study. J Card Fail 2004; 10: 490-495. PMID: 15599839

92. Nagaya N, Satoh T, Nishikimi T, et al. Hemodynamic, renal, and hormonal effects of adrenomedullin infusion in patients with congestive heart failure. Circulation 2000; 101: 498-503. PMID: 10662746

93. Wiener-Kronish JP, Matthay MA, Callen PW, et al. Relationship of pleural effusions to pulmonary hemodynamics in patients with congestive heart failure. Am Rev Respir Dis 1985; 132: 1253-1256. PMID: 3907444

94. Gehlbach BK, Geppert E. The pulmonary manifestations of left heart failure. Chest 2004; 125: 669-682. PMID: 14769751

95. Daimon M, Watanabe H, Abe Y, et al. JAMP Study Investigators. Normal values of echocardiographic parameters in relation to age in a healthy Japanese population: The JAMP study. Circ J 2008; 72: 1859-1866. PMID: 18827372

96. Lang RM, Badano LP, Mor-Avi V, et al. Recommendations for cardiac chamber quantification by echocardiography in adults: An update from the American Society of Echocardiography and the European Association of Cardiovascular Imaging. $J$ Am Soc Echocardiogr 2015; 28: 1-39.e14. PMID: 25559473

97. Voigt JU, Pedrizzetti G, Lysyansky P, et al. Definitions for a common standard for 2D speckle tracking echocardiography: Consensus document of the EACVI/ASE/Industry Task Force to standardize deformation imaging. $J$ Am Soc Echocardiogr 2015; 28: 183-193. PMID: 25623220

98. Ommen SR, Nishimura RA, Appleton CP, et al. Clinical utility 
of Doppler echocardiography and tissue Doppler imaging in the estimation of left ventricular filling pressures: A comparative simultaneous Doppler-catheterization study. Circulation 2000; 102: 1788-1794. PMID: 11023933

99. Geske JB, Sorajja P, Nishimura RA, et al. Evaluation of left ventricular filling pressures by Doppler echocardiography in patients with hypertrophic cardiomyopathy: Correlation with direct left atrial pressure measurement at cardiac catheterization. Circulation 2007; 116: 2702-2708. PMID: 18025528

100. Pritchett AM, Mahoney DW, Jacobsen SJ, et al. Diastolic dysfunction and left atrial volume: A population-based study. J Am Coll Cardiol 2005; 45: 87-92. PMID: 15629380

101. Nagueh SF, Smiseth OA, Appleton CP, et al. Recommendations for the evaluation of left ventricular diastolic function by echocardiography: An update from the American Society of Echocardiography and the European Association of Cardiovascular Imaging. Eur Heart J Cardiovasc Imaging 2016; 17: 1321 - 1360. PMID: 27422899

102. Andersen OS, Smiseth OA, Dokainish H, et al. Estimating left ventricular filling pressure by echocardiography. $\mathrm{J} \mathrm{Am} \mathrm{Coll}$ Cardiol 2017; 69: 1937-1948. PMID: 28408024

103. Donal E, Lund LH, Oger E, et al. KaRen investigators. Value of exercise echocardiography in heart failure with preserved ejection fraction: A substudy from the KaRen study. Eur Heart $J$ Cardiovasc Imaging 2016; 17: 106-113. PMID: 26082167

104. Picano E, Pellikka PA. Ultrasound of extravascular lung water: A new standard for pulmonary congestion. Eur Heart J 2016; 37: 2097-2104. PMID: 27174289

105. Karamitsos TD, Francis JM, Myerson S, et al. The role of cardiovascular magnetic resonance imaging in heart failure. $J$ Am Coll Cardiol 2009; 54: 1407-1424. PMID: 19796734

106. The Japanese Circulation Society. Guidelines for Diagnosis and Treatment of Patients with Hypertrophic Cardiomyopathy (JCS 2012). http://www.j-circ.or.jp/guideline/pdf/JCS2012_doi_h. pdf

107. The Japanese Circulation Society. Guidelines for Management of Dilated Cardiomyopathy and Secondary Cardiomyopathy (JCS 2011). http://www.j-circ.or.jp/guideline/pdf/JCS2011_ tomoike_h.pdf

108. Babu-Narayan SV, Giannakoulas G, Valente AM, et al. Imaging of congenital heart disease in adults. Eur Heart $J$ 2016; 37: 1182-1195. PMID: 26424866

109. Moon JC, Messroghli DR, Kellman P, et al. Myocardial T1 mapping and extracellular volume quantification: A Society for Cardiovascular Magnetic Resonance (SCMR) and CMR Working Group of the European Society of Cardiology consensus statement. J Cardiovasc Magn Reson 2013; 15: 92-92. PMID: 24124732

110. Ghostine S, Caussin C, Habis M, et al. Non-invasive diagnosis of ischaemic heart failure using 64-slice computed tomography. Eur Heart J 2008; 29: 2133-2140. PMID: 18385120

111. The Japanese Circulation Society. Guidelines for diagnostic evaluation of patients with chronic ischemic heart disease (JCS 2010). http://www.j-circ.or.jp/guideline/pdf/JCS2010_yamagishi_h. pdf

112. The Japanese Circulation Society. Guidelines for clinical use of cardiac nuclear medicine (JCS 2010). Circ J 2005; 69(Suppl IV): $1125-1202$

113. Bonow RO, Maurer G, Lee KL, et al. STICH Trial Investigators. Myocardial viability and survival in ischemic left ventricular dysfunction. N Engl J Med 2011; 364: 1617-1625. PMID: 21463153

114. Imamura $\mathrm{Y}$, Ando $\mathrm{H}$, Mitsuoka W, et al. Iodine-123 metaiodobenzylguanidine images reflect intense myocardial adrenergic nervous activity in congestive heart failure independent of underlying cause. J Am Coll Cardiol 1995; 26: 1594-1599. PMID: 7594091

115. Schofer J, Spielmann R, Schuchert A, et al. Iodine-123 metaiodobenzylguanidine scintigraphy: A noninvasive method to demonstrate myocardial adrenergic nervous system disintegrity in patients with idiopathic dilated cardiomyopathy. $\mathrm{J} \mathrm{Am} \mathrm{Coll}$ Cardiol 1988; 12: 1252-1258. PMID: 3170968

116. Matsuo S, Nakamura Y, Tsutamoto T, et al. Impairments of myocardial sympathetic activity may reflect the progression of myocardial damage or dysfunction in hypertrophic cardiomyopathy. J Nucl Cardiol 2002; 9: 407-412. PMID: 12161717

117. Hongo M, Urushibata K, Kai R, et al. Iodine-123 metaiodobenzylguanidine scintigraphic analysis of myocardial sympathetic innervation in patients with AL (primary) amyloidosis. $\mathrm{Am}$ Heart J 2002; 144: 122-129. PMID: 12094198
118. Tsutsui H, Ando S, Kubota T, et al. Abnormalities of cardiac sympathetic neuronal and left ventricular function in chronic mitral regurgitation: Assessment by iodine-123 metaiodobenzylguanidine scintigraphy. Am J Card Imaging 1996; 10: 14-22. PMID: 8680129

119. Nakata T, Nakajima K, Yamashina S, et al. A pooled analysis of multicenter cohort studies of (123)I-mIBG imaging of sympathetic innervation for assessment of long-term prognosis in heart failure. JACC Cardiovasc Imaging 2013; 6: 772-784. PMID: 23845574

120. Tamaki N, Yoshinaga K. Novel iodinated tracers, MIBG and BMIPP, for nuclear cardiology. J Nucl Cardiol 2011; 18: 135-143. PMID: 21082300

121. Kasama S, Toyama T, Kurabayashi M. Usefulness of cardiac sympathetic nerve imaging using (123)iodine-metaiodobenzylguanidine scintigraphy for predicting sudden cardiac death in patients with heart failure. Int Heart $J$ 2016; 57: 140-144. PMID: 26973278

122. Yamazaki J, Muto H, Kabano T, et al. Evaluation of beta-blocker therapy in patients with dilated cardiomyopathy--Clinical meaning of iodine 123-metaiodobenzylguanidine myocardial single-photon emission computed tomography. Am Heart $J$ 2001; 141: 645-652. PMID: 11275933

123. Kasama S, Toyama T, Kumakura H, et al. Spironolactone improves cardiac sympathetic nerve activity and symptoms in patients with congestive heart failure. $J$ Nucl Med 2002; 43: 1279-1285. PMID: 12368364

124. Takeishi Y, Atsumi H, Fujiwara S, et al. ACE inhibition reduces cardiac iodine-123-MIBG release in heart failure. $J$ Nucl Med 1997; 38: 1085-1089. PMID: 9225795

125. Maurer MS. Noninvasive Identification of ATTRwt Cardiac Amyloid: The Re-emergence of Nuclear Cardiology. Am J Med 2015; 128: 1275-1280. PMID: 26091765

126. Høilund-Carlsen PF, Lauritzen SL, Marving J, et al. The reliability of measuring left ventricular ejection fraction by radionuclide cardiography: Evaluation by the method of variance components. Br Heart J 1988; 59: 653-662. PMID: 3395524

127. Sakata K, Yoshino H, Kurihara H, et al. Prognostic significance of persistent right ventricular dysfunction as assessed by radionuclide angiocardiography in patients with inferior wall acute myocardial infarction. Am J Cardiol 2000; 85: 939-944. PMID: 10760330

128. Le Guludec D, Gauthier H, Porcher R, et al. Prognostic value of radionuclide angiography in patients with right ventricular arrhythmias. Circulation 2001; 103: 1972-1976. PMID: 11306526

129. The Japanese Circulation Society. Guidelines for Diagnosis and Treatment of Cardiac Sarcoidosis (JCS 2016). http://www.j-circ. or.jp/guideline/pdf/JCS2016_terasaki_h.pdf

130. Youssef G, Leung E, Mylonas I, et al. The use of 18F-FDG PET in the diagnosis of cardiac sarcoidosis: A systematic review and metaanalysis including the Ontario experience. J Nucl Med 2012; 53: 241-248. PMID: 22228794

131. The criteria committee of the New York Heart Association. In: Nomenclature and Criteria for Diagnosis of Diseases of the Heart and Great Vessels 9th edn. Little Brown \& Co, 1994: $253-256$

132. Sasayama S, Asanoi H, Ishizaka S, et al. Evaluation of functional capacity of patients with congestive heart failure. In: Yasuda $\mathrm{H}$, Kawaguchi $\mathrm{H}$, editors. New aspects in the treatment of failing heart syndrome. Springer-Verlag, 1992: 113-117.

133. The Japanese Intractable Diseases Information Center. idiopathic dilated cardiomyopathy (IDCM) (Designated intractable disease No. 57). http://www.or.jp/entry/3986

134. Onishi Y, Sato H, Koretsune Y, et al. Study on distribution of normal values and factors determining 6-minute walking distance. Jpn Circ J 1998; 61(Suppl III): 856.

135. Bittner V, Weiner DH, Yusuf S, et al. SOLVD Investigators. Prediction of mortality and morbidity with a 6-minute walk test in patients with left ventricular dysfunction. JAMA 1993; 270: 1702-1707. PMID: 8411500

136. Forman DE, Fleg JL, Kitzman DW, et al. 6-min walk test provides prognostic utility comparable to cardiopulmonary exercise testing in ambulatory outpatients with systolic heart failure. J Am Coll Cardiol 2012; 60: 2653-2661. PMID: 23177293

137. Cheetham C, Taylor R, Burke V, et al. The 6-minute walk test does not reliably detect changes in functional capacity of patients awaiting cardiac transplantation. J Heart Lung Transplant 2005; 24: 848-853. PMID: 15982612

138. Mancini DM, Eisen H, Kussmaul W, et al. Value of peak exercise 
oxygen consumption for optimal timing of cardiac transplantation in ambulatory patients with heart failure. Circulation 1991; 83: 778-786. PMID: 1999029

139. Nakanishi M, Takaki H, Kumasaka R, et al. Targeting of high peak respiratory exchange ratio is safe and enhances the prognostic power of peak oxygen uptake for heart failure patients. Circ J 2014; 78: 2268-2275. PMID: 25056425

140. Koike A, Koyama Y, Itoh H, et al. Prognostic significance of cardiopulmonary exercise testing for 10-year survival in patients with mild to moderate heart failure. Jpn Circ J 2000; 64: 915 920. PMID: 11194282

141. Aaronson KD, Schwartz JS, Chen TM, et al. Development and prospective validation of a clinical index to predict survival in ambulatory patients referred for cardiac transplant evaluation. Circulation 1997; 95: 2660-2667. PMID: 9193435

142. Mudge GH, Goldstein S, Addonizio LJ, et al. 24th Bethesda conference: Cardiac transplantation. Task Force 3: Recipient guidelines/prioritization. J Am Coll Cardiol 1993; 22: 21-31. PMID: 8509544

143. Fletcher GF, Ades PA, Kligfield P, et al. American Heart Association Exercise, Cardiac Rehabilitation, and Prevention Committee of the Council on Clinical Cardiology, Council on Nutrition, Physical Activity and Metabolism, Council on Cardiovascular and Stroke Nursing, and Council on Epidemiology and Prevention. Exercise standards for testing and training: A scientific statement from the American Heart Association. Circulation 2013; 128: 873-934. PMID: 23877260

144. Matsumura N, Nishijima H, Kojima S, et al. Determination of anaerobic threshold for assessment of functional state in patients with chronic heart failure. Circulation 1983; 68: 360-367. PMID: 6222847

145. Stelken AM, Younis LT, Jennison SH, et al. Prognostic value of cardiopulmonary exercise testing using percent achieved of predicted peak oxygen uptake for patients with ischemic and dilated cardiomyopathy. J Am Coll Cardiol 1996; 27: 345-352. PMID: 8557904

146. Wasserman K, Hansen JE, Sue D. Physiology of Exercise. In: Principles of Exercise Testing and Interpretation. Lea \& Febiger, 1994.

147. The Japanese Circulation Society. Guidelines for exercise eligibility at schools, work-sites, and sports in patients with heart diseases (JCS 2008). http://www.j-circ.or.jp/guideline/pdf/ JCS2008_nagashima_h.pdf

148. The Japanese Circulation Society. Guidelines for rehabilitation in patients with cardiovascular disease (JCS 2012). http:// www.j-circ.or.jp/guideline/pdf/JCS2012 nohara h.pdf

149. Arena R, Myers J, Aslam SS, et al. Peak VO2 and VE/VCO2 slope in patients with heart failure: A prognostic comparison. Am Heart J 2004; 147: 354-360. PMID: 14760336

150. Kostis JB, Davis BR, Cutler J, et al. SHEP Cooperative Research Group. Prevention of heart failure by antihypertensive drug treatment in older persons with isolated systolic hypertension. JAMA 1997; 278: 212-216. PMID: 9218667

151. Beckett NS, Peters R, Fletcher AE, et al. HYVET Study Group. Treatment of hypertension in patients 80 years of age or older. N Engl J Med 2008; 358: 1887-1898. PMID: 18378519

152. Sciarretta S, Palano F, Tocci G, et al. Antihypertensive treatment and development of heart failure in hypertension: A Bayesian network meta-analysis of studies in patients with hypertension and high cardiovascular risk. Arch Intern Med 2011; 171: 384-394. PMID: 21059964

153. Wright JT, Williamson JD, Whelton PK, et al. SPRINT Research Group. A randomized trial of intensive versus standard blood-pressure control. $N$ Engl J Med 2015; 373: 2103-2116. PMID: 26551272

154. The Japanese Society of Hypertension. Guidelines for the management of hypertension 2014. Tokyo: Life Science Shuppan, 2014.

155. Dagenais GR, Pogue J, Fox K, et al. Angiotensin-convertingenzyme inhibitors in stable vascular disease without left ventricular systolic dysfunction or heart failure: A combined analysis of three trials. Lancet 2006; 368: 581-588. PMID: 16905022

156. Pfeffer MA, Braunwald E, Moyé LA, et al. SAVE Investigators. Effect of captopril on mortality and morbidity in patients with left ventricular dysfunction after myocardial infarction. Results of the survival and ventricular enlargement trial. $N$ Engl J Med 1992; 327: 669-677. PMID: 1386652

157. Køber L, Torp-Pedersen C, Carlsen JE, et al. Trandolapril Cardiac Evaluation (TRACE) Study Group. A clinical trial of the angiotensin-converting-enzyme inhibitor trandolapril in patients with left ventricular dysfunction after myocardial infarction. $N$ Engl J Med 1995; 333: 1670-1676. PMID: 7477219

158. Abdulla J, Barlera S, Latini R, et al. A systematic review: Effect of angiotensin converting enzyme inhibition on left ventricular volumes and ejection fraction in patients with a myocardial infarction and in patients with left ventricular dysfunction. Eur J Heart Fail 2007; 9: 129-135. PMID: 16829187

159. Dargie HJ. Effect of carvedilol on outcome after myocardial infarction in patients with left-ventricular dysfunction: The CAPRICORN randomised trial. Lancet 2001; 357: 1385-1390. PMID: 11356434

160. Kjekshus J, Pedersen TR, Olsson AG, et al. The effects of simvastatin on the incidence of heart failure in patients with coronary heart disease. J Card Fail 1997; 3: 249-254. PMID: 9547437

161. Scirica BM, Morrow DA, Cannon CP, et al. PROVE IT-TIMI 22 Investigators. Intensive statin therapy and the risk of hospitalization for heart failure after an acute coronary syndrome in the PROVE IT-TIMI 22 study. J Am Coll Cardiol 2006; 47: 2326-2331. PMID: 16750703

162. Afilalo J, Majdan AA, Eisenberg MJ. Intensive statin therapy in acute coronary syndromes and stable coronary heart disease: A comparative meta-analysis of randomised controlled trials. Heart 2007; 93: 914-921. PMID: 17277349

163. Pitt B, Remme W, Zannad F, et al. Eplerenone Post-Acute Myocardial Infarction Heart Failure Efficacy and Survival Study Investigators. Eplerenone, a selective aldosterone blocker, in patients with left ventricular dysfunction after myocardial infarction. $N$ Engl J Med 2003; 348: 1309-1321. PMID: 12668699

164. Zannad F, McMurray JJ, Krum H, et al. EMPHASIS-HF Study Group. Eplerenone in patients with systolic heart failure and mild symptoms. $N$ Engl J Med 2011; 364: 11-21. PMID: 21073363

165. Montalescot G, Pitt B, Lopez de Sa E, et al. REMINDER Investigators. Early eplerenone treatment in patients with acute ST-elevation myocardial infarction without heart failure: The Randomized Double-Blind Reminder Study. Eur Heart J 2014; 35: 2295-2302. PMID: 24780614

166. The Japanese Circulation Society. Guidelines for Secondary Prevention of Myocardial Infarction (JCS 2011). http://www.j-circ. or.jp/guideline/pdf/JCS2011_ogawah_h.pdf

167. Dickstein K, Kjekshus J. OPTIMAAL Steering Committee of the OPTIMAAL Study Group. Effects of losartan and captopril on mortality and morbidity in high-risk patients after acute myocardial infarction: The OPTIMAAL randomised trial. Optimal Trial in Myocardial Infarction with Angiotensin II Antagonist Losartan. Lancet 2002; 360: 752-760. PMID: 12241832

168. Pfeffer MA, McMurray JJ, Velazquez EJ, et al. Valsartan in Acute Myocardial Infarction Trial Investigators. Valsartan, captopril, or both in myocardial infarction complicated by heart failure, left ventricular dysfunction, or both. $N$ Engl J Med 2003; 349: 1893-1906. PMID: 14610160

169. Hochman JS, Lamas GA, Buller CE, et al. Occluded Artery Trial Investigators. Coronary intervention for persistent occlusion after myocardial infarction. N Engl J Med 2006; 355: 2395-2407. PMID: 17105759

170. Kenchaiah S, Evans JC, Levy D, et al. Obesity and the risk of heart failure. N Engl J Med 2002; 347: 305-313. PMID: 12151467

171. Nichols GA, Gullion CM, Koro CE, et al. The incidence of congestive heart failure in type 2 diabetes: An update. Diabetes Care 2004; 27: 1879-1884. PMID: 15277411

172. Wilhelmsen L, Rosengren A, Eriksson H, et al. Heart failure in the general population of men: Morbidity, risk factors and prognosis. J Intern Med 2001; 249: 253-261. PMID: 11285045

173. Bibbins-Domingo K, Lin F, Vittinghoff E, et al. Predictors of heart failure among women with coronary disease. Circulation 2004; 110: 1424-1430. PMID: 15353499

174. The Japan Diabetes Society. Guidelines for the treatment of diabetes mellitus 2016-2017. Tokyo: Bunkodo, 2016.

175. Zinman B, Wanner C, Lachin JM, et al. EMPA-REG OUTCOME Investigators. Empagliflozin, cardiovascular outcomes, and mortality in type 2 diabetes. N Engl J Med 2015; 373: $2117-$ 2128. PMID: 26378978

176. Fitchett D, Zinman B, Wanner C, et al. EMPA-REG OUTCOME $^{\circledR}$ trial investigators. Heart failure outcomes with empagliflozin in patients with type 2 diabetes at high cardiovascular risk: Results of the EMPA-REG OUTCOME ${ }^{\circledR}$ trial. Eur 
Heart J 2016; 37: 1526-1534. PMID: 26819227

177. Fitchett D, Butler J, van de Borne P, et al. EMPA-REG OUTCOME ${ }^{\circledR}$ trial investigators. Effects of empagliflozin on risk for cardiovascular death and heart failure hospitalization across the spectrum of heart failure risk in the EMPA-REG OUTCOME $^{\circledR}$ trial. Eur Heart $J$ 2018; 39: 363-370. PMID: 29020355

178. Neal B, Perkovic V, Mahaffey KW, et al. CANVAS Program Collaborative Group. Canagliflozin and cardiovascular and renal events in type 2 diabetes. $N$ Engl J Med 2017; 377: 644-657. PMID: 28605608

179. Dorans KS, Mostofsky E, Levitan EB, et al. Alcohol and incident heart failure among middle-aged and elderly men: Cohort of Swedish men. Circ Heart Fail 2015; 8: 422-427. PMID: 25872788

180. Gonçalves A, Claggett B, Jhund PS, et al. Alcohol consumption and risk of heart failure: The Atherosclerosis Risk in Communities Study. Eur Heart J 2015; 36: 939-945. PMID: 25602025

181. Gémes K, Janszky I, Ahnve S, et al. Light-to-moderate drinking and incident heart failure: The Norwegian HUNT study. Int $J$ Cardiol 2016; 203: 553-560. PMID: 26569362

182. CONSENSUS Trial Study Group. Effects of enalapril on mortality in severe congestive heart failure. Results of the Cooperative North Scandinavian Enalapril Survival Study (CONSENSUS). $N$ Engl J Med 1987; 316: 1429-1435. PMID: 2883575

183. SOLVD Investigators. Effect of enalapril on mortality and the development of heart failure in asymptomatic patients with reduced left ventricular ejection fractions. $N$ Engl J Med 1992; 327: 685-691. PMID: 1463530

184. SOLVD Investigators. Effect of enalapril on survival in patients with reduced left ventricular ejection fractions and congestive heart failure. $N$ Engl J Med 1991; 325: 293-302. PMID: 2057034

185. Jong P, Yusuf S, Rousseau MF, et al. Effect of enalapril on 12-year survival and life expectancy in patients with left ventricular systolic dysfunction: A follow-up study. Lancet 2003; 361: 1843-1848. PMID: 12788569

186. Matsumori A. Assessment of Response to Candesartan in Heart Failure in Japan (ARCH-J) Study Investigators. Efficacy and safety of oral candesartan cilexetil in patients with congestive heart failure. Eur J Heart Fail 2003; 5: 669-677. PMID: 14607207

187. Granger CB, McMurray JJ, Yusuf S, et al. CHARM Investigators and Committees. Effects of candesartan in patients with chronic heart failure and reduced left-ventricular systolic function intolerant to angiotensin-converting-enzyme inhibitors: The CHARM-Alternative trial. Lancet 2003; 362: 772-776. PMID: 13678870

188. Pitt B, Poole-Wilson PA, Segal R, et al. Effect of losartan compared with captopril on mortality in patients with symptomatic heart failure: Randomised trial--the Losartan Heart Failure Survival Study ELITE II. Lancet 2000; 355: 1582-1587. PMID: 10821361

189. Pitt B, Zannad F, Remme WJ, et al. Randomized Aldactone Evaluation Study Investigators. The effect of spironolactone on morbidity and mortality in patients with severe heart failure. $N$ Engl J Med 1999; 341: 709-717. PMID: 10471456

190. Tsutsui H, Ito H, Kitakaze M, et al. J-EMPHASIS-HF Study Group. Double-blind, randomized, placebo-controlled trial evaluating the efficacy and safety of eplerenone in Japanese patients with chronic heart failure (J-EMPHASIS-HF). Circ $J$ 2018; 82: 148-158. PMID: 28824029

191. Juurlink DN, Mamdani MM, Lee DS, et al. Rates of hyperkalemia after publication of the randomized aldactone evaluation study. $N$ Engl J Med 2004; 351: 543-551. PMID: 15295047

192. Packer M, Bristow MR, Cohn JN, et al. The effect of carvedilol on morbidity and mortality in patients with chronic heart failure. U.S. Carvedilol Heart Failure Study Group. N Engl J Med 1996; 334: 1349-1355. PMID: 8614419

193. CIBIS-II Investigators and Committees. The Cardiac Insufficiency Bisoprolol Study II (CIBIS-II): A randomised trial. Lancet 1999; 353: 9-13. PMID: 10023943

194. Effect of metoprolol CR/XL in chronic heart failure: Metoprolol CR/XL Randomised Intervention Trial in Congestive Heart Failure (MERIT-HF). Lancet 1999; 353: 2001-2007. PMID: 10376614

195. Packer M, Coats AJ, Fowler MB, et al. Carvedilol Prospective Randomized Cumulative Survival Study Group. Effect of carvedilol on survival in severe chronic heart failure. $N$ Engl $J$ Med 2001; 344: 1651-1658. PMID: 11386263

196. Gattis WA, O'Connor CM, Gallup DS, et al. IMPACT-HF
Investigators and Coordinators. Predischarge initiation of carvedilol in patients hospitalized for decompensated heart failure: Results of the Initiation Management Predischarge: Process for Assessment of Carvedilol Therapy in Heart Failure (IMPACT-HF) trial. J Am Coll Cardiol 2004; 43: 1534-1541. PMID: 15120808

197. Fonarow GC, Abraham WT, Albert NM, et al. OPTIMIZEHF Investigators and Coordinators. Influence of beta-blocker continuation or withdrawal on outcomes in patients hospitalized with heart failure: Findings from the OPTIMIZE-HF program. J Am Coll Cardiol 2008; 52: 190-199. PMID: 18617067

198. Domanski M, Norman J, Pitt B, et al. Diuretic use, progressive heart failure, and death in patients in the Studies Of Left Ventricular Dysfunction (SOLVD). J Am Coll Cardiol 2003; 42: 705-708. PMID: 12932605

199. Ahmed A, Husain A, Love TE, et al. Heart failure, chronic diuretic use, and increase in mortality and hospitalization: An observational study using propensity score methods. Eur Heart $J$ 2006; 27: 1431-1439. PMID: 16709595

200. Eshaghian S, Horwich TB, Fonarow GC. Relation of loop diuretic dose to mortality in advanced heart failure. Am J Cardiol 2006; 97: 1759-1764. PMID: 16765130

201. Domanski M, Tian X, Haigney M, et al. Diuretic use, progressive heart failure, and death in patients in the DIG study. J Card Fail 2006; 12: 327-332. PMID: 16762792

202. Masuyama T, Tsujino T, Origasa H, et al. Superiority of longacting to short-acting loop diuretics in the treatment of congestive heart failure. Circ J 2012; 76: 833-842. PMID: 22451450

203. Gheorghiade M, Konstam MA, Burnett JC, et al. Efficacy of Vasopressin Antagonism in Heart Failure Outcome Study With Tolvaptan (EVEREST) Investigators. Short-term clinical effects of tolvaptan, an oral vasopressin antagonist, in patients hospitalized for heart failure: The EVEREST Clinical Status Trials. JAMA 2007; 297: 1332-1343. PMID: 17384438

204. Konstam MA, Gheorghiade M, Burnett JC, et al. Efficacy of Vasopressin Antagonism in Heart Failure Outcome Study With Tolvaptan (EVEREST) Investigators. Effects of oral tolvaptan in patients hospitalized for worsening heart failure: The EVEREST Outcome Trial. JAMA 2007; 297: 1319-1331. PMID: 17384437

205. Cohn JN, Archibald DG, Ziesche S, et al. Effect of vasodilator therapy on mortality in chronic congestive heart failure: Results of a veterans administration cooperative study. $N$ Engl J Med 1986; 314: 1547-1552. PMID: 3520315

206. Cohn JN, Johnson G, Ziesche S, et al. A comparison of enalapril with hydralazine-isosorbide dinitrate in the treatment of chronic congestive heart failure. $N$ Engl J Med 1991; 325: 303-310. PMID: 2057035

207. Digitalis Investigation Group. The effect of digoxin on mortality and morbidity in patients with heart failure. N Engl J Med 1997; 336: 525-533. PMID: 9036306

208. Packer M, Carver JR, Rodeheffer RJ, et al. PROMISE Study Research Group. Effect of oral milrinone on mortality in severe chronic heart failure. N Engl J Med 1991; 325: 1468-1475. PMID: 1944425

209. Cohn JN, Goldstein SO, Greenberg BH, et al. Vesnarinone Trial Investigators. A dose-dependent increase in mortality with vesnarinone among patients with severe heart failure. $N$ Engl $J$ Med 1998; 339: 1810-1816. PMID: 9854116

210. Davis BR, Cutler JA, Furberg CD, et al. ALLHAT Collaborative Research Group. Relationship of antihypertensive treatment regimens and change in blood pressure to risk for heart failure in hypertensive patients randomly assigned to doxazosin or chlorthalidone: Further analyses from the Antihypertensive and Lipid-Lowering treatment to prevent Heart Attack Trial. Ann Intern Med 2002; 137: 313-320. PMID: 12204014

211. Cleland JG, Tendera M, Adamus J, et al. PEP-CHF Investigators. The perindopril in elderly people with chronic heart failure (PEP-CHF) study. Eur Heart J 2006; 27: 2338-2345. PMID: 16963472

212. Yusuf S, Pfeffer MA, Swedberg K, et al. CHARM Investigators and Committees. Effects of candesartan in patients with chronic heart failure and preserved left-ventricular ejection fraction: The CHARM-Preserved Trial. Lancet 2003; 362: 777-781. PMID: 13678871

213. Massie BM, Carson PE, McMurray JJ, et al. I-PRESERVE Investigators. Irbesartan in patients with heart failure and preserved ejection fraction. $N$ Engl J Med 2008; 359: 2456-2467. PMID: 19001508

214. Yamamoto K, Origasa H, Hori M, et al. J-DHF Investigators. Effects of carvedilol on heart failure with preserved ejection 
fraction: The Japanese Diastolic Heart Failure Study (J-DHF). Eur J Heart Fail 2013; 15: 110-118. PMID: 22983988

215. Pitt B, Pfeffer MA, Assmann SF, et al. TOPCAT Investigators. Spironolactone for heart failure with preserved ejection fraction. N Engl J Med 2014; 370: 1383-1392. PMID: 24716680

216. Ahmed A, Rich MW, Fleg JL, et al. Effects of digoxin on morbidity and mortality in diastolic heart failure: The ancillary digitalis investigation group trial. Circulation 2006; 114: 397403. PMID: 16864724

217. Lund LH, Benson L, Dahlström U, et al. Association between use of renin-angiotensin system antagonists and mortality in patients with heart failure and preserved ejection fraction. JAMA 2012; 308: 2108-2117. PMID: 23188027

218. Liu F, Chen Y, Feng X, et al. Effects of beta-blockers on heart failure with preserved ejection fraction: A meta-analysis. PLoS One 2014; 9: e90555. PMID: 24599093

219. Lund LH, Benson L, Dahlström U, et al. Association between use of $\beta$-blockers and outcomes in patients with heart failure and preserved ejection fraction. JAMA 2014; 312: 2008-2018. PMID: 25399276

220. Redfield MM, Anstrom KJ, Levine JA, et al. NHLBI Heart Failure Clinical Research Network. Isosorbide mononitrate in heart failure with preserved ejection fraction. $N$ Engl $J$ Med 2015; 373: 2314-2324. PMID: 26549714

221. Lim SL, Benson L, Dahlström U, et al. Association between use of long-acting nitrates and outcomes in heart failure with preserved ejection fraction. Circ Heart Fail 2017; 10: e003534. PMID: 28377439

222. Antiarrhythmics versus Implantable Defibrillators (AVID) Investigators. A comparison of antiarrhythmic-drug therapy with implantable defibrillators in patients resuscitated from near-fatal ventricular arrhythmias. $N$ Engl J Med 1997; 337: 1576-1583. PMID: 9411221

223. Kuck KH, Cappato R, Siebels J, et al. Randomized comparison of antiarrhythmic drug therapy with implantable defibrillators in patients resuscitated from cardiac arrest: The Cardiac Arrest Study Hamburg (CASH). Circulation 2000; 102: $748-754$. PMID: 10942742

224. Connolly SJ, Gent M, Roberts RS, et al. Canadian implantable defibrillator study (CIDS): A randomized trial of the implantable cardioverter defibrillator against amiodarone. Circulation 2000; 101: 1297-1302. PMID: 10725290

225. Connolly SJ, Hallstrom AP, Cappato R, et al. Meta-analysis of the implantable cardioverter defibrillator secondary prevention trials. AVID, CASH and CIDS studies. Antiarrhythmics vs Implantable Defibrillator study. Cardiac Arrest Study Hamburg. Canadian Implantable Defibrillator Study. Eur Heart J 2000; 21: 2071-2078. PMID: 11102258

226. Russo AM, Stainback RF, Bailey SR, et al. ACCF/HRS/AHA/ ASE/HFSA/SCAI/SCCT/SCMR 2013 appropriate use criteria for implantable cardioverter-defibrillators and cardiac resynchronization therapy: A report of the American College of Cardiology Foundation appropriate use criteria task force, Heart Rhythm Society, American Heart Association, American Society of Echocardiography, Heart Failure Society of America, Society for Cardiovascular Angiography and Interventions, Society of Cardiovascular Computed Tomography, and Society for Cardiovascular Magnetic Resonance. J Am Coll Cardiol 2013; 61: 1318-1368. PMID: 23453819

227. Zipes DP, Camm AJ, Borggrefe M, et al. European Heart Rhythm Association. ACC/AHA/ESC 2006 guidelines for management of patients with ventricular arrhythmias and the prevention of sudden cardiac death: A report of the American College of Cardiology/American Heart Association Task Force and the European Society of Cardiology Committee for Practice Guidelines (Writing Committee to Develop Guidelines for Management of Patients With Ventricular Arrhythmias and the Prevention of Sudden Cardiac Death). J Am Coll Cardiol 2006; 48: e247-e346. PMID: 16949478

228. Kuck KH, Schaumann A, Eckardt L, et al. VTACH study group. Catheter ablation of stable ventricular tachycardia before defibrillator implantation in patients with coronary heart disease (VTACH): A multicentre randomised controlled trial. Lancet 2010; 375: 31-40. PMID: 20109864

229. Moss AJ, Hall WJ, Cannom DS, et al. Multicenter Automatic De fibrillator Implantation Trial Investigators. Improved survival with an implanted defibrillator in patients with coronary disease at high risk for ventricular arrhythmia. $N$ Engl $J$ Med 1996; 335: 1933-1940. PMID: 8960472

230. Moss AJ, Zareba W, Hall WJ, et al. Multicenter Automatic
Defibrillator Implantation Trial II Investigators. Prophylactic implantation of a defibrillator in patients with myocardial infarction and reduced ejection fraction. $N$ Engl J Med 2002; 346: 877-883. PMID: 11907286

231. Buxton AE, Lee KL, Fisher JD, et al. Multicenter Unsustained Tachycardia Trial Investigators. A randomized study of the prevention of sudden death in patients with coronary artery disease. $N$ Engl J Med 1999; 341: 1882 - 1890. PMID: 10601507

232. Hohnloser SH, Kuck KH, Dorian P, et al. DINAMIT Investigators. Prophylactic use of an implantable cardioverter-defibrillator after acute myocardial infarction. $N$ Engl J Med 2004; 351: 2481-2488. PMID: 15590950

233. Kadish A, Dyer A, Daubert JP, et al. Defibrillators in NonIschemic Cardiomyopathy Treatment Evaluation (DEFINITE) Investigators. Prophylactic defibrillator implantation in patients with nonischemic dilated cardiomyopathy. N Engl J Med 2004; 350: 2151-2158. PMID: 15152060

234. Bardy GH, Lee KL, Mark DB, et al. Sudden Cardiac Death in Heart Failure Trial (SCD-HeFT) Investigators. Amiodarone or an implantable cardioverter-defibrillator for congestive heart failure. $N$ Engl J Med 2005; 352: 225-237. PMID: 15659722

235. Bänsch D, Antz M, Boczor S, et al. Primary prevention of sudden cardiac death in idiopathic dilated cardiomyopathy: The Cardiomyopathy Trial (CAT). Circulation 2002; 105: 1453-1458. PMID: 11914254

236. Strickberger SA, Hummel JD, Bartlett TG, et al. AMIOVIRT Investigators. Amiodarone versus implantable cardioverterdefibrillator:randomized trial in patients with nonischemic dilated cardiomyopathy and asymptomatic nonsustained ventricular tachycardia--AMIOVIRT. J Am Coll Cardiol 2003; 41: 1707-1712. PMID: 12767651

237. Bristow MR, Saxon LA, Boehmer J, et al. Comparison of Medical Therapy, Pacing, and Defibrillation in Heart Failure (COMPANION) Investigators. Cardiac-resynchronization therapy with or without an implantable defibrillator in advanced chronic heart failure. $N$ Engl J Med 2004; 350: 2140-2150. PMID: 15152059

238. Køber L, Thune JJ, Nielsen JC, et al. DANISH Investigators. Defibrillator implantation in patients with nonischemic systolic heart failure. $N$ Engl J Med 2016; 375: 1221-1230. PMID 27571011

239. Shiba N, Shimokawa H. Chronic heart failure in Japan: Implications of the CHART studies. Vasc Health Risk Manag 2008; 4: 103-113. PMID: 18629369

240. Cazeau S, Leclercq C, Lavergne T, et al. Multisite Stimulation in Cardiomyopathies (MUSTIC) Study Investigators. Effects of multisite biventricular pacing in patients with heart failure and intraventricular conduction delay. $N$ Engl J Med 2001; 344: 873-880. PMID: 11259720

241. Abraham WT, Fisher WG, Smith AL, et al. MIRACLE Study Group. Cardiac resynchronization in chronic heart failure. $N$ Engl J Med 2002; 346: 1845-1853. PMID: 12063368

242. Leclercq C, Walker S, Linde C, et al. Comparative effects of permanent biventricular and right-univentricular pacing in heart failure patients with chronic atrial fibrillation. Eur Heart $J$ 2002; 23: 1780 -1787. PMID: 12419298

243. Auricchio A, Stellbrink C, Sack S, et al. Pacing Therapies in Congestive Heart Failure (PATH-CHF) Study Group. Longterm clinical effect of hemodynamically optimized cardiac resynchronization therapy in patients with heart failure and ventricular conduction delay. J Am Coll Cardiol 2002; 39: 2026 2033. PMID: 12084604

244. Young JB, Abraham WT, Smith AL, et al. Multicenter InSync ICD Randomized Clinical Evaluation (MIRACLE ICD) Trial Investigators. Combined cardiac resynchronization and implantable cardioversion defibrillation in advanced chronic heart failure: The MIRACLE ICD Trial. JAMA 2003; 289: 2685-2694. PMID: 12771115

245. Higgins SL, Hummel JD, Niazi IK, et al. Cardiac resynchronization therapy for the treatment of heart failure in patients with intraventricular conduction delay and malignant ventricular tachyarrhythmias. J Am Coll Cardiol 2003; 42: 1454-1459. PMID: 14563591

246. Abraham WT, Young JB, León AR, et al. Multicenter InSync ICD II Study Group. Effects of cardiac resynchronization on disease progression in patients with left ventricular systolic dysfunction, an indication for an implantable cardioverterdefibrillator, and mildly symptomatic chronic heart failure. Circulation 2004; 110: 2864-2868. PMID: 15505095

247. Cleland JG, Daubert JC, Erdmann E, et al. Cardiac Resynchro- 
nization-Heart Failure (CARE-HF) Study Investigators. The effect of cardiac resynchronization on morbidity and mortality in heart failure. $N$ Engl $J$ Med 2005; 352: 1539-1549. PMID: 15753115

248. Salukhe TV, Dimopoulos K, Francis D. Cardiac resynchronisation may reduce all-cause mortality: Meta-analysis of preliminary COMPANION data with CONTAK-CD, InSync ICD, MIRACLE and MUSTIC. Int J Cardiol 2004; 93: 101-103. PMID: 14975534

249. Leclercq C, Cazeau S, Lellouche D, et al. Upgrading from single chamber right ventricular to biventricular pacing in permanently paced patients with worsening heart failure: The RD-CHF Study. Pacing Clin Electrophysiol 2007; 30: S23-S30. PMID: 17302711

250. Curtis AB, Worley SJ, Adamson PB, et al. Biventricular versus Right Ventricular Pacing in Heart Failure Patients with Atrioventricular Block (BLOCK HF) Trial Investigators. Biventricular pacing for atrioventricular block and systolic dysfunction. N Engl J Med 2013; 368: 1585-1593. PMID: 23614585

251. Auricchio A, Metra M, Gasparini M, et al. Multicenter Longitudinal Observational Study (MILOS) Group. Long-term survival of patients with heart failure and ventricular conduction delay treated with cardiac resynchronization therapy. Am J Cardiol 2007; 99: 232-238. PMID: 17223424

252. Wilkoff BL, Fauchier L, Stiles MK, et al. Document Reviewers. $2015 \mathrm{HRS} / \mathrm{EHRA} / \mathrm{APHRS} / \mathrm{SOLAECE}$ expert consensus statement on optimal implantable cardioverter-defibrillator programming and testing. Europace 2016; 18: 159-183. PMID: 26585598

253. Sipahi I, Chou JC, Hyden M, et al. Effect of QRS morphology on clinical event reduction with cardiac resynchronization therapy: Meta-analysis of randomized controlled trials. $\mathrm{Am}$ Heart J 2012; 163: 260-267.e3. PMID: 22305845

254. Beshai JF, Grimm RA, Nagueh SF, et al. RethinQ Study Investigators. Cardiac-resynchronization therapy in heart failure with narrow QRS complexes. N Engl J Med 2007; 357: 2461 2471. PMID: 17986493

255. Ruschitzka F, Abraham WT, Singh JP, et al. EchoCRT Study Group. Cardiac-resynchronization therapy in heart failure with a narrow QRS complex. $N$ Engl J Med 2013; 369: 1395-1405. PMID: 23998714

256. Linde C, Abraham WT, Gold MR, et al. REVERSE (REsynchronization reVErses Remodeling in Systolic left vEntricular dysfunction) Study Group. Randomized trial of cardiac resynchronization in mildly symptomatic heart failure patients and in asymptomatic patients with left ventricular dysfunction and previous heart failure symptoms. $\mathrm{J} \mathrm{Am} \mathrm{Coll}$ Cardiol 2008; 52: 1834-1843. PMID: 19038680

257. Moss AJ, Hall WJ, Cannom DS, et al. MADIT-CRT Trial Investigators. Cardiac-resynchronization therapy for the prevention of heart-failure events. $N$ Engl J Med 2009; 361: 1329-1338. PMID: 19723701

258. Tang AS, Wells GA, Talajic M, et al. ResynchronizationDefibrillation for Ambulatory Heart Failure Trial Investigators. Cardiac-resynchronization therapy for mild-to-moderate heart failure. N Engl J Med 2010; 363: 2385-2395. PMID: 21073365

259. Mullens W, Kepa J, De Vusser P, et al. Importance of adjunctive heart failure optimization immediately after implantation to improve long-term outcomes with cardiac resynchronization therapy. Am J Cardiol 2011; 108: 409-415. PMID: 21550578

260. Varma N, Epstein AE, Irimpen A, et al. TRUST Investigators. Efficacy and safety of automatic remote monitoring for implantable cardioverter-defibrillator follow-up: The Lumos-T Safely Reduces Routine Office Device Follow-up (TRUST) trial. Circulation 2010; 122: 325-332. PMID: 20625110

261. Watanabe E, Kasai A, Fujii E, et al. Reliability of implantable cardioverter defibrillator home monitoring in forecasting the need for regular office visits, and patient perspective. Japanese HOME-ICD study. Circ J 2013; 77: 2704-2711. PMID: 23903000

262. Guédon-Moreau L, Lacroix D, Sadoul N, et al. ECOST trial Investigators. A randomized study of remote follow-up of implantable cardioverter defibrillators: Safety and efficacy report of the ECOST trial. Eur Heart J 2013; 34: 605-614. PMID: 23242192

263. Parthiban N, Esterman A, Mahajan R, et al. Remote monitoring of implantable cardioverter-defibrillators: A systematic review and meta-analysis of clinical outcomes. J Am Coll Cardiol 2015; 65: 2591-2600. PMID: 25983009

264. Slotwiner D, Varma N, Akar JG, et al. HRS Expert Consensus
Statement on remote interrogation and monitoring for cardiovascular implantable electronic devices. Heart Rhythm 2015; 12: e69-e100. PMID: 25981148

265. Hindricks G, Taborsky M, Glikson M, et al. IN-TIME study group. Implant-based multiparameter telemonitoring of patients with heart failure (IN-TIME): A randomised controlled trial. Lancet 2014; 384: 583-590. PMID: 25131977

266. Yamada S, Sakakibara M, Yokota T, et al. Acute hemodynamic effects of adaptive servo-ventilation in patients with heart failure. Circ J 2013; 77: 1214-1220. PMID: 23363644

267. Yoshida M, Kadokami T, Momii H, et al. Enhancement of cardiac performance by bilevel positive airway pressure ventilation in heart failure. J Card Fail 2012; 18: 912-918. PMID: 23207079

268. Ushijima R, Joho S, Akabane T, et al. Differing effects of adaptive servoventilation and continuous positive airway pressure on muscle sympathetic nerve activity in patients with heart failure. Circ J 2014; 78: 1387-1395. PMID: 24705391

269. Koyama $\mathrm{T}$, Watanabe H, Igarashi $\mathrm{G}$, et al. Short-term prognosis of adaptive servo-ventilation therapy in patients with heart failure. Circ J 2011; 75: 710-712. PMID: 21266785

270. Momomura S, Seino Y, Kihara Y, et al. SAVIOR-C investigators. Adaptive servo-ventilation therapy for patients with chronic heart failure in a confirmatory, multicenter, randomized, controlled study. Circ J 2015; 79: 981-990. PMID: 25912560

271. The Japanese Circulation Society, the Japanese Heart Failure Society. Second statement on appropriate use of ASV for heart failure. http://www.j-circ.or.jp/information/ASV_tekiseiriyou_ rep2.pdf

272. Cowie MR, Woehrle H, Wegscheider K, et al. Adaptive servoventilation for central sleep apnea in systolic heart failure. $N$ Engl J Med 2015; 373: 1095-1105. PMID: 26323938

273. Belardinelli R, Georgiou D, Cianci G, et al. Randomized, controlled trial of long-term moderate exercise training in chronic heart failure: Effects on functional capacity, quality of life, and clinical outcome. Circulation 1999; 99: 1173-1182. PMID: 10069785

274. Stolen KQ, Kemppainen J, Ukkonen H, et al. Exercise training improves biventricular oxidative metabolism and left ventricular efficiency in patients with dilated cardiomyopathy. J Am Coll Cardiol 2003; 41: 460-467. PMID: 12575976

275. Coats AJ, Adamopoulos S, Radaelli A, et al. Controlled trial of physical training in chronic heart failure: Exercise performance, hemodynamics, ventilation, and autonomic function. Circulation 1992; 85: 2119-2131. PMID: 1591831

276. Piña IL, Apstein CS, Balady GJ, et al. Exercise and heart failure: A statement from the American Heart Association Committee on exercise, rehabilitation, and prevention. Circulation 2003; 107: 1210 -1225. PMID: 12615804

277. Jetté M, Heller R, Landry F, et al. Randomized 4-week exercise program in patients with impaired left ventricular function. Circulation 1991; 84: 1561-1567. PMID: 1914097

278. Adamopoulos S, Coats AJ, Brunotte F, et al. Physical training improves skeletal muscle metabolism in patients with chronic heart failure. J Am Coll Cardiol 1993; 21: 1101-1106. PMID: 8459063

279. Hambrecht R, Niebauer J, Fiehn E, et al. Physical training in patients with stable chronic heart failure: Effects on cardiorespiratory fitness and ultrastructural abnormalities of leg muscles. J Am Coll Cardiol 1995; 25: 1239-1249. PMID: 7722116

280. Belardinelli R, Georgiou D, Scocco V, et al. Low intensity exercise training in patients with chronic heart failure. $\mathrm{J} \mathrm{Am}$ Coll Cardiol 1995; 26: 975-982. PMID: 7560627

281. Belardinelli R, Georgiou D, Cianci G, et al. Exercise training improves left ventricular diastolic filling in patients with dilated cardiomyopathy. Clinical and prognostic implications. Circulation 1995; 91: 2775-2784. PMID: 7758184

282. Kavanagh T, Myers MG, Baigrie RS, et al. Quality of life and cardiorespiratory function in chronic heart failure: Effects of 12 months' aerobic training. Heart 1996; 76: 42-49. PMID: 8774326

283. Demopoulos L, Bijou R, Fergus I, et al. Exercise training in patients with severe congestive heart failure: Enhancing peak aerobic capacity while minimizing the increase in ventricular wall stress. J Am Coll Cardiol 1997; 29: 597-603. PMID: 9060899

284. Ohtsubo M, Yonezawa K, Nishijima H, et al. Metabolic abnormality of calf skeletal muscle is improved by localised muscle training without changes in blood flow in chronic heart failure. Heart 1997; 78: 437-443. PMID: 9415000

285. Mancini DM, Henson D, La Manca J, et al. Benefit of selective respiratory muscle training on exercise capacity in patients with 
chronic congestive heart failure. Circulation 1995; 91: 320-329. PMID: 7805234

286. Chua TP, Anker SD, Harrington D, et al. Inspiratory muscle strength is a determinant of maximum oxygen consumption in chronic heart failure. Br Heart J 1995; 74: 381-385. PMID: 7488451

287. Kobayashi N, Tsuruya Y, Iwasawa T, et al. Exercise training in patients with chronic heart failure improves endothelial function predominantly in the trained extremities. Circ J 2003; 67: 505510. PMID: 12808267

288. Hambrecht R, Fiehn E, Weigl C, et al. Regular physical exercise corrects endothelial dysfunction and improves exercise capacity in patients with chronic heart failure. Circulation 1998; 98: 2709-2715. PMID: 9851957

289. Kasapis C, Thompson PD. The effects of physical activity on serum C-reactive protein and inflammatory markers: A systematic review. J Am Coll Cardiol 2005; 45: 1563-1569. PMID: 15893167

290. Adamopoulos S, Parissis J, Karatzas D, et al. Physical training modulates proinflammatory cytokines and the soluble Fas/ soluble Fas ligand system in patients with chronic heart failure. J Am Coll Cardiol 2002; 39: 653-663. PMID: 11849865

291. Oya M, Itoh H, Kato K, et al. Effects of exercise training on the recovery of the autonomic nervous system and exercise capacity after acute myocardial infarction. Jpn Circ J 1999; 63: 843-848. PMID: 10598888

292. Dimopoulos S, Anastasiou-Nana M, Sakellariou D, et al Effects of exercise rehabilitation program on heart rate recovery in patients with chronic heart failure. Eur J Cardiovasc Prev Rehabil 2006; 13: 67-73. PMID: 16449866

293. Adamopoulos S, Ponikowski P, Cerquetani E, et al. Circadian pattern of heart rate variability in chronic heart failure patients: Effects of physical training. Eur Heart J 1995; 16: 1380-1386. PMID: 8746907

294. Maria Sarullo F, Gristina T, Brusca I, et al. Effect of physical training on exercise capacity, gas exchange and $\mathrm{N}$-terminal pro-brain natriuretic peptide levels in patients with chronic heart failure. Eur J Cardiovasc Prev Rehabil 2006; 13: 812-817. PMID: 17001223

295. Piepoli MF, Davos C, Francis DP, et al. ExTraMATCH Collaborative. Exercise training meta-analysis of trials in patients with chronic heart failure (ExTraMATCH). BMJ 2004; 328: 189-189. PMID: 14729656

296. O'Connor CM, Whellan DJ, Lee KL, et al. HF-ACTION Investigators. Efficacy and safety of exercise training in patients with chronic heart failure: HF-ACTION randomized controlled trial. JAMA 2009; 301: 1439-1450. PMID: 19351941

297. Sagar VA, Davies EJ, Briscoe S, et al. Exercise-based rehabilitation for heart failure: Systematic review and meta-analysis. Open Heart 2015; 2: e000163. PMID: 25685361

298. Edelmann F, Gelbrich G, Düngen HD, et al. Exercise training improves exercise capacity and diastolic function in patients with heart failure with preserved ejection fraction: Results of the Ex-DHF (Exercise training in Diastolic Heart Failure) pilot study. J Am Coll Cardiol 2011; 58: 1780-1791. PMID: 21996391

299. Nolte K, Herrmann-Lingen C, Wachter R, et al. Effects of exercise training on different quality of life dimensions in heart failure with preserved ejection fraction: The Ex-DHF-P trial Eur J Prev Cardiol 2015; 22: 582-593. PMID: 24627449

300. Kitzman DW, Brubaker PH, Herrington DM, et al. Effect of endurance exercise training on endothelial function and arterial stiffness in older patients with heart failure and preserved ejection fraction: A randomized, controlled, single-blind trial. $J$ Am Coll Cardiol 2013; 62: 584-592. PMID: 23665370

301. Pandey A, Parashar A, Kumbhani D, et al. Exercise training in patients with heart failure and preserved ejection fraction: Meta-analysis of randomized control trials. Circ Heart Fail 2015; 8: 33-40. PMID: 25399909

302. Belardinelli R, Capestro F, Misiani A, et al. Moderate exercise training improves functional capacity, quality of life, and endothelium-dependent vasodilation in chronic heart failure patients with implantable cardioverter defibrillators and cardiac resynchronization therapy. Eur J Cardiovasc Prev Rehabil 2006; 13: $818-825$. PMID: 17001224

303. Patwala AY, Woods PR, Sharp L, et al. Maximizing patient benefit from cardiac resynchronization therapy with the addition of structured exercise training: A randomized controlled study. J Am Coll Cardiol 2009; 53: 2332 -2339. PMID: 19539142

304. Mereles D, Ehlken N, Kreuscher S, et al. Exercise and respiratory training improve exercise capacity and quality of life in patients with severe chronic pulmonary hypertension. Circulation 2006;
114: $1482-1489$. PMID: 16982941

305. Galiè N, Humbert M, Vachiery JL, et al. 2015 ESC/ERS Guidelines for the diagnosis and treatment of pulmonary hypertension: The Joint Task Force for the Diagnosis and Treatment of Pulmonary Hypertension of the European Society of Cardiology (ESC) and the European Respiratory Society (ERS): Endorsed by: Association for European Paediatric and Congenital Cardiology (AEPC), International Society for Heart and Lung Transplantation (ISHLT). Eur Heart $J$ 2016; 37: 67-119. PMID: 26320113

306. Conraads VM, Beckers P, Vaes J, et al. Combined endurance/ resistance training reduces NT-proBNP levels in patients with chronic heart failure. Eur Heart J 2004; 25: 1797-1805. PMID: 15474694

307. Beckers PJ, Denollet J, Possemiers NM, et al. Combined endurance-resistance training vs. endurance training in patients with chronic heart failure: A prospective randomized study. Eur Heart J 2008; 29: 1858-1866. PMID: 18515805

308. Feiereisen P, Delagardelle C, Vaillant M, et al. Is strength training the more efficient training modality in chronic heart failure? Med Sci Sports Exerc 2007; 39: 1910-1917. PMID: 17986897

309. Jewiss D, Ostman C, Smart NA. The effect of resistance training on clinical outcomes in heart failure: A systematic review and meta-analysis. Int J Cardiol 2016; 221: 674-681. PMID: 27423089

310. Vigorito C, Abreu A, Ambrosetti M, et al. Frailty and cardiac rehabilitation: A call to action from the EAPC Cardiac Rehabilitation Section. Eur J Prev Cardiol 2017; 24: 577-590. PMID: 27940954

311. Wisløff U, Støylen A, Loennechen JP, et al. Superior cardiovascular effect of aerobic interval training versus moderate continuous training in heart failure patients: A randomized study. Circulation 2007; 115: 3086-3094. PMID: 17548726

312. Ellingsen $\varnothing$, Halle M, Conraads V, et al. SMARTEX Heart Failure Study (Study of Myocardial Recovery After Exercise Training in Heart Failure) Group. High-intensity interval training in patients with heart failure with reduced ejection fraction. Circulation 2017; 135: 839-849. PMID: 28082387

313. Demopoulos L, Yeh M, Gentilucci M, et al. Nonselective beta-adrenergic blockade with carvedilol does not hinder the benefits of exercise training in patients with congestive heart failure. Circulation 1997; 95: 1764-1767. PMID: 9107160

314. Schnabel RB, Sullivan LM, Levy D, et al. Development of a risk score for atrial fibrillation (Framingham Heart Study): A community-based cohort study. Lancet 2009; 373: 739-745. PMID: 19249635

315. Kotecha D, Flather MD, Altman DG, et al. Beta-Blockers in Heart Failure Collaborative Group. Heart rate and rhythm and the benefit of beta-blockers in patients with heart failure. $J \mathrm{Am}$ Coll Cardiol 2017; 69: 2885-2896. PMID: 28467883

316. Prystowsky EN, Benson DW, Fuster V, et al. Management of patients with atrial fibrillation: A Statement for Healthcare Professionals. From the Subcommittee on Electrocardiography and Electrophysiology, American Heart Association. Circulation 1996; 93: $1262-1277$. PMID: 8653857

317. Hart RG, Halperin JL. Atrial fibrillation and thromboembolism: A decade of progress in stroke prevention. Ann Intern Med 1999; 131: 688-695. PMID: 10577332

318. Mancini GB, Goldberger AL. Cardioversion of atrial fibrillation: Consideration of embolization, anticoagulation, prophylactic pacemaker, and long-term success. Am Heart J 1982; 104: $617-$ 621. PMID: 7113903

319. Fresco C, Proclemer A. Clinical challenge. II. Management of recent onset atrial fibrillation. PAFIT-2 Investigators. Eur Heart $J$ 1996; 17(Suppl C): 41-47. PMID: 8809538

320. Nagai R, Kinugawa K, Inoue H, et al. J-Land Investigators Urgent management of rapid heart rate in patients with atrial fibrillation/flutter and left ventricular dysfunction: Comparison of the ultra-short-acting $\beta 1$-selective blocker landiolol with digoxin (J-Land Study). Circ J 2013; 77: 908-916. PMID: 23502991

321. Li SJ, Sartipy U, Lund LH, et al. Prognostic significance of resting heart rate and use of $\beta$-blockers in atrial fibrillation and sinus rhythm in patients with heart failure and reduced ejection fraction: Findings from the Swedish Heart Failure Registry. Circ Heart Fail 2015; 8: 871 -879. PMID: 26243796

322. Rawles JM. What is meant by a "controlled" ventricular rate in atrial fibrillation? Br Heart $J$ 1990; 63: 157-161. PMID: 2183858

323. The Japanese Circulation Society. Guidelines for pharmacotherapy of atrial fibrillation (JCS 2013). http://www.j-circ.or.jp/ guideline/pdf/JCS2013_inoue_h.pdf 
324. Khand AU, Rankin AC, Martin W, et al. Carvedilol alone or in combination with digoxin for the management of atrial fibrillation in patients with heart failure? $\mathrm{J} \mathrm{Am}$ Coll Cardiol 2003; 42: 1944-1951. PMID: 14662257

325. Fauchier L, Grimard C, Pierre B, et al. Comparison of beta blocker and digoxin alone and in combination for management of patients with atrial fibrillation and heart failure. Am J Cardiol 2009; 103: 248-254. PMID: 19121446

326. Shiga T, Wakaumi M, Imai T, et al. Effect of low-dose amiodarone on atrial fibrillation or flutter in Japanese patients with heart failure. Circ J 2002; 66: 600-604. PMID: 12074281

327. Flaker GC, Blackshear JL, McBride R, et al. Stroke Prevention in Atrial Fibrillation Investigators. Antiarrhythmic drug therapy and cardiac mortality in atrial fibrillation. $\mathrm{J}$ Am Coll Cardiol 1992; 20: 527-532. PMID: 1512329

328. Gage BF, Waterman AD, Shannon W, et al. Validation of clinical classification schemes for predicting stroke: Results from the National Registry of Atrial Fibrillation. JAMA 2001; 285: 2864-2870. PMID: 11401607

329. Lip GY, Frison L, Halperin JL, et al. Identifying patients at high risk for stroke despite anticoagulation: A comparison of contemporary stroke risk stratification schemes in an anticoagulated atrial fibrillation cohort. Stroke 2010; 41: 2731-2738. PMID: 20966417

330. Camm AJ, Kirchhof P, Lip GY, et al. European Heart Rhythm Association. Guidelines for the management of atrial fibrillation: The Task Force for the Management of Atrial Fibrillation of the European Society of Cardiology (ESC). Eur Heart J 2010; 31: 2369-2429. PMID: 20802247

331. Giugliano RP, Ruff CT, Braunwald E, et al. ENGAGE AF-TIMI 48 Investigators. Edoxaban versus warfarin in patients with atrial fibrillation. $N$ Engl J Med 2013; 369: 2093-2104. PMID: 24251359

332. Granger CB, Alexander JH, McMurray JJ, et al. ARISTOTLE Committees and Investigators. Apixaban versus warfarin in patients with atrial fibrillation. $N$ Engl J Med 2011; 365: 981 992. PMID: 21870978

333. Houston DS, Zarychanski R. Dabigatran versus warfarin in patients with atrial fibrillation. $N$ Engl J Med 2009; 361: 2671; author reply 2674-2675. PMID: 20042760

334. Pearson S, Troughton R, Richards AM. Rivaroxaban versus warfarin in nonvalvular atrial fibrillation. $N$ Engl J Med 2011; 365: 2334-2335; author reply 2335. PMID: 22168653

335. Ruff CT, Giugliano RP, Braunwald E, et al. Comparison of the efficacy and safety of new oral anticoagulants with warfarin in patients with atrial fibrillation: A meta-analysis of randomised trials. Lancet 2014; 383: 955-962. PMID: 24315724

336. Xiong Q, Lau YC, Senoo K, et al. Non-vitamin K antagonist oral anticoagulants (NOACs) in patients with concomitant atrial fibrillation and heart failure: A systemic review and meta-analysis of randomized trials. Eur J Heart Fail 2015; 17: 1192-1200. PMID: 26335355

337. Eikelboom JW, Connolly SJ, Brueckmann M, et al. RE-ALIGN Investigators. Dabigatran versus warfarin in patients with mechanical heart valves. $N$ Engl J Med 2013; 369: 1206-1214. PMID: 23991661

337a. Pisters R, Lane DA, Nieuwlaat R, et al. A novel user-friendly score (HAS-BLED) to assess 1-year risk of major bleeding in patients with atrial fibrillation: The Euro Heart Survey. Chest 2010; 138: 1093-1100. PMID: 20299623

338. Dewilde WJ, Oirbans T, Verheugt FW, et al. WOEST study investigators. Use of clopidogrel with or without aspirin in patients taking oral anticoagulant therapy and undergoing percutaneous coronary intervention: An open-label, randomised, controlled trial. Lancet 2013; 381: 1107-1115. PMID: 23415013

339. Kirchhof P, Benussi S, Kotecha D, et al. 2016 ESC Guidelines for the management of atrial fibrillation developed in collaboration with EACTS. Eur Heart J 2016; 37: 2893-2962. PMID: 27567408

340. Shiga T, Kasanuki H. Drug therapy for ventricular tachyarrhythmia in heart failure. Circ $J$ 2007; 71(Suppl): A90-A96. PMID: 17587746

341. Katoh T, Mitamura H, Matsuda N, et al. Emergency treatment with nifekalant, a novel class III anti-arrhythmic agent, for life-threatening refractory ventricular tachyarrhythmias: Postmarketing special investigation. Circ J 2005; 69: 1237-1243. PMID: 16195624

342. Itoh $\mathrm{H}, \mathrm{Crotti} \mathrm{L}, \mathrm{Aiba} \mathrm{T}$, et al. The genetics underlying acquired long QT syndrome: Impact for genetic screening. Eur Heart $J$ 2016; 37: 1456-1464. PMID: 26715165

343. Tzivoni D, Banai S, Schuger C, et al. Treatment of torsade de pointes with magnesium sulfate. Circulation 1988; 77: 392-397. PMID: 3338130

344. Carbucicchio C, Santamaria M, Trevisi N, et al. Catheter ablation for the treatment of electrical storm in patients with implantable cardioverter-defibrillators: Short- and long-term outcomes in a prospective single-center study. Circulation 2008; 117: 462 -469. PMID: 18172038

345. Hayashi M, Miyauchi Y, Murata H, et al. Urgent catheter ablation for sustained ventricular tachyarrhythmias in patients with acute heart failure decompensation. Europace 2014; 16: 92-100. PMID: 23858022

346. Amiodarone Trials Meta-Analysis Investigators. Effect of prophylactic amiodarone on mortality after acute myocardial infarction and in congestive heart failure: Meta-analysis of individual data from 6500 patients in randomised trials. Lancet 1997; 350: 1417-1424. PMID: 9371164

347. Tsutsui H, Tsuchihashi-Makaya M, Kinugawa S, et al. JCAREGENERAL Investigators. Characteristics and outcomes of patients with heart failure in general practices and hospitals. Circ J 2007; 71: 449-454. PMID: 17384441

348. Sakata Y, Shimokawa H. Epidemiology of heart failure in Asia. Circ J 2013; 77: 2209-2217. PMID: 23955345

349. Kajimoto K, Sato N, Takano T. investigators of the Acute Decompensated Heart Failure Syndromes (ATTEND) registry. Relation of left ventricular ejection fraction and clinical features or co-morbidities to outcomes among patients hospitalized for acute heart failure syndromes. Am J Cardiol 2015; 115: $334-$ 340. PMID: 25476557

350. Shiba N, Watanabe J, Shinozaki T, et al. Poor prognosis of Japanese patients with chronic heart failure following myocardial infarction: Comparison with nonischemic cardiomyopathy. Circ J 2005; 69: 143-149. PMID: 15671603

351. Kajimoto K, Minami Y, Sato N, et al. Investigators of the Acute Decompensated Heart Failure Syndromes (ATTEND) Registry. Etiology of heart failure and outcomes in patients hospitalized for acute decompensated heart failure with preserved or reduced ejection fraction. Am J Cardiol 2016; 118: 18811887. PMID: 27720439

352. Ricci R, Coletta C, Ceci V, et al. RIMA Researchers. Effect of early treatment with captopril and metoprolol singly and together on postinfarction left ventricular remodeling. $\mathrm{Am}$ Heart J 2001; 142: E5. PMID: 11579369

353. Califf RM, Lokhnygina Y, Velazquez EJ, et al. Usefulness of beta blockers in high-risk patients after myocardial infarction in conjunction with captopril and/or valsartan (from the VALsartan In Acute Myocardial Infarction [VALIANT] trial). Am J Cardiol 2009; 104: 151 -157. PMID: 19576338

354. Fearon WF, Shah M, Ng M, et al. Predictive value of the index of microcirculatory resistance in patients with ST-segment elevation myocardial infarction. J Am Coll Cardiol 2008; 51: 560-565. PMID: 18237685

355. Lorell BH, Isoyama S, Grice WN, et al. Effects of ouabain and isoproterenol on left ventricular diastolic function during low-flow ischemia in isolated, blood-perfused rabbit hearts. Circ Res 1988; 63: 457-467. PMID: 3396161

356. Isoyama S, Apstein CS, Wexler LF, et al. Acute decrease in left ventricular diastolic chamber distensibility during simulated angina in isolated hearts. Circ Res 1987; 61: 925-933. PMID: 3677344

357. Slezak J, Tribulova N, Okruhlicova L, et al. Hibernating myocardium: Pathophysiology, diagnosis, and treatment. Can J Physiol Pharmacol 2009; 87: 252-265. PMID: 19370079

358. Poole-Wilson PA, Swedberg K, Cleland JG, et al. Carvedilol Or Metoprolol European Trial Investigators. Comparison of carvedilol and metoprolol on clinical outcomes in patients with chronic heart failure in the Carvedilol Or Metoprolol European Trial (COMET): Randomised controlled trial. Lancet 2003; 362: 7-13. PMID: 12853193

359. Mancini GB, Henry GC, Macaya C, et al. Angiotensin-converting enzyme inhibition with quinapril improves endothelial vasomotor dysfunction in patients with coronary artery disease: The TREND (Trial on Reversing ENdothelial Dysfunction) Study. Circulation 1996; 94: 258-265. PMID: 8759064

360. Kitakaze M, Asanuma H, Funaya H, et al. Angiotensin-converting enzyme inhibitors and angiotensin II receptor blockers synergistically increase coronary blood flow in canine ischemic myocardium: Role of bradykinin. J Am Coll Cardiol 2002; 40: 162-166. PMID: 12103271

361. Elkayam U, Johnson JV, Shotan A, et al. Double-blind, placebocontrolled study to evaluate the effect of organic nitrates in 
patients with chronic heart failure treated with angiotensinconverting enzyme inhibition. Circulation 1999; 99: 2652-2657. PMID: 10338458

362. Passamani E, Davis KB, Gillespie MJ, et al. A randomized trial of coronary artery bypass surgery: Survival of patients with a low ejection fraction. $N$ Engl J Med 1985; 312: 1665-1671. PMID: 3873614

363. Gibbons RJ, Chatterjee K, Daley J, et al. ACC/AHA/ACPASIM guidelines for the management of patients with chronic stable angina: A report of the American College of Cardiology/ American Heart Association Task Force on Practice Guidelines (Committee on Management of Patients With Chronic Stable Angina). J Am Coll Cardiol 1999; 33: 2092-2197. PMID 10362225

364. Marui A, Kimura T, Nishiwaki N, et al. CREDO-Kyoto PCI/ CABG Registry Cohort-2 Investigators. Three-year outcomes after percutaneous coronary intervention and coronary artery bypass grafting in patients with heart failure: From the CREDO-Kyoto percutaneous coronary intervention/coronary artery bypass graft registry cohort- $2 \uparrow$. Eur J Cardiothorac Surg 2015; 47: 316-321; discussion 321. PMID: 24662243

365. The Japanese Circulation Society. Guidelines for non-pharmacotherapy of cardiac arrhythmias (JCS 2011). http://www.j-circ. or.jp/guideline/pdf/JCS2011_okumura_h.pdf

366. The Japanese Circulation Society. Guidelines for surgical and interventional treatment of valvular heart disease (JCS 2012). http://www.j-circ.or.jp/guideline/pdf/JCS2012_ookita_h.pdf

367. Michler RE, Smith PK, Parides MK, et al. CTSN. Two-year outcomes of surgical treatment of moderate ischemic mitral regurgitation. $N$ Engl J Med 2016; 374: 1932-1941. PMID: 27040451

368. Nishimura RA, Otto CM, Bonow RO, et al. 2017 AHA/ACC focused update of the 2014 AHA/ACC guideline for the management of patients with valvular heart disease: A report of the American College of Cardiology/American Heart Association Task Force on Clinical Practice Guidelines. J Am Coll Cardiol 2017; 70: 252-289. PMID: 28315732

369. Koelling TM, Aaronson KD, Cody RJ, et al. Prognostic significance of mitral regurgitation and tricuspid regurgitation in patients with left ventricular systolic dysfunction. Am Heart J 2002; 144: 524-529. PMID: 12228791

370. Nishimura RA, Otto CM, Bonow RO, et al. 2014 AHA/ACC guideline for the management of patients with valvular heart disease: Executive summary: A report of the American College of Cardiology/American Heart Association Task Force on Practice Guidelines. J Am Coll Cardiol 2014; 63: 2438-2488. PMID: 24603192

371. Vahanian A, Alfieri O, Andreotti F, et al. Joint Task Force on the Management of Valvular Heart Disease of the European Society of Cardiology (ESC). Guidelines on the management of valvular heart disease (version 2012). Eur Heart $J$ 2012; 33: 2451-2496. PMID: 22922415

372. Levy D, Larson MG, Vasan RS, et al. The progression from hypertension to congestive heart failure. JAMA 1996; 275: 1557-1562. PMID: 8622246

373. Messerli FH, Mancia G, Conti CR, et al. Dogma disputed: Can aggressively lowering blood pressure in hypertensive patients with coronary artery disease be dangerous? Ann Intern Med 2006; 144: 884-893. PMID: 16785477

374. Cooper-DeHoff RM, Gong Y, Handberg EM, et al. Tight blood pressure control and cardiovascular outcomes among hypertensive patients with diabetes and coronary artery disease. JAMA 2010; 304: 61-68. PMID: 20606150

375. Bozkurt B, Aguilar D, Deswal A, et al. Contributory risk and management of comorbidities of hypertension, obesity, diabetes mellitus, hyperlipidemia, and metabolic syndrome in chronic heart failure: A scientific statement from the American Heart Association. Circulation 2016; 134: e535-e578. PMID: 27799274

376. Garg R, Yusuf S. Overview of randomized trials of angiotensinconverting enzyme inhibitors on mortality and morbidity in patients with heart failure: Collaborative Group on ACE Inhibitor Trials. JAMA 1995; 273: 1450-1456. PMID: 7654275

377. Hjalmarson A, Goldstein S, Fagerberg B, et al. Effects of controlled-release metoprolol on total mortality, hospitalizations, and well-being in patients with heart failure: The Metoprolo CR/XL Randomized Intervention Trial in congestive heart failure (MERIT-HF). MERIT-HF Study Group. JAMA 2000; 283: 1295-1302. PMID: 10714728

378. Packer M, Fowler MB, Roecker EB, et al. Carvedilol Prospective Randomized Cumulative Survival (COPERNICUS) Study
Group. Effect of carvedilol on the morbidity of patients with severe chronic heart failure: Results of the carvedilol prospective randomized cumulative survival (COPERNICUS) study. Circulation 2002; 106: 2194-2199. PMID: 12390947

379. Packer M, O'Connor CM, Ghali JK, et al. Prospective Randomized Amlodipine Survival Evaluation Study Group. Effect of amlodipine on morbidity and mortality in severe chronic heart failure. $N$ Engl J Med 1996; 335: 1107-1114. PMID: 8813041

380. Senni M, Paulus WJ, Gavazzi A, et al. New strategies for heart failure with preserved ejection fraction: The importance of targeted therapies for heart failure phenotypes. Eur Heart $J$ 2014; 35: 2797-2815. PMID: 25104786

381. Ferrari R, Böhm M, Cleland JG, et al. Heart failure with preserved ejection fraction: Uncertainties and dilemmas. Eur $J$ Heart Fail 2015; 17: 665-671. PMID: 26079097

382. Udelson JE. Heart failure with preserved ejection fraction Circulation 2011; 124: e540-e543. PMID: 22105201

383. Choy CK, Rodgers JE, Nappi JM, et al. Type 2 diabetes mellitus and heart failure. Pharmacotherapy 2008; 28: 170-192. PMID: 18225964

384. Boyer JK, Thanigaraj S, Schechtman KB, et al. Prevalence of ventricular diastolic dysfunction in asymptomatic, normotensive patients with diabetes mellitus. Am J Cardiol 2004; 93: 870-875. PMID: 15050491

385. From AM, Scott CG, Chen HH. The development of heart failure in patients with diabetes mellitus and pre-clinical diastolic dysfunction a population-based study. J Am Coll Cardiol 2010; 55: 300-305. PMID: 20117433

386. Miura M, Sakata Y, Miyata S, et al. CHART-2 Investigators. Prognostic impact of diabetes mellitus in chronic heart failure according to presence of ischemic heart disease: With special reference to nephropathy. Circ J 2015; 79: 1764-1772. PMID: 26004750

387. Shekelle PG, Rich MW, Morton SC, et al. Efficacy of angiotensinconverting enzyme inhibitors and beta-blockers in the management of left ventricular systolic dysfunction according to race, gender, and diabetic status: A meta-analysis of major clinical trials. J Am Coll Cardiol 2003; 41: 1529-1538. PMID: 12742294

388. McMurray JJ, Ostergren J, Swedberg K, et al. CHARM Investigators and Committees. Effects of candesartan in patients with chronic heart failure and reduced left-ventricular systolic function taking angiotensin-converting-enzyme inhibitors: The CHARM-Added trial. Lancet 2003; 362: 767-771. PMID: 13678869

389. Haas SJ, Vos T, Gilbert RE, et al. Are beta-blockers as efficacious in patients with diabetes mellitus as in patients without diabetes mellitus who have chronic heart failure? A meta-analysis of large-scale clinical trials. Am Heart J 2003; 146: 848-853. PMID: 14597934

390. Deedwania PC, Giles TD, Klibaner M, et al. MERIT-HF Study Group. Efficacy, safety and tolerability of metoprolol CR/XL in patients with diabetes and chronic heart failure: Experiences from MERIT-HF. Am Heart $J$ 2005; 149: 159-167. PMID: 15660048

391. Fernandez HM, Leipzig RM. Spironolactone in patients with heart failure. N Engl J Med 2000; 342: 132; author reply 133134. PMID: 10636750

392. Scirica BM, Bhatt DL, Braunwald E, et al. SAVOR-TIMI 53 Steering Committee and Investigators. Saxagliptin and cardiovascular outcomes in patients with type 2 diabetes mellitus. $N$ Engl J Med 2013; 369: 1317-1326. PMID: 23992601

393. Scirica BM, Braunwald E, Raz I, et al. SAVOR-TIMI 53 Steering Committee and Investigators. Heart failure, saxagliptin, and diabetes mellitus: Observations from the SAVOR-TIMI 53 randomized trial. Circulation 2014; 130: 1579-1588. PMID: 25189213

394. Krum H, Roecker EB, Mohacsi P, et al. Carvedilol Prospective Randomized Cumulative Survival (COPERNICUS) Study Group. Effects of initiating carvedilol in patients with severe chronic heart failure: Results from the COPERNICUS Study. JAMA 2003; 289: 712-718. PMID: 12585949

395. Wali RK, Iyengar M, Beck GJ, et al. Efficacy and safety of carvedilol in treatment of heart failure with chronic kidney disease: A meta-analysis of randomized trials. Circ Heart Fail 2011; 4: 18-26. PMID: 21036889

396. Castagno D, Jhund PS, McMurray JJ, et al. Improved survival with bisoprolol in patients with heart failure and renal impairment: An analysis of the cardiac insufficiency bisoprolol study II (CIBIS-II) trial. Eur J Heart Fail 2010; 12: 607-616. PMID: 


\section{2}

397. Tang CH, Wang CC, Chen TH, et al. Prognostic benefits of carvedilol, bisoprolol, and metoprolol controlled release/extended release in hemodialysis patients with heart failure: A 10-year cohort. J Am Heart Assoc 2016; 5: e002584. PMID: 26738790

398. Edner M, Benson L, Dahlström U, et al. Association between renin-angiotensin system antagonist use and mortality in heart failure with severe renal insufficiency: A prospective propensity score-matched cohort study. Eur Heart J 2015; 36: 2318-2326. PMID: 26069212

399. The Japanese Society of Nephrology. Guidelines for the treatment of chronic kidney disease 2012. Tokyo: Tokyo Igakusha, 2012

400. Vardeny O, Wu DH, Desai A, et al. RALES Investigators. Influence of baseline and worsening renal function on efficacy of spironolactone in patients with severe heart failure: Insights from RALES (Randomized Aldactone Evaluation Study). $J$ Am Coll Cardiol 2012; 60: 2082-2089. PMID: 23083787

401. Eschalier R, McMurray JJ, Swedberg K, et al. EMPHASIS-HF Investigators. Safety and efficacy of eplerenone in patients at high risk for hyperkalemia and/or worsening renal function: Analyses of the EMPHASIS-HF study subgroups (Eplerenone in Mild Patients Hospitalization And SurvIval Study in Heart Failure). J Am Coll Cardiol 2013; 62: 1585-1593. PMID: 23810881

402. Cosín J, Díez J. TORIC investigators. Torasemide in chronic heart failure: Results of the TORIC study. Eur J Heart Fail 2002; 4: 507-513. PMID: 12167392

403. Shlipak MG, Smith GL, Rathore SS, et al. Renal function, digoxin therapy, and heart failure outcomes: Evidence from the digoxin intervention group trial. J Am Soc Nephrol 2004; 15: 2195-2203. PMID: 15284305

404. Gheorghiade M, Böhm M, Greene SJ, et al. ASTRONAUT Investigators and Coordinators. Effect of aliskiren on postdischarge mortality and heart failure readmissions among patients hospitalized for heart failure: The ASTRONAUT randomized trial. JAMA 2013; 309: 1125-1135. PMID: 23478743

405. Nigwekar SU, Navaneethan SD, Parikh CR, et al. Atrial natriuretic peptide for management of acute kidney injury: A systematic review and meta-analysis. Clin J Am Soc Nephrol 2009; 4: 261-272. PMID: 19073785

406. Matsue Y, Suzuki M, Torii S, et al. Clinical effectiveness of tolvaptan in patients with acute heart failure and renal dysfunction. J Card Fail 2016; 22: 423-432. PMID: 26915749

407. Guideline Revision Committee of the Japanese Society of Goat and Nucleic Acid Metabolism. Guidelines for the treatment of hyperuricemia and gout, 2nd edition. Tokyo: Medical View Sha, 2010

408. Givertz MM, Anstrom KJ, Redfield MM, et al. NHLBI Heart Failure Clinical Research Network. Effects of xanthine oxidase inhibition in hyperuricemic heart failure patients: The Xanthine Oxidase Inhibition for Hyperuricemic Heart Failure Patients (EXACT-HF) Study. Circulation 2015; 131: 1763-1771. PMID: 25986447

409. Global Initiative for Asthma. 2016 GINA Report, Global Strategy for Asthma Management and Prevention. http://ginasthma.org/ wp-content/uploads/2016/04/wms-GINA-2016-main-report-final. pdf

410. Global Initiative for Chronic Obstructive Lung Disease. GOLD 2017: Global Strategy for the Diagnosis, Management and Prevention of COPD. http://goldcopd.org/gold-2017-global-stra tegy-diagnosis-management-prevention-copd/

411. Bhatt SP, Dransfield MT. Chronic obstructive pulmonary disease and cardiovascular disease. Transl Res 2013; 162: 237251. PMID: 23727296

412. Le Jemtel TH, Padeletti M, Jelic S. Diagnostic and therapeutic challenges in patients with coexistent chronic obstructive pulmonary disease and chronic heart failure. $\mathrm{J} \mathrm{Am} \mathrm{Coll} \mathrm{Cardiol}$ 2007; 49: 171-180. PMID: 17222727

413. Yoshihisa A, Takiguchi M, Shimizu T, et al. Cardiovascular function and prognosis of patients with heart failure coexistent with chronic obstructive pulmonary disease. J Cardiol 2014; 64: 256-264. PMID: 24674751

414. Chen W, Thomas J, Sadatsafavi M, et al. Risk of cardiovascular comorbidity in patients with chronic obstructive pulmonary disease: A systematic review and meta-analysis. Lancet Respir Med 2015; 3: 631-639. PMID: 26208998

415. Rutten FH, Cramer MJ, Grobbee DE, et al. Unrecognized heart failure in elderly patients with stable chronic obstructive pulmonary disease. Eur Heart $J$ 2005; 26: 1887-1894. PMID: 15860516
416. Hawkins NM, Virani S, Ceconi C. Heart failure and chronic obstructive pulmonary disease: The challenges facing physicians and health services. Eur Heart $J$ 2013; 34: 2795-2803. PMID: 23832490

417. Lipworth B, Wedzicha J, Devereux G, et al. Beta-blockers in COPD: Time for reappraisal. Eur Respir J 2016; 48: 880-888. PMID: 27390282

418. Morales DR, Jackson C, Lipworth BJ, et al. Adverse respiratory effect of acute $\beta$-blocker exposure in asthma: A systematic review and meta-analysis of randomized controlled trials. Chest 2014; 145: 779-786. PMID: 24202435

419. Forth R, Montgomery H. ACE in COPD: A therapeutic target? Thorax 2003; 58: 556-558. PMID: 12832663

420. Kajimoto K, Sato N, Takano T. investigators of the Acute Decompensated Heart Failure Syndromes (ATTEND) registry. Association between anemia, clinical features and outcome in patients hospitalized for acute heart failure syndromes. Eur Heart J Acute Cardiovasc Care 2015; 4: 568 - 576. PMID: 25315117

421. Yamauchi T, Sakata Y, Takada T, et al. CHART-2 investigators. Prognostic impact of anemia in patients with chronic heart failure: With special reference to clinical background: Report from the CHART-2 Study. Circ J 2015; 79: 1984-1993. PMID: 26050711

422. Oldenburg O, Lamp B, Faber L, et al. Sleep-disordered breathing in patients with symptomatic heart failure: A contemporary study of prevalence in and characteristics of 700 patients. Eur J Heart Fail 2007; 9: 251 - 257. PMID: 17027333

423. Yumino D, Wang H, Floras JS, et al. Prevalence and physiological predictors of sleep apnea in patients with heart failure and systolic dysfunction. $J$ Card Fail 2009; 15: 279-285. PMID: 19398074

424. Javaheri S. Sleep disorders in systolic heart failure: A prospective study of 100 male patients. The final report. Int J Cardiol 2006; 106: 21 -28. PMID: 16321661

425. Chan J, Sanderson J, Chan W, et al. Prevalence of sleepdisordered breathing in diastolic heart failure. Chest 1997; 111: 1488-1493. PMID: 9187161

426. Bitter T, Faber L, Hering D, et al. Sleep-disordered breathing in heart failure with normal left ventricular ejection fraction. Eur J Heart Fail 2009; 11: 602-608. PMID: 19468022

427. The Japanese Circulation Society. Guidelines for diagnosis and treatment of sleep disordered breathing in cardiovascular disease (JCS 2010). Circ J 2010; 74(Suppl II): 963-1084.

428. Kasai T, Floras JS, Bradley TD. Sleep apnea and cardiovascular disease: A bidirectional relationship. Circulation 2012; 126: 1495-1510. PMID: 22988046

429. Marin JM, Carrizo SJ, Vicente E, et al. Long-term cardiovascular outcomes in men with obstructive sleep apnoea-hypopnoea with or without treatment with continuous positive airway pressure: An observational study. Lancet 2005; 365: 1046-1053. PMID: 15781100

430. Gottlieb DJ, Yenokyan G, Newman AB, et al. Prospective study of obstructive sleep apnea and incident coronary heart disease and heart failure: The sleep heart health study. Circulation 2010; 122: 352-360. PMID: 20625114

431. Kasai T. Sleep apnea and heart failure. J Cardiol 2012; 60: 78-85. PMID: 22824295

432. Yumino D, RedolfiS, Ruttanaumpawan $P$, et al. Nocturnal rostral fluid shift: A unifying concept for the pathogenesis of obstructive and central sleep apnea in men with heart failure. Circulation 2010; 121: 1598-1605. PMID: 20351237

433. Wang H, Parker JD, Newton GE, et al. Influence of obstructive sleep apnea on mortality in patients with heart failure. $J \mathrm{Am}$ Coll Cardiol 2007; 49: 1625-1631. PMID: 17433953

434. Javaheri S, Shukla R, Zeigler H, et al. Central sleep apnea, right ventricular dysfunction, and low diastolic blood pressure are predictors of mortality in systolic heart failure. J Am Coll Cardiol 2007; 49: 2028-2034. PMID: 17512359

435. Arzt M, Young T, Finn L, et al. Sleepiness and sleep in patients with both systolic heart failure and obstructive sleep apnea. Arch Intern Med 2006; 166: 1716-1722. PMID: 16983049

436. Kaneko Y, Floras JS, Usui K, et al. Cardiovascular effects of continuous positive airway pressure in patients with heart failure and obstructive sleep apnea. $N$ Engl J Med 2003; 348: $1233-$ 1241. PMID: 12660387

437. Sun H, Shi J, Li M, et al. Impact of continuous positive airway pressure treatment on left ventricular ejection fraction in patients with obstructive sleep apnea: A meta-analysis of randomized controlled trials. PLoS One 2013; 8: e62298. PMID: 23650511 
438. Kasai T, Narui K, Dohi T, et al. Prognosis of patients with heart failure and obstructive sleep apnea treated with continuous positive airway pressure. Chest 2008; 133: 690-696. PMID: 18198253

439. Damy T, Margarit L, Noroc A, et al. Prognostic impact of sleep-disordered breathing and its treatment with nocturnal ventilation for chronic heart failure. Eur J Heart Fail 2012; 14: 1009-1019. PMID: 22730336

440. Bradley TD, Logan AG, Kimoff RJ, et al. CANPAP Investigators. Continuous positive airway pressure for central sleep apnea and heart failure. $N$ Engl J Med 2005; 353: 2025-2033. PMID: 16282177

441. Arzt M, Floras JS, Logan AG, et al. CANPAP Investigators. Suppression of central sleep apnea by continuous positive airway pressure and transplant-free survival in heart failure: A post hoc analysis of the Canadian Continuous Positive Airway Pressure for Patients with Central Sleep Apnea and Heart Failure Trial (CANPAP). Circulation 2007; 115: 3173-3180. PMID: 17562959

442. Kasai T, Kasagi S, Maeno K, et al. Adaptive servo-ventilation in cardiac function and neurohormonal status in patients with heart failure and central sleep apnea nonresponsive to continuous positive airway pressure. JACC Heart Fail 2013; 1: 58-63. PMID: 24621799

443. Kasai T, Usui Y, Yoshioka T, et al. JASV Investigators. Effect of flow-triggered adaptive servo-ventilation compared with continuous positive airway pressure in patients with chronic heart failure with coexisting obstructive sleep apnea and CheyneStokes respiration. Circ Heart Fail 2010; 3: 140-148. PMID: 19933407

444. Sharma BK, Bakker JP, McSharry DG, et al. Adaptive servoventilation for treatment of sleep-disordered breathing in heart failure: A systematic review and meta-analysis. Chest 2012; 142: 1211-1221. PMID: 22722232

445. Aurora RN, Chowdhuri S, Ramar K, et al. The treatment of central sleep apnea syndromes in adults: Practice parameters with an evidence-based literature review and meta-analyses. Sleep 2012; 35: 17-40. PMID: 22215916

446. Yoshihisa A, Shimizu T, Owada T, et al. Adaptive servo ventilation improves cardiac dysfunction and prognosis in chronic heart failure patients with Cheyne-Stokes respiration. Int Heart $J$ 2011; 52: 218-223. PMID: 21828947

447. Javaheri S. Pembrey's dream: The time has come for a long-term trial of nocturnal supplemental nasal oxygen to treat central sleep apnea in congestive heart failure. Chest 2003; 123: 322 325. PMID: 12576341

448. Shigemitsu M, Nishio K, Kusuyama T, et al. Nocturnal oxygen therapy prevents progress of congestive heart failure with central sleep apnea. Int J Cardiol 2007; 115: 354-360. PMID: 16806535

449. Toyama T, Seki R, Kasama S, et al. Effectiveness of nocturnal home oxygen therapy to improve exercise capacity, cardiac function and cardiac sympathetic nerve activity in patients with chronic heart failure and central sleep apnea. Circ J 2009; 73: 299-304. PMID: 19122308

450. Sasayama S, Izumi T, Seino Y, et al. CHF-HOT Study Group. Effects of nocturnal oxygen therapy on outcome measures in patients with chronic heart failure and cheyne-stokes respiration. Circ J 2006; 70: 1-7. PMID: 16377916

451. Sasayama S, Izumi T, Matsuzaki M, et al. CHF-HOT Study Group. Improvement of quality of life with nocturnal oxygen therapy in heart failure patients with central sleep apnea. Circ $J$ 2009; 73: 1255-1262. PMID: 19448327

452. Mebazaa A, Gheorghiade M, Piña IL, et al. Practical recommendations for prehospital and early in-hospital management of patients presenting with acute heart failure syndromes. Crit Care Med 2008; 36: S129-S139. PMID: 18158472

453. Killip T, Kimball JT. Treatment of myocardial infarction in a coronary care unit: A two year experience with 250 patients. Am J Cardiol 1967; 20: 457-464. PMID: 6059183

454. Mebazaa A, Tolppanen H, Mueller C, et al. Acute heart failure and cardiogenic shock: A multidisciplinary practical guidance. Intensive Care Med 2016; 42: 147-163. PMID: 26370690

455. The Japanese Circulation Society. Guidelines for diagnosis and treatment of myocarditis (JCS 2009). http://www.j-circ.or.jp/ guideline/pdf/JCS2009_izumi_h.pdf

456. The Japanese Circulation Society. Guidelines for the management of patients with ST-elevation acute myocardial infarction (JCS 2013). http://www.j-circ.or.jp/guideline/pdf/JCS2013_kimura_h. pdf

457. The Japanese Circulation Society. Guidelines for management of acute coronary syndrome without persistent ST segment elevation (JCS 2012). http://www.j-circ.or.jp/guideline/pdf/ JCS2012_kimura_h.pdf

458. The Japanese Circulation Society. Guidelines for the diagnosis, treatment and prevention of pulmonary thromboembolism and deep vein thrombosis (JCS 2009). http://www.j-circ.or.jp/ guideline/pdf/JCS2009_andoh_h.pdf

459. Stevenson LW. Tailored therapy to hemodynamic goals for advanced heart failure. Eur J Heart Fail 1999; 1: 251-257. PMID: 10935671

460. Kajimoto K, Sato N, Sakata Y, et al. Acute Decompensated Heart Failure Syndromes (ATTEND) investigators. Relationship between systolic blood pressure and preserved or reduced ejection fraction at admission in patients hospitalized for acute heart failure syndromes. Int J Cardiol 2013; 168: 4790-4795. PMID: 23962780

461. Bristow MR, Shakar SF, Linseman JV, et al. Inotropes and beta-blockers: Is there a need for new guidelines? J Card Fail 2001; 7: 8-12. PMID: 11605160

462. Vismara LA, Leaman DM, Zelis R. The effects of morphine on venous tone in patients with acute pulmonary edema. Circulation 1976; 54: 335-337. PMID: 939031

463. Iakobishvili Z, Cohen E, Garty M, et al. Heart Failure Survey in Isarel (HFSIS) Investigators. Use of intravenous morphine for acute decompensated heart failure in patients with and without acute coronary syndromes. Acute Card Care 2011; 13: 76-80. PMID: 21627393

464. Peacock WF, Hollander JE, Diercks DB, et al. Morphine and outcomes in acute decompensated heart failure: An ADHERE analysis. Emerg Med J 2008; 25: 205-209. PMID: 18356349

465. Cotter G, Metzkor E, Kaluski E, et al. Randomised trial of high-dose isosorbide dinitrate plus low-dose furosemide versus high-dose furosemide plus low-dose isosorbide dinitrate in severe pulmonary oedema. Lancet 1998; 351: 389-393. PMID: 9482291

466. Matsue Y, Damman K, Voors AA, et al. Time-to-furosemide treatment and mortality in patients hospitalized with acute heart failure. J Am Coll Cardiol 2017; 69: 3042-3051. PMID: 28641794

467. Ellison DH. Diuretic therapy and resistance in congestive heart failure. Cardiology 2001; 96: 132-143. PMID: 11805380

468. Dormans TP, van Meyel JJ, Gerlag PG, et al. Diuretic efficacy of high dose furosemide in severe heart failure: Bolus injection versus continuous infusion. J Am Coll Cardiol 1996; 28: 376382. PMID: 8800113

469. Tsutamoto T, Kinoshita M, Nakae I, et al. Absence of hemodynamic tolerance to nicorandil in patients with severe congestive heart failure. Am Heart J 1994; 127: 866-873. PMID: 8154425

470. Tsutamoto T, Kinoshita M, Hisanaga T, et al. Comparison of hemodynamic effects and plasma cyclic guanosine monophosphate of nicorandil and nitroglycerin in patients with congestive heart failure. Am J Cardiol 1995; 75: 1162-1165. PMID: 7762505

471. Tanaka K, Kato K, Takano T, et al. Acute effects of intravenous nicorandil on hemodynamics in patients hospitalized with acute decompensated heart failure. J Cardiol 2010; 56: 291-299. PMID: 20709498

472. Suwa M, Seino Y, Nomachi Y, et al. Multicenter prospective investigation on efficacy and safety of carperitide for acute heart failure in the 'real world' of therapy. Circ J 2005; 69: 283-290. PMID: 15731532

473. Dobutamine Study Group. Comparative study of dobutamine and dopamine in patients with cardiac pump failure: Multiclinical cooperative controlled study. The Medical Frontline 1984; 39: 1657-1672.

474. Spear GS. Eosinophilic explant carditis with eosinophilia?: Hypersensitivity to dobutamine infusion. J Heart Lung Transplant 1995; 14: 755-760. PMID: 7578186

475. O'Connor CM, Gattis WA, Uretsky BF, et al. Continuous intravenous dobutamine is associated with an increased risk of death in patients with advanced heart failure: Insights from the Flolan International Randomized Survival Trial (FIRST). Am Heart J 1999; 138: 78-86. PMID: 10385768

476. Giamouzis G, Butler J, Starling RC, et al. Impact of dopamine infusion on renal function in hospitalized heart failure patients: Results of the Dopamine in Acute Decompensated Heart Failure (DAD-HF) Trial. J Card Fail 2010; 16: 922-930. PMID: 21111980

477. Bellomo R, Chapman M, Finfer S, et al. Australian and New Zealand Intensive Care Society (ANZICS) Clinical Trials Group. Low-dose dopamine in patients with early renal dysfunction: A placebo-controlled randomised trial. Lancet 2000; 356: 2139 2143. PMID: 11191541 
478. Chen HH, Anstrom KJ, Givertz MM, et al. NHLBI Heart Failure Clinical Research Network. Low-dose dopamine or low-dose nesiritide in acute heart failure with renal dysfunction: The ROSE acute heart failure randomized trial. JAMA 2013; 310: 2533-2543. PMID: 24247300

479. Triposkiadis FK, Butler J, Karayannis G, et al. Efficacy and safety of high dose versus low dose furosemide with or without dopamine infusion: The Dopamine in Acute Decompensated Heart Failure II (DAD-HF II) trial. Int J Cardiol 2014; 172: 115-121. PMID: 24485633

480. Ribner HS, Plucinski DA, Hsieh AM, et al. Acute effects of digoxin on total systemic vascular resistance in congestive heart failure due to dilated cardiomyopathy: A hemodynamic-hormonal study. Am J Cardiol 1985; 56: 896-904. PMID: 3904388

481. Seino Y, Momomura S, Takano T, et al. Japan Intravenous Milrinone Investigators. Multicenter, double-blind study of intravenous milrinone for patients with acute heart failure in Japan. Crit Care Med 1996; 24: 1490-1497. PMID: 8797620

482. Lowes BD, Tsvetkova T, Eichhorn EJ, et al. Milrinone versus dobutamine in heart failure subjects treated chronically with carvedilol. Int J Cardiol 2001; 81: 141 - 149. PMID: 11744130

483. Guyton AC, Lindsey AW. Effect of elevated left atrial pressure and decreased plasma protein concentration on the development of pulmonary edema. Circ Res 1959; 7: 649-657. PMID: 13663218

484. Johnson A, Mackway-Jones K. Towards evidence based emergency medicine: Best BETs from the Manchester Royal Infirmary. Frusemide or nitrates in acute left ventricular failure. Emerg Med J 2001; 18: 59-60. PMID: 11310465

485. Brochard L. Mechanical ventilation: Invasive versus noninvasive. Eur Respir J Suppl 2003; 47: 31s-37s. PMID: 14621115

486. MacIntyre NR, Cook DJ, Ely EW, et al. Evidence-based guidelines for weaning and discontinuing ventilatory support: A collective task force facilitated by the American College of Chest Physicians; the American Association for Respiratory Care; and the American College of Critical Care Medicine. Chest 2001; 120: 375S-395S. PMID: 11742959

487. Hernández G, Vaquero C, González P, et al. Effect of postextubation high-flow nasal cannula vs conventional oxygen therapy on reintubation in low-risk patients: A randomized clinical trial. JAMA 2016; 315: 1354-1361. PMID: 26975498

488. Bonow RO, Carabello BA, Chatterjee K, et al. ACC/AHA 2006 guidelines for the management of patients with valvular heart disease: A report of the American College of Cardiology/ American Heart Association Task Force on Practice Guidelines (writing Committee to Revise the 1998 guidelines for the management of patients with valvular heart disease) developed in collaboration with the Society of Cardiovascular Anesthesiologists endorsed by the Society for Cardiovascular Angiography and Interventions and the Society of Thoracic Surgeons. J Am Coll Cardiol 2006; 48: e1-e148. PMID: 16875962

489. Pappas PJ, Cernaianu AC, Baldino WA, et al. Ventricular free-wall rupture after myocardial infarction. Treatment and outcome. Chest 1991; 99: 892 -895. PMID: 2009791

490. Thompson CR, Buller CE, Sleeper LA, et al. Cardiogenic shock due to acute severe mitral regurgitation complicating acute myocardial infarction: A report from the SHOCK Trial Registry. SHould we use emergently revascularize Occluded Coronaries in cardiogenic shocK? J Am Coll Cardiol 2000; 36: 1104-1109. PMID: 10985712

491. Tamaki Y, Konishi H, Horiike S, et al. Introduction of early cardiac rehabilitation program for severe heart failure patients in cardiac intensive care unit. Journal of Japanese Association of Cardiac Rehabilitation 2016; 22: 71-76.

492. Dor V, Sabatier M, Di Donato M, et al. Efficacy of endoventricular patch plasty in large postinfarction akinetic scar and severe left ventricular dysfunction: Comparison with a series of large dyskinetic scars. J Thorac Cardiovasc Surg 1998; 116: 50-59. PMID: 9671897

493. Jones RH, Velazquez EJ, Michler RE, et al. STICH Hypothesis 2 Investigators. Coronary bypass surgery with or without surgical ventricular reconstruction. $N$ Engl J Med 2009; 360: 1705-1717. PMID: 19329820

494. Kainuma S, Taniguchi K, Toda K, et al. Restrictive mitral annuloplasty with or without surgical ventricular reconstruction in ischaemic cardiomyopathy: Impacts on neurohormonal activation, reverse left ventricular remodelling and survival. Eur J Heart Fail 2014; 16: 189-200. PMID: 24464828

495. Wakasa S, Matsui $Y$, Isomura T, et al. Risk scores for predicting mortality after surgical ventricular reconstruction for ischemic cardiomyopathy: Results of a Japanese multicenter study. $J$
Thorac Cardiovasc Surg 2014; 147: 1868-1874, 1874.e1-e2. PMID: 23968870

496. The Japanese Circulation Society. Guidelines for catheter intervention for congenital heart disease and structural heart disease (JCS 2014). http://www.j-circ.or.jp/guideline/pdf/JCS2014_ nakanishi_h.pdf

497. Leon MB, Smith CR, Mack M, et al. PARTNER Trial Investigators. Transcatheter aortic-valve implantation for aortic stenosis in patients who cannot undergo surgery. $N$ Engl $J$ Med 2010; 363: 1597-1607. PMID: 20961243

498. Kapadia SR, Leon MB, Makkar RR, et al. PARTNER trial investigators. 5-year outcomes of transcatheter aortic valve replacement compared with standard treatment for patients with inoperable aortic stenosis (PARTNER 1): A randomised controlled trial. Lancet 2015; 385: 2485-2491. PMID: 25788231

499. Reardon MJ, Adams DH, Kleiman NS, et al. 2-Year outcomes in patients undergoing surgical or self-expanding transcatheter aortic valve replacement. J Am Coll Cardiol 2015; 66: 113-121. PMID: 26055947

500. Adams DH, Popma JJ, Reardon MJ, et al. U.S. CoreValve Clinical Investigators. Transcatheter aortic-valve replacement with a self-expanding prosthesis. N Engl J Med 2014; 370: 1790-1798. PMID: 24678937

501. Smith CR, Leon MB, Mack MJ, et al. PARTNER Trial Investigators. Transcatheter versus surgical aortic-valve replacement in high-risk patients. $N$ Engl J Med 2011; 364: 2187-2198. PMID: 21639811

502. Mack MJ, Leon MB, Smith CR, et al. PARTNER 1 trial investigators. 5-year outcomes of transcatheter aortic valve replacement or surgical aortic valve replacement for high surgical risk patients with aortic stenosis (PARTNER 1): A randomised controlled trial. Lancet 2015; 385: 2477-2484. PMID: 25788234

503. Vahanian A, Alfieri O, Al-Attar N, et al. Transcatheter valve implantation for patients with aortic stenosis: A position statement from the European Association of Cardio-Thoracic Surgery (EACTS) and the European Society of Cardiology (ESC), in collaboration with the European Association of Percutaneous Cardiovascular Interventions (EAPCI). Eur Heart $J$ 2008; 29: 1463-1470. PMID: 18474941

504. Monin JL, Quéré JP, Monchi M, et al. Low-gradient aortic stenosis: Operative risk stratification and predictors for long-term outcome: A multicenter study using dobutamine stress hemodynamics. Circulation 2003; 108: 319-324. PMID: 12835219

505. Levy F, Laurent M, Monin JL, et al. Aortic valve replacement for low-flow/low-gradient aortic stenosis operative risk stratification and long-term outcome: A European multicenter study. J Am Coll Cardiol 2008; 51: 1466-1472. PMID: 18402902

506. Pereira JJ, Lauer MS, Bashir M, et al. Survival after aortic valve replacement for severe aortic stenosis with low transvalvular gradients and severe left ventricular dysfunction. $\mathrm{J} \mathrm{Am} \mathrm{Coll}$ Cardiol 2002; 39: 1356-1363. PMID: 11955855

507. Bauer F, Coutant V, Bernard M, et al. Patients with severe aortic stenosis and reduced ejection fraction: Earlier recovery of left ventricular systolic function after transcatheter aortic valve implantation compared with surgical valve replacement. Echocardiography 2013; 30: 865-870. PMID: 23489257

508. Pilgrim T, Wenaweser P, Meuli F, et al. Clinical outcome of high-risk patients with severe aortic stenosis and reduced left ventricular ejection fraction undergoing medical treatment or TAVI. PLoS One 2011; 6: e27556. PMID: 22102909

509. Sannino A, Gargiulo G, Schiattarella GG, et al. Increased mortality after transcatheter aortic valve implantation (TAVI) in patients with severe aortic stenosis and low ejection fraction: A meta-analysis of 6898 patients. Int J Cardiol 2014; 176: 32-39. PMID: 25042666

510. Eleid MF, Goel K, Murad MH, et al. Meta-analysis of the prognostic impact of stroke volume, gradient, and ejection fraction after transcatheter aortic valve implantation. Am J Cardiol 2015; 116: 989-994. PMID: 26195275

511. Stevenson LW, Pagani FD, Young JB, et al. INTERMACS profiles of advanced heart failure: The current picture. J Heart Lung Transplant 2009; 28: 535-541. PMID: 19481012

512. The Japanese Association for Thoracic Surgery. J-MACS Statistical Report (From June 2010 to July 2017). http://www. jpats.org/uploads/uploads/files/J-MACS $\% 20$ Statistical $\% 20$ Report $\%$ EF\%BC $\% 882010 \% \mathrm{E} 5 \% \mathrm{~B} 9 \% \mathrm{~B} 46 \% \mathrm{E} 6 \% 9 \mathrm{C} \% 88-2017$ $\%$ E5\%B9 $\%$ B $47 \%$ E6 $\% 9$ C $\% 88 \%$ EF $\%$ BC $\% 89$.pdf

513. Kinugawa K. How to treat stage D heart failure?: When to implant left ventricular assist devices in the era of continuous flow pumps? Circ J 2011; 75: 2038 -2045. PMID: 21817817 
514. Saito S, Matsumiya G, Sakaguchi T, et al. Fifteen-year experience with Toyobo paracorporeal left ventricular assist system. J Artif Organs 2009; 12: 27-34. PMID: 19330502

515. Sasaoka T, Kato TS, Komamura K, et al. Improved long-term performance of pulsatile extracorporeal left ventricular assist device. J Cardiol 2010; 56: 220-228. PMID: 20615667

516. Shiga T, Kinugawa K, Hatano M, et al. Age and preoperative total bilirubin level can stratify prognosis after extracorporeal pulsatile left ventricular assist device implantation. Circ J 2011; 75: $121-128$. PMID: 21116070

517. The Japanese Circulation Society, the Japanese Society for Cardiovascular Surgery. Guidelines for device therapy: Implantable left ventricular assist device for patients with severe heart failure (JCS/JSCVS2013). http://www.j-circ.or.jp/guideline/pdf/ JCS2013 kyo h.pdf

518. Nakatani T, Sase K, Oshiyama H, et al. J-MACS investigators. Japanese registry for mechanically assisted circulatory support: First report. J Heart Lung Transplant 2017; 36: 1087-1096. PMID: 28942783

519. Kirklin JK, Pagani FD, Kormos RL, et al. Eighth annual INTERMACS report: Special focus on framing the impact of adverse events. $J$ Heart Lung Transplant 2017; 36: 1080-1086. PMID: 28942782

520. Rose EA, Gelijns AC, Moskowitz AJ, et al. Randomized Evaluation of Mechanical Assistance for the Treatment of Congestive Heart Failure (REMATCH) Study Group. Longterm use of a left ventricular assist device for end-stage heart failure. $N$ Engl J Med 2001; 345: 1435-1443. PMID: 11794191

521. Slaughter MS, Rogers JG, Milano CA, et al. HeartMate II Investigators. Advanced heart failure treated with continuous-flow left ventricular assist device. N Engl J Med 2009; 361: 2241 2251. PMID: 19920051

522. The Heart Translation Committee of Japanese Circulation Society. Basic criteria for heart transplant recipients. http:// www.j-circ.or.jp/hearttp/HTRecCriteria.html

523. Fukushima N, Ono M, Saiki Y, et al. Registry report on heart transplantation in Japan (June 2016). Circ J 2017; 81: 298-303. PMID: 28070058

524. Stehlik J, Bavaria JE, Bax J, et al. Heart, lung, and vascular registries: Evolving goals, successful approaches, and ongoing innovation. J Heart Lung Transplant 2016; 35: 1149-1157. PMID: 27772667

525. Jonkman NH, Westland H, Groenwold RH, et al. Do selfmanagement interventions work in patients with heart failure? An individual patient data meta-analysis. Circulation 2016; 133: 1189-1198. PMID: 26873943

526. Otsu H, Moriyama M. Effectiveness of an educational selfmanagement program for outpatients with chronic heart failure. Jpn J Nurs Sci 2011; 8: 140-152. PMID: 22117578

527. Kato N, Kinugawa K, Nakayama E, et al. Insufficient self-care is an independent risk factor for adverse clinical outcomes in Japanese patients with heart failure. Int Heart J 2013; 54: 382 389. PMID: 24309448

528. Lainscak M, Blue L, Clark AL, et al. Self-care management of heart failure: Practical recommendations from the Patient Care Committee of the Heart Failure Association of the European Society of Cardiology. Eur J Heart Fail 2011; 13: 115-126. PMID: 21148593

529. Kato N, Kinugawa K, Ito N, et al. Adherence to self-care behavior and factors related to this behavior among patients with heart failure in Japan. Heart Lung 2009; 38: 398-409. PMID: 19755190

530. Matsuoka S, Tsuchihashi-Makaya M, Kayane T, et al. Health literacy is independently associated with self-care behavior in patients with heart failure. Patient Educ Couns 2016; 99: 1026 1032. PMID: 26830514

531. The Japanese Heart Failure Society. Heart failure patient diary. http://www.asas.or.jp/jhfs/topics/20130301.html

532. van der Wal MH, Jaarsma T. Adherence in heart failure in the elderly: Problem and possible solutions. Int J Cardiol 2008; 125: 203-208. PMID: 18031843

533. Kitzman DW. Outcomes in patients with heart failure with preserved ejection fraction: It is more than the heart. $\mathrm{J} \mathrm{Am}$ Coll Cardiol 2012; 59: 1006-1007. PMID: 22402072

534. McAlister FA, Stewart S, Ferrua S, et al. Multidisciplinary strategies for the management of heart failure patients at high risk for admission: A systematic review of randomized trials. $J$ Am Coll Cardiol 2004; 44: 810-819. PMID: 15312864

535. Holland R, Battersby J, Harvey I, et al. Systematic review of multidisciplinary interventions in heart failure. Heart 2005; 91:
899-906. PMID: 15958358

536. Fonarow GC. Heart failure disease management programs: Not a class effect. Circulation 2004; 110: 3506-3508. PMID 15583088

537. Powell LH, Calvin JE, Richardson D, et al. HART Investigators. Self-management counseling in patients with heart failure: The heart failure adherence and retention randomized behavioral trial. JAMA 2010; 304: 1331 - 1338. PMID: 20858878

538. Galbreath AD, Krasuski RA, Smith B, et al. Long-term healthcare and cost outcomes of disease management in a large, randomized, community-based population with heart failure. Circulation 2004; 110: 3518-3526. PMID: 15531765

539. Riegel B, Moser DK, Anker SD, et al. State of the science: Promoting self-care in persons with heart failure: A scientific statement from the American Heart Association. Circulation 2009; 120: 1141 -1163. PMID: 19720935

540. Ades PA, Keteyian SJ, Balady GJ, et al. Cardiac rehabilitation exercise and self-care for chronic heart failure. JACC Heart Fail 2013; 1: 540-547. PMID: 24622007

541. Davidson PM, Cockburn J, Newton PJ, et al. Can a heart failurespecific cardiac rehabilitation program decrease hospitalizations and improve outcomes in high-risk patients? Eur J Cardiovasc Prev Rehabil 2010; 17: 393-402. PMID: 20498608

542. Goto Y. How to operate out-patient cardiac rehabilitation as a heart failure management program. Heart View 2014; 18: $520-527$

543. Goto Y. Cardiac rehabilitation and exercise therapy for patients with heart failure. Saito M, Goto Y, editors. Rehabilitation for angina pectoris and myocardial infarction, revised 4th edition. Tokyo: Nankodo, 2009; 253-268.

544. World Health Organization. Organization. Global atlas of palliative care at the end of life. (Jan 2014) http://www.who.int/ nmh/Global_Atlas_of_Palliative_Care.pdf

545. Allen LA, Yager JE, Funk MJ, et al. Discordance between patient-predicted and model-predicted life expectancy among ambulatory patients with heart failure. JAMA 2008; 299: 25332542. PMID: 18523222

546. Allen LA, Stevenson LW, Grady KL, et al. Decision making in advanced heart failure: A scientific statement from the American Heart Association. Circulation 2012; 125: 1928-1952. PMID: 22392529

547. Detering KM, Hancock AD, Reade MC, et al. The impact of advance care planning on end of life care in elderly patients: Randomised controlled trial. BMJ 2010; 340: c1345. PMID: 20332506

548. The Ministry of Health, Labour and Welfare. Guidelines for decision making with end-of-life care (Published in May 2007 and revised in March 2015) http://www.mhlw.go.jp/file/ 06-Seisakujouhou-10800000-Iseikyoku/0000078981.pdf

549. The Guideline Committee of the Japanese Heart Failure Society. Statement on treatment of elderly patients with heart failure in 2016. http://www.asas.or.jp/jhfs/pdf/Statement_HeartFailurel. pdf

550. The Japanese Society of Intensive Care Medicine. Advice on Do Not Attempt Resuscitation (DNAR) order. J Jpn Soc Intensive Care Med 2017; 24: 208-209. http://www.jsicm.org/ pdf/DNAR20170105.pdf

551. Qaseem A, Snow V, Shekelle P, et al. Evidence-based interventions to improve the palliative care of pain, dyspnea, and depression at the end of life: A clinical practice guideline from the American College of Physicians. Ann Intern Med 2008; 148: 141-146. PMID: 18195338

552. Lynn J. Perspectives on care at the close of life. Serving patients who may die soon and their families: The role of hospice and other services. JAMA 2001; 285: 925-932. PMID: 11180736

553. Yancy CW, Jessup M, Bozkurt B, et al. 2013 ACCF/AHA guideline for the management of heart failure: A report of the American College of Cardiology Foundation/American Heart Association Task Force on Practice Guidelines. $\mathrm{J} \mathrm{Am} \mathrm{Coll}$ Cardiol 2013; 62: e147-e239. PMID: 23747642

554. The Japanese Circulation Society. Statement for end-stage cardiovascular care (JCS 2011). http://www.j-circ.or.jp/guideline/ pdf/JCS2010_nonogi_h.pdf

555. Gibbs JS, McCoy AS, Gibbs LM, et al. Living with and dying from heart failure: The role of palliative care. Heart 2002; 88(Suppl): ii36-ii39. PMID: 12213799

556. Krumholz HM, Phillips RS, Hamel MB, et al. Resuscitation preferences among patients with severe congestive heart failure: Results from the SUPPORT project. Study to understand prognoses and preferences for outcomes and risks of treatments. 
Circulation 1998; 98: 648-655. PMID: 9715857

557. Levenson JW, McCarthy EP, Lynn J, et al. The last six months of life for patients with congestive heart failure. $J$ Am Geriatr Soc 2000; 48: S101-S109. PMID: 10809463

558. Solano JP, Gomes B, Higginson IJ. A comparison of symptom prevalence in far advanced cancer, AIDS, heart disease, chronic obstructive pulmonary disease and renal disease. J Pain Symptom Manage 2006; 31: 58-69. PMID: 16442483

559. Rutledge T, Reis VA, Linke SE, et al. Depression in heart failure a meta-analytic review of prevalence, intervention effects, and associations with clinical outcomes. J Am Coll Cardiol 2006; 48: 1527-1537. PMID: 17045884

560. Johnson MJ, McDonagh TA, Harkness A, et al. Morphine for the relief of breathlessness in patients with chronic heart failure: A pilot study. Eur J Heart Fail 2002; 4: 753-756. PMID: 12453546

561. Williams SG, Wright DJ, Marshall P, et al. Safety and potential benefits of low dose diamorphine during exercise in patients with chronic heart failure. Heart 2003; 89: 1085-1086. PMID: 12923038

562. Evangelista LS, Sackett E, Dracup K. Pain and heart failure: Unrecognized and untreated. Eur J Cardiovasc Nurs 2009; 8: 169-173. PMID: 19150255

563. Schaefer KM, Shober Potylycki MJ. Fatigue associated with congestive heart failure: Use of Levine's Conservation Model. $J$ Adv Nurs 1993; 18: 260-268. PMID: 8436716

564. Sherwood A, Blumenthal JA, Trivedi R, et al. Relationship of depression to death or hospitalization in patients with heart failure. Arch Intern Med 2007; 167: 367-373. PMID: 17325298

565. Fosbøl EL, Gislason GH, Poulsen HE, et al. Prognosis in heart failure and the value of $\beta$-blockers are altered by the use of antidepressants and depend on the type of antidepressants used. Circ Heart Fail 2009; 2: 582-590. PMID: 19919983

566. O'Connor CM, Jiang W, Kuchibhatla M, et al. SADHART-CHF Investigators. Safety and efficacy of sertraline for depression in patients with heart failure: Results of the SADHART-CHF (Sertraline Against Depression and Heart Disease in Chronic Heart Failure) trial. J Am Coll Cardiol 2010; 56: 692-699. PMID: 20723799

567. May HT, Horne BD, Carlquist JF, et al. Depression after coronary artery disease is associated with heart failure. $J \mathrm{Am}$ Coll Cardiol 2009; 53: 1440-1447. PMID: 19371828

568. Angermann CE, Gelbrich G, Störk S, et al. MOOD-HF Study Investigators and Committee Members. Effect of escitalopram on all-cause mortality and hospitalization in patients with heart failure and depression: The MOOD-HF Randomized Clinical Trial. JAMA 2016; 315: 2683-2693. PMID: 27367876

569. Milani RV, Lavie CJ. Impact of cardiac rehabilitation on depression and its associated mortality. Am J Med 2007; 120: 799-806. PMID: 17765050

570. Tu RH, Zeng ZY, Zhong GQ, et al. Effects of exercise training on depression in patients with heart failure: A systematic review and meta-analysis of randomized controlled trials. Eur J Heart Fail 2014; 16: 749-757. PMID: 24797230

571. Padeletti L, Arnar DO, Boncinelli L, et al. EHRA Expert Consensus Statement on the management of cardiovascular implantable electronic devices in patients nearing end of life or requesting withdrawal of therapy. Europace 2010; 12: 1480-1489. PMID: 20675674

572. Japan VAD Council. Concept of optimizing the indications for ventricular assist devices in Japan: Destination therapy (DT). https://www.jacvas.com/view-dt

573. Swetz KM, Kamal AH, Matlock DD, et al. Preparedness planning before mechanical circulatory support: A "how-to" guide for palliative medicine clinicians. J Pain Symptom Manage 2014; 47: 926-935.e6. PMID: 24094703

574. The Japanese Association for Acute Medicine, the Japanese Society of Intensive Care Medicine, the Japanese Circulation Society. Guidelines for terminal care in emergency and intensive care medicine - Proposal from three scientific societies. http:// www.jaam.jp/html/info/2014/pdf/info-20141104_02_01_02.pdf

575. Swedberg K, Komajda M, Böhm M, et al. SHIFT Investigators. Ivabradine and outcomes in chronic heart failure (SHIFT): A randomised placebo-controlled study. Lancet 2010; 376: 875885. PMID: 20801500

576. Böhm M, Swedberg K, Komajda M, et al. SHIFT Investigators. Heart rate as a risk factor in chronic heart failure (SHIFT): The association between heart rate and outcomes in a randomised placebo-controlled trial. Lancet 2010; 376: 886-894. PMID: 20801495

577. McMurray JJ, Packer M, Desai AS, et al. PARADIGM-HF
Investigators and Committees. Angiotensin-neprilysin inhibition versus enalapril in heart failure. $N$ Engl J Med 2014; 371: 993-1004. PMID: 25176015

578. Yancy CW, Jessup M, Bozkurt B, et al. 2016 ACC/AHA/HFSA Focused Update on New Pharmacological Therapy for Heart Failure: An Update of the 2013 ACCF/AHA Guideline for the Management of Heart Failure: A Report of the American College of Cardiology/American Heart Association Task Force on Clinical Practice Guidelines and the Heart Failure Society of America. Circulation 2016; 134: e282-e293. PMID: 27208050

579. Tsutsui H, Momomura S, Saito Y, et al. Efficacy and safety of sacubitril/valsartan (LCZ696) in Japanese patients with chronic heart failure and reduced ejection fraction: Rationale for and design of the randomized, double-blind PARALLEL-HF study. J Cardiol 2017; 70: 225-231. PMID: 28024961

580. Solomon SD, Zile M, Pieske B, et al. Prospective comparison of ARNI with ARB on Management Of heart failUre with preserved ejectioN fracTion (PARAMOUNT) Investigators. The angiotensin receptor neprilysin inhibitor LCZ696 in heart failure with preserved ejection fraction: A phase 2 double-blind randomised controlled trial. Lancet 2012; 380: 1387-1395. PMID: 22932717

581. Gheorghiade M, Marti CN, Sabbah HN, et al. Academic Research Team in Heart Failure (ART-HF). Soluble guanylate cyclase: A potential therapeutic target for heart failure. Heart Fail Rev 2013; 18: 123-134. PMID: 22622468

582. Greenberg B. Novel therapies for heart failure: Where do they stand? Circ J 2016; 80: 1882-1891. PMID: 27545139

583. Nossaman B, Pankey E, Kadowitz P. Stimulators and activators of soluble guanylate cyclase: Review and potential therapeutic indications. Crit Care Res Pract 2012; 2012: 290805. PMID: 22482042

584. Pieske B, Butler J, Filippatos G, et al. SOCRATES Investigators and Coordinators. Rationale and design of the SOluble guanylate Cyclase stimulatoR in heArT failurE Studies (SOCRATES). Eur J Heart Fail 2014; 16: 1026-1038. PMID: 25056511

585. Gheorghiade M, Greene SJ, Butler J, et al. SOCRATESREDUCED Investigators and Coordinators. Effect of vericiguat, a soluble guanylate cyclase stimulator, on natriuretic peptide levels in patients with worsening chronic heart failure and reduced ejection fraction: The SOCRATES-REDUCED Randomized Trial. JAMA 2015; 314: 2251-2262. PMID: 26547357

586. A study of vericiguat in participants with heart failure with reduced ejection fraction (HFrEF) (MK-1242-001) (VICTORIA). https://clinicaltrials.gov/show/NCT02861534

587. Malik FI, Hartman JJ, Elias KA, et al. Cardiac myosin activation: A potential therapeutic approach for systolic heart failure. Science 2011; 331: 1439-1443. PMID: 21415352

588. Cleland JG, Teerlink JR, Senior R, et al. The effects of the cardiac myosin activator, omecamtiv mecarbil, on cardiac function in systolic heart failure: A double-blind, placebocontrolled, crossover, dose-ranging phase 2 trial. Lancet 2011; 378: 676-683. PMID: 21856481

589. Teerlink JR, Felker GM, McMurray JJV, et al. ATOMIC-AHF Investigators. Acute treatment with omecamtiv mecarbil to increase contractility in acute heart failure: The ATOMIC-AHF Study. J Am Coll Cardiol 2016; 67: 1444-1455. PMID: 27012405

590. Teerlink JR, Felker GM, McMurray JJ, et al. COSMIC-HF Investigators. Chronic Oral Study of Myosin Activation to Increase Contractility in Heart Failure (COSMIC-HF): A phase 2, pharmacokinetic, randomised, placebo-controlled trial. Lancet 2016; 388: 2895-2903. PMID: 27914656

591. A double-blind, randomized, placebo-controlled, multicenter study to assess the efficacy and safety of omecamtiv mecarbil on mortality and morbidity in subjects with chronic heart failure with reduced ejection fraction (GALACTIC-HF). https:// clinicaltrials.gov/ct2/show/NCT02929329

592. Sawa Y, Miyagawa S. Present and future perspectives on cell sheetbased myocardial regeneration therapy. Biomed Res Int 2013; 2013: 583912. PMID: 24369013

593. Yoshikawa Y, Miyagawa S, Toda K, et al. Myocardial regenerative therapy using a scaffold-free skeletal-muscle-derived cell sheet in patients with dilated cardiomyopathy even under a left ventricular assist device: A safety and feasibility study. Surg Today 2018; 48: 200-210. PMID: 28821963

594. Miyagawa S, Domae K, Yoshikawa Y, et al. Phase I clinical trial of autologous stem cell-sheet transplantation therapy for treating cardiomyopathy. J Am Heart Assoc 2017; 6: e003918. PMID: 28381469 
595. Sawa Y, Yoshikawa Y, Toda K, et al. Safety and efficacy of autologous skeletal myoblast sheets (TCD-51073) for the treatment of severe chronic heart failure due to ischemic heart disease. Circ J 2015; 79: 991-999. PMID: 25912561

596. Tei C. Waon therapy: Soothing warmth therapy. J Cardiol 2007; 49: 301-304. PMID: 17633566

597. Tei C, Horikiri Y, Park JC, et al. Acute hemodynamic improvement by thermal vasodilation in congestive heart failure. Circulation 1995; 91: 2582-2590. PMID: 7743620

598. Tei C, Tanaka N. Thermal vasodilation as a treatment of congestive heart failure: A novel approach. J Cardiol 1996; 27: 29-30. PMID: 8683432

599. Miyata M, Kihara T, Kubozono T, et al. Beneficial effects of Waon therapy on patients with chronic heart failure: Results of a prospective multicenter study. J Cardiol 2008; 52: 79-85. PMID: 18922381

600. Sobajima M, Nozawa T, Fukui Y, et al. Waon therapy improves quality of life as well as cardiac function and exercise capacity in patients with chronic heart failure. Int Heart J 2015; 56: 203-208. PMID: 25740582

601. Kisanuki A, Daitoku S, Kihara T, et al. Thermal therapy improves left ventricular diastolic function in patients with congestive heart failure: A tissue doppler echocardiographic study. J Cardiol 2007; 49: 187-191. PMID: 17460879

602. Kihara T, Biro S, Imamura M, et al. Repeated sauna treatment improves vascular endothelial and cardiac function in patients with chronic heart failure. J Am Coll Cardiol 2002; 39: 754-759. PMID: 11869837

603. Kuwahata S, Miyata M, Fujita S, et al. Improvement of autonomic nervous activity by Waon therapy in patients with chronic heart failure. J Cardiol 2011; 57: 100-106. PMID: 20884178

604. Kihara T, Biro S, Ikeda Y, et al. Effects of repeated sauna treatment on ventricular arrhythmias in patients with chronic heart failure. Circ J 2004; 68: 1146-1151. PMID: 15564698

605. Kihara T, Miyata M, Fukudome T, et al. Waon therapy improves the prognosis of patients with chronic heart failure. $J$ Cardiol 2009; 53: 214-218. PMID: 19304125

606. Tei C, Imamura T, Kinugawa K, et al. WAON-CHF Study Investigators. Waon therapy for managing chronic heart failure: Results from a multicenter prospective randomized WAONCHF study. Circ J 2016; 80: 827-834. PMID: 27001189

\section{Appendix 1. JCS Joint Working Group}

Chair:

- Hiroyuki Tsutsui, Department of Cardiovascular Medicine, Kyushu University Graduate School of Medical Sciences

Members:

- Yoichi Goto, Yoka Municipal Hospital

- Taiki Higo, Department of Cardiovascular Medicine, Kyushu University Graduate School of Medical Sciences

- Atsushi Hirayama, The Division of Cardiology, Department of Medicine, Nihon University Graduate School of Medicine

- Mitsuaki Isobe, Sakakibara Heart Institute

- Hiroshi Ito, Department of Cardiovascular and Respiratory Medicine, Akita University Graduate School of Medicine

- Hiroshi Ito, Department of Cardiovascular Medicine, Division of Biophysiological Sciences, Okayama University Graduate School of Medicine, Dentistry and Pharmaceutical Sciences

- Yasuki Kihara, Department of Cardiovascular Medicine, Graduate School of Biomedical and Health Sciences, Hiroshima University

- Koichiro Kinugawa, Second Department of Internal Medicine, University of Toyama

- Masafumi Kitakaze, Department of Clinical Medicine and Development, National Cerebral and Cardiovascular Center

- Issei Komuro, Department of Cardiovascular Medicine, Graduate School of Medicine, The University of Tokyo

- Miyuki Makaya, Kitasato University Graduate School of Nursing

- Tohru Masuyama, Cardiovascular Division, Department of Internal Medicine, Hyogo College of Medicine

- Shin-ichi Momomura, Saitama Medical Center, Jichi Medical University

- Toyoaki Murohara, Department of Cardiology, Nagoya University Graduate School of Medicine

- Koichi Node, Department of Cardiovascular Medicine, Saga University

- Ken Okumura, Division of Cardiology, Saiseikai Kumamoto Hospital Cardiovascular Center

- Minoru Ono, Department of Cardiac Surgery, Graduate School of Medicine, The University of Tokyo

- Yoshikatsu Saiki, Department of Cardiovascular Surgery, Tohoku University Graduate School of Medicine

- Yoshihiko Saito, Department of Cardiovascular Medicine, Nara Medical University

- Yasushi Sakata, Department of Cardiovascular Medicine, Osaka University Graduate School of Medicine

- Naoki Sato, Department of Cardiovascular Medicine, Kawaguchi Cardiovascular and Respiratory Hospital

- Yoshiki Sawa, Department of Cardiovascular Surgery, Osaka University Graduate School of Medicine

- Yoshihiko Seino, Nippon Medical School Chiba Hokusoh Hospital

- Wataru Shimizu, Department of Cardiovascular Medicine, Nippon Medical School

- Hiroaki Shimokawa, Department of Cardiovascular Medicine, Tohoku University Graduate School of Medicine

- Akira Shiose, Department of Cardiovascular Surgery, Kyushu University Graduate School of Medical Sciences
- Kazuhiro Yamamoto, Department of Molecular Medicine and Therapeutics, Faculty of Medicine, Tottori University

- Kenji Yamazaki, Department of Cardiology Surgery, Tokyo Women's Medical University

- Masafumi Yano, Department of Medicine and Clinical Science, Yamaguchi University Graduate School of Medicine

- Tsutomu Yoshikawa, Department of Cardiology, Sakakibara Heart Institute

- Michihiro Yoshimura, Division of Cardiology, Department of Internal Medicine, The Jikei University School of Medicine

Collaborators:

- Masatoshi Akiyama, Department of Cardiovascular Surgery, Tohoku University School of Medicine

- Toshihisa Anzai, Department of Cardiovascular Medicine, Hokkaido University Graduate School of Medicine

- Takeo Fujino, Department of Advanced Cardiopulmonary Failure, Kyushu University Graduate School of Medical Sciences

- Masaru Hatano, Department of Cardiovascular Medicine, The University of Tokyo Hospital

- Takayuki Hidaka, Department of Cardiovascular Medicine, Hiroshima University

- Teruhiko Imamura, Department of Medicine, University of Chicago Medical Center

- Takayuki Inomata, Department of Cardiovascular Medicine, Kitasato University Kitasato Institute Hospital

- Shiro Ishihara, Department of Cardiology, Nippon Medical School Musashi-Kosugi Hospital

- Yu-ki Iwasaki, Department of Cardiovascular Medicine, Nippon Medical School

- Takatoshi Kasai, Cardiovascular Respiratory Sleep Medicine, Department of Cardiovascular Medicine, Juntendo University Graduate School of Medicine

- Mahoto Kato, Department of Cardiovascular Medicine, Nihon University Graduate School of Medicine

- Makoto Kawai, Division of Cardiology, Department of Internal Medicine, The Jikei University School of Medicine

- Yoshiharu Kinugasa, Department of Cardiovascular Medicine, Tottori University Hospital

- Shintaro Kinugawa, Department of Cardiovascular Medicine, Hokkaido University Graduate School of Medicine

- Shigeki Kobayashi, Department of Medicine and Clinical Science, Yamaguchi University Graduate School of Medicine

- Toru Kuratani, Department of Minimally Invasive Cardiovascular Medicine, Osaka University Graduate School of Medicine

- Shigeru Makita, Department of Cardiac Rehabilitation, Saitama Medical University International Medical Center

- Kotaro Nochioka, Department of Cardiovascular Medicine, Tohoku University School of Medicine

- Takashi Noda, Department of Cardiovascular Medicine, National Cerebral and Cardiovascular Center

- Tomohito Ohtani, Department of Cardiovascular Medicine, Osaka University Graduate School of Medicine

- Katsuya Onishi, Onishi Heart Clinic 
- Yasuhiko Sakata, Department of Cardiovascular Medicine, Tohoku University Graduate School of Medicine

- Atsushi Tanaka, Department of Cardiovascular Medicine, Saga University

- Koichi Toda, Department of Cardiovascular Surgery, Osaka University Graduate School of Medicine

- Osamu Yamaguchi, Department of Cardiovascular Medicine, Osaka University Graduate School of Medicine

Independent Assessment Committee:

- Uichi Ikeda, Nagano Municipal Hospital
- Takeshi Kimura, Department of Cardiovascular Medicine, Graduate School of Medicine and Faculty of Medicine, Kyoto University

- Shun Kohsaka, Department of Cardiology, Keio University School of Medicine

- Masami Kosuge, Division of Cardiology, Yokohama City University Medical Center

- Masakazu Yamagishi, Department of Cardiovascular and Internal Medicine, Kanazawa University Graduate School of Medicine

- Akira Yamashina, Medical Education Promotion Center, Tokyo Medical University

(The affiliations of the members are as of November 2017)

Appendix 2. Disclosure of Potential Conflicts of Interest (COI):

JCS 2017/JHFS 2017 Guideline on Diagnosis and Treatment of Acute and Chronic Heart Failure

\begin{tabular}{|c|c|c|c|c|c|c|c|c|c|}
\hline Author & $\begin{array}{c}\text { Employer/ } \\
\text { leadership } \\
\text { position } \\
\text { (private company) }\end{array}$ & Stakeholder & $\begin{array}{l}\text { Patent } \\
\text { royalty }\end{array}$ & Honorarium & $\begin{array}{l}\text { Payment for } \\
\text { manuscripts }\end{array}$ & Research grant & $\begin{array}{l}\text { Scholarship (educational) } \\
\text { grant/endowed chair }\end{array}$ & $\begin{array}{c}\text { Other } \\
\text { rewards }\end{array}$ & \begin{tabular}{|c|} 
Potential \\
COI of the \\
marital \\
partner, \\
first-degree \\
family \\
members, \\
or those \\
who share \\
income and \\
property
\end{tabular} \\
\hline $\begin{array}{l}\text { Group leader: } \\
\text { Hiroyuki } \\
\text { Tsutsui }\end{array}$ & & & & $\begin{array}{l}\cdot \text { MSD K.K. } \\
\text {-Otsuka Pharmaceutical } \\
\text { Co., Ltd. } \\
\text {-Takeda Pharmaceutical } \\
\text { Company Limited } \\
\text {-Mitsubishi Tanabe } \\
\text { Pharma Corporation } \\
\text {-Daiichi Sankyo } \\
\text { Company, Limited } \\
\text {-Boehringer Ingelheim } \\
\text { Japan, Inc. } \\
\text {-Novartis Pharma K.K. } \\
\text {-Bayer Yakuhin, Ltd. } \\
\text {-Pfizer Japan Inc. }\end{array}$ & & $\begin{array}{l}\text { Japan Tobacco Inc. } \\
\text {-Boehringer Ingelheim } \\
\text { Japan, Inc. } \\
\text {-Actelion } \\
\text { Pharmaceuticals } \\
\text { Japan Ltd. }\end{array}$ & $\begin{array}{l}\text { MSD K.K. } \\
\text { Daiichi Sankyo Company, } \\
\text { Limited } \\
\text {-Mitsubishi Tanabe Pharma } \\
\text { Corporation }\end{array}$ & & \\
\hline $\begin{array}{l}\text { Member: } \\
\text { Mitsuaki Isobe }\end{array}$ & & & & $\begin{array}{l}\text { Daiichi Sankyo } \\
\text { Company, Limited }\end{array}$ & & $\begin{array}{l}\text { Chugai } \\
\text { Pharmaceutical } \\
\text { Co.,Ltd. } \\
\text { Ono Pharmaceutical } \\
\text { Co., Ltd. }\end{array}$ & $\begin{array}{l}\text {-Teijin Pharma Limited } \\
\text { Otsuka Pharmaceutical } \\
\text { Co., Ltd. } \\
\text {-Daiichi Sankyo Company, } \\
\text { Limited } \\
\text { Ono Pharmaceutical Co., } \\
\text { Ltd. } \\
\text {-Mitsubishi Tanabe Pharma } \\
\text { Corporation } \\
\end{array}$ & & \\
\hline $\begin{array}{l}\text { Member: } \\
\text { Hiroshi Ito }\end{array}$ & & & & $\begin{array}{l}\text {-Daiichi Sankyo } \\
\text { Company, Limited } \\
\text {-Mitsubishi Tanabe } \\
\text { Pharma Corporation } \\
\text {-MSD K.K. } \\
\text { - Bayer Yakuhin, Ltd. } \\
\text {-Boehringer Ingelheim } \\
\text { Japan, Inc. } \\
\text {-Kowa Pharmaceutical } \\
\text { Co., Ltd. }\end{array}$ & & $\begin{array}{l}\text { ·Novartis Pharma } \\
\text { K.K. } \\
\text {-Kowa } \\
\text { Pharmaceutical } \\
\text { Co., Ltd. }\end{array}$ & $\begin{array}{l}\text {-Daiichi Sankyo Company, } \\
\text { Limited } \\
\text {-Takeda Pharmaceutical } \\
\text { Company Limited } \\
\text {-Mitsubishi Tanabe Pharma } \\
\text { Corporation } \\
\text {-MSD K.K. } \\
\text { - Bayer Yakuhin, Ltd. } \\
\text {-Boehringer Ingelheim } \\
\text { Japan, Inc. } \\
\text {-Kowa Pharmaceutical Co., } \\
\text { Ltd. } \\
\text {-Otsuka Pharmaceutical } \\
\text { Co., Ltd. } \\
\text {-Sanofi K.K. } \\
\text {-Mochida Pharmaceutical } \\
\text { Co.,Ltd. } \\
\text {-Actelion Pharmaceuticals } \\
\text { Japan Ltd. } \\
\text { Boston Scientific } \\
\text { Corporation } \\
\text {-BIOTRONIK Japan, Inc. } \\
\text { Fukuda Denshi Co., Ltd. } \\
\text {-St. Jude Medical Japan } \\
\text { Co., Ltd. } \\
\text {-Medtronic Japan Co., Ltd. }\end{array}$ & & \\
\hline $\begin{array}{l}\text { Member: } \\
\text { Ken Okumura }\end{array}$ & & & & $\begin{array}{l}\text { Daiichi Sankyo } \\
\text { Company, Limited } \\
\text {-Boehringer Ingelheim } \\
\text { Japan, Inc. } \\
\text { Johnson \& Johnson } \\
\text { K.K. }\end{array}$ & & & & & \\
\hline $\begin{array}{l}\text { Member: } \\
\text { Minoru Ono }\end{array}$ & & & & & & & $\begin{array}{l}\text { ·Edwards Lifesciences } \\
\text { Corporation } \\
\text {-TERUMO } \\
\text { CORPORATION } \\
\text {-Astellas Pharma Inc. } \\
\text {-Abbott Vascular Japan } \\
\text { Co., Ltd. } \\
\text {-Kono Seisakusho Co., Ltd. }\end{array}$ & & \\
\hline
\end{tabular}




\begin{tabular}{|c|c|c|c|c|c|c|c|c|c|}
\hline Author & $\begin{array}{c}\text { Employer/ } \\
\text { leadership } \\
\text { position } \\
\text { (private company) }\end{array}$ & Stakeholder & $\begin{array}{c}\text { Patent } \\
\text { royalty }\end{array}$ & Honorarium & $\begin{array}{l}\begin{array}{l}\text { Payment for } \\
\text { manuscripts }\end{array} \\
\text { mats }\end{array}$ & Research grant & $\begin{array}{l}\text { Scholarship (educational) } \\
\text { grant/endowed chair }\end{array}$ & \begin{tabular}{|c|c} 
Other \\
rewards
\end{tabular} & $\begin{array}{c}\text { Potential } \\
\text { COI of the } \\
\text { marital } \\
\text { partner, } \\
\text { first-degree } \\
\text { family } \\
\text { members, } \\
\text { or those } \\
\text { who share } \\
\text { income and } \\
\text { property }\end{array}$ \\
\hline $\begin{array}{l}\text { Member: } \\
\text { Masafumi } \\
\text { Kitakazeze }\end{array}$ & & & & $\begin{array}{l}\text { AstraZeneca K.K. } \\
\text {-Mitsubishi Tanabe } \\
\text { Pharma Corporation } \\
\text {-Takeda Pharmaceutical } \\
\text { Company Limited } \\
\text { Ono Pharmaceutical } \\
\text { Co., thd. }\end{array}$ & & $\begin{array}{l}\text {-KUREHA } \\
\text { CORPORATION } \\
\text {-Boehringer Ingelheim } \\
\text { Japan, Inc. } \\
\text {-Takeda } \\
\text { Pharmaceutical } \\
\text { Company Limited } \\
\text {-AstraZeneca K.K. }\end{array}$ & $\begin{array}{l}\text { Takeda Pharmaceutical } \\
\text { Company Limited }\end{array}$ & & \\
\hline \begin{tabular}{|l|} 
Member: \\
Koichiro \\
Kinugawa
\end{tabular} & & & & $\begin{array}{l}\text {-Otsuka Pharmaceutical } \\
\text { Co., Ltd. } \\
\text {-TERUMO } \\
\text { CORPORATION } \\
\text {-Astellas Pharma Inc. } \\
\text {-Daiiih Sankyo } \\
\text { Company, Limited } \\
\text { Ono Pharmaceutical } \\
\text { Co., Ltd. } \\
\text {-Boehringer Ingelheim } \\
\text { Japan, Inc. } \\
\text {-Mitsubishi Tanabe } \\
\text { Pharma Corporation } \\
\text {-Nipro Corporation } \\
\end{array}$ & & & $\begin{array}{l}\text { Otsuka Pharmaceutical } \\
\text { Co., Ltd. }\end{array}$ & & \\
\hline \begin{tabular}{|l|} 
Member: \\
Yasuki Kihara
\end{tabular} & & & & $\begin{array}{l}\cdot \text { Medical Corporation } \\
\text { Ichiyokai } \\
\cdot \text { Medical Corporation } \\
\text { Kenkou Club } \\
\cdot \text { Medical Corporation } \\
\text { Keiseikai } \\
\text { Shobara Redcross } \\
\text { Hospital }\end{array}$ & & $\begin{array}{l}\text { EP-CRSU Co., Ltd. } \\
\text {-HuBit genomix }\end{array}$ & 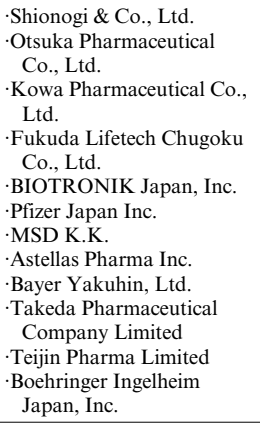 & & \\
\hline \begin{tabular}{|l|} 
Member: \\
Issei Komuro
\end{tabular} & & & & $\begin{array}{l}\text {-Actelion } \\
\text { Pharmaceuticals } \\
\text { Japan Ltd. } \\
\text { MSD K... } \\
\text {-Daiichi Sankyo } \\
\text { Company, Limited } \\
\text { Takeda Pharmaceutical } \\
\text { Company Limited } \\
\text {-Mitsubishi Tanabe } \\
\text { Pharma Corporation } \\
\text { - Boehringer Ingelheim } \\
\text { Japan, Inc. } \\
\text { Ono Pharmaceutical } \\
\text { Co., Ltd. } \\
\text {-TOA EIYO LTD. }\end{array}$ & & $\begin{array}{l}\text { Ono Pharmaceutical } \\
\text { Co., Ltd. }\end{array}$ & 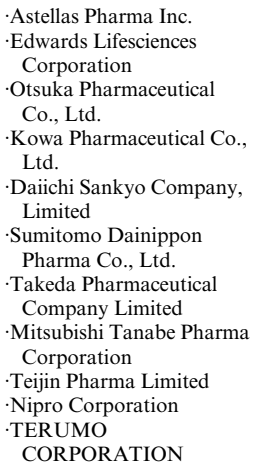 & & \\
\hline $\begin{array}{l}\begin{array}{l}\text { Member: } \\
\text { Yoshikatsu } \\
\text { Saiki }\end{array} \\
\end{array}$ & & & & & & & $\begin{array}{l}\text { SENKO MEDICAL } \\
\text { INSTRUMENT Mfg. } \\
\text { Co., Ltd. } \\
\text { Century Medical,Inc. } \\
\text { Terumo Corporation } \\
\text { Cardiac \& Vascular } \\
\text { Company }\end{array}$ & & \\
\hline
\end{tabular}




\begin{tabular}{|c|c|c|c|c|c|c|c|c|c|}
\hline Author & $\begin{array}{c}\text { Employer/ } \\
\text { leadership } \\
\text { position } \\
\text { (private company) }\end{array}$ & Stakeholder & $\begin{array}{l}\text { Patent } \\
\text { royalty }\end{array}$ & Honorarium & $\begin{array}{l}\text { Payment for } \\
\text { manuscripts }\end{array}$ & Research grant & $\begin{array}{l}\text { Scholarship (educational) } \\
\text { grant/endowed chair }\end{array}$ & $\begin{array}{l}\text { Other } \\
\text { rewards }\end{array}$ & $\begin{array}{l}\text { Potential } \\
\text { COI of the } \\
\text { marital } \\
\text { partner, } \\
\text { first-degree } \\
\text { family } \\
\text { members, } \\
\text { or those } \\
\text { who share } \\
\text { income and } \\
\text { property }\end{array}$ \\
\hline $\begin{array}{l}\text { Member: } \\
\text { Yoshihiko } \\
\text { Saito }\end{array}$ & & & & \begin{tabular}{|l|}
-Novartis Pharma K.K. \\
-Mitsubishi Tanabe \\
Pharma Corporation \\
-Otsuka Pharmaceutical \\
Co., Ltd. \\
-Kowa Pharmaceutical \\
Co., Ltd. \\
-Daiichi Sankyo \\
Company, Limited \\
-Pfizer Japan Inc.
\end{tabular} & & $\begin{array}{l}\text {-Novartis Pharma } \\
\text { K.K. } \\
\text { Ono Pharmaceutical } \\
\text { Co., Ltd. } \\
\text {-TERUMO } \\
\text { CORPORATION } \\
\text { St. Jude Medical } \\
\text { Japan Co., Ltd. } \\
\text { - Bayer Yakuhin, Ltd. }\end{array}$ & 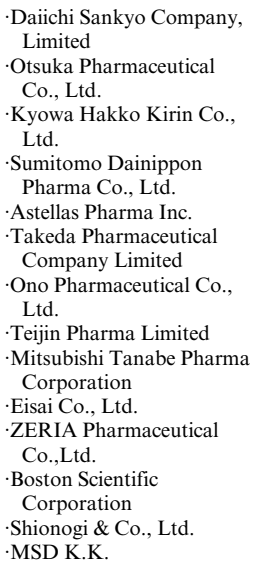 & & \\
\hline $\begin{array}{l}\text { Member: } \\
\text { Yasushi } \\
\text { Sakata }\end{array}$ & & & & $\begin{array}{l}\text {-Otsuka Pharmaceutical } \\
\text { Co., Ltd. } \\
\text {-Daiichi Sankyo } \\
\text { Company, Limited } \\
\text {-Takeda Pharmaceutical } \\
\text { Company Limited } \\
\text {-Mitsubishi Tanabe } \\
\text { Pharma Corporation } \\
\text {-Medtronic Japan Co., } \\
\text { Ltd. } \\
\text {-Boehringer Ingelheim } \\
\text { Japan, Inc. }\end{array}$ & & $\begin{array}{l}\text {-Edwards Lifesciences } \\
\text { Corporation } \\
\text { ·FUJIFILM RI } \\
\text { Pharma Co., Ltd. } \\
\text {-REGiMMUNE Co., } \\
\text { Ltd. } \\
\text {-Roche Diagnostics } \\
\text { K.K. }\end{array}$ & $\begin{array}{l}\cdot \text { Otsuka Pharmaceutical } \\
\text { Co., Ltd. } \\
\cdot \text { Johnson \& Johnson K.K. } \\
\cdot \text { St. Jude Medical Japan } \\
\text { Co., Ltd. } \\
\text {-Daiichi Sankyo Company, } \\
\text { Limited } \\
\text {-Takeda Pharmaceutical } \\
\text { Company Limited } \\
\cdot \text {-Mitsubishi Tanabe Pharma } \\
\text { Corporation } \\
\text {-Teijin Pharma Limited } \\
\text {-Boehringer Ingelheim } \\
\text { Japan, Inc. } \\
\text {-Bayer Yakuhin, Ltd. } \\
\text {-BIOTRONIK Japan, Inc. } \\
\text {-Boston Scientific } \\
\text { Corporation } \\
\text {-Medtronic Japan Co., Ltd. }\end{array}$ & & \\
\hline $\begin{array}{l}\text { Member: } \\
\text { Naoki Sato }\end{array}$ & & & & $\begin{array}{l}\text {-Otsuka Pharmaceutical } \\
\text { Co., Ltd. } \\
\text {-Novartis Pharma K.K. } \\
\text {-Ono Pharmaceutical } \\
\text { Co., Ltd. } \\
\text {-Daiichi Sankyo } \\
\text { Company, Limited }\end{array}$ & $\begin{array}{l}\text { Otsuka } \\
\text { Pharmaceutical } \\
\text { Co., Ltd. }\end{array}$ & $\begin{array}{l}\text { Novartis Pharma } \\
\text { K.K. }\end{array}$ & - Bayer Yakuhin, Ltd. & & \\
\hline $\begin{array}{l}\text { Member: } \\
\text { Yoshiki Sawa }\end{array}$ & & Cuorips Inc. & $\begin{array}{l}\text {-TERUMO } \\
\text { CORPORATION }\end{array}$ & & & $\begin{array}{l}\text {-TERUMO } \\
\text { CORPORATION } \\
\text {-Asubio Pharma Co., } \\
\text { Ltd. } \\
\text {-Daikin Industries, } \\
\text { Ltd. } \\
\text {-Astellas Pharma Inc. } \\
\text { ·JEC Corporation } \\
\text {-Nacalai Tesque, Inc. } \\
\text { Edwards Lifesciences } \\
\text { Corporation } \\
\text {-Novartis Pharma } \\
\text { K.K. } \\
\text { Sun Medical } \\
\text { Technology } \\
\text { Research Corp. } \\
\text {-Nipro Corporation } \\
\text { Johnson \& Johnson } \\
\text { K.K. } \\
\text {-Medtronic Japan } \\
\text { Co., Ltd. } \\
\text { W. L. Gore \& } \\
\text { Associates, Inc. } \\
\text {-Boston Scientific } \\
\text { Corporation }\end{array}$ & $\begin{array}{l}\text { Edwards Lifesciences } \\
\text { Corporation } \\
\text { Konishi Medical } \\
\text { Instruments Co., Ltd. } \\
\text {-Medtronic Japan Co., Ltd. }\end{array}$ & & \\
\hline
\end{tabular}




\begin{tabular}{|c|c|c|c|c|c|c|c|c|c|}
\hline Author & $\begin{array}{c}\text { Employer/ } \\
\text { leadership } \\
\text { position } \\
\text { (private company) }\end{array}$ & Stakeholder & $\begin{array}{c}\text { Patent } \\
\text { royalty }\end{array}$ & Honorarium & $\begin{array}{l}\text { Payment for } \\
\text { manuscripts }\end{array}$ & Research grant & $\begin{array}{l}\text { Scholarship (educational) } \\
\text { grant/endowed chair }\end{array}$ & \begin{tabular}{|c|} 
Other \\
rewards \\
\end{tabular} & $\begin{array}{l}\text { Potential } \\
\text { COI of the } \\
\text { marital } \\
\text { partner, } \\
\text { first-degree } \\
\text { family } \\
\text { members, } \\
\text { or those } \\
\text { who share } \\
\text { income and } \\
\text { property }\end{array}$ \\
\hline \begin{tabular}{|l|} 
Member: \\
Akira Shiose
\end{tabular} & & & & & & & $\begin{array}{l}\text { Edwards Lifesciences } \\
\text { Corporation. } \\
\text { Kanaya Ikakikai } \\
\text { St. Jude Medical Japan } \\
\text { Co., Ltd. } \\
\text { Terumo Corporation } \\
\text { Cardiac \& Vascular } \\
\text { Company } \\
\text { BIOTRONIK Japan, Inc. } \\
\text { - LivaNovi Japan K.K. } \\
\text {-KISHIYA INC } \\
\text { SENKO MEDICAL } \\
\text { INSTRUMENT Mfg. } \\
\text { Co., Ldt. } \\
\text { Japan Lifeline Co., Ltd. } \\
\text { 'HEIWA BUSSAN Co., } \\
\text { Ltd. }\end{array}$ & & \\
\hline \begin{tabular}{|l|} 
Member: \\
Wataru \\
Shimizu
\end{tabular} & & & & $\begin{array}{l}\text { Daiichi Sankyo } \\
\text { Company, Limited } \\
\text { Bristol-Myers Squibb } \\
\text { Boehringer Ingelheim } \\
\text { Japan, Inc. } \\
\text { Bayer Yakuhin, Ltd. } \\
\text { Pfizer Japan Inc. } \\
\text {-Mitsubishi Tanabe } \\
\text { Pharma Corporation } \\
\text { Ono Pharmaceutical } \\
\text { Co., Ltd. }\end{array}$ & & & 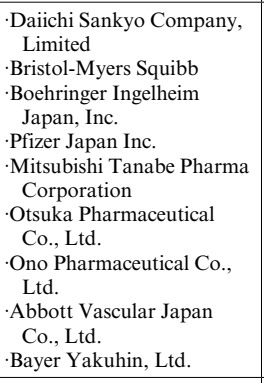 & & \\
\hline \begin{tabular}{|l|} 
Member: \\
Hiroaki \\
Shimokawa
\end{tabular} & & & & $\begin{array}{l}\text {-Bayer Yakuhin, Ltd. } \\
\text { Boehringer Ingelheim } \\
\text { Japan, Inc. } \\
\text { Daiichi Sankyo } \\
\text { Company, Limited }\end{array}$ & & Bayer Yakuhin, Ltd. & 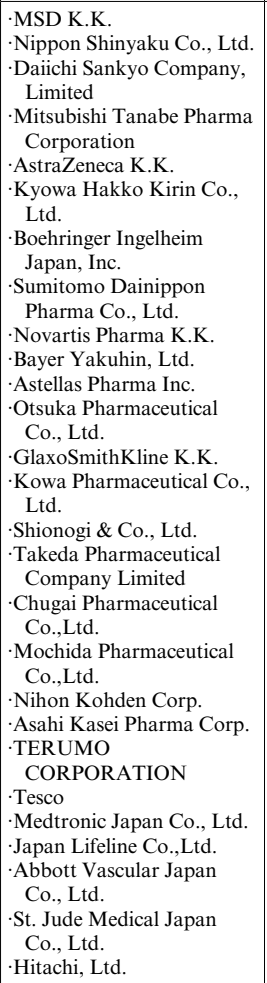 & & \\
\hline \begin{tabular}{|l|} 
Member: \\
Koichi Node
\end{tabular} & & & & & & $\begin{array}{l}\text {-Teijin Pharma } \\
\text { Limited } \\
\text {-Mitsubishi Tanabe } \\
\text { Pharma } \\
\text { Corporation } \\
\text {-Boehringer Ingelheim } \\
\text { Japan, Inc. } \\
\text {-Eli Lilly and } \\
\text { Company. } \\
\text {-Astellas Pharma Inc. }\end{array}$ & & & \\
\hline
\end{tabular}




\begin{tabular}{|c|c|c|c|c|c|c|c|c|c|}
\hline Author & $\begin{array}{c}\text { Employer/ } \\
\text { leadership } \\
\text { position } \\
\text { (private company) }\end{array}$ & Stakeholder & $\begin{array}{l}\text { Patent } \\
\text { royalty }\end{array}$ & Honorarium & $\begin{array}{l}\text { Payment for } \\
\text { manuscripts }\end{array}$ & Research grant & $\begin{array}{l}\text { Scholarship (educational) } \\
\text { grant/endowed chair }\end{array}$ & $\begin{array}{c}\text { Other } \\
\text { rewards }\end{array}$ & \begin{tabular}{|c|} 
Potential \\
COI of the \\
marital \\
partner, \\
first-degree \\
family \\
members, \\
or those \\
who share \\
income and \\
property \\
\end{tabular} \\
\hline $\begin{array}{l}\text { Member: } \\
\text { Atsushi } \\
\text { Hirayama }\end{array}$ & & & & $\begin{array}{l}\text {-TOA EIYO LTD. } \\
\text {-Boehringer Ingelheim } \\
\text { Japan, Inc. } \\
\text {-Sanofi K.K. } \\
\text {-Astellas Pharma Inc. } \\
\text {-Sumitomo Dainippon } \\
\text { Pharma Co., Ltd. } \\
\text {-Bristol-Myers Squibb } \\
\text {-Amgen Astellas } \\
\text { BioPharma K.K. } \\
\text {-AstraZeneca K.K. } \\
\text {-Daiichi Sankyo } \\
\text { Company, Limited } \\
\text {-Bayer Yakuhin, Ltd. } \\
\end{array}$ & & & \begin{tabular}{|l}
-Boston Scientific \\
Corporation \\
-Otsuka Pharmaceutical \\
Co., Ltd. \\
- Fukuda Denshi Co., Ltd. \\
-St. Jude Medical Japan \\
Co., Ltd. \\
-Medtronic Japan Co., Ltd. \\
-Japan Lifeline Co.,Ltd.
\end{tabular} & & \\
\hline $\begin{array}{l}\text { Member: } \\
\text { Tohru } \\
\text { Masuyama }\end{array}$ & & & & & & & \begin{tabular}{|l}
-Actelion Pharmaceuticals \\
Japan Ltd. \\
-Astellas Pharma Inc. \\
- MSD K.K. \\
-Otsuka Pharmaceutical \\
Co., Ltd. \\
-Kowa Pharmaceutical Co., \\
Ltd. \\
-Daiichi Sankyo Company, \\
Limited \\
-Takeda Pharmaceutical \\
Company Limited \\
-Mitsubishi Tanabe Pharma \\
Corporation \\
-Teijin Pharma Limited \\
-Nippon Shinyaku Co., Ltd. \\
- Boehringer Ingelheim \\
Japan, Inc. \\
- Novartis Pharma K.K. \\
- Bayer Yakuhin, Ltd. \\
-Pfizer Japan Inc. \\
- Fukuda Denshi Co., Ltd. \\
-St. Jude Medical Japan \\
Co., Ltd. \\
-Medtronic Japan Co., Ltd. \\
-
\end{tabular} & & \\
\hline $\begin{array}{l}\text { Member: } \\
\text { Toyoaki } \\
\text { Murohara }\end{array}$ & & & & $\begin{array}{l}\text {-AstraZeneca K.K. } \\
\text {-MSD K.K. } \\
\text {-Daiichi Sankyo } \\
\text { Company, Limited } \\
\text {-Takeda Pharmaceutical } \\
\text { Company Limited } \\
\text {-Mitsubishi Tanabe } \\
\text { Pharma Corporation } \\
\text {-Bayer Yakuhin, Ltd. } \\
\text { Pfizer Japan Inc. }\end{array}$ & & & \begin{tabular}{|l|}
-Boehringer Ingelheim \\
Japan, Inc. \\
-Pfizer Japan Inc. \\
-Otsuka Pharmaceutical \\
Co., Ltd. \\
- Bayer Yakuhin, Ltd. \\
-Astellas Pharma Inc. \\
- MSD K.K. \\
-Sanofi K.K. \\
-Daiichi Sankyo Company, \\
Limited \\
-Sumitomo Dainippon \\
Pharma Co., Ltd. \\
-BIOTRONIK Japan, Inc. \\
- Takeda Pharmaceutical \\
Company Limited \\
-Teijin Pharma Limited \\
-Mitsubishi Tanabe Pharma \\
Corporation \\
\end{tabular} & & \\
\hline $\begin{array}{l}\text { Member: } \\
\text { Shin-ichi } \\
\text { Momomura }\end{array}$ & & & & $\begin{array}{l}\cdot \text { Novartis Pharma K.K. } \\
\cdot \text { Boehringer Ingelheim } \\
\text { Japan, Inc. } \\
\cdot \text { Bayer Yakuhin, Ltd. } \\
\text {-Daiichi Sankyo } \\
\text { Company, Limited } \\
\text { Bristol-Myers Squibb } \\
\end{array}$ & & & - Roche Diagnostics K.K. & & \\
\hline $\begin{array}{l}\text { Member: } \\
\text { Masafumi } \\
\text { Yano }\end{array}$ & & & & $\begin{array}{l}\text { Ono Pharmaceutical } \\
\text { Co., Ltd. }\end{array}$ & & & $\begin{array}{l}\text {-Otsuka Pharmaceutical } \\
\text { Co., Ltd. } \\
\text {-MSD K.K. } \\
\text {-Boston Scientific } \\
\text { Corporation } \\
\text {-Ono Pharmaceutical Co., } \\
\text { Ltd. } \\
\text {-Daiichi Sankyo Company, } \\
\text { Limited } \\
\text {-Takeda Pharmaceutical } \\
\text { Company Limited } \\
\text {-Pfizer Japan Inc. } \\
\text {-Astellas Pharma Inc. } \\
\text {-Bristol-Myers Squibb } \\
\text {-Novartis Pharma K.K. }\end{array}$ & & \\
\hline
\end{tabular}




\begin{tabular}{|c|c|c|c|c|c|c|c|c|c|}
\hline Author & $\begin{array}{c}\text { Employer/ } \\
\text { leadership } \\
\text { position } \\
\text { (private company) }\end{array}$ & Stakeholder & $\begin{array}{l}\text { Patent } \\
\text { royalty }\end{array}$ & Honorarium & $\begin{array}{l}\text { Payment for } \\
\text { manuscripts }\end{array}$ & Research grant & $\begin{array}{l}\text { Scholarship (educational) } \\
\text { grant/endowed chair }\end{array}$ & $\begin{array}{c}\text { Other } \\
\text { rewards }\end{array}$ & \begin{tabular}{|c|} 
Potential \\
COI of the \\
marital \\
partner, \\
first-degree \\
family \\
members, \\
or those \\
who share \\
income and \\
property
\end{tabular} \\
\hline $\begin{array}{l}\text { Member: } \\
\text { Kenji } \\
\text { Yamazaki }\end{array}$ & $\begin{array}{l}\text { Sun Medical } \\
\text { Technology } \\
\text { Research Corp. }\end{array}$ & & & & & & $\begin{array}{l}\text { Edwards Lifesciences } \\
\text { Corporation } \\
\text { Century Medical, Inc. } \\
\text { Luana Traum } \\
\text { FrontierMedic Co., Ltd }\end{array}$ & & \\
\hline $\begin{array}{l}\text { Member: } \\
\text { Kazuhiro } \\
\text { Yamamoto }\end{array}$ & & & & $\begin{array}{l}\text { Otsuka Pharmaceutical } \\
\text { Co., Ltd. } \\
\text {-Novartis Pharma K.K. }\end{array}$ & & & $\begin{array}{l}\text {-BIOTRONIK Japan, Inc. } \\
\text {-Johnson \& Johnson K.K. } \\
\text {-Japan Lifeline Co.,Ltd. } \\
\text {-Otsuka Pharmaceutical } \\
\text { Co., Ltd. } \\
\text { - Boehringer Ingelheim } \\
\text { Japan, Inc. } \\
\text {-Mitsubishi Tanabe Pharma } \\
\text { Corporation } \\
\text {-Takeda Pharmaceutical } \\
\text { Company Limited } \\
\text {-Pfizer Japan Inc. } \\
\text {-Daiichi Sankyo Company, } \\
\text { Limited } \\
\text {-Teijin Pharma Limited } \\
\text {-St. Jude Medical Japan } \\
\text { Co., Ltd. }\end{array}$ & & \\
\hline $\begin{array}{l}\text { Member: } \\
\text { Michihiro } \\
\text { Yoshimura }\end{array}$ & & & & $\begin{array}{l}\text {-Pfizer Japan Inc. } \\
\text {-Mitsubishi Tanabe } \\
\text { Pharma Corporation } \\
\text {-Daiichi Sankyo } \\
\text { Company, Limited } \\
\text {-Mochida } \\
\text { Pharmaceutical } \\
\text { Co.,Ltd. } \\
\text {-Kowa Pharmaceutical } \\
\text { Co., Ltd. }\end{array}$ & & & $\begin{array}{l}\text {-Shionogi \& Co., Ltd. } \\
\text {-Teijin Pharma Limited } \\
\cdot \text {-Astellas Pharma Inc. }\end{array}$ & & \\
\hline $\begin{array}{l}\text { Collaborator: } \\
\text { Toshihisa } \\
\text { Anzai }\end{array}$ & & & & $\begin{array}{l}\text { Otsuka Pharmaceutical } \\
\text { Co., Ltd. }\end{array}$ & & & - Bayer Yakuhin, Ltd. & & \\
\hline $\begin{array}{l}\text { Collaborator: } \\
\text { Shiro Ishihara }\end{array}$ & & & & $\begin{array}{l}\text { BIOTRONIK Japan, } \\
\text { Inc. }\end{array}$ & & & & & \\
\hline $\begin{array}{l}\text { Collaborator: } \\
\text { Takayuki } \\
\text { Inomata }\end{array}$ & & & & \begin{tabular}{|l|} 
Daiichi Sankyo \\
Company, Limited \\
Otsuka Pharmaceutical \\
Co., Ltd. \\
Boehringer Ingelheim \\
Japan, Inc. \\
\end{tabular} & & & & & \\
\hline $\begin{array}{l}\text { Collaborator: } \\
\text { Teruhiko } \\
\text { Imamura }\end{array}$ & $\begin{array}{l}\text { Teijin Pharma } \\
\text { Limited }\end{array}$ & & & & & & & & \\
\hline $\begin{array}{l}\text { Collaborator: } \\
\text { Tomohito } \\
\text { Ohtani }\end{array}$ & $\begin{array}{l}\text { Takeda } \\
\text { Pharmaceutical } \\
\text { Company } \\
\text { Limited } \\
\end{array}$ & & & & & & & & \\
\hline $\begin{array}{l}\text { Collaborator: } \\
\text { Katsuya } \\
\text { Onishi }\end{array}$ & & & & \begin{tabular}{|l}
-Takeda Pharmaceutical \\
Company Limited \\
-Mitsubishi Tanabe \\
Pharma Corporation \\
- Daiichi Sankyo \\
Company, Limited \\
- Boehringer Ingelheim \\
Japan, Inc. \\
-AstraZeneca K.K. \\
-Otsuka Pharmaceutical \\
Co., Ltd. \\
\end{tabular} & & & & & \\
\hline $\begin{array}{l}\text { Collaborator: } \\
\text { Takatoshi } \\
\text { Kasai }\end{array}$ & & & & & & $\begin{array}{l}\text { Sanwa Kagaku } \\
\text { Kenkyusho Co., } \\
\text { Ltd. } \\
\text {-Asahi Kasei Pharma } \\
\text { Corp. }\end{array}$ & $\begin{array}{l}\text { Koninklijke Philips N.V. } \\
\text { 'Fukuda Denshi Co., Ltd. } \\
\text { 'ResMed }\end{array}$ & & \\
\hline $\begin{array}{l}\text { Collaborator: } \\
\text { Makoto } \\
\text { Kawai }\end{array}$ & & & & & & & $\begin{array}{l}\text { Daiichi Sankyo Company, } \\
\text { Limited }\end{array}$ & & \\
\hline $\begin{array}{l}\text { Collaborator: } \\
\text { Shigeki } \\
\text { Kobayashi } \\
\end{array}$ & & & & $\begin{array}{l}\text { Ono Pharmaceutical } \\
\text { Co., Ltd. }\end{array}$ & & & & & \\
\hline $\begin{array}{l}\text { Collaborator: } \\
\text { Takashi Noda }\end{array}$ & & & & $\begin{array}{l}\text {-Medtronic Japan Co., } \\
\text { Ltd. } \\
\text { BIOTRONIK Japan, } \\
\text { Inc. }\end{array}$ & & $\begin{array}{l}\text { - Medtronic Japan } \\
\text { Co., Ltd. } \\
\text { Boston Scientific } \\
\text { Corporation }\end{array}$ & & & \\
\hline
\end{tabular}




\begin{tabular}{|c|c|c|c|c|c|c|c|c|c|}
\hline Author & $\begin{array}{c}\text { Employer/ } \\
\text { leadership } \\
\text { position } \\
\text { (private company) }\end{array}$ & Stakeholder & $\begin{array}{l}\text { Patent } \\
\text { royalty }\end{array}$ & Honorarium & $\begin{array}{l}\text { Payment for } \\
\text { manuscripts }\end{array}$ & Research grant & $\begin{array}{l}\text { Scholarship (educational) } \\
\text { grant/endowed chair }\end{array}$ & $\begin{array}{l}\text { Other } \\
\text { rewards }\end{array}$ & \begin{tabular}{|c|} 
Potential \\
COI of the \\
marital \\
partner, \\
first-degree \\
family \\
members, \\
or those \\
who share \\
income and \\
property
\end{tabular} \\
\hline $\begin{array}{l}\text { Collaborator: } \\
\text { Masaru } \\
\text { Hatano }\end{array}$ & & & & & & & $\begin{array}{l}\text { Otsuka Pharmaceutical } \\
\text { Co., Ltd. } \\
\text { Daiichi Sankyo Company, } \\
\text { Limited }\end{array}$ & & \\
\hline $\begin{array}{l}\text { Collaborator: } \\
\text { Takeo Fujino }\end{array}$ & & & & & & & $\begin{array}{l}\text {-Medtronic Japan Co., Ltd. } \\
\text { Social Medical } \\
\text { Corporation Chiyukai } \\
\text {-St. Jude Medical Japan } \\
\text { Co., Ltd. } \\
\text {-Nipro Corporation }\end{array}$ & & \\
\hline
\end{tabular}

Companies are listed only by name. The members and the collaborators other than the above have no relevant COIs. Member: Hiroshi Ito, none

Member: Yoichi Goto, none

Member: Yoshihiko Seino, none

Member: Taiki Higo, none

Member: Miyuki Makaya, none

Member: Tsutomu Yoshikawa, none

Collaborator: Masatoshi Akiyama, none

Collaborator: Yu-ki Iwasaki, none

Collaborator: Mahoto Kato, none

Collaborator: Yoshiharu Kinugasa, none

Collaborator: Shintaro Kinugawa, none

Collaborator: Toru Kuratani, none

Collaborator: Yasuhiko Sakata, none

Collaborator: Atsushi Tanaka, none

Collaborator: Koichi Toda, none

Collaborator: Kotaro Nochioka, none

Collaborator: Takayuki Hidaka, none

Collaborator: Shigeru Makita, none

Collaborator: Osamu Yamaguchi, none 